OAK RIDGE NATIONAL LABORATORY

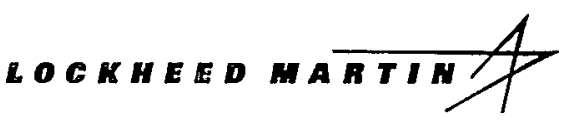

TECEIVED

MAY 121999

OSTI

ORNL Superconducting Technology Program for Electric Power Systems

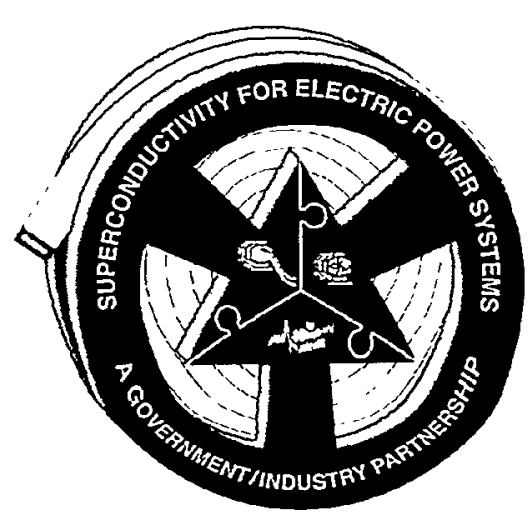

MANAGED AKD OPERATED BY

LOCKHEED MARTIN ENERGY RESEARCH CORPORATION FOR THE URTED STATES

DEPARTMENT OF ENERGY 
This report has been reproduced from the best available copy.

Reports are available to the public from the following source.

National Technical Information Service

5285 Port Royal Road

Springfield, VA 22161

Telephone 703-605-6000 (1-800-553-6847)

TDD 703-487-4639

Fax 703-605-6900

E-mail orders@ntis.fedworld.gov

Web site http://www.ntis.gov/ordering.htm

Reports are available to U.S. Department of Energy (DOE) employees, DOE contractors, Energy Technology Data Exchange (ETDE) representatives, and International Nuclear Information System (INIS) representatives from the following source.

Office of Scientific and Technical Information

P.O. Box 62

Oak Ridge, TN 37831

Telephone 423-576-8401

Fax 423-576-5728

E-mail reports@adonis.osti.gov

Web site http://www.osti.gov/products/sources.html

Reports produced after January 1, 1996, are generally available via the DOE Information Bridge.

Web site http://www.doe.gov/bridge

This report was prepared as an account of work sponsored by an agency of the United States government. Neither the United States government nor any agency thereof, nor any of their employees, makes any warranty, express or implied, or assumes any legal liability or responsibility for the accuracy, completeness, or usefulness of any information, apparatus, product, or process disclosed, or represents that its use would not infringe privately owned rights. Reference herein to any specific commercial product, process, or service by trade name, trademark, manufacturer, or otherwise, does not necessarily constitute or imply its endorsement, recommendation, or favoring by the United States government or any agency thereof. The views and opinions of authors expressed herein do not necessarily state or reflect those of the United States government or any agency thereof. 


\section{DISCLAIMER}

Portions of this document may be illegible in electronic image products. Images are produced from the best available original document. 


\title{
ORNL SUPERCONDUCTING TECHNOLOGY PROGRAM FOR ELECTRIC POWER SYSTEMS
}

\section{ANNUAL REPORT FOR FY 1998}

\author{
Compiled by \\ R. A. Hawsey \\ A. W. Murphy \\ Edited by \\ L. M. O'Hara \\ W. S. Koncinski
}

Manuscript Completed: December 1998

Date Published: April 1999

\author{
Prepared for the \\ Office of Power Technologies \\ Office of Energy Efficiency and Renewable Energy \\ U.S. DEPARTMENT OF ENERGY \\ (EB 5001000$)$ \\ Prepared by \\ OAK RIDGE NATIONAL LABORATORY \\ P.O. Box 2008 \\ Oak Ridge, TN 37831-6285 \\ Managed by \\ LOCKHEED MARTIN ENERGY RESEARCH CORP. \\ for the \\ U.S. DEPARTMENT OF ENERGY \\ under contract DE-AC05-96OR22464
}





\section{Contributors}

D. B. Beach

J. D. Budai

T. G. Chirayil ${ }^{1}$

D. K. Christen

X. Cui ${ }^{1}$

J. A. Demko

A. Ellis

R. Feenstra

M. J. Gouge

A. Goyal

R. A. Hawsey

H. $\mathrm{Hsu}^{2}$

D. R. James

H. R. Kerchner

D. M. Kroeger

D. F. Lee

F. A. List III
J. W. Lue

P. M. Martin

J. E. Mathis

I. Matsubora ${ }^{3}$

B. W. McConnell

D. P. Norton

M. Paranthaman

C. Park ${ }^{1}$

V. Patania

I. Sauers

S. W. Schwenterly

V. K. Sikka

E. D. Specht

J. P. Stovall

D. T. Verebelyi ${ }^{1}$

R. K. Williams

'ORISE postdoctoral research fellow

${ }^{2}$ Imtech Corporation

${ }^{3}$ Osaka National Research Institute visiting scientist 


\section{.}




\section{Contents}

CONTRIBUTORS $\ldots \ldots \ldots \ldots \ldots \ldots \ldots \ldots \ldots \ldots \ldots \ldots \ldots \ldots \ldots \ldots \ldots \ldots \ldots \ldots$, iii

LIST OF FIGURES $\ldots \ldots \ldots \ldots \ldots \ldots \ldots \ldots \ldots \ldots \ldots \ldots \ldots \ldots \ldots \ldots \ldots \ldots \ldots \ldots$ vii

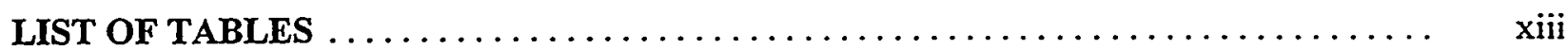

ACRONYMS AND INITIALISMS $\ldots \ldots \ldots \ldots \ldots \ldots \ldots \ldots \ldots \ldots \ldots \ldots \ldots \ldots \ldots$

EXECUTIVE SUMMARY $\ldots \ldots \ldots \ldots \ldots \ldots \ldots \ldots \ldots \ldots \ldots \ldots \ldots \ldots \ldots \ldots \ldots \ldots \ldots$ xvii

HIGHLIGHTS FOR FISCAL YEAR $1998 \ldots \ldots \ldots \ldots \ldots \ldots \ldots \ldots \ldots \ldots \ldots \ldots \ldots \ldots$

TECHNICAL PROGRESS IN WIRE DEVELOPMENT $\ldots \ldots \ldots \ldots \ldots \ldots \ldots \ldots \ldots$

A PRECURSOR APPROACH YIELDS HIGH CRITICAL CURRENT DENSITY

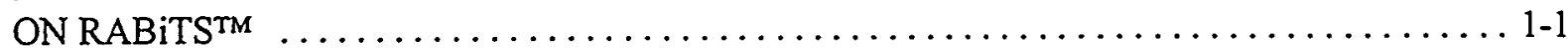

A REEL-TO-REEL VAPOR DEPOSITION SYSTEM FOR FABRICATING BUFFERS

AND LONG LENGTHS OF SUPERCONDUCTORS $\ldots \ldots \ldots \ldots \ldots \ldots \ldots \ldots \ldots \ldots \ldots 1-4$

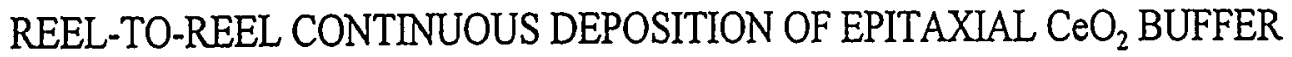

LAYERS ON BIAXIALLY TEXTURED Ni TAPES BY ELECTRON BEAM

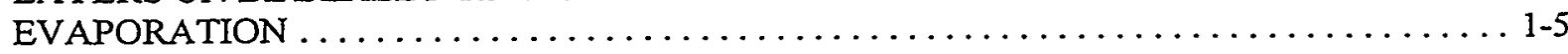

NONMAGNETIC, STRENGTHENED SUBSTRATES FOR RABiTSTM $\ldots \ldots \ldots \ldots \ldots \ldots$

MIDWEST SUPERCONDUCTIVITY CRADA SUMMARY REPORT $\ldots \ldots \ldots \ldots \ldots \ldots 1-11$

AN ALTERNATIVE APPROACH: Bi-2223-COATED CONDUCTOR DEVELOPMENT . . . 1-15

ALTERNATIVE BUFFER ARCHITECTURES FOR HIGH- $J_{c}$ YBCO

SUPERCONDUCTING DEPOSITS ON RABITS ${ }^{\mathrm{TM}}$

PREPARATION OF TEXTURED YBCO FILMS ON SrTiO ${ }_{3}(100)$ SINGLE-CRYSTAL

SUBSTRATES USING ALL-IODIDE PRECURSORS $\ldots \ldots \ldots \ldots \ldots \ldots \ldots \ldots \ldots \ldots \ldots \ldots \ldots$

DEMONSTRATION OF THE GROWTH OF HIGH-CURRENT YBCO ON SOL-GEL

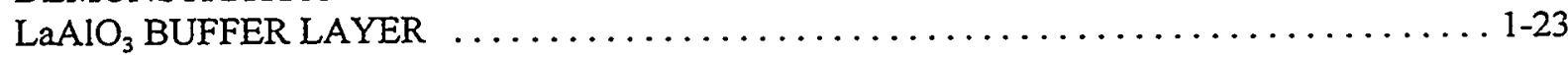

SOLUTION PROCESSING OF YBa $\mathrm{Cu}_{3} \mathrm{O}_{7-\mathrm{x}}$ THIN FILMS $\ldots \ldots \ldots \ldots \ldots \ldots \ldots \ldots \ldots \ldots \ldots$

GROWTH OF TEXTURED BUFFER LAYERS AND SUPERCONDUCTORS ON ROLLED-Ni SUBSTRATES USING SOL-GEL ALKOXIDE PRECURSORS $\ldots \ldots \ldots \ldots \ldots 1-27$ 
OPTIMIZATION OF BUFFER LAYERS ON ROLLED-Ni SUBSTRATES FOR HIGH-CURRENT YBCO AND T1,Bi-1223-COATED CONDUCTORS USING EX SITU PRECURSOR APPROACHES

LOW-COST COMBUSTION CHEMICAL VAPOR DEPOSITION OF EPITAXIAL BUFFER LAYERS AND SUPERCONDUCTORS $1-36$

MELTING BEHAVIOR OF Bi-2212/Ag CONDUCTORS $\ldots \ldots \ldots \ldots \ldots \ldots \ldots \ldots \ldots \ldots \ldots 1-40$

THERMAL CONDUCTIVITY OF PARTIALLY SUBSTITUTED $\mathrm{YBa}_{2} \mathrm{Cu}_{3} \mathrm{O}_{7-\delta} \ldots \ldots \ldots 1-41$

PLUME-INDUCED STRESS IN PULSED-LASER DEPOSITED $\mathrm{CeO}_{2}$ FILMS $\ldots \ldots \ldots \ldots$ 1-44

TECHNICAL PROGRESS IN APPLICATIONS DEVELOPMENT $\ldots \ldots \ldots \ldots \ldots \ldots \ldots .1$

HIGH-TEMPERATURE SUPERCONDUCTING CABLE $\ldots \ldots \ldots \ldots \ldots \ldots \ldots \ldots \ldots \ldots \ldots$

SUPERCONDUCTING TRANSFORMER PROJECT $\ldots \ldots \ldots \ldots \ldots \ldots \ldots \ldots \ldots \ldots \ldots \ldots$

INSULATION STUDIES AT ORNL IN SUPPORT OF SUPERCONDUCTING

POWER APPLICATIONS

SUMMARY OF TECHNOLOGY PARTNERSHIP ACTIVTTES $\ldots \ldots \ldots \ldots \ldots \ldots \ldots \ldots$.

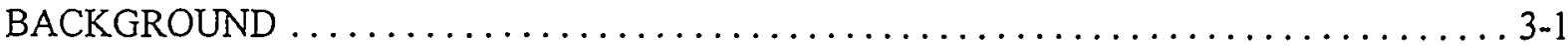

RELATIONSHIP TO THE DOE MISSION $\ldots \ldots \ldots \ldots \ldots \ldots \ldots \ldots \ldots \ldots \ldots \ldots \ldots \ldots \ldots \ldots \ldots \ldots$

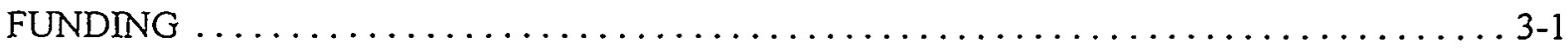

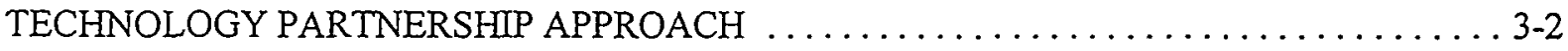

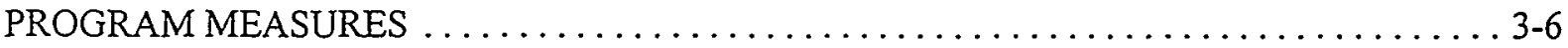

FY 1998 PRESENTATIONS AND PUBLICATIONS $\ldots \ldots \ldots \ldots \ldots \ldots \ldots \ldots \ldots \ldots \ldots \ldots$ 


\section{List of Figures}

Figure

Page

1.1 Field dependence of the critical current density $\left(J_{c}\right)$ in ex situ processed

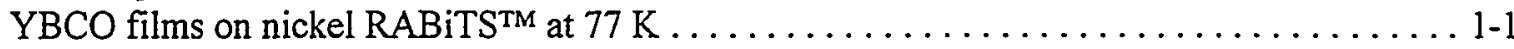

1.2 Histogram showing the critical current density $\left(J_{c}\right)$ (at $77 \mathrm{~K}$ in self-field) of

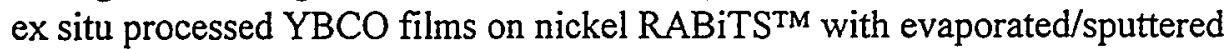

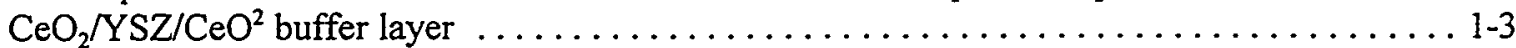

$1.3 \quad$ Reel-to-reel vapor deposition system $\ldots \ldots \ldots \ldots \ldots \ldots \ldots \ldots \ldots \ldots \ldots \ldots \ldots \ldots \ldots$

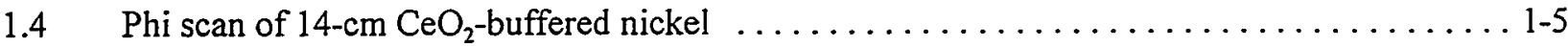

1.5 Relative intensity of $\mathrm{CeO}_{2}(200)$ as a function of forming gas pressure $4 \% \mathrm{H}_{2}$

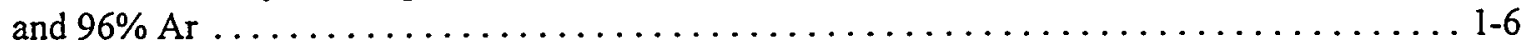

1.6 XRD $\theta-2 \theta$ scan of $20-\mathrm{nm} \mathrm{CeO}_{2}$ deposited by e-beam evaporation $\ldots \ldots \ldots \ldots \ldots \ldots$

1.7 In-plane $\phi$ scans and out-of-plane $\omega$ scans of $\mathrm{Ni}$ and 20 -nm-thick $\mathrm{CeO}_{2}$

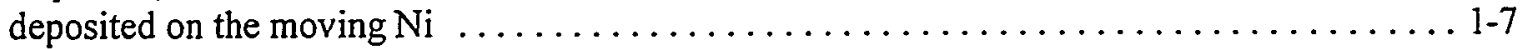

$1.8 \quad$ FWHM of (111) $\phi$ scan as a function of the length over a 30-nm-thick,

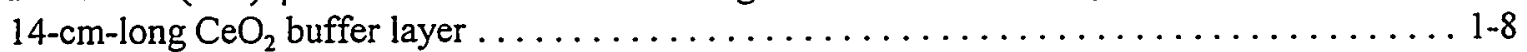

1.9 SEM image of a 30 -nm-thick $\mathrm{CeO}_{2}$ buffer layer on rolled $\mathrm{Ni}$ tape $\ldots \ldots \ldots \ldots \ldots \ldots$

1.10 Magnetic hysteresis data for cube-textured samples of identical geometry and with

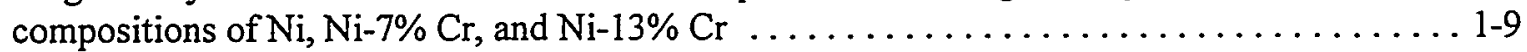

1.11 Stress-strain curves for cube-textured, dog-bone-shaped samples of $\mathrm{Ni}, \mathrm{Ni}-7 \% \mathrm{Cr}$, and $\mathrm{Ni}-13 \% \mathrm{Cr}$, with the load applied along the $[100]$ direction. $\ldots \ldots \ldots \ldots \ldots \ldots \ldots$

1.12 Rocking curves and $\phi$-scans showing the progression of out-of-plane and in-plane

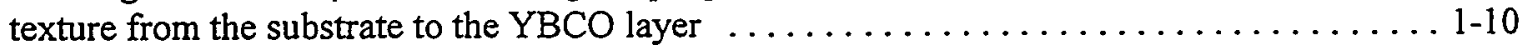

1.13 Scanning electron micrograph of the YBCO layer showing a dense film morphology

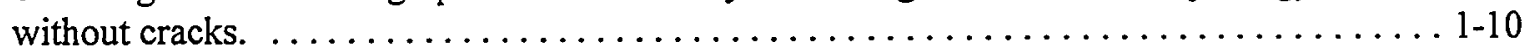

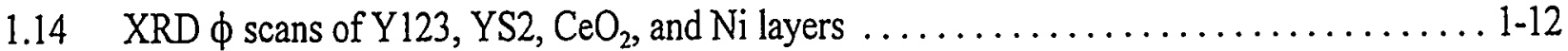

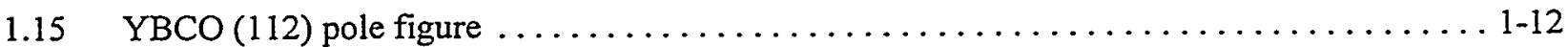

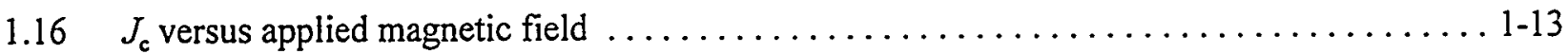

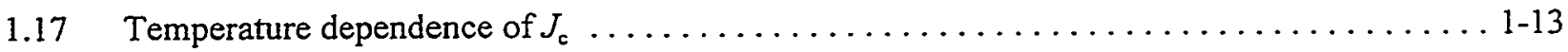

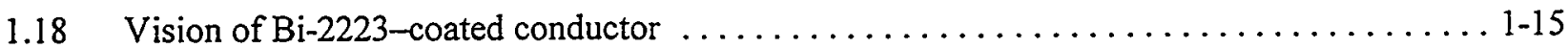


1.19 Schematic of the Bi-2223-coated-conductor fabrication procedure $\ldots \ldots \ldots \ldots \ldots \ldots 16$

1.20 Longitudinal cross-section SEM image of Bi-2223-coated conductor fabricated

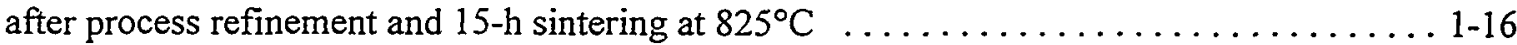

1.21 Formation kinetics of $\mathrm{Bi}-2223$-coated conductors $\ldots \ldots \ldots \ldots \ldots \ldots \ldots \ldots \ldots \ldots \ldots \ldots \ldots \ldots \ldots$

1.22 Plan view of a $\mathrm{Bi}-2223$-coated conductor fabricated through process refinement and sintered under typical thermomechanical treatment schedule $\ldots \ldots \ldots \ldots \ldots \ldots \ldots 1-17$

1.23 Various alternative buffer architectures for high- $J_{c}$ YBCO deposits on RABiTSTM $\ldots \ldots \ldots 1-18$

1.24 Microstructure of $Y S Z$ deposited by e-beam evaporation $\ldots \ldots \ldots \ldots \ldots \ldots \ldots \ldots \ldots$

1.25 Microstructure of $Y S Z$ deposited by $R F$ sputtering $\ldots \ldots \ldots \ldots \ldots \ldots \ldots \ldots \ldots$

1.26 Out-of-plane and in-plane textures of various layers in the $\mathrm{YBCO} / \mathrm{Yb}_{2} \mathrm{O}_{3} / \mathrm{YSZ} / \mathrm{CeO}_{2} / \mathrm{Ni} \mathrm{RABiTS}^{\mathrm{TM}}$ sample

1.27 Temperature dependencies of $J_{\mathrm{c}}$ of YBCO deposited on various

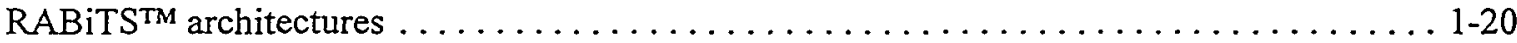

1.28 Magnetic field dependencies of normalized $J_{\mathrm{c}}$ of YBCO deposited on various

RABiTS $^{\mathrm{TM}}$ architectures . . . . . . . . . . . . . . . . . . . . . . . . . . 1-20

1.29 Out-of-plane and in-plane textures of various layers in the $\mathrm{YBCO} / \mathrm{Yb}_{2} \mathrm{O}_{3} / \mathrm{CeO}_{2} / \mathrm{Ni}$

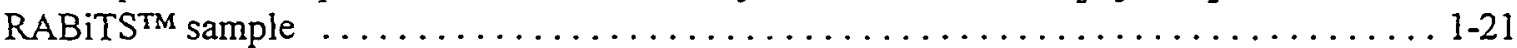

1.30 Microstructure of $\mathrm{Yb}_{2} \mathrm{O}_{3}$ buffer after $\mathrm{YBCO}$ has been chemically etched from

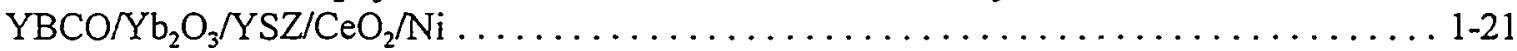

1.31 Microstructure of $\mathrm{Yb}_{2} \mathrm{O}_{3}$ buffer after $\mathrm{YBCO}$ has been chemically etched from

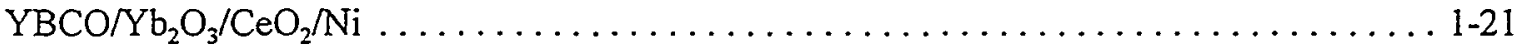

1.32 Out-of-plane and in-plane textures of various layers in the $\mathrm{YBCO} / \mathrm{Yb}_{2} \mathrm{O}_{3} / \mathrm{Y}_{2} \mathrm{O}_{3} \mathrm{Ni}$

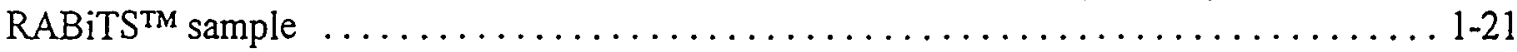

1.33 The typical $\theta-2 \theta$ scan for a $2000-\AA$-thick $\mathrm{YBCO}$ film on $\mathrm{SrTiO}_{3}(100)$ substrates indicating the

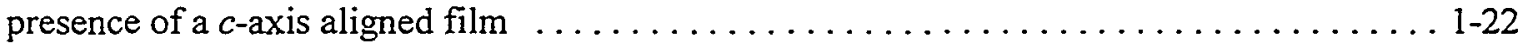

$1.34 \mathrm{LaAlO}_{3}(111)$ pole figure for $\sim 0.2-\mu \mathrm{m}$-thick $\mathrm{LaAlO}_{3}$ film deposited on $\mathrm{SrTiO}_{3}$

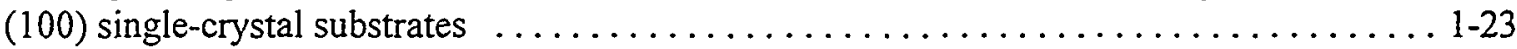

1.35 The temperature-dependence resistance for $0.2-\mu \mathrm{m}$-thick YBCO film on $\mathrm{LaAlO}_{3}$-buffered $\mathrm{SrTiO}_{3}(100)$ substrates

1.36 The temperature-dependence $J_{c}$ values (a) and $I_{c}$ values (b) for $0.2-\mu \mathrm{m}$-thick YBCO film on $\mathrm{LaAlO}_{3}(100)$ substrates 
1.37 Thermal gravimetric analysis (TGA) plots of barium, copper, and

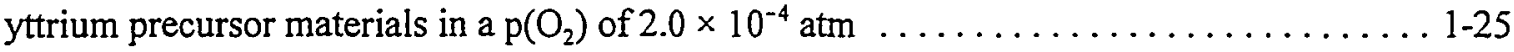

1.38 The room temperature powder X-ray diffraction pattern of YBCO films on

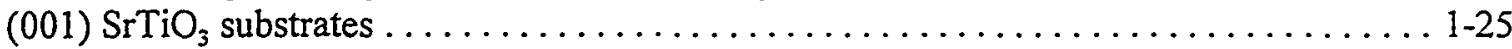

1.39 A typical $\phi$ scan featuring the epitaxial nature of $c$-axis oriented YBCO films

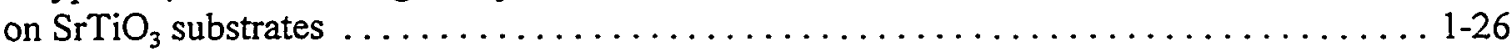

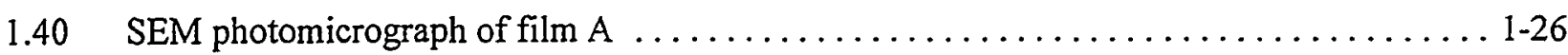

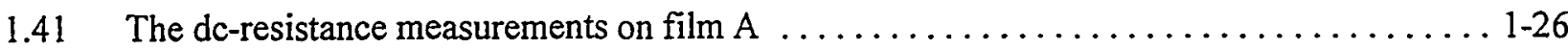

1.42 The X-ray powder diffraction pattern for the sol-gel YBCO film grown

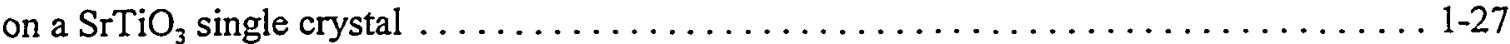

1.43 Correlation of the texture (FWHM values of $\omega$ and $\phi$ scans) of sol-gel grown $\mathrm{REAlO}_{3}$ films on $\mathrm{SrTiO}_{3}(100)$ substrates with the lattice mismatch between

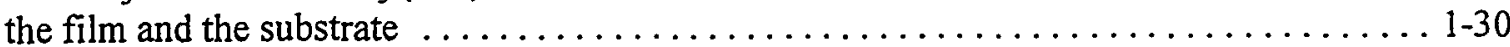

1.44 The typical $\theta-2 \theta$ scan for a 1000 - $\AA$-thick $\mathrm{NdAlO}_{3}$ film on $\mathrm{Ni}(100)$ substrates $\ldots \ldots \ldots 1-30$

1.45 Correlation of the texture (FWHM values of omega and phi scans) of sol-gel grown $\mathrm{REAlO}_{3}$ films of $\mathrm{SrTiO}_{3}$ substrates with the lattice mismatch between

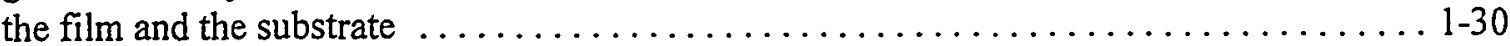

1.46 The room-temperature powder pattern for $\sim 0.3-\mu \mathrm{m}$-thick YBCO film on sol-gel $\mathrm{LaAlO}_{3}$-buffered Ni substrates $\ldots \ldots \ldots \ldots \ldots \ldots \ldots \ldots \ldots \ldots \ldots \ldots$

1.47 The field dependence of $J_{c}$ for $0.25-\mu \mathrm{m}$-thick YBCO film on sol-gel $\mathrm{NdGaO}_{3}$-buffered $\mathrm{SrTiO}_{3}(100)$ single-crystal substrates at $77 \mathrm{~K} \ldots \ldots \ldots \ldots \ldots \ldots \ldots$

1.48 SEM micrograph for a $2000-\AA$-thick $\mathrm{CeO}_{2}$-buffered $\mathrm{Ni}$ substrate $\ldots \ldots \ldots \ldots \ldots \ldots \ldots$

1.49 SEM micrograph for a $5000-\AA$-thick e-beam $\mathrm{YSZ}$-buffered $\mathrm{CeO}_{2} / \mathrm{Ni}$ substrate $\ldots \ldots \ldots 1-33$

1.50 Rutherford backscattering spectra of all e-beam buffers with the architecture of

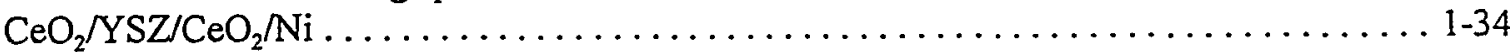

1.51 Rutherford backscattering spectra of e-beam $\mathrm{CeO}_{2}$ and sputtered $\mathrm{YSZ}$ buffers with the

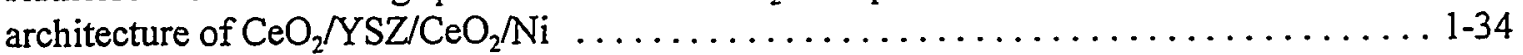

1.52 Comparisons of the measured transport $J_{c} s$ for $\mathrm{YBCO}$ and Tl,Bi-1223 films on RABiTSTM with that of films on single-crystal substrate with/without a $\mathrm{CeO}_{2}$ cap layer $\ldots \ldots \ldots \ldots \ldots$ 1-35

1.53 The photograph of the 5-cm-long YBCO film on e-beam/sputtered

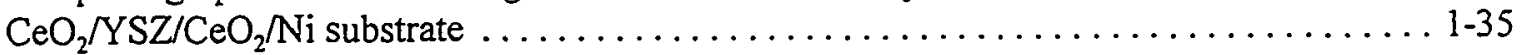

1.54 Schematic representation of the system to deposit CCVD coatings $\ldots \ldots \ldots \ldots \ldots \ldots$ 


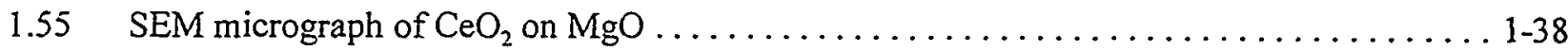

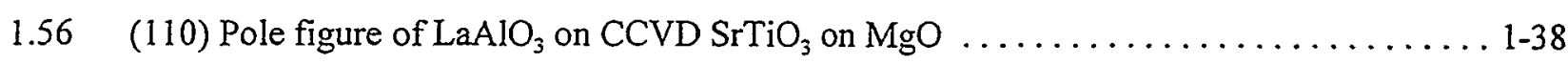

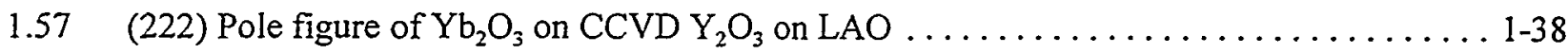

$1.58 \mathrm{SEM}$ micrograph of epitaxial $\mathrm{YBCO}(5 \mathrm{wt} \% \mathrm{Ag})$ on $\mathrm{LaAlO}_{3} \ldots \ldots \ldots \ldots \ldots \ldots \ldots \ldots . . . \ldots \ldots$

$1.59 \mathrm{SEM}$ micrograph of epitaxial $\mathrm{YbBCO}$ on $\mathrm{LaAlO}_{3} \ldots \ldots \ldots \ldots \ldots \ldots \ldots \ldots \ldots \ldots \ldots .39$

1.60 Resistance vs temperature curve for a $0.3-\mu$ m-thick $\mathrm{YbBCO}$ film on $\mathrm{LaAlO}_{3} \ldots \ldots \ldots \ldots$ 1-40

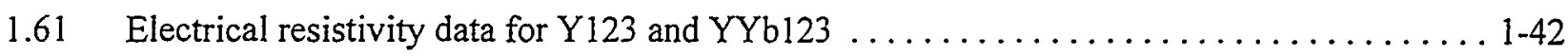

1.62 Ambient temperature thermal conductivity data for five partially substituted

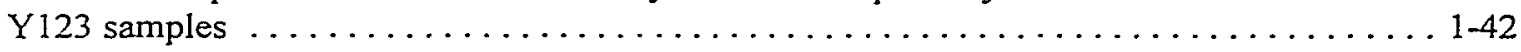

1.63 Thermal conductivity data for polycrystalline $\mathrm{Y} 123$ and $\mathrm{Y}_{0.5} \mathrm{Yb}_{0.5} \mathrm{Ba}_{2} \mathrm{Cu}_{3} \mathrm{O}_{7-\delta} \ldots \ldots \ldots \ldots$ 1-43

1.64 Estimated phonon thermal resistivity curves for $\mathrm{Y} 123$ and $\mathrm{Y}_{0.5} \mathrm{Yb}_{0.5} \mathrm{Ba}_{2} \mathrm{Cu}_{3} \mathrm{O}_{7-\delta} \ldots \ldots \ldots 1-43$

1.65 Surface profile scan of $\mathrm{CeO}_{2}$ film deposited on thin $\mathrm{Si}(111) \ldots \ldots \ldots \ldots \ldots \ldots \ldots \ldots$

1.66 Plot of (a) out-of-plane lattice parameter and (b) XRD I(200)/I(111) intensity ratio as a function of total background pressure for $\mathrm{CeO}_{2}$ films deposited using PLD $\ldots \ldots \ldots 1-46$

1.67 Cross-section transmission electron microscope image of $\mathrm{CeO}_{2}$ film deposited on

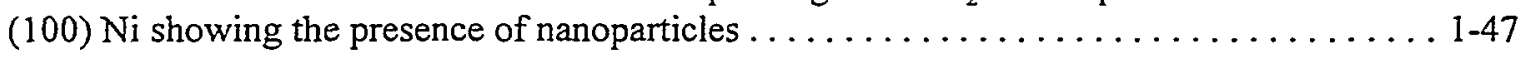

2.1 AC loss of cable \#3 measured by two different techniques $\ldots \ldots \ldots \ldots \ldots \ldots \ldots \ldots \ldots \ldots \ldots$

2.2 AC loss of cable $\# 9$ measured by two different techniques $\ldots \ldots \ldots \ldots \ldots \ldots \ldots \ldots \ldots \ldots \ldots$

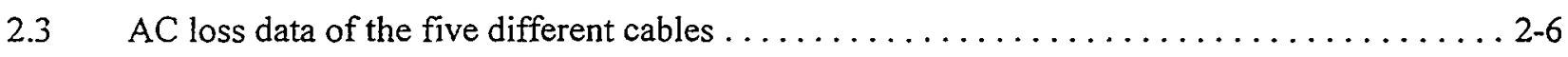

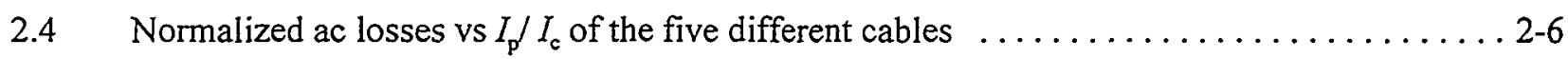

2.5 Southwire Company HTS cable \#7 V-I curves for the four-, three-, two-, and

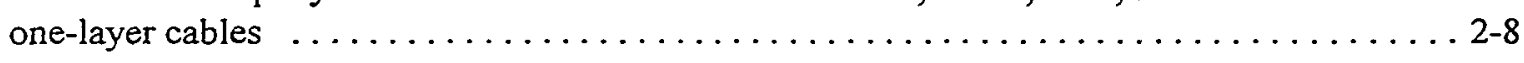

2.6 Temperature rise during a thermal runaway of Southwire Company four-layer

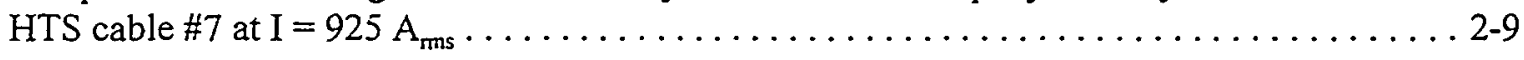

2.7 Southwire Company HTS cable \#7 ac loss measurements for four-, three-, two-,

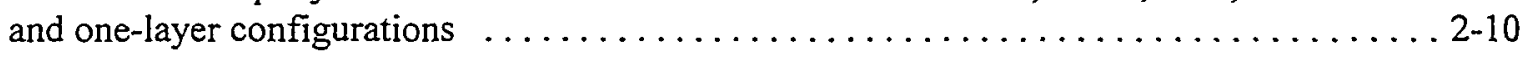

2.8 Southwire Company HTS prototype cable \#7 normalized ac loss comparison

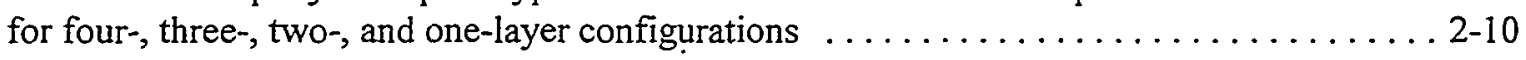


2.9 Comparisons of four-layer and one-layer cable configuration ac loss measurements with monoblock theory and Dresner theory $\ldots \ldots \ldots \ldots \ldots \ldots \ldots \ldots \ldots \ldots \ldots \ldots \ldots \ldots \ldots \ldots$

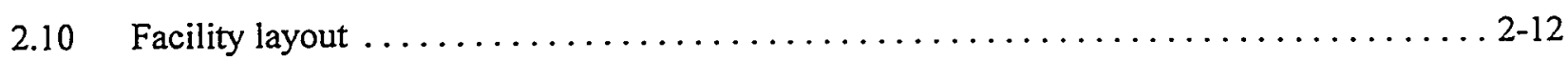

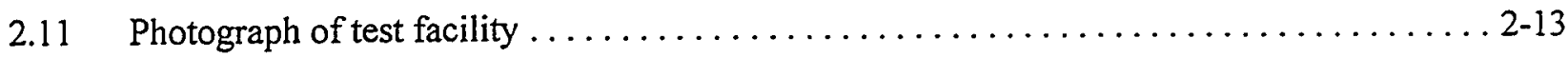

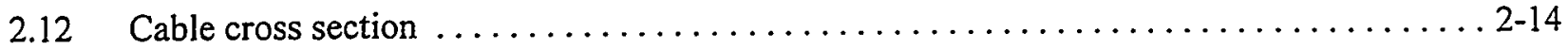

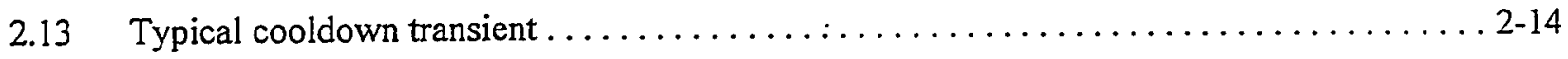

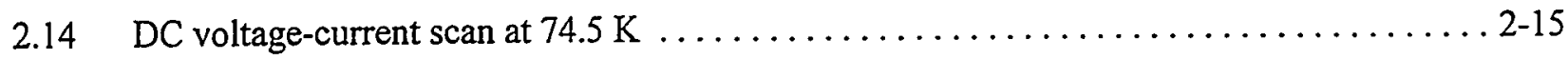

2.15 Cable critical current as a function of temperature $\ldots \ldots \ldots \ldots \ldots \ldots \ldots \ldots \ldots \ldots \ldots \ldots$

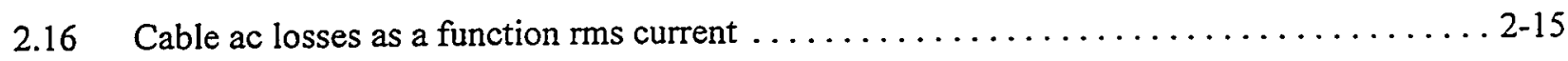

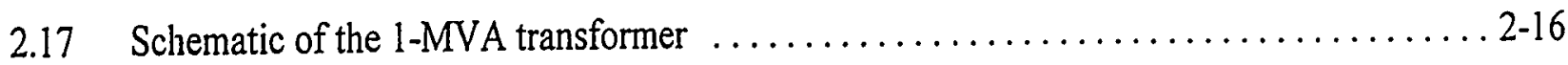

2.18 Completed 1-MVA transformer assembly before tanking $\ldots \ldots \ldots \ldots \ldots \ldots \ldots \ldots \ldots \ldots$

2.19 Overall view of completed transformer on test at Waukesha $\ldots \ldots \ldots \ldots \ldots \ldots \ldots \ldots .17$

2.20 Winding cooldown temperatures and voltages vs time $\ldots \ldots \ldots \ldots \ldots \ldots \ldots \ldots \ldots \ldots \ldots$

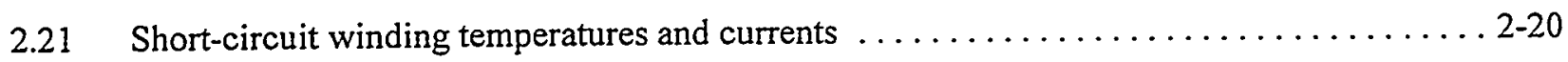

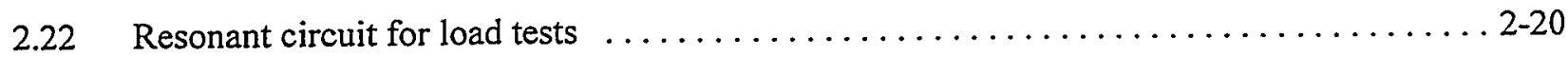

2.23 High-bay high-voltage laboratory and control room at ORNL $\ldots \ldots \ldots \ldots \ldots \ldots \ldots \ldots 21$

2.24 Laboratory at ORNL for in-house construction of model cables $\ldots \ldots \ldots \ldots \ldots \ldots \ldots 2-21$

2.25 Ratio of impulse breakdown to $\mathrm{AC}$ as a function of $\mathrm{LN}_{2}$ pressure for cryoflex insulation ... 2-22 


\section{List of Tables}

1.1. Phi and omega scan results of epitaxial buffer layers $\ldots \ldots \ldots \ldots \ldots \ldots \ldots \ldots \ldots \ldots 1-38$

1.2. Phi and omega scan results of epitaxial superconductors $\ldots \ldots \ldots \ldots \ldots \ldots \ldots \ldots \ldots \ldots$

1.3. Characteristics of cut-bar thermal conductivity samples $\ldots \ldots \ldots \ldots \ldots \ldots \ldots \ldots \ldots \ldots 1$

1.4. Characteristics of samples used for low temperature measurements $\ldots \ldots \ldots \ldots \ldots \ldots \ldots 1-42$

1.5. Lattice spacing and strain for various $\mathrm{CeO}_{2}$ films $\ldots \ldots \ldots \ldots \ldots \ldots \ldots \ldots \ldots \ldots \ldots \ldots \ldots \ldots$

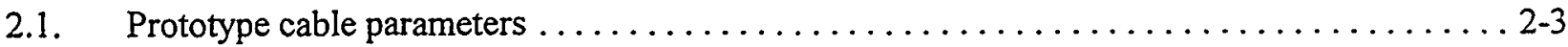

2.2. Southwire Company HTS cable \#7 construction details $\ldots \ldots \ldots \ldots \ldots \ldots \ldots \ldots .7$

2.3. Southwire Company HTS cable \#7 dc characteristics for different numbers of

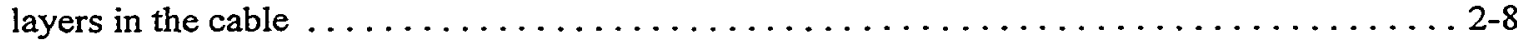

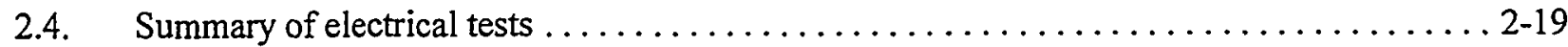

3.1. Superconducting Technology Program funding: authorization and outlay by fiscal year $\ldots \ldots 3-2$

3.2 Superconductivity Program Summary of Cooperative Agreements active in FY $1998 \ldots \ldots$. . . 3-3

3.3 Superconducting Technology Program (FY 1998) invention disclosures . . . . . . . . . 3-7

3.4 Superconducting Technology Program (FY 1998) patent license agreements .......... 3-8

3.5 Superconducting Technology Program patents issued $\ldots \ldots \ldots \ldots \ldots \ldots \ldots \ldots \ldots \ldots$ 
. 


\section{Acronyms and Initialisms}

\begin{tabular}{|c|c|}
\hline ac & alternating current \\
\hline AEM & analytical electron microscopy \\
\hline ASC & American Superconductor Corporation \\
\hline BKD & backscatter Kikuchi diffraction \\
\hline CCVD & combustion chemical vapor deposition \\
\hline CRADA & cooperative research and development agreement \\
\hline dc & direct current \\
\hline DOE & U.S. Department of Energy \\
\hline DOE-HQ & DOE Headquarters \\
\hline DTA & differential thermal analysis \\
\hline DTA/TGA & differential thermal analysis/thermogravimetric analysis \\
\hline e-beam & electron beam \\
\hline EDS & energy-dispersive spectroscopy \\
\hline FEG & field emission gun \\
\hline FWHM & full width at half maximum \\
\hline GB & grain boundary \\
\hline HTS & high-temperature superconductivity/superconductor/superconducting \\
\hline HV & high vacuum \\
\hline IBAD & ion-beam-assisted deposition \\
\hline$I_{c}$ & critical current \\
\hline IEC & International Electric Commission \\
\hline IGC & Intermagnetics General Corporation \\
\hline$I_{\mathrm{p}}$ & peak current \\
\hline$I_{\text {ms }}$ & root mean square cable current \\
\hline$J_{c}$ & critical current density \\
\hline$J_{e}$ & engineering critical current density \\
\hline$K_{\mathrm{c}}$ & critical current per unit width of conductor $\left(I_{c} / w\right)$ \\
\hline $\mathrm{KU}$ & University of Kansas \\
\hline LANL & Los Alamos National Laboratory. \\
\hline $\mathrm{LN}_{2}$ & liquid nitrogen \\
\hline LTS & low-temperature superconductor \\
\hline MOCVD & metal-organic chemical vapor deposition \\
\hline MOD & metal organic decomposition \\
\hline MSI & Midwest Superconductivity, Inc. \\
\hline ORNL & Oak Ridge National Laboratory \\
\hline PIT & power-in-tube \\
\hline PLD & pulsed-laser deposition \\
\hline RABiTSTM & rolling-assisted biaxially textured substrates \\
\hline RBS & Rutherford Backscattering Spectroscopy \\
\hline rf & radio frequency \\
\hline RG\&E & Rochester Gas and Electric Company \\
\hline rms & root mean square \\
\hline RTA & rapid thermal annealer \\
\hline SAD & selected area diffraction \\
\hline SEM & scanning electron microscopy \\
\hline SEM-EDAX & $\begin{array}{l}\text { scanning electron microscopy-energy-dispersive X-ray microanalysis } \\
\text { self field }\end{array}$ \\
\hline
\end{tabular}




$\begin{array}{ll}\text { SFO } & \text { surface flashover } \\ \text { SMES } & \text { Superconducting Magnetic Energy Storage } \\ \text { SPI } & \text { Superconductivity Partnership Initiative } \\ \text { STEM } & \text { scanning transmission electron microscopy } \\ \text { SUNY } & \text { State University of New York } \\ T_{c} & \text { critical temperature/transition temperature } \\ \text { TEM } & \text { transmission electron microscopy } \\ \text { TGA } & \text { thermogravimetric analysis } \\ \text { thd } & \text { tetra-methyl-heptane-dionate } \\ \text { ULPA } & \text { ultra-low penetrating air } \\ \text { WDG } & \text { Wire Development Group } \\ \text { WEC } & \text { Westinghouse Electric Company } \\ \text { WES } & \text { Waukesha Electric Systems } \\ \text { XRD } & \text { X-ray diffraction } \\ \text { YBCO } & \text { yttrium barium copper oxide } \\ \text { YSZ } & \text { yttria-stabilized zirconia } \\ \text { Z-STEM } & \text { Z-contrast scanning transmission electron microscopy }\end{array}$




\section{Executive Summary}

The Oak Ridge National Laboratory (ORNL) Superconducting Technology Program is conducted as part of a national effort by the U.S. Department of Energy's Office of Energy Efficiency and Renewable Energy to develop the science and technology base needed by U.S. industry for commercial development of electric power applications of high temperature superconductivity. The two major elements of this program are wire development and applications development. This document describes the major research and development activities for this program together with related accomplishments. The technical progress reported was summarized from recent open literature publications, presentations, and information prepared for the FY 1998 Annual Program Review held July 20-22, 1998. Aspects of ORNL's work that were presented at the Applied Superconductivity Conference (September 1998) are included in this report, as well. This ORNL program is highly leveraged by the staff and other resources of U.S. industry and universities. In fact, nearly three-fourths of the ORNL effort is devoted to cooperative projects with private companies. Interlaboratory teams are also in place on a number of industry-driven projects. Patent disclosures, working group meetings, staff exchanges, and joint publications and presentations ensure that there is technology transfer with U.S. industry. Working together, the collaborative teams are making rapid progress in solving the scientific and technical issues necessary for the commercialization of long lengths of practical high temperature superconductor wire and wire-using systems. 



\section{Highlights for Fiscal Year 1998}

\section{Wire Development}

- First high critical current density $\left(J_{c}\right)$ results are reported for ex situ deposited YBCO precursor on rolling-assisted, biaxially textured substrates (RABiTS ${ }^{\text {TM }}$ ). By decoupling the deposition and epitaxial growth processing steps using the "barium fluoride" approach, the robustness of the overall process is enhanced, which may facilitate scale-up to long tape lengths. Films exceeding $1 \mathrm{MA} / \mathrm{cm}^{2}$ have been demonstrated on buffered, $2-\mathrm{mil}(50-\mu \mathrm{m})$ nickel. In addition, a first demonstration by CRADA partner $3 \mathrm{M}$ has yielded a $J_{\mathrm{c}} \sim 300,000 \mathrm{~A} / \mathrm{cm}^{2}$ on $3 \mathrm{M}$ nickel and ORNL buffers.

- The continuous deposition of multilayer oxide films on moving long-length metallic substrates using pulsed laser deposition (PLD), and using noncontact heating for the first time, was achieved. Epitaxial $\mathrm{YBCO} / \mathrm{CeO}_{2} / \mathrm{yttria}$-stabilized zirconia (YSZ) $/ \mathrm{CeO}_{2}$ layers were grown on $1 \mathrm{~cm} \times 10 \mathrm{~cm}$ rolled-Ni tape substrates. The $\mathrm{Ni}$ tape was heated radiantly and translated while oxide layers were continuously deposited. The biaxial texture of the 10-cm Ni tape was transferred through the buffer layers to the topmost YBCO during the continuous deposition. The in-plane and out-of-plane texturing of YBCO and buffer layers were uniform along the scanning direction with variations less than $\pm 10 \%$ and $\pm 5 \%$, respectively. The average transport zero field $J_{c}(77 \mathrm{~K})$ for numerous $10-\mathrm{cm}$ samples was about $200,000 \mathrm{~A} / \mathrm{cm}^{2}$, with the highest $J_{c}$ and critical current $\left(I_{c}\right)$ values at $77 \mathrm{~K}, 0 \mathrm{~T}$ of $270,000 \mathrm{~A} / \mathrm{cm}^{2}$ and $16.7 \mathrm{~A}$, respectively. This study demonstrates the feasibility of continuous multilayer, multicomponent oxide film deposition on rolled-textured metal with uniform thickness, composition, and crystallographic orientation using PLD.

- Conductors coated with $\mathrm{YBa}_{2} \mathrm{Cu}_{3} \mathrm{O}_{7-\mathrm{y}}(\mathrm{YBCO})$ have emerged as the second generation of superconducting wires for high-temperature and high-field applications. In continuation of our effort to develop a non-vacuum process to produce coated conductors, we are presently using a metalorganic precursor route. The buffer layers chosen in this study are $\mathrm{REAlO}_{3}(\mathrm{RE}=\mathrm{La}, \mathrm{Nd}, \mathrm{Gd}$, and $\mathrm{Y}$ ) (rare earth aluminates) and $\mathrm{NdGaO}_{3}$ (neodymium gallate). All the rare earth aluminates and $\mathrm{NdGaO}_{3}$ were grown epitaxially on $\mathrm{SrTiO}_{3}(100)$ (strontium titanate) single-crystal substrates using sol-gel alkoxide precursors. The texture of the $\mathrm{REAlO}_{3}$ films was correlated with the lattice mismatch between the $\mathrm{SrTiO}_{3}$ substrates and the $\mathrm{REAlO}_{3}$ films. Films of $\mathrm{LaAlO}_{3}$ and $\mathrm{NdAlO}_{3}$ were also grown epitaxially on roll-textured $\mathrm{Ni}(100)$ substrates with two in-plane orientations. The YBCO films were then grown on the $\mathrm{LaAlO}_{3}$ and $\mathrm{NdAlO}_{3}$ buffer layers by PLD. A transport $J_{\mathrm{c}}$ of $\sim 1 \times 10^{6} \mathrm{~A} / \mathrm{cm}^{2}$ at $77 \mathrm{~K}$ was obtained for $0.25-\mu \mathrm{m}$-thick $\mathrm{YBCO}$ films on $\mathrm{NdGaO}_{3}$ buffer layers.

- Bi-2223 tapes have been fabricated using an alternative coated-conductor approach. This technique allows the examination of critical issues, such as $c$-axis alignment of $\mathrm{Bi}-2223$ grains, influence of the impurity channel, filament uniformity, fill factor, and $\mathrm{Ag}$ sheath, which are not easily accessible through the powder-in-tube approach. Basic developmental issues in coated-conductor fabrication have been addressed. The initial formation kinetics of these coated conductors is rapid, resulting in a need to re-evaluate the thermomechanical treatment schedule. A self-field $J_{\mathrm{c}}$ of $41,000 \mathrm{~A} / \mathrm{cm}^{2}$ at $77 \mathrm{~K}$ has been achieved in a crack-containing coated-conductor sample sintered under nonideal conditions.

- The $J_{c}$ of fully processed $\mathrm{Bi}-2223$ conductor is influenced by a large number of processing parameters. Among these are the thermomechanical processing schedule and the extent of $\mathrm{Bi}-2223$ phase conversion, which are, in turn, affected by the precursor stoichiometry. Powder precursors with 
varying $\mathrm{Cu}$ content were prepared using an aerosol pyrolysis technique, and powder-in-tube conductors were fabricated using these precursors. Both fast and slow cooling rates were employed during thermomechanical processing, and different treatment schedules are correlated to the $J_{c}$.

- A high $J_{\mathrm{c}}$ of $2.2 \times 10^{6} \mathrm{~A} / \mathrm{cm}^{2}$ at $77 \mathrm{~K}$ (extrapolated from $0.5 \times 10^{6} \mathrm{~A} / \mathrm{cm}^{2}$ at $86 \mathrm{~K}$ ) was obtained for $0.2-\mu \mathrm{m}$-thick YBCO film on sol-gel $\mathrm{LaAlO}_{3}$-buffered $\mathrm{SrTiO}_{3}(100)$ substrates. This work was done as part of the effort to develop non-vacuum processes for deposition of YBCO on RABiTSTM. The $\mathrm{YBCO}$ was deposited using an all-iodide precursor approach, which permits YBCO formation without water vapor.

- A Ni-13\% Cr alloy tape has been developed for coated-conductor applications that require nonmagnetic superconducting wire. The alloy is nonmagnetic at $77 \mathrm{~K}$. Furthermore, the alloy has increased yield and ultimate tensile stress properties compared to rolled, pure nickel tape. YBCO films deposited on buffered $\mathrm{Ni}-13 \% \mathrm{Cr}$ alloy have yielded a crack-free high-temperature superconducting (HTS) layer with $J_{c}=200,000 \mathrm{~A} / \mathrm{cm}^{2}(77 \mathrm{~K}, \mathrm{H}=0)$.

- In-plane aligned, epitaxial $\mathrm{CeO}_{2}$ has been deposited on moving nickel tape up to 0.7-m long using a new reel-to-reel vapor deposition system. The system provides for in situ annealing of the moving, as-rolled nickel tape, buffer layers, and, in a separate chamber, deposition of $\mathrm{BaF}_{2}, \mathrm{Y}$, and $\mathrm{Cu}$.

- High-current $\mathrm{YBa}_{2} \mathrm{Cu}_{3} \mathrm{O}_{7-\mathrm{y}}(\mathrm{YBCO})$ and $\mathrm{Tl}_{0.78} \mathrm{Bi}_{0.22} \mathrm{Sr}_{1.6} \mathrm{Ba}_{0.4} \mathrm{Ca}_{2} \mathrm{Cu}_{3} \mathrm{O}_{9-\mathrm{y}}(\mathrm{Tl}, \mathrm{Bi}-1223)$ coated conductors were fabricated on RABiTS ${ }^{\mathrm{TM}}$ with a layer sequence of $\mathrm{CeO}_{2} / \mathrm{YSZ} / \mathrm{CeO}_{2} / \mathrm{Ni}$. The Tl,Bi-1223 films were grown on all electon-beam (e-beam) buffers using pulsed laser ablation of precursor films followed by post-annealing. A transport $J_{c}$ of $4.3 \times 10^{5} \mathrm{~A} / \mathrm{cm}^{2}$ at $77 \mathrm{~K}$ and zero field was measured. The YBCO films were grown on e-beam/sputtered buffers using e-beam co-evaporated $\mathrm{Y}-\mathrm{BaF}_{2}-\mathrm{Cu}$ precursors followed by post-annealing. A transport $J_{\mathrm{c}}$ of $1.6 \times 10^{6} \mathrm{~A} / \mathrm{cm}^{2}$ at $77 \mathrm{~K}$ was obtained on a $\sim 0.3-\mu \mathrm{m}$-thick YBCO film in zero field.

- Residual compressive stress due to plume-induced energetic particle bombardment in $\mathrm{CeO}_{2}$ films deposited by PLD is reported. For laser ablation film growth in low pressures, stresses as high as $2 \mathrm{GPa}$ were observed as determined by substrate curvature and four-circle $\mathrm{X}$-ray diffraction. The amount of stress in the films could be manipulated by controlling the kinetic energies of the ablated species in the plume through gas-phase collisions with an inert background gas. The film stress decreased to near zero for argon background pressures greater than $50 \mathrm{~m}$ Torr. However, at these higher background pressures, the formation of nanoparticles in the deposited film was observed.

- Measurements of $J_{c}$ in large magnetic fields of thin-film YBCO grain boundaries (GBs) show a transition from grain-like to weak-link type behavior with increasing misorientation angle. Low-angle GBs and RABiTS ${ }^{\mathrm{rM}}$ samples retain power law V-I characteristics that are indicative of single-crystal samples. This behavior is the result of a distribution of dislocation cores along the GB that allows grain-like channels to exist. The best YBCO/RABiTSTM tapes will have limits to $J_{c}$ limited by GBs of a few degrees (the nearest neighbor misorientation), not the typical 8 to $10^{\circ}$ full width at half maximum measured by $\mathrm{X}$-ray diffraction analysis over an ensemble of grains.

- A new low-cost, open-atmosphere deposition technique, Combustion Chemical Vapor Deposition (CCVD), was used to deposit epitaxial buffer layers and high-temperature superconductors on oxide single-crystal substrates. The CCVD process has the potential for manufacturing buffer layers and superconductors onto textured-metal substrates in a continuous reel-to-reel production. CCVD does not use vacuum equipment or a reaction chamber required by conventional techniques, but its coating quality rivals and even exceeds that of conventional methods. Compounds being studied with the 
CCVD process include the buffer layers cerium oxide $\left(\mathrm{CeO}_{2}\right)$, yttria stabilized zirconia (YSZ), strontium titanate $\left(\mathrm{SrTiO}_{3}\right)$, lanthanum aluminate $\left(\mathrm{LaAlO}_{3}\right)$, yttria $\left(\mathrm{Y}_{2} \mathrm{O}_{3}\right)$, and ytterbium oxide $\left(\mathrm{Yb}_{2} \mathrm{O}_{3}\right)$ and two rare earth superconductors, $\mathrm{YBa}_{2} \mathrm{Cu}_{3} \mathrm{O}_{7-\mathrm{x}}(\mathrm{YBCO})$ and $\mathrm{YbBa}_{2} \mathrm{Cu}_{3} \mathrm{O}_{7-\mathrm{x}}(\mathrm{YbBCO})$.

- Partially substituted $\mathrm{YBa}_{2} \mathrm{Cu}_{3} \mathrm{O}_{7-\delta}, \mathrm{Y} 123$, samples are produced by replacing part of the $\mathrm{Y}$ with appropriate rare earth elements and/or part of the $\mathrm{Ba}$ with Sr. Partial substitution has little effect on the normal state resistivity or superconducting transition temperature, but should reduce the phonon part of the thermal conductivity, $\lambda_{\mathrm{p}}$. Ambient temperature measurements on several polycrystalline samples show a thermal conductivity, $\lambda$, reduction relative to $Y 123$. The effect persists to lower temperatures, and data for $\mathrm{Y} 123$ and $\mathrm{Y}_{0.5} \mathrm{Yb}_{0.5} \mathrm{Ba}_{2} \mathrm{Cu}_{3} \mathrm{O}_{7-\delta}$ show that the $\lambda$ peak at $T_{c} / 2$ is also affected.

\section{Systems Development}

- The United States' first HTS complete cable system is operational in a joint ORNL/Southwire facility located at Oak Ridge.

- The dc current measurement of Southwire Company's 1-m cable \#8 resulted in a 70\% increase in critical current over previous cables, demonstrating a very substantial improvement in tape performance. The ac loss data lie between the values predicted by Norris and Dresner. For this cable, losses are about $0.4 \mathrm{~W} / \mathrm{m}$ at the design current of $1250 \mathrm{~A}$.

- Significant progress has been made in constructing the 5-m HTS cable test facility. Cable end terminations for the 5-m cable tests arrived at ORNL in December 1997. The terminations were jointly designed with Southwire and fabricated by Southwire and their subcontractors. Initial partial discharge testing of the cable terminations was completed. Southwire completed the construction of the first fully insulated, 5-m HTS cable in their manufacturing facility in Carrollton, Georgia, and installed the cable in the cable test facility at ORNL in March 1998. Testing of cable \#7, a 1-m prototype HTS cable, was completed. Dielectric testing of Cryoflex and liquid nitrogen continues, and significant progress has been made in the construction of the model cable (pressurized cryogenic dielectric) test facility. The critical current of the first Southwire 5-m HTS cable has been measured at a variety of temperatures. At the lowest temperature achieved to date, the critical current was around $1200 \mathrm{~A}($ at $74 \mathrm{~K}$ ). The cable and all subsystems (dielectrics, vacuum, cryogenics, terminations, and instrumentation) are being tested to provide design data for Southwire's 30-m Superconductivity Partnership Initiative (SPI) cable.

- The nominal 1-MVA, single-phase Waukesha/Intermagnetics General Corporation transformer and test bed were constructed with windings and core cross sections comparable to those expected for a reference commercial 138-kV, 30-MVA transformer but operating at one-tenth the voltage and power per phase. Scale-up would thus be minimized in the subsequent construction of 5/10-MVA alpha and 30-MVA beta prototypes planned for Phases II and III. The windings were made with a low-cost, surface-coated BSCCO-2212 conductor, cryocooled closed cycle to $25 \mathrm{~K}$. Despite higher-thandesigned-for ac losses and an indication of excess partial discharge, short-duration tests under load achieved $150 \mathrm{~A}$ at $4.5 \mathrm{kV}$ for a delivered power of $0.68 \mathrm{MVA}$. The separately achieved maximum open-circuit primary voltage and the maximum primary amperes indicate a basic transformer capability of $(11 \mathrm{kV}) \times(150 \mathrm{~A})=1.65 \mathrm{MVA}$. The vacuum, structure, and cryogenic cooling systems performed well, indicating the technical feasibility of the HTS transformer concept and allowing a confident scale-up to the 5/10-MVA class transformer in Phase II. 


\section{Programmatic}

- Three new U.S. patent license agreements were executed during the fiscal year: MicroCoating Technologies, EURUS Technologies, and 3M Company. There are now a total of five companies that have licensed ORNL's RABiTS TM technology.

- The first two U.S. patents on ORNL's RABiTSTM for HTS wire technology were issued in FY 1998: Patent number 5,739,086 issued on April 14 and number 5,741,377 issued on April 21. The patents describe a biaxially textured article that includes a rolled and annealed, biaxially textured substrate of a metal with a face-centered cubic, body-centered cubic, or hexagonal close-packed crystalline structure and an epitaxial superconductor or other device epitaxially deposited thereon. RABiTSTM provides the template upon which YBCO and other superconductors, or precursors to superconductors, may be deposited. The RABiTS ${ }^{\mathrm{TM}}$ structure presently being used by ORNL and some of its partners consists of rolled-and-annealed nickel, followed by one or more buffer layers. ORNL has demonstrated critical current densities of up to $3 \mathrm{MA} / \mathrm{cm}^{2}$ for $Y B C O$ films deposited by PLD on short samples (measured in self field, at $77 \mathrm{~K}$ ). Recently, in collaboration with $3 \mathrm{M}$ Company, Southwire Company, and Los Alamos National Laboratory, ORNL demonstrated ex situ growth of YBCO films by the "barium fluoride" electron beam evaporation process on RABiTSTM with critical current densities around 1.5 million $\mathrm{A} / \mathrm{cm}^{2}$. The work was done with funding provided by the U.S. Department of Energy's Office of Energy Efficiency and Renewable Energy, Office of Power Technologies, and Office of Science, Division of Materials Science. 


\section{Technical Progress \\ in Wire Development}

\section{A PRECURSOR APPROACH YIELDS HIGH CRITICAL CURRENT DENSITY ON RABITS ${ }^{\text {TM }}$}

In search of scalable methods for coatedconductor technology, the $\mathrm{BaF}_{2}$ ex situ precursor process has been successfully tested and developed as a promising alternative approach for making high-critical currentdensity $\left(J_{\mathrm{c}}\right)$ yttrium barium copper oxide (YBCO) films on rolling-assisted biaxially textured substrates (RABiTS ${ }^{\mathrm{TM}}$ ). The ex situ precursor approach differs from the more commonly used in situ techniques in that it features a two-step approach whereby the YBCO layer is first deposited as an insulating precursor film on essentially unheated substrates and then annealed in a furnace to form the superconductor structure. By contrast, singlestep in situ processes involve YBCO epitaxial growth immediately as the film is being deposited, depending sensitively on details of the deposition process. By decoupling the deposition and epitaxial growth processing steps, the robustness of the overall process is enhanced, which may facilitate scale-up to long tape lengths. For example, high-rate and/or nonvacuum precursor deposition techniques and batch processing for the ex situ anneal may be used. Possible implications of these advantages are currently being evaluated as part of the $3 \mathrm{M}$ Southwire-Los Alamos National Laboratory (LANL)-Oak Ridge National Laboratory (ORNL) cooperative research and development agreement ( CRADA).

Using the $\mathrm{BaF}_{2}$ precursor method, epitaxial YBCO films were grown on RABiTS ${ }^{\mathrm{TM}}$ with basically a single orientation as determined by $X$-ray diffraction (XRD) pole-figure analysis. For the best films, $J_{c} s$ at $77 \mathrm{~K}$ are well in excess of $1 \mathrm{MA} / \mathrm{cm}^{2}$, indicating strong supercurrent transport. The results are equivalent to the best films produced by in situ pulsed-laser deposition (PLD), previously the only available technique for high- $J_{\mathrm{c}}$ films on RABiTS ${ }^{\mathrm{TM}}$. This comparison is highlighted in Fig. 1.1, where we have plotted the dependence of $J_{c}$ on the applied magnetic field oriented parallel to the $c$-axis (i.e., perpendicular to the film surface). Results are presented for ex situ YBCO films on two types of Ni metal tape, having a thickness of 125 or $50 \mathrm{~mm}$. As indicated in Fig. 1.1, reducing the metal tape thickness had a negligible effect on the supercurrent transport performance with $J_{c}>1 \mathrm{MA} / \mathrm{cm}^{2}$ for the best films on either tape. The technological implication of the thickness reduction is that less $\mathrm{Ni}$ needs to be used in the coated conductor, raising significantly the engineering critical current density $\left(J_{\mathrm{e}}\right)$. For example, the ex situ YBCO films featured in Fig. 1.1 had a standard thickness of $0.3 \mathrm{~mm}$, from which a $J_{\mathrm{e}} @ 11,000 \mathrm{~A} / \mathrm{cm}^{2}$ may be calculated for the film on $50-\mathrm{mm} \mathrm{Ni}$. It seems likely that by increasing the YBCO film thickness, conductors with $J_{\mathrm{e}} \mathrm{s}$ in the practical range $>30,000 \mathrm{~A} / \mathrm{cm}^{2}$ will be realized in the near future with the $\mathrm{BaF}_{2}$ precursor method.

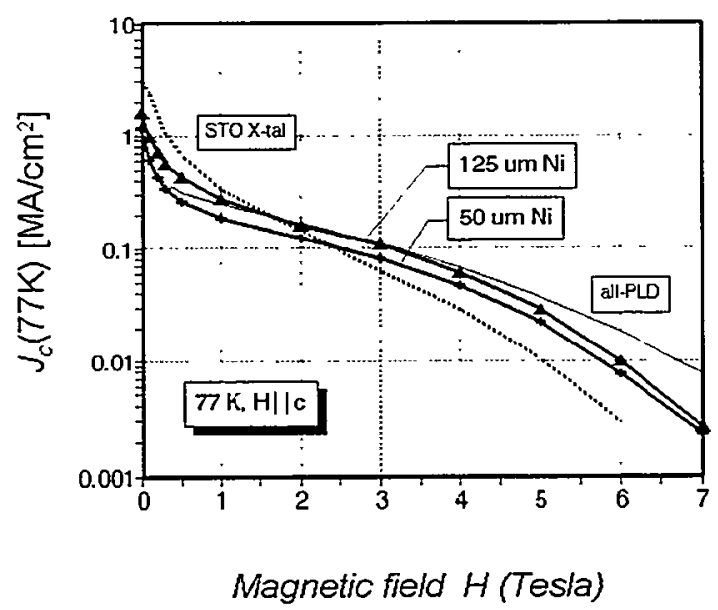

Fig. 1.1. Field dependence of the critical current density $\left(J_{c}\right)$ in ex situ processed YBCO films on nickel RABiTS ${ }^{\mathrm{rm}}$ at $77 \mathrm{~K}$. Also included are results for a YBCO film made by in situ PLD and a high- $J_{c}$ film on $\mathrm{SrTiO}_{3}(100)$ single-crystal substrate. 
It is interesting that for both techniques (in situ PLD and ex situ $\mathrm{BaF}_{2}$ precursor) transport properties for films on RABiTS ${ }^{\mathrm{TM}}$, in fact. closely approach the best results for films on lattice-matched $\mathrm{SrTiO}_{3}$ single-crystal substrates. At low fields, the $J_{c}$ for high-quality films on RABiTS ${ }^{\mathrm{TM}}$ typically is 2 to 3 times lower, but the $J_{c}$ curves across at the high magnetic field, indicating that for greater fields the films on RABiTSTM carry a higher $J_{\mathrm{c}}$. This crossover probably indicates the influence of greater densities of favorable flux-pinning defects in the films on RABiTSTM; however, the nature of the defects has not yet been identified, nor has a consistent relationship with the presence of low-angle grain boundaries. A map of grain orientations was obtained by electronbeam (e-beam) backscattering diffraction for the high- $J_{c}$ film on 125-mm Ni shown in Fig. 1.1. From this map, a percolation threshold for current transport of only 2 to $3^{\circ}$ was determined, meaning that current can pass from one end of the sample to the other via adjacent grain boundaries that are tilted by 2 to $3^{\circ}$ or less. Considering the intrinsic relationship between $J_{\mathrm{c}}$ and grain boundary misorientation, this low threshold clearly underpins the observed strong supercurrent transport, while providing unequivocal evidence of the high degree of biaxial texturing in the YBCO film achieved via the ex situ process.

The buffer layer architecture used for the films depicted in Fig. 1.1 consists of three oxide sublayers, grown outside of the vacuum chamber used for the $\mathrm{BaF}_{2}-\mathrm{Y}-\mathrm{Cu}$ precursor layer deposition. The architecture was derived from the yttrium-stablized zirconia ( $\mathrm{YSZ}$ ) $/ \mathrm{CeO}_{2} / \mathrm{Ni}$ architecture, previously developed for the in situ PLD process, by adding a thin $\mathrm{CeO}_{2}$ cap layer to enhance compatibility with the precursor approach. Thus. starting from the biaxially textured, rolled Ni tape, the first layer is thin $\mathrm{CeO}_{2}(20$ to $40 \mathrm{~nm})$ grown by reactive e-beam evaporation, then YSZ grown by radio frequency $(\mathrm{rf})$ magnetron sputtering, and finally a thin $\mathrm{CeO}_{2}$ cap layer with a thickness similar to that of the bottom layer. Either the evaporation or sputtering technique was used for this cap layer. To reduce bending of the Ni tape upon decreasing the metal thickness, the YSZ thickness was reduced from an original value of $1 \mathrm{~mm}$ to $0.25 \mathrm{~mm}$. The $\mathrm{BaF}_{2}-\mathrm{Y}-\mathrm{Cu}$ precursor layer was grown by e-beam co-evaporation from three sources, using $\mathrm{Y}$ and $\mathrm{Cu}$ metals and compound $\mathrm{BaF}_{2}$. In the absence of a $\mathrm{CeO}_{2}$ cap layer, film properties are strongly impaired because of a debilitating chemical reaction between the $\mathrm{BaF}_{2}-\mathrm{Y}-\mathrm{Cu}$ precursor and $\mathrm{YSZ}$. Apparently, a thin $\mathrm{CeO}_{2}$ cap layer of 20 to $40 \mathrm{~nm}$ eliminates this reaction; however, it was found that, likewise, $\mathrm{CeO}_{2}$ may react with the precursor layer during the ex situ anneal. Depending on the degree of interdiffusion, this reaction may completely perturb the $\mathrm{YBCO}$ epitaxial growth process, leading to severely impaired supercurrent transport or even insulating behavior. However, unlike the experience with YSZ, it was found that the adverse reaction may be strongly suppressed by optimizing the structural properties of the deposited $\mathrm{CeO}_{2}$ cap layer and adjusting the YBCO processing conditions. This was determined via a series of systematic tests using buffered single-crystal substrates to eliminate the influence of alternative process variables potentially responsible for deteriorating the YBCO properties. Once optimized, high- $J_{\mathrm{c}}$ YBCO films were obtained consistently using the same buffer layer architecture, providing at once evidence for robustness of the $\mathrm{BaF}_{2}$ precursor approach, consistency in buffer layer preparation, and consistent quality of the rolled $\mathrm{Ni}$. Indeed, the interconnected nature of the multiple processes involved provided the greatest challenge to arriving at the present results. Conversely, these results signal progress not only with respect to the development of an alternative YBCO preparation technique, but also a greater understanding of issues involved in all intermediate steps underlying the preparation of consistent and reproducible RABiTSTM.

A summary of the progress made in the course of this research is presented in Fig. 1.2. 


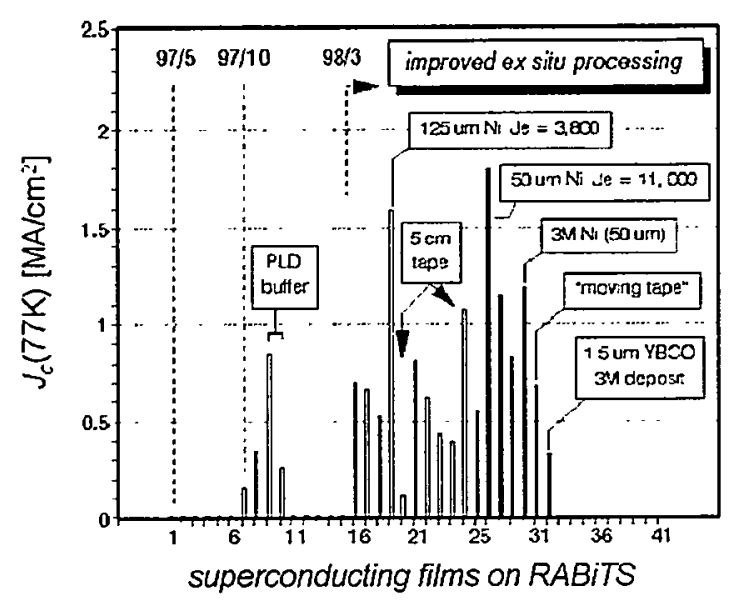

Fig. 1.2. Histogram showing the critical current density $\left(J_{c}\right)$ (at $77 \mathrm{~K}$ in self-field) of ex situ processed YBCO films on nickel RABiTS ${ }^{\text {TM }}$ with evaporated/sputtered $\mathrm{CeO}_{2} / \mathrm{YSZ} / \mathrm{CeO}_{2}$ buffer layer. Open bars indicate $125-\mu \mathrm{m}$-thick Ni tape; shaded bars indicate $50-\mu \mathrm{m}$-thick $\mathrm{Ni}$.

Only superconducting films made with the $\mathrm{BaF}_{2}$ process on the described buffer layer are included because this architecture proved clearly superior to others that were tried. Because of the many interdependent parameters, however, it cannot be concluded that some of the attempted architectures (featuring permutations of sublayer deposition techniques and alternative buffer-layer materials) may eventually prove equally applicable as the one presented here, once further optimization is completely carried out. The subtle nature of this interdependence for the $\mathrm{BaF}_{2}$ precursor method is illustrated in Fig. 1.2 by the arrow indicating "improved ex situ processing." Following the first achievement of high- $J_{c}$ films on RABiTS ${ }^{\mathrm{TM}}$, these positive results initially could not be reproduced. In all these attempts (films 1 to 15 ), essentially the same ex situ anneal was used, based on a successful recipe for YBCO films on $\mathrm{SrTiO}_{3}$ single-crystal substrates. High$J_{c}$ films continued to be obtained on $\mathrm{SrTiO}_{3}$ using this anneal for samples processed in parallel with the RABiTS ${ }^{\mathrm{TM}}$, indicating that the poor results on the metal substrates resulted from a subtle variability in buffer-layer quality. Significantly, with the improved ex situ annealing recipe, high- $J_{c}$ films were consistently obtained on RABiTS ${ }^{\mathrm{TM}}$ as well, without changing the buffer-layer preparation. Clearly, the later formulated annealing recipe is more robust and better suited for application to RABiTSTM. Research is ongoing to further improve the ex situ annealing process, with an emphasis on further increasing the robustness.

Intermediate highlights showing the direction of our research are also indicated in Fig. 1.2. For example, starting with the sample labeled 25 , a transition was made from $\mathrm{Ni}$ tape with a thickness of $125 \mu \mathrm{m}$ to tape with a thickness of $50 \mu \mathrm{m}$, accompanied by a reduction of the YSZ buffer-layer thickness. The thinner tape is softer and more difficult to handle than the thicker tape; however, as the results indicate, the transition was made without compromising the film quality. Recently, the technology for rolling (100) cube-textured $\mathrm{Ni}$ was transferred to $3 \mathrm{M}$ as part of our ongoing CRADA. Long lengths of properly textured $\mathrm{Ni}$ were produced and a high- $J_{c}$ film was grown readily on this $\mathrm{Ni}$ using the $\mathrm{BaF}_{2}$ precursor method and ORNL buffer-layer technology. This result clearly demonstrates the successful transfer of Ni texturing procedures. In preparation of a continuous process, a first high$J_{c}$ film was grown on RABiTS ${ }^{\mathrm{TM}}$ whereby the $\mathrm{Ni}$ was annealed and the first $\mathrm{CeO}_{2}$ sublayer deposited while the tape was moving through the vacuum chamber, using noncontact heating. Eventually, the moving tape technology will be applied to all layers, greatly helped by the relatively large buffer and precursor deposition areas. For the precursor film, the homogenous area in the available vacuum chamber is approximately $5 \times 5 \mathrm{~cm}^{2}$, and using the full range of this deposition zone a first high- $J_{c}$ film of 5-cm length was formed. The $J_{c}$ was measured over two sections of this tape, both exhibiting a $J_{c}>1 \mathrm{MA} / \mathrm{cm}^{2}$ at $77 \mathrm{~K}$, differing by less than $10 \%$. Although obtained for a 
stationary substrate, this result bodes well for future scale-up attempts.

Finally. a beginning of the transfer of the $\mathrm{BaF}_{2}$ precursor process to $3 \mathrm{M}$ was made. As part of this transfer, a precursor film was deposited at $3 \mathrm{M}$ on RABiTS ${ }^{\mathrm{TM}}$ consisting of $3 \mathrm{M}$ nickel tape coated with ORNL buffer. The film (approximately 5 times thicker than the standardized 0.3-mm ORNL YBCO films) was subsequently transported to ORNL for ex situ processing, yielding an encouraging result of a $J_{\mathrm{c}} @ 330 \mathrm{kA} / \mathrm{cm}^{2}$ at $77 \mathrm{~K}$. Joint research efforts are currently under way to maintain and improve the $3 \mathrm{M}$ precursor quality while enhancing the deposition rate and to optimize the ex situ anneal for thicker YBCO deposits.

In summary, it has been demonstrated that the $\mathrm{BaF}_{2}$ ex situ precursor process represents a viable alternative approach for making high- $J_{c}$ YBCO films on RABiTS ${ }^{\mathrm{TM}}$ metal tapes, providing a simpler method that is potentially faster. more reliable. and more flexible than current in situ techniques. Highly textured YBCO films exhibiting strong supercurrent transport properties were formed on a variety of substrates, enabled by the identification of a robust combination of buffer-layer architecture and ex situ processing conditions. In collaboration with our industrial partner (3M), efforts are currently under way to identify critical issues associated with scale-up of the $\mathrm{BaF}_{2}$-based coated conductor process.

\section{A REEL-TO-REEL VAPOR DEPOSITION SYSTEM FOR FABRICATING BUFFERS AND LONG LENGTHS OF SUPERCONDUCTORS}

A reel-to-reel vapor deposition system (Fig. 1.3) has been designed and constructed to fabricate lengths of RABiTSTM from rolled metal tapes. The all-metal sealed system consists of a series of interconnected chambers. A pair of motor-driven reels transports a tape along the center line of these chambers. In the in situ annealing chamber, the moving as-rolled tape is heated to a temperature of $800^{\circ} \mathrm{C}$ in a controlled pressure of $4 \% \mathrm{H}_{2} / \mathrm{Ar}$ to develop biaxial texture. In the buffer-layer deposition chamber, single-component epitaxial buffer layers (up to four) are sequentially deposited by e-beam evaporation on the moving tape.

Simultaneous deposition of $\mathrm{BaF}_{2}, \mathrm{Y}$, and $\mathrm{Cu}$ can be accomplished on the moving RABiTS ${ }^{\mathrm{TM}}$ tape

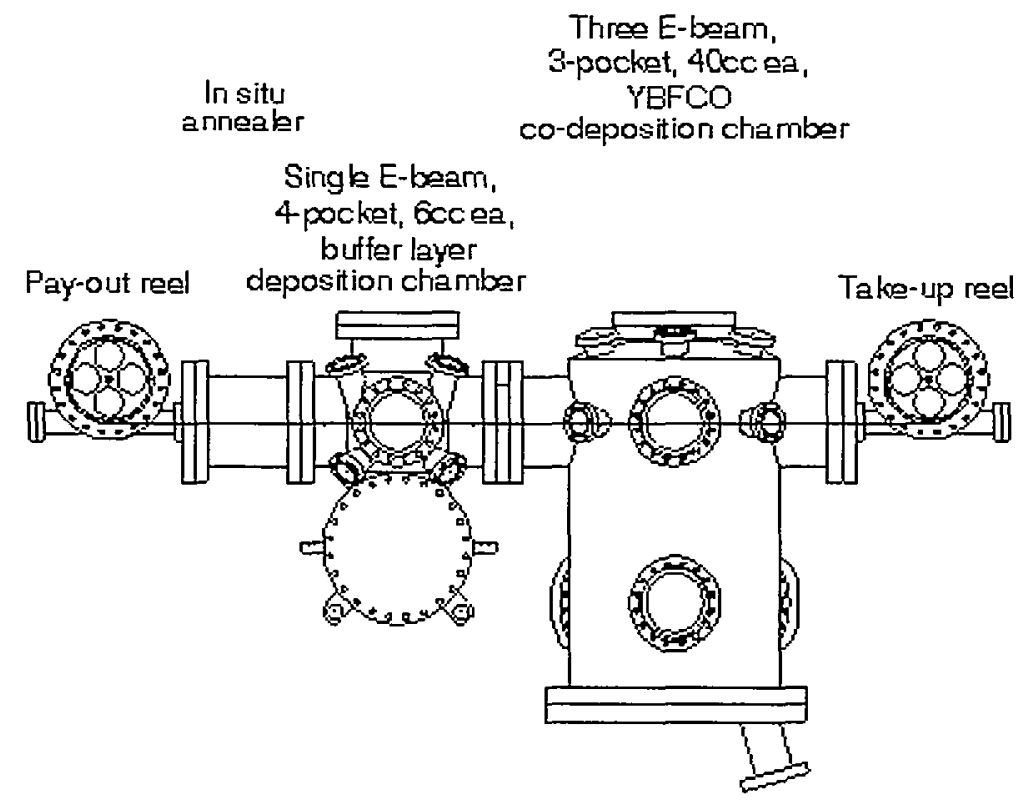

Fig. 1.3. Reel-to-reel vapor deposition system. 
in the co-deposition chamber. The present system has a capacity to deposit $1-\mu$ m-thick $\mathrm{BaF}_{2}$ precursor and $0.5-\mu \mathrm{m}$-thick buffer on $2-\mathrm{m}$ lengths of 1-cm-wide metal tape. Because the system's design is both linear and modular, additional deposition modules (e.g., sputtering) can be easily added.

Good epitaxial $\mathrm{CeO}_{2}$ has been deposited in this system on lengths of moving nickel tape up to $70 \mathrm{~cm}$. Results of an X-ray phi $(\phi)$-scan for a 14-cm length of $\mathrm{CeO}_{2}$-buffered nickel are shown in Fig. 1.4. The in-plane texture of the $\mathrm{CeO}_{2}$ is consistently good throughout the length: $\mathrm{CeO}_{2}[111]$ full width at half maximum (FWHM) $8.5 \pm 0.2^{\circ}$. Currently, efforts are under way to improve the surface morphology of the YSZ that is deposited by e-beam evaporation on lengths of $\mathrm{CeO}_{2}$-buffered nickel.

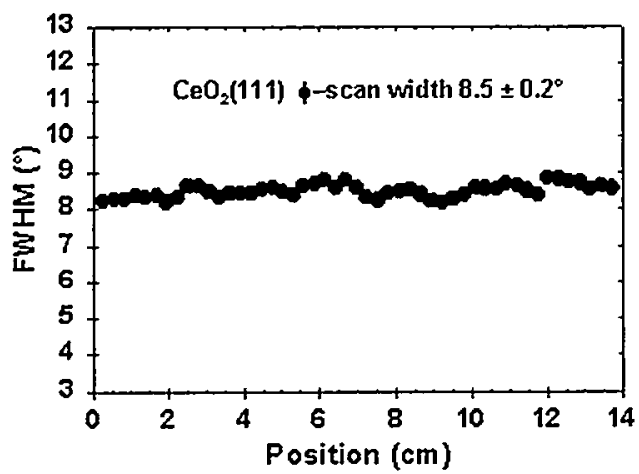

Fig. 1.4. Phi scan of $14-\mathrm{cm} \mathrm{CeO}_{2}-$ buffered nickel.

\section{REEL-TO-REEL CONTINUOUS DEPOSITION OF EPITAXIAL $\mathrm{CeO}_{2}$ BUFFER LAYERS ON BIAXIALLY TEXTURED Ni TAPES BY ELECTRON BEAM EVAPORATION}

\section{Introduction}

High $J_{\mathrm{c}} \mathrm{s}$ greater than $10^{6} \mathrm{~A} / \mathrm{cm}^{2}$ have been obtained in short samples of deposited YBCO conductors made by the RABiTSTM approach. ${ }^{1.2}$
Although hundreds of meters of rolled Ni tapes have been made by our industrial partners, meter lengths of YBCO conductors with high $J_{\mathrm{c}}$ on RABiTS $^{\text {MM }}$ have not yet been fabricated. Starting with as-rolled Ni tapes, four additional steps must be performed in a continuous fashion: annealing the $\mathrm{Ni}$ to obtain the cube texture, depositing suitable epitaxial buffer layers, depositing YBCO films, and postprocessing YBCO films.

A successful RABiTS ${ }^{\mathrm{TM}}$ architecture for short samples is $\mathrm{CeO}_{2} / \mathrm{YSZ} / \mathrm{CeO}_{2} / \mathrm{Ni}^{2+}{ }^{2+} \mathrm{A}$ reel-to-reel e-beam evaporation system has been developed in our laboratory to continuously anneal $\mathrm{Ni}$ tape and deposit the initial $\mathrm{CeO}_{2}$ and/or other oxide buffer layers. A difficulty involved in the deposition of epitaxial oxides on $\mathrm{Ni}$ is the tendency for the formation of unfavorably oriented $\mathrm{NiO}$ during rolling and annealing processes. Nickel oxide formation can be prevented, and existing oxide removed, by controlling the partial pressures of $\mathrm{H}_{2}, \mathrm{H}_{2} \mathrm{O}$, and $\mathrm{O}_{2}$ during the annealing and deposition steps. On this tape, high-quality buffer layers must be deposited that are epitaxial, uniform, scratchfree, and reproducible. Using e-beam evaporation, we have successfully deposited 20 to 30 -nm-thick epitaxial $\mathrm{CeO}_{2}$ buffer layers on 70-cm-long, 1-cm-wide cube-textured $\mathrm{Ni}$ tapes.

In this report, we present an in situ approach to continuously anneal moving $\mathrm{Ni}$ tapes and deposit on such tapes an initial $\mathrm{CeO}_{2}$ buffer layer by e-beam evaporation. Examinations of the buffer-layer structure by XRD and scanning electron microscopy (SEM) and results for YBCO films deposited on short segments of these buffered $\mathrm{Ni}$ are presented.

\section{Experimental}

The reel-to-reel e-beam evaporation system includes three interconnected high-vacuum (HV) chambers: one for annealing the as-rolled Ni tape, one for depositing buffer layers by e-beam evaporation, and one for depositing YBCO films. A 1 -cm-wide, $50-\mu \mathrm{m}$-thick $\mathrm{Ni}$ tape is mounted on two reels and is driven 
continuously along the centerline of these chambers by a stepper motor and a variabletorque motor. The travel speed of the tape can be varied from $5 \mathrm{~cm} / \mathrm{h}$ to $2500 \mathrm{~cm} / \mathrm{h}$. To avoid significant plastic deformation during moving, the tension on the tape can be varied via the torque motor from 0.5 to $2.0 \mathrm{~N}$. The integral reel-to-reel system has the capability of processing up to $2 \mathrm{~m}$ of buffered tape without breaking vacuum to refill the crucibles. The base pressure of the system is $1 \times 10^{-8}$ Torr. Noncontacted heater assemblies are used in the system for $\mathrm{Ni}$ annealing and oxide buffer-layer deposition to temperatures up to $800^{\circ} \mathrm{C}$. The partial pressures of $\mathrm{H}_{2} \mathrm{O}$ and $\mathrm{Ar}-\mathrm{H}_{2}$ are controlled by precision leak valves, and the partial pressures of $\mathrm{H}_{2} \mathrm{O}, \mathrm{Ar}, \mathrm{H}_{2}$ and $\mathrm{O}_{2}$ are monitored by mass spectrometry. Tapes are cleaned with methanol and acetone solution before being loaded onto the reels. The buffer layers are deposited using a four-pocket $6-\mathrm{cm}^{3}$ rotary electron-evaporation source.

\section{Results and Discussion}

\section{In Situ Annealing}

Annealing at elevated temperatures is required to develop a sharp cube texture in as-rolled $\mathrm{Ni}$ tape..$^{5}$ During annealing. the $\mathrm{Ni}$ surface is exposed to oxygen. which can lead to the formation of NiO. Typical conditions for annealing $\mathrm{Ni}$ in this evaporation system are $700^{\circ} \mathrm{C}$ and oxygen partial pressure $\left(\mathrm{PO}_{2}\right)$ of $5 \times 10^{-10}$ Torr. However, at $700^{\circ} \mathrm{C}, \mathrm{NiO}$ can form and is thermodynamically stable for oxygen partial pressures greater than $1 \times 10^{-15}$ Torr. $^{6}$ The $\mathrm{NiO}$ that forms on the cube surface of nickel at elevated temperatures has been shown to exhibit a variety of complex crystallographic structures and not simply $\mathrm{NiO}(100){ }^{7}$ These complex NiO structures may interfere with the ability of the oxide buffer layers to grow epitaxially with respect to the underlying cube-textured-nickel tape. In order to suppress or retard the formation of $\mathrm{NiO}$ near the $\mathrm{Ni}$ surface. we have introduced forming gas
( $4 \% \mathrm{H}_{2}$ in $\mathrm{Ar}$ ) in the vacuum chamber during annealing. ${ }^{8}$ Hydrogen in the forming gas can react with oxygen at the $\mathrm{Ni}$ surface to form water. As long as the ratio of $\mathrm{H}_{2} / \mathrm{H}_{2} \mathrm{O}$ is greater than $10^{2}$ at $700^{\circ} \mathrm{C}, \mathrm{NiO}$ is not stable and can be reduced.

To examine the effect of hydrogen on $\mathrm{CeO}_{2}$ epitaxy during annealing, several as-rolled $\mathrm{Ni}$ tapes were annealed at $700^{\circ} \mathrm{C}$ for $60 \mathrm{~min}$ and under different forming gas pressures. The $\mathrm{CeO}_{2}$ buffer layer was then deposited onto each tape at $700^{\circ} \mathrm{C}$ and a rate of $0.1 \mathrm{~nm} / \mathrm{s}$ to a thickness of 20 to $30 \mathrm{~nm}$ in a $1 \times 10^{-6}$ Torr forming gas. $X R D$ measurements using a $\theta-2 \theta$ diffraction geometry were used to characterize the epitaxy of the $\mathrm{CeO} 2$ buffer layers. Figure 1.5 shows the intensity ratio of $(200)$ to $(200)+(111)$ for the $\mathrm{CeO}_{2}$ buffer layer as a function of the forming gas pressure during $\mathrm{Ni}$ annealing. The forming gas pressure was varied from $2 \times 10^{-6}$ to $8 \times 10^{-3}$ Torr. As seen from this figure, the quality of epitaxy of the $\mathrm{CeO}_{2}$ is reduced for both low and high forming gas pressures. At the lowest forming gas pressure $\left(2 \times 10^{-6}\right.$ Torr $)$, the hydrogen partial pressure is apparently insufficient to completely reduce the surface oxides. At the highest forming gas pressure $\left(8 \times 10^{-3}\right.$ Torr $)$, the partial pressure of oxygen arising from forming gas impurities may suppress the reduction of $\mathrm{NiO}$. Good $\mathrm{CeO}_{2}$

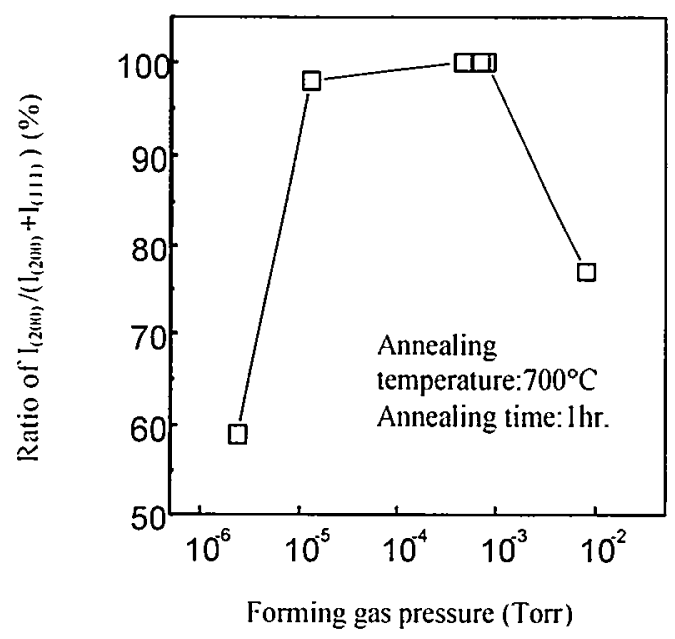

Fig. 1.5. Relative intensity of $\mathrm{CeO}_{2}$ (200) as a function of forming gas pressure $4 \% \mathrm{H}_{2}$ and $96 \% \mathrm{Ar}$. 
epitaxy is obtained only for $\mathrm{Ni}$ tapes annealed in the pressure range of $5 \times 10^{-5}$ to $1 \times 10^{-3}$ Torr where an insignificant amount of $\mathrm{CeO}_{2}(111)$ is observed. From this result, long-length as-rolled $\mathrm{Ni}$ tapes to be used for continuous $\mathrm{CeO}_{2}$ deposition were annealed at $7 \times 10^{-4}$ Torr of flowing forming gas. It is worth mentioning that the appropriate forming gas pressure to anneal $\mathrm{Ni}$ may be vacuum-system dependent and vary with the characteristic background partial pressure of oxygen.

\section{Uniformity of $\mathrm{CeO}_{2}$ Buffer Layer over the Length}

The $\mathrm{CeO}_{2}$ buffer layers were continuously deposited onto moving in situ annealed $\mathrm{Ni}$ tapes by e-beam evaporation using Ce metal at $450^{\circ} \mathrm{C}$ and a rate of $0.1 \mathrm{~nm} / \mathrm{s}$ under an $\mathrm{H}_{2} \mathrm{O}$ partial pressure of 1 to $2 \times 10^{-6}$ Torr. XRD measurements were used to examine the epitaxy of $\mathrm{CeO}_{2}$ buffer layers. Figure 1.6 shows a typical XRD $\theta-2 \mathrm{\theta}$ measurement of $\mathrm{CeO}_{2}$ buffer layers deposited under these conditions. The strong $\mathrm{CeO}_{2}(200)$ peak as well as the less than $1 \%$ intensity ratio of $(111)$ to $(200)$ components indicate the presence of a good out-of-plane texture. Figure 1.7 shows the in-plane ( $\phi$ scans) and out-of-plane ( $\omega$ scans) texture measurements of the $\mathrm{CeO}_{2}$ buffer layer on

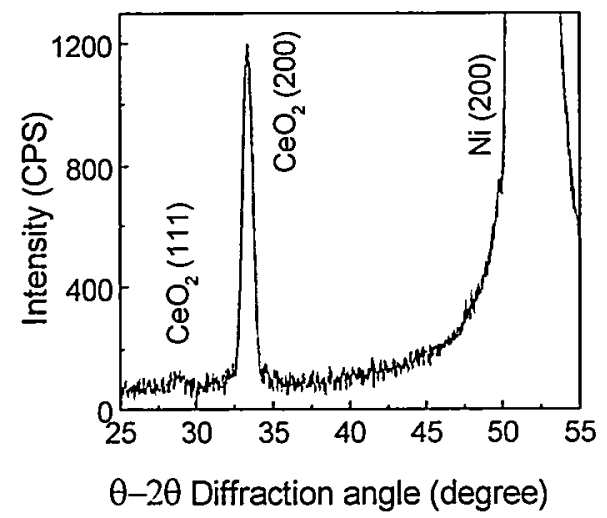

Fig. 1.6. XRD $\theta-2 \theta$ scan of 20-nm $\mathrm{CeO}_{2}$ deposited by e-beam evaporation. moving Ni tape. The FWHM of the $\phi$ scans for $\mathrm{Ni}(111)$ and $\mathrm{CeO}_{2}(111)$ are $8.9^{\circ}$ and $10.6^{\circ}$, respectively, whereas the FWHM of the $\omega$ scans for $\mathrm{Ni}(200)$ and $\mathrm{CeO}_{2}(200)$ are $7.8^{\circ}$ and $9.0^{\circ}$. These XRD results show that $\mathrm{CeO}_{2}$ can be grown epitaxially on moving cube-textured $\mathrm{Ni}$ tapes. Although the FWHMs of the in-plane and out-of-plane textures of the $\mathrm{CeO}_{2}$ buffer deposited on a moving tape are slightly higher than those of $\mathrm{Ni}$, they are similar to the values measured from $\mathrm{CeO}_{2}$ deposited on the same $\mathrm{Ni}$ under stationary condition.

Rutherford Backscattering Spectrometry (RBS) measurements performed on both moving and stationary tapes showed that the buffer layer thickness is more homogeneous over the length in samples deposited under the moving tape condition. XRD $\phi$-scan measurements have been performed in order to examine the uniformity of the $\mathrm{CeO}_{2}$ buffer layer texture over the length. We have examined a $14-\mathrm{cm}$-long. 1-cm-wide, and 30-nm-thick $\mathrm{CeO}_{2}$ buffer layer deposited on rolled $\mathrm{Ni}$ tape, the length of which is limited by the dimensions of the XRD sample holder. Figure 1.8 shows the FWHM of the in-plane (111) $\phi$-scan of the $\mathrm{CeO}_{2}$ buffer layer as a function of position along the length. As seen from this figure, the $\mathrm{CeO}_{2}$ buffer layer exhibits excellent in-plane texture with a deviation in the FWHM of less than $0.6^{\circ}$ and

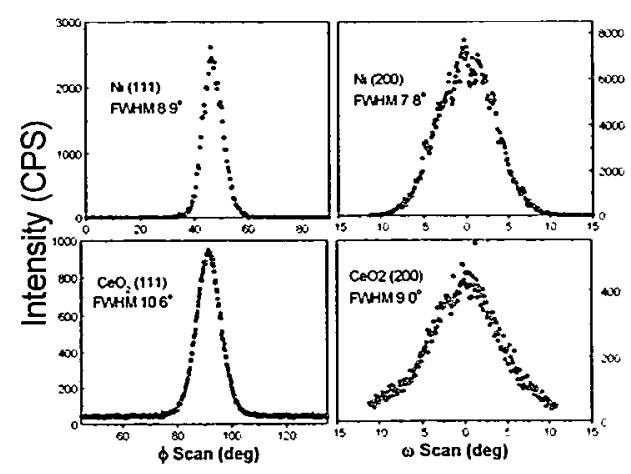

Fig. 1.7. In-plane $\phi$ scans and out-of-plane $\omega$ scans of $\mathrm{Ni}$ and 20-nm-thick $\mathrm{CeO}_{2}$ deposited on the moving $\mathrm{Ni}$. 


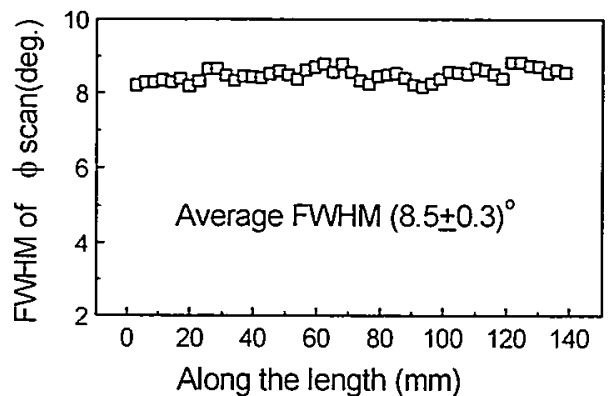

Fig. 1.8. FWHM of (111) $\phi$ scan as a function of the length over a $30-\mathrm{nm}$ thick, 14-cm-long $\mathrm{CeO}_{2}$ buffer layer.

demonstrates the excellent uniformity of the epitaxial buffer layer.

Scanning electron microscopy (SEM) measurements have been employed to examine the surface morphology of the $\mathrm{CeO}_{2}$ buffer layers. Figure 1.9 shows an SEM image of the $\mathrm{CeO}_{2}$ buffer layer deposited by e-beam evaporation under the moving tape condition. No cracks have been observed on the $\mathrm{CeO}_{2}$ buffer layer grown under the present conditions. However, cracks in the $\mathrm{CeO}_{2}$ buffer layers have been observed if the deposition temperatures are $700^{\circ} \mathrm{C}$ and higher. In addition, if the buffer thickness is more than $40 \mathrm{~nm}$. cracks can also be found. ${ }^{3}$

\section{Results on Short Segment of Moving Tape}

To ultimately verify the quality of these $\mathrm{CeO}_{2}$ buffer layers grown under the moving tape condition. high $J_{\mathrm{c}}$ YBCO superconductors have to be obtained. We have deposited intermediate YSZ buffers and $\mathrm{CeO}_{2}$ cap-layers on short segments of these buffered tapes using $\mathrm{rf}$ magnetron sputtering. YBCO films were grown by two methods: either via an in situ pulsedlaser deposition or via an ex situ method using $\mathrm{BaF}_{2}-\mathrm{Y}-\mathrm{Cu}$ precursor layers. ${ }^{9}$ The $J_{\mathrm{c}}$ of $\mathrm{YBCO}$

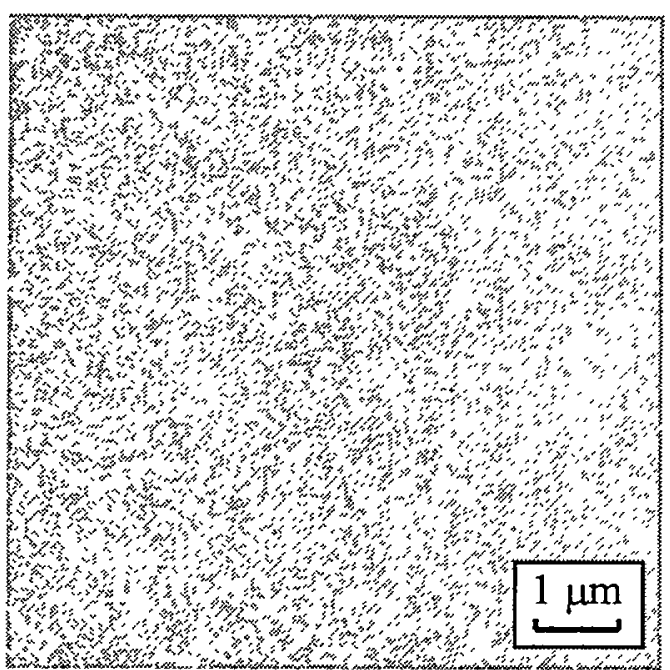

Fig. 1.9. SEM image of a $30-\mathrm{nm}$ thick $\mathrm{CeO}_{2}$ buffer layer on rolled $\mathrm{Ni}$ tape. The lines shown in the image are the grain boundary of rolled $\mathrm{Ni}$.

films at $77 \mathrm{~K}$ in a self-field was $0.35 \mathrm{MA} / \mathrm{cm}^{2}$ for the film made by pulsed-laser ablation and $0.7 \mathrm{MA} / \mathrm{cm}^{2}$ for the ex situ processed film (unpublished data. R. Feenstra, September 1998). These results demonstrate that in situ annealing of as-rolled $\mathrm{Ni}$ tape and e-beam evaporation of the $\mathrm{CeO}_{2}$ buffer under a moving tape condition result in textured substrates with the excellent cube epitaxy required for high $J_{\mathrm{c}}$. Efforts are under way to fabricate dense, smooth, and scratch-free YSZ buffers under the moving tape condition on these initial $\mathrm{CeO}_{2}$ buffer layers. In addition, improvements in YBCO deposition techniques are being studied in order to fabricate uniform, high-quality YBCO superconductors on these long-length RABiTSTM.

\section{Conclusion}

We have developed reel-to-reel vacuum systems to continuously deposit epitaxial buffer layers on rolled Ni substrates. Biaxially textured $\mathrm{CeO}_{2}$ buffer layers have been successfully deposited by e-beam evaporation on in situ annealed $\mathrm{Ni}$ tapes under a moving tape condition. The texture and surface quality of these initial $\mathrm{CeO}_{2}$ buffer layers are excellent and 
have resulted in high $J_{c}$ YBCO superconducting films.

\section{References}

1. A. Goyal, D. P. Norton, J. D. Budai, M. Paranthaman, E. D. Specht, D. M. Kroeger, D. K. Christen, Qing He, B. Saffian, F. A. List, D. F. Lee, P. M. Martin, C. E. Klabunde, E. Hatfield, and V. K. Sikka, "High critical current density superconducting tapes by epitaxial deposition of $\mathrm{YBa}_{2} \mathrm{Cu}_{3} \mathrm{O}_{\lambda}$ thick films on biaxially textured metals," Appl. Phys. Lett. 69(12): 1795-97 (September 1996).

2. D. P. Norton, A. Goyal, J. D. Budai, D. K. Christen, D. M. Kreger, E. D. Specht, Q. He, B. Saffian, M. Paranthaman, C. E. Klabunde, D. F. Lee, B. C. Sales, and F. A. List, "Epitaxial $\mathrm{YBa}_{2} \mathrm{Cu}_{3} \mathrm{O}_{7}$ on biaxially textured nickel (001): An approach to superconducting tapes with high critical current density," Science, 274: 755-57 (November 1996).

3. M. Paranthaman, A. Goyal, F. A. List, E. D. Specht, D. F. Lee, P. M. Martin, Qing He, K. K. Christen, D. P. Norton, J. D. Budai, and D. M. Kroeger, "Growth of biaxially textured buffer layers on rolled-Ni substrates by electron beam evaporation," Physica C, 275: 266-72 (1997).

4. Qing He, D. K. Christen, J. D. Budai, E. D. Specht, D. F. Lee, A. Goyal, D. P. Norton, M. Paranthaman, F. A. List, and D. M. Kroeger, "Deposition of biaxially-oriented metal and oxide buffer-layer films on textured $\mathrm{Ni}$ tapes: New substrates for high-current, hightemperature superconductors," Physica C, 275: 155-61 (1997).

5. E. D. Specht, A. Goyal, D. F. Lee, F. A. List, D. M. Kroeger, M. Paranthaman, R. K. Williams, and D. K. Christen, "Cube-Textured Nickel Substrates for High-Temperature Superconductors," Superconductor Science and Technology 11 (10): 945-49 (October 1998).

6. F. D. Richardson and J. H. E. Jeffes, "The thermodynamics of substances of interest in iron and steel making from $0^{\circ} \mathrm{C}$ to $2400^{\circ} \mathrm{C}$ " J. Iron Steel Inst. 160: 261-70 (November 1948).
7. W. D. Wang, N. J. Wu, and P. A. Thiel, "Structural steps to oxidation of Ni (100)," $J$. Chem. Phys., 92(3): 2025-35 (February 1990).

8. T. J. Jackson, B. A. Glowacki, and J. E. Evetts, "Oxidation thermodynamics of metal substrates during the deposition of buffer layer oxides," Physica C, 296: 215-24 (1998).

9. R. Feenstra, T. B. Lindemer, J. D. Budai, and M. D. Galloway, "Effect of oxygen pressure on the synthesis of $\mathrm{YBa}_{2} \mathrm{Cu}_{3} \mathrm{O}_{7}$ - $\mathrm{x}$ thin films by post-deposition annealing," J. Appl. Phys. 69: 6569-74 (1991).

\section{NONMAGNETIC, STRENGTHENED SUBSTRATES FOR RABITS ${ }^{\text {TM }}$}

For many conductor applications, a nonmagnetic substrate or a substrate with reduced magnetism is desired for minimization of alternating current (ac) losses. For other applications, substrates with increased mechanical strength are desired. In an effort to address both these concerns, a variety of substrates have been developed at ORNL. Two examples are reported here. Figure 1.10 shows magnetic hysteresis loops taken at $77 \mathrm{~K}$ for samples of pure $\mathrm{Ni}, \mathrm{Ni}-7 \% \mathrm{Cr}$. and $\mathrm{Ni}-13 \% \mathrm{Cr}$.

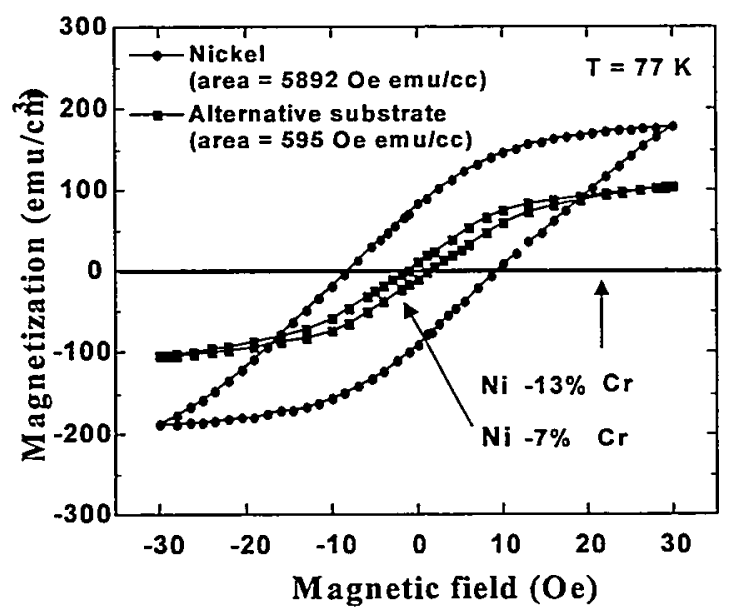

Fig. 1.10. Magnetic hysteresis data for cube-textured samples of identical geometry and with compositions of $\mathrm{Ni}$, $\mathrm{Ni}-7 \% \mathrm{Cr}$, and $\mathrm{Ni}-13 \% \mathrm{Cr}$. 
Each of these substrates was fabricated by progressive rolling followed by annealing to form a sharp cube texture. The size and geometry of all three samples were identical, enabling a direct comparison of the substrates. It can be seen that the magnetism is greatly reduced in the $\mathrm{Ni}-7 \% \mathrm{Cr}$ substrate and that the $\mathrm{Ni}-13 \% \mathrm{Cr}$ is nonmagnetic at $77 \mathrm{~K}$.

Figure 1.11 shows tensile data for the three substrates: $\mathrm{Ni}, \mathrm{Ni}-7 \% \mathrm{Cr}$, and $\mathrm{Ni}-13 \% \mathrm{Cr}$. Dogbone-shaped tensile samples were lasermachined from as-rolled strips of the three compositions such that the rolling direction was parallel to the gauge length. The samples were then annealed to form the cube texture with the [100] direction aligned along the gauge length. The samples were then tested using standard procedures. Several loading-unloading cycles were employed to get an accurate measure of the slope of the loading curve to extract a yield stress. It can be seen clearly that both the yield stress and the ultimate tensile stress increase considerably with alloy additions.
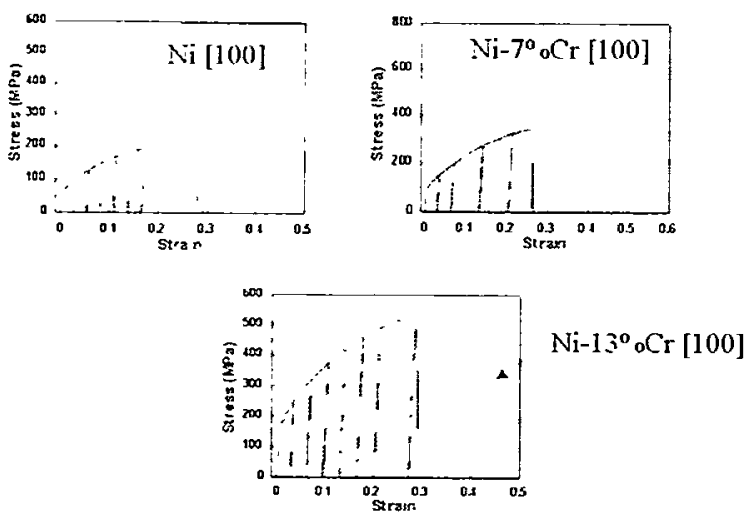

Fig. 1.11. Stress-strain curves for cubetextured, dog-bone-shaped samples of $\mathrm{Ni}$, $\mathrm{Ni}-7 \% \mathrm{Cr}$, and $\mathrm{Ni}-13 \% \mathrm{Cr}$, with the load applied along the [100] direction.

Epitaxial buffer layers have been deposited on $\mathrm{Ni}-7 \% \mathrm{Cr}$ and $\mathrm{Ni}-13 \% \mathrm{Cr}$ substrates using laser ablation as well as e-beam evaporation. YBCO films deposited on these buffer layers have yielded $J_{c} s$ of $223.000 \mathrm{~A} / \mathrm{cm}^{2}$ and $200.000 \mathrm{~A} / \mathrm{cm}^{2}$ on $\mathrm{Ni}-7 \% \mathrm{Cr}$ and $\mathrm{Ni}-13 \% \mathrm{Cr}$, respectively. As an example, Fig. 1.12 shows $X$-ray rocking curves and $\phi$-scans for the various layers of the multilayer structure, indicating a good transference of epitaxy to the YBCO layer.

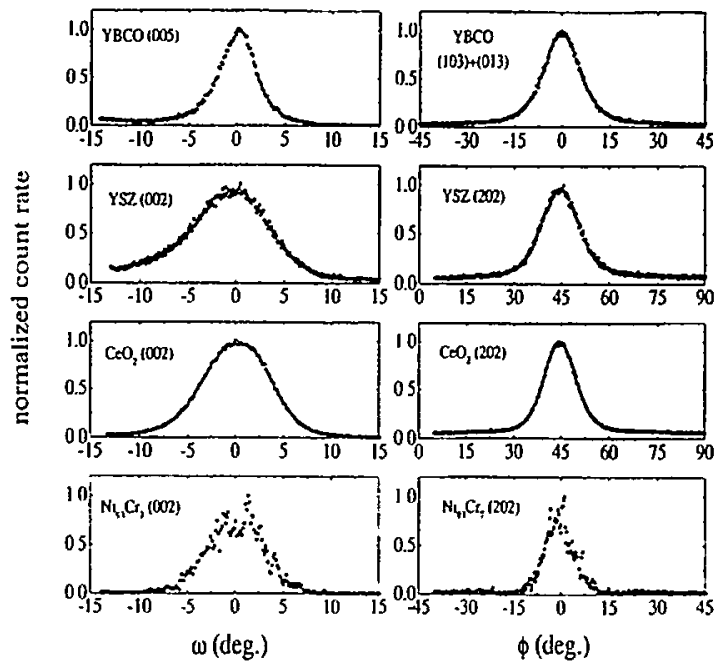

Fig. 1.12. Rocking curves and $\phi$-scans showing the progression of out-of-plane and in-plane texture from the substrate to the YBCO layer.

Figure 1.13 shows a scanning electron micrograph of the YBCO film. The film is dense and crack free. Efforts are under way to optimize the deposition conditions to obtain higher $J_{c} s$ on both substrates.

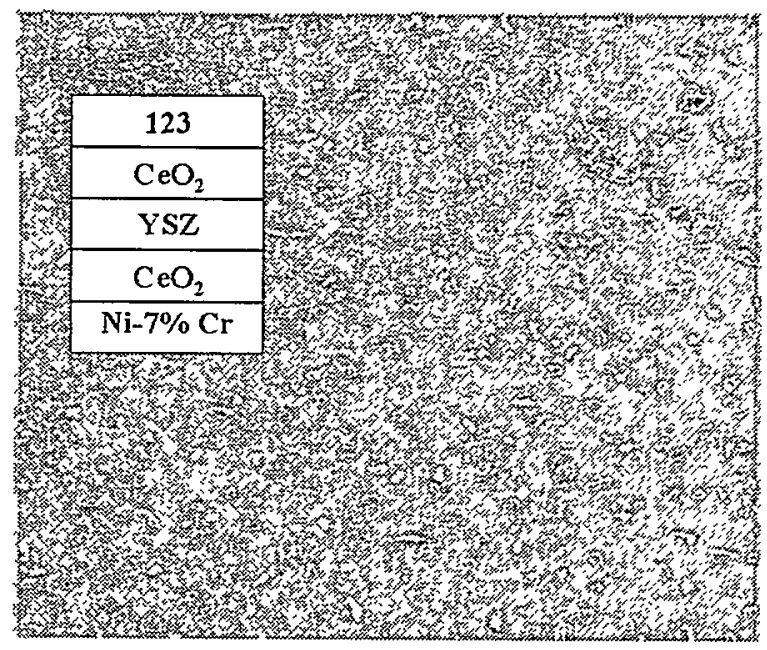

Fig. 1.13. Scanning electron micrograph of the YBCO layer showing a dense film morphology without cracks. 


\section{MIDWEST SUPERCONDUCTIVITY CRADA SUMMARY REPORT}

The objective of the CRADA between ORNL, Midwest Superconductivity, Inc., (MSI), and Westinghouse Electric Company (WEC) was to demonstrate a commercially viable process to make long lengths of $\mathrm{YBCO}$ tapes for superconductivity applications. The YBCO deposition method chosen by MSI was metal organic chemical vapor deposition (MOCVD), and the substrate technology selected by MSI was RABiTS ${ }^{\mathrm{TM}}$.

MSI had the primary responsibility for establishing the technology base for continuous deposition of YBCO on RABiTS ${ }^{\mathrm{TM}}$ using MOCVD. Particular attention was to be paid to the definition of handling, qualification, and purification of the metal tetra-methyl-heptanedionate (thd) complexes typically used as precursors for YBCO deposition by MOCVD. In addition to establishing process variables for high-quality film deposition, various powder-feed mechanisms, substrate heating methods, and overall reactor design were to be considered.

WEC had the primary responsibility for establishing the process variables for producing long lengths of nickel tape that were suitable not only for annealing to produce a high degree of texture but also for directly feeding into the buffer layer and superconductor deposition processes without further surface preparation. Through a series of rolling and annealing trials, WEC was successful in identifying the appropriate degree of reduction per pass, total reduction, back tension, and lubrication to achieve these goals while eliminating surface defects from the finished tape. WEC also provided guidance on the impact of coated conductor on the commercialization of Superconducting Magnetic Energy Storage (SMES) systems in the form of a report.

ORNL was responsible for transfer of technology dealing with fabrication of all aspects of the RABiTS ${ }^{\mathrm{TM}}$ substrate and technical guidance by means of joint development for deposition of YBCO by MOCVD. ORNL was also tasked with providing buffered RABiTS ${ }^{\mathrm{TM}}$ to MSI for YBCO deposition; with performing detailed microstructural, structural. and superconducting property measurements of the materials fabricated by MSI and WEC; and with assisting MSI in duplicating buffer layers and textured nickel at MSI's subcontractor, American Thin Films, Inc.

\section{Evaluation of the MOCVD Process}

MSI began the CRADA effort using a MOCVD reactor based upon a design developed by Professor Judy Wu at the University of Kansas (KU) under contract to MSI. The precursors typically used for MOCVD of YBCO are metal-ligand complexes with thd as the ligand. While the copper thd was known to be thermally stable, the barium and, to a much lesser degree, yttrium precursors were suspect in terms of thermal stability and resistance to moisture. The sensitivity to extended exposure to elevated temperature precluded the use of standard bubblers for delivery of the individual precursors in the vapor phase. Therefore, special handling and processing steps needed to be developed to ensure consistent YBCO film quality. To that end, the reactor designed at $\mathrm{KU}$ used an earlier development at Hewlett-Packard in which the three metal-organic precursors are pre-mixed in a quartz tube and fed through a temperature gradient. In this way, the precursors are kept well below their sublimation and decomposition temperatures until immediately prior to vaporization. Although it was recognized that such a system was not appropriate for continuous deposition on long lengths of tape, it was decided to demonstrate the feasibility of using MOCVD in conjunction with RABiTS ${ }^{\mathrm{TM}}$ using this approach while exploring other precursor feed options for continuous deposition.

Early in the CRADA it was realized that the commercial precursor supply, particularly of barium thd, was erratic in quality. As a result of a cooperative effort, MSI established in-house capabilities for the long-term storage and 
handling of the environmentally sensitive thd precursors. Product quality as determined by thermogravimetric analysis (TGA) was added as a routine qualification procedure, and a specification for the thd precursors was developed. A rigorous qualification procedure was established with two vendors of the barium precursor to ensure a long-term supply of a quality product. The specification also resulted in sufficient process optimization at one of the vendors to result in a significant cost reduction in the precursor product. Any increase in volume purchasing should bring the cost of all precursors in the range of $\$ 1 / \mathrm{g}$. Although this may appear excessive. the quantities required per meter of tape are very small. Finally, Schlenk lines were built at MSI to allow for routine in-house purification of the yttrium and copper precursors prior to use in the reactor. All of these efforts had a significant effect on film quality and reproducibility.

Film development using the powder-feed method progressed with the demonstration of YBCO films with $J_{c} s$ in excess of $1.5 \mathrm{MA} / \mathrm{cm}^{2}$ on lanthanum aluminate substrates. The parameters and process steps used to achieve those results were then applied to short segments of RABiTS ${ }^{\mathrm{TM}}$. The best result with RABiTS ${ }^{\mathrm{TM}}$ was a $J_{\mathrm{c}}$ of $640 \mathrm{kA} / \mathrm{cm}^{2}$ on a substrate where the $\mathrm{CeO}_{2}$ and YSZ layers had both been applied by PLD. This particular RABiTS ${ }^{\mathrm{TM}}$ had a configuration of $\mathrm{Ni}(125 \mu \mathrm{m}) / \mathrm{CeO}_{2}(0.9 \mu \mathrm{m}) / \mathrm{YSZ}(0.2 \mu \mathrm{m})$. The YBCO film was $0.5-\mathrm{mm}$ thick. Figure 1.14 shows XRD $\phi$ scans of the various layers, indicating good transfer of epitaxy from the $\mathrm{Ni}$ to the YBCO film. Figure 1.15 shows a (112) pole figure for the YBCO film. Only $\sim 80 \%$ of the YBCO film is $c$-axis-perpendicular and cubetextured (aligned with $\mathrm{Ni}$ ). Almost $\sim 20 \%$ was $a$-axis-perpendicular and rotated $\pm 11^{\circ}$ in-plane, as indicated in the pole figure. A small component consists of large crystals with apparently random orientations.

Figure 1.16 shows $J_{c}$ versus applied magnetic field for this YBCO film. The data are compared with a typical YBCO film on RABiTSTM grown using PLD. The field dependence for the

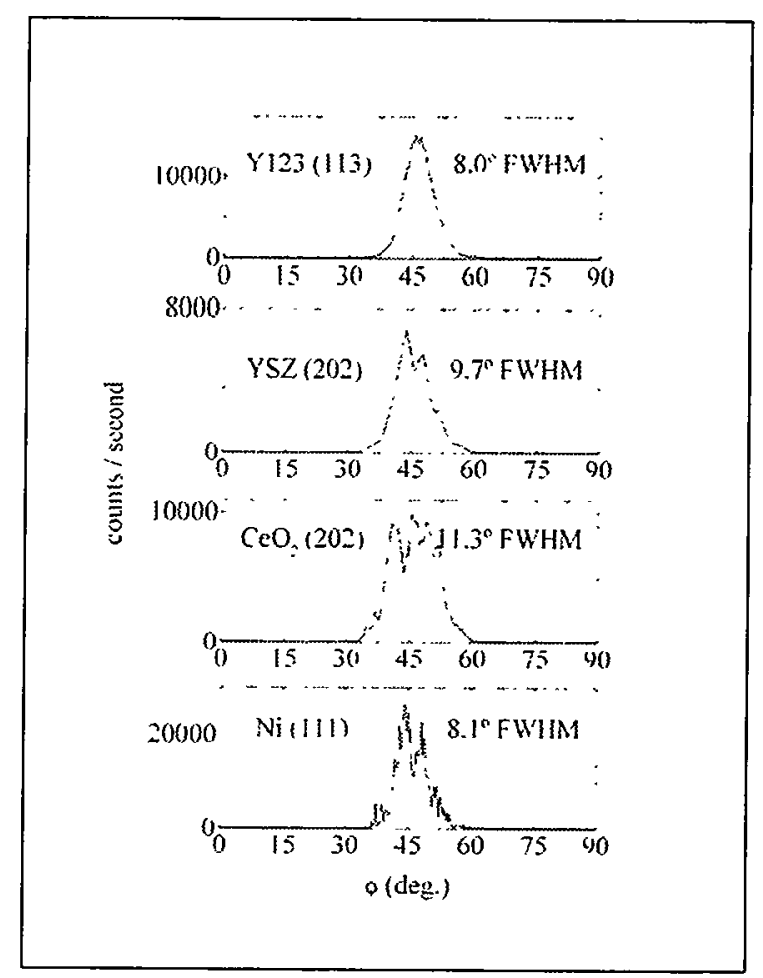

Fig. 1.14. XRD $\phi$ scans of $Y 123, Y S 2$, $\mathrm{CeO}_{2}$, and $\mathrm{Ni}$ layers.

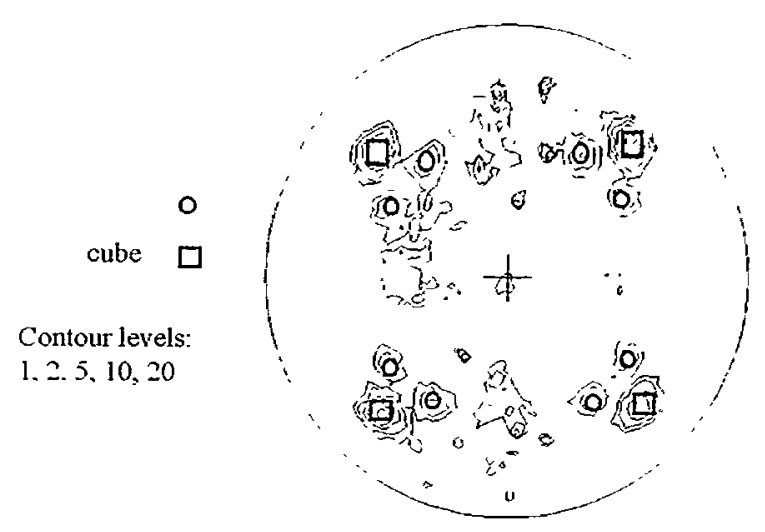

Fig. 1.15. YBCO (112) pole figure.

MOCVD film appears quite similar to that of the PLD-grown YBCO film, perhaps with a slightly greater component of weak links. Figure 1.17 shows the temperature dependence of $J_{c}$ for this YBCO film grown by MOCVD and a typical YBCO film grown using PLD on RABiTS $^{T M}$. The difference in slopes is 


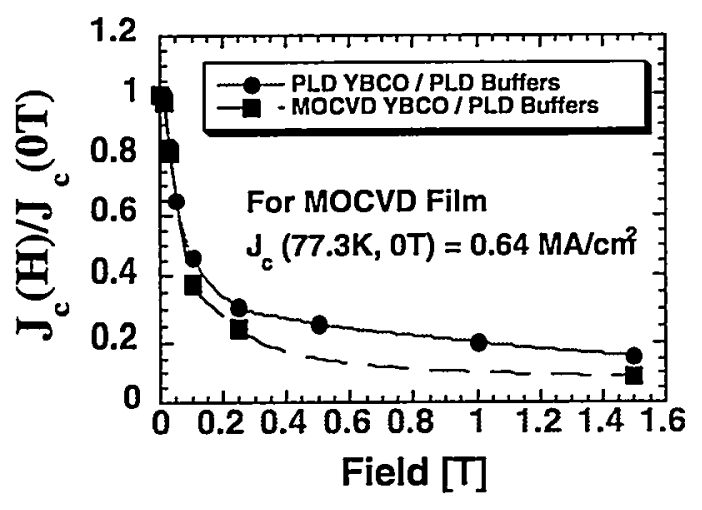

Fig. 1.16. $J_{c}$ versus applied magnetic field.

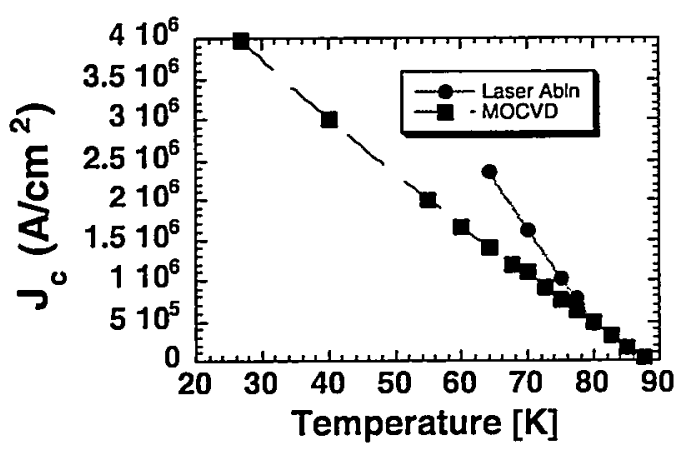

Fig. 1.17. Temperature dependence of $J_{c}$.

attributed to different types of defect structures in the films grown using the two different techniques and resulting in different pinning structures.

Since this result was achieved, other films have been grown on buffered substrates where the buffer layers were deposited by various combinations of e-beam and sputter deposition. While films with excellent transition temperature and epitaxy with the YSZ layer have been grown, the early result with PLD buffer layers remains the highest recorded to date.

Once the feasibility of using MOCVD to deposit YBCO on buffered RABiTS ${ }^{\text {TM }}$ had been established, the effort at MSI shifted to consider the issue of deposition on continuous lengths of buffered tape. Various forms of precursor feed systems were examined in order to allow for continuous deposition. In the first method, a load-lock chamber was added to the bottom of the reactor to allow for exchange of precursor feed tubes without breaking the vacuum of the process chamber.

A pull-through tape-feed system was designed and built to replace the substrate holder on the reactor. The system was capable of handling tapes up to $1 \mathrm{~m}$ in length. The system was tested out in static runs on lanthanum aluminate substrates to establish the appropriate processing window for the new configuration. Because no buffered RABiTS ${ }^{\mathrm{TM}}$ was available in $1-\mathrm{m}$ lengths, it was decided to test the system using tape that was buffered with either ceria or yttria deposited by MOCVD. There was no expectation that high-quality, aligned superconductor would be deposited on the tape during subsequent deposition trials, but these trials would allow for testing of the system configuration. As described, the resulting deposition trials showed a banded structure, indicating that either the powder-feed method resulted in a pulsed flow of vapor to the substrate or that the pull-through mechanism was not smooth enough. The width of the bands was more consistent with the former possibility.

At that point, it was decided to proceed on the basis that continuous deposition, while based on the results achieved with static depositions, really required a complete change in reactor design to be properly tested. A commercial liquid-feed system that relied on the precision metering of a solution of precursor through a vaporizer attached to the reactor by a feed tube was procured. In addition, a production prototype reactor was consigned that would be capable of processing lengths of buffered tape in excess of 50 meters in length. A substrate heating system more appropriate for uniform heating of a tape over large distances was also designed and ordered. The fact that MOCVD is not a line-of-sight deposition method was used to combine the best aspects of radiant heating and the ability to pipe warm process gases around obstacles to establish a uniform hot zone with smooth delivery of precursor to the substrate. 
The liquid-based delivery system was set up and tested on the development reactor while the production prototype reactor and substrate heating assembly were being fabricated. An appropriate solvent was identified for carrying the precursors that did not degrade subsequent film performance. A load-lock system for rapid introduction and retrieval of substrates without breaking vacuum was also incorporated into the reactor. Using a single solution containing the appropriate ratio of all three precursors, the liquid delivery system was optimized for film quality. Near the end of the CRADA. it was possible to make extended series of runs with resulting films of high quality and consistency. As an example, a series of six runs at identical conditions using lanthanum aluminate substrates yielded $J_{\mathrm{c}} \mathrm{s}$ in excess of $1 \mathrm{MA} / \mathrm{cm}^{2}$.

Finally, the production prototype reactor was commissioned at MSI in early 1998. The reel-toreel system. vacuum system, and substrate heating assembly were all installed and tested. The liquid delivery system was not installed in the production prototype reactor by the end of the program because of the lack of availability of long lengths of buffered substrate. It was decided that optimization trials in the development reactor at static conditions were more important than mere demonstration of the continuous deposition on inferior substrates at that point.

\section{Commercial Process for Textured Metal Tape}

WEC performed an extensive set of rolling/annealing experiments in order to determine the appropriate conditions for rolling and annealing long lengths of nickel tape with the appropriate texture and surface finish for subsequent use as a substrate for epitaxial buffer layer and YBCO deposition. The thermomechanical schedules transferred from ORNL were successfully used to produce tapes up to $30 \mathrm{~m}$ in length with thicknesses down to $37.5 \mu \mathrm{m}$ which showed, on subsequent heat treatment. textures as strong as 8 to $10^{\circ} \mathrm{FWHM}$ in a $\phi$ scan. Subsequent depositions of buffer layers on WEC-rolled material were successful in generating epitaxial growth of the buffer layers.

\section{Impact of High-Temperature Superconducting Coated Conductor on SMES Applications}

WEC conducted a preliminary investigation to determine the impact of high-temperature superconducting (HTS) wire based on coated conductor on SMES applications. The main conclusions were that the intrinsic stability of the coated conductor will probably not require micron-size filamentary structures, that thick films (up to $100 \mu \mathrm{m}$ in thickness) are necessary for usable conductors, that current densities in the conductor should be greater than $100 \mathrm{kA} / \mathrm{cm}^{2}$ to be of interest, and that new techniques in both conductor fabrication and field shaping are necessary for the rapid ramping needed for power-quality SMES magnets. In addition, these superconductors must be available at less than $\$ 70 / \mathrm{kA} \mathrm{m}$ to be considered at all and can result in $30 \%$ reductions in net present value cost if they are available at the present-day low-temperature superconductor (LTS) cost of less than $\$ 10 / \mathrm{kA} \mathrm{m}$. Finally, the benefit of an HTS coated conductor diminishes rapidly as the stored energy increases and refrigeration becomes a smaller element of the total system cost.

At the end of the CRADA, MSI decided to terminate development of its MOCVD-based HTS wire in order to concentrate on a different business area (infrared sensors) with potential for very near-term commercial sales.

\section{Summary and Conclusions}

- MOCVD is a viable candidate for manufacturing long lengths of high-quality coated conductor.

- Rigorous control of precursor quality is required for consistent film properties.

- Long-term, continuous tape processing may require splitting the feed system into two 
liquid feed sources (one for barium and one for a mixed solution of yttrium and copper) to allow for tuning the vaporizer temperature more closely to the vaporization temperatures of the individual precursors and provide the opportunity for longer operation times between system shutdowns.

- Precursors that are liquids at room temperature would maximize the delivery rate of a liquid feed system by eliminating the need to dilute solutions of precursor powder in solvents.

- Rolling and annealing of nickel tape to long lengths and thin sections while maintaining high texture and good surface finish appears to be a very robust process.

- An HTS coated conductor could have a cost advantage in smaller SMES systems where the superconductor cost dominates the system if cost levels similar to those for present-day LTS wire are achieved.

\section{AN ALTERNATIVE APPROACH: Bi-2223-COATED CONDUCTOR DEVELOPMENT}

Since the discovery of HTS, tremendous progress has been achieved in the fabrication of the materials into conductor forms. Among the different types of HTS, Bi-based materials are the only ones that have been successfully processed in long lengths. Powder-in-tube (PIT) (Bi,Pb) ${ }_{2} \mathrm{Sr}_{2} \mathrm{Ca}_{2} \mathrm{Cu}_{3} \mathrm{O}_{10}(\mathrm{Bi}-2223)$ superconducting tapes have been reported to possess a $J_{\mathrm{c}}$ in excess of $70,000 \mathrm{~A} / \mathrm{cm}^{2}$ at $77 \mathrm{~K}$ and self field (s.f.) and have been used in various applications. Even with this level of performance, higher $J_{\mathrm{c}}$ and $J_{\mathrm{e}}$ values are necessary for the HTS to be widely accepted as a practical conductor. The Wire Development Group (WDG) has identified several critical issues where enhancements may lead to significant improvement in conductor performance. These issues include the $c$-axis alignment of the $\mathrm{Bi}-2223$ grains, the existence of an impurity channel in the center of the filaments, filament uniformity, fill factor of the HTS, and the high cost of the weak silver sheath. Because of the occurrence of instability during the deformation processing, these issues cannot easily be probed by the standard PIT fabrication approach. Consequently, a coatedconductor approach was initiated at ORNL to investigate these issues and as a potential alternative technique to fabricate better, cheaper, and stronger superconducting conductors.

The Bi-2223-coated conductor envisioned in this initiative is shown schematically in Fig. 1.18. A thin $\mathrm{Bi}-2223$ layer is deposited onto a low-cost high-strength flexible metallic substrate, with the inclusion of a silver $(\mathrm{Ag})$ cap-layer to prevent lead loss. In this coatedconductor approach, a variety of substrate materials, from polycrystalline Ag foil to biaxially textured RABiTS ${ }^{T M}$ substrates, may be employed. The $\mathrm{Bi}-2223$ precursor can be deposited by various techniques, such as spray pyrolysis and dip coating, whereas the Ag caplayer can be deposited by thermal evaporation and sputtering, etc. Eventually, multilayered $\mathrm{Bi}-2223$-coated conductors can be fabricated to increase the fill factor and therefore the $J_{\mathrm{e}}$.

We have investigated the basic issues involved in the fabrication of $\mathrm{Bi}-2223$-coated
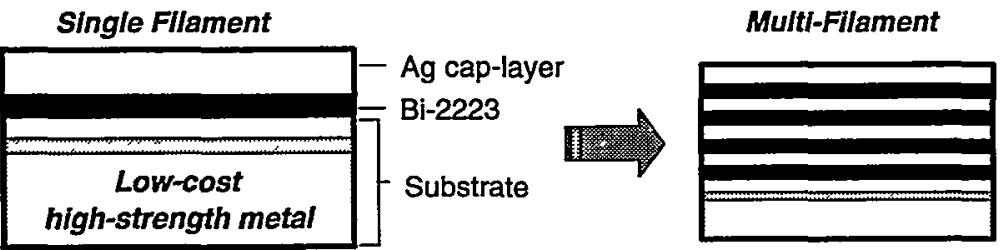

Fig. 1.18. Vision of Bi-2223-coated conductor. 
conductors. A schematic of the processing procedure is shown in Fig. 1.19. Unpolished offthe-shelf $\mathrm{Ag}$ foil was cut and attached to a heating block within a spray pyrolysis system.

$\mathrm{A} \mathrm{Bi}-2223$ precursor layer was then spray pyrolyzed onto the Ag foil using a cationcontaining nitric acid solution. Once the desired thickness of precursor had been obtained, the sample was pre-treated in a furnace to decompose the nitrates. A Ag cap-layer was then deposited onto the precursor layer by rf magnetron sputtering at room temperature. This was followed by thermomechanical treatment to convert the precursor into the $\mathrm{Bi}-2223 \mathrm{HTS}$ phase.
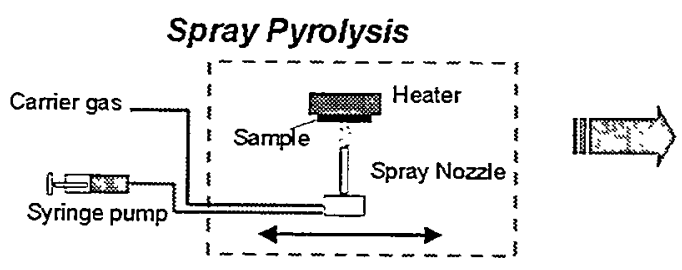

Pre-Treatment
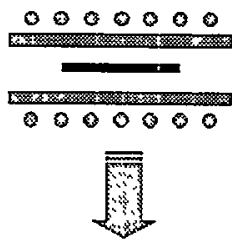

Themomechanical Treatment

(2 intermediate pressings)
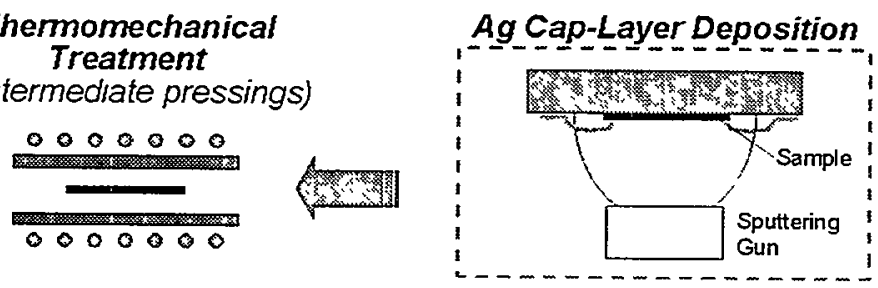

Fig. 1.19. Schematic of the Bi-2223-coated-conductor fabrication procedure.

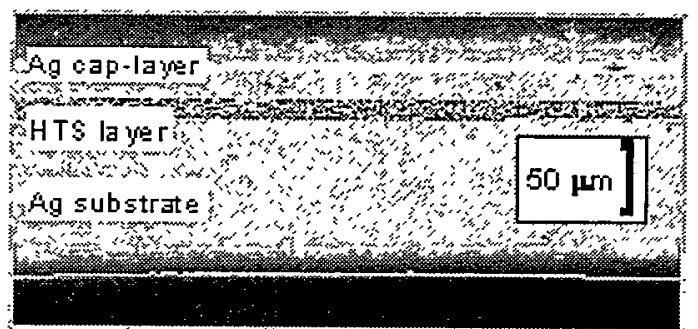

Fig. 1.20. Longitudinal cross-section SEM image of Bi-2223-coated conductor fabricated after process refinement and 15 -h sintering at $825^{\circ} \mathrm{C}$.

these coated conductors were investigated by quenching studies. As seen in Fig. 1.21, initial phase formation of the coated conductor fabricated through process refinement was considerably faster than that of the conductor obtained without refinement. In addition, the $\mathrm{Bi}-2223$ phase initially formed more rapidly for both coated conductors when compared with a high- $J_{\mathrm{c}}$ $\left(\sim 60,000 \mathrm{~A} / \mathrm{cm}^{2}\right)$ PIT tape. After 10 to 15 hours of sintering, formation kinetics of these coated conductors slowed and eventually converged with that of the high- $J_{c}$ PIT tape. These results indicate that the typical thermomechanical treatment schedule, which was developed for PIT tapes,

A number of issues were encountered during the basic capability developmental phase of this approach. Among them are the initial precursor phase assemblage. the attack of the Ag substrate by acidic precursor solution, and the precipitation of Ag during pyrolysis, as well as the nonuniform thickness of the sprayed precursor layer. These issues have all. to a large degree, been addressed through process refinement. For example, a thin and uniform precursor/HTS layer can be obtained on a coated conductor as shown in Fig. 1.20. In fact. the roughest precursor/HTS-Ag interface was found at the unpolished $\mathrm{Ag}$ foil, which led us to believe that further improvement in smoothness of the precursor/HTS-Ag interface can be achieved. Bi-2223-formation kinetics of

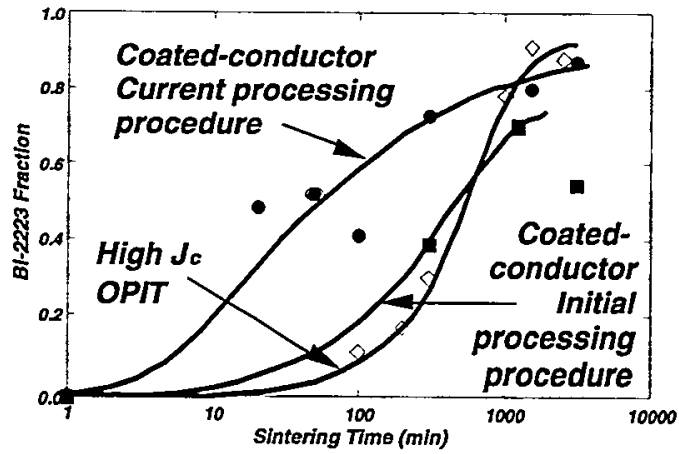

Fig. 1.21. Formation kinetics of Bi-2223-coated conductors. Also included is the behavior of a high- $J_{c}$ PIT tape for comparison. 
is not suitable for coated conductors. Selected Bi-2223-coated conductor samples were fully processed under the typical thermomechanical treatment scheduling for $J_{\mathrm{c}}$ characterization. Figure 1.22 shows the plan view of a coated conductor sintered for 100 hours at $825^{\circ} \mathrm{C}$ with the Ag cap-layer chemically etched away. Numerous cracks can be seen within the $\mathrm{Bi}-2223$ grains, reflecting the nonideal nature of the thermomechanical treatment schedule. Even with the presence of these cracks, this sample possessed a self-field $J_{\mathrm{c}}$ of $41,000 \mathrm{~A} / \mathrm{cm}^{2}$ at $77 \mathrm{~K}$. The attainment of this good $J_{\mathrm{c}}$ value in a nonideal sample from a small sample set of 14 indicates the potential of the coated-conductor approach. Work is under way to determine the appropriate thermomechanical treatment schedule as well as further development of Bi-2223-coated conductors.

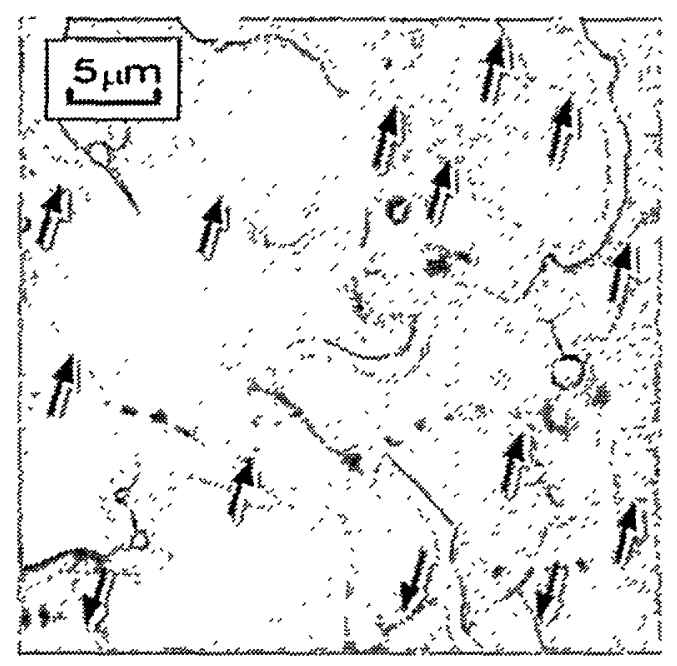

Fig. 1.22. Plan view of a Bi-2223coated conductor fabricated through process refinement and sintered under typical thermomechanical treatment schedule. The Ag cap-layer has been chemically etched away, and cracks are indicated by arrows.

\section{ALTERNATIVE BUFFER ARCHITECTURES FOR HIGH- $J_{c}$ YBCO SUPERCONDUCTING DEPOSITS ON RABITS ${ }^{\text {TM }}$}

Since the initial discovery of HTS, a large effort has been expended toward the fabrication of long, flexible conductors with high $J_{\mathrm{c}} \mathrm{s}$. Progress, however, has been hindered by a variety of problems, the most important being the strong dependence of $J_{c}$ on grain-boundary misorientation angle. An effective way to circumvent this problem is by depositing the HTS on single-crystalline or biaxially textured polycrystalline substrates. Recently, we have demonstrated a new method termed RABiTS ${ }^{\mathrm{TM}}$ that employs thermomechanical processing of base metals to obtain a very sharp, welldeveloped cube texture. The annealed metal tape possesses the $\{100\}<001>$ orientation and resembles a single crystal with slightly misoriented grains. Epitaxial ceramic buffers, which act as diffusion barriers as well as promote subsequent YBCO epitaxy, are then deposited onto the textured metal by a variety of techniques, including PLD, e-beam evaporation, and $\mathrm{rf}$ magnetron sputtering. Values of $J_{\mathrm{c}}$ as high as $3 \times 10^{6} \mathrm{~A} / \mathrm{cm}^{2}$ have been demonstrated at $77 \mathrm{~K}$ and s.f. in thin PLD YBCO deposited onto RABiTSTM with a $\mathrm{YSZ} / \mathrm{CeO}_{2} / \mathrm{Ni}$ architecture.

Even though high $J_{c}$ can be obtained on this RABiTS TM architecture with or without a $\mathrm{CeO}_{2}$ cap-layer, reproducibility of these high values is poor. Two main factors are likely to be responsible. The first factor is cracking of the $\mathrm{CeO}_{2}$ buffer, which can occur on thermal cycling or when a critical thickness is exceeded. When this happens, $\mathrm{NiO}$ particles often form along the cracks and lead to disruption of the buffer and YBCO layers as well as possible contamination of the YBCO. The second factor is the occurrence of a two-component epitaxy $\left(45^{\circ}\right.$ inplane rotation between components) of $\mathrm{YBCO}$ on YSZ. While the inclusion of cap-layers, such as $\mathrm{CeO}_{2}$, can provide single-component $\mathrm{YBCO}$ epitaxy, cracking, in the case of the $\mathrm{CeO}_{2}$, and 
added complexity for cap-layers in general make it less desirable. These limitations point toward the need for alternative buffer materials and architectures. In this report, we present, for the first time, the utilization of $\mathrm{Yb}_{2} \mathrm{O}_{3}$ and $\mathrm{Y}_{2} \mathrm{O}_{3}$ as alternative buffer materials to obtain high $J_{\mathrm{c}}$ in YBCO deposits. Three alternative RABiTS ${ }^{\mathrm{TM}}$ architectures were considered. In the first, a $\mathrm{Yb}_{2} \mathrm{O}_{3}$ cap-layer is added to the standard $\mathrm{YSZ} / \mathrm{CeO}_{2} / \mathrm{Ni}$ to demonstrate excellent $\mathrm{YBCO}$ epitaxy on $\mathrm{Yb}_{2} \mathrm{O}_{3}$. Next. YSZ is replaced by $\mathrm{Yb}_{2} \mathrm{O}_{3}$, thereby simplifying the architecture. Finally, we describe a $\mathrm{Yb}_{2} \mathrm{O}_{3} / \mathrm{Y}_{2} \mathrm{O}_{3} / \mathrm{Ni}$ substrate that we believe will provide increased reliability.

In the fabrication of RABiTS ${ }^{\mathrm{TM}}, 125-\mu \mathrm{m}-$ thick Ni tapes were prepared by cold-rolling a $\mathrm{Ni}$ rod to over $90 \%$ reduction. Then $1.5-\mathrm{cm}$-long as-rolled $\mathrm{Ni}$ substrates were recrystallized to the desired $\{100\}<001>$ cube texture by annealing at $800^{\circ} \mathrm{C}$ for 2 hours in a vacuum of $10^{-6}$ Torr. In order to demonstrate the single-component epitaxial relationship between $\mathrm{Yb}_{2} \mathrm{O}_{3}$ and $\mathrm{YBCO}$, a 50-nm-thick $\mathrm{Yb}_{2} \mathrm{O}_{3}$ cap-layer was deposited onto the standard $\mathrm{YSZ} / \mathrm{CeO}_{2} / \mathrm{Ni}$ architecture as shown schematically in Fig. 1.23(a). First, a thin $\mathrm{CeO}_{2}$ buffer was e-beam deposited onto cube-textured $\mathrm{Ni}$ without any substrate polishing. Briefly, a biaxially textured $\mathrm{Ni}$ substrate was mounted onto a heater and the chamber was evacuated to $1 \times 10^{-6}$ Torr. A gas mixture of $4 \% \mathrm{H}_{2}$ and $96 \% \mathrm{Ar}$ was then introduced, and the textured $\mathrm{Ni}$ substrate was annealed at $625^{\circ} \mathrm{C}$ for 1 hour at 1 Torr. After annealing, the pressure was reduced to $10^{-5}$ Torr and a 20-nm-thick $\mathrm{CeO}_{2}$ buffer was grown onto the $\mathrm{Ni}$ substrate at $600^{\circ} \mathrm{C}$ and a deposition rate of 0.1 to $0.5 \mathrm{~nm} / \mathrm{s}$ using cerium metal as the source. E-beam was used to deposit this first buffer immediately adjacent to the $\mathrm{Ni}$ because a metallic source can be used with $\mathrm{H}_{2} \mathrm{O}$ acting as the reactive gas. This process serves to eliminate or reduce the formation of unfavorably orientated $\mathrm{NiO}$ on the substrate surface which typically leads to a deviation from the desired cube texture.

Oxide buffers deposited by e-beam evaporation typically exhibit a porous columnar microstructure, which is less than ideal for YBCO deposition (Fig. 1.24). Therefore, buffer(s) other than that immediately adjacent to $\mathrm{Ni}$ were deposited using rf magnetron sputtering, which provides a consistently dense and smooth surface as shown in Fig. 1.25. Following the initial buffer deposition, YSZ and $\mathrm{Yb}_{2} \mathrm{O}_{3}$ layers were deposited using a single-gun rf magnetron sputtering system. A biaxially textured $\mathrm{CeO}_{2} / \mathrm{Ni}$ substrate was mounted onto a heater and was evacuated to a pressure of $1 \times 10^{-6}$ Torr. The system was then back-filled with a $4 \% \mathrm{H}_{2}$ and $96 \%$ Ar mixture to $5 \times 10^{-2}$ Torr, and the substrate was heated to $780^{\circ} \mathrm{C}$. After a holding period of $15 \mathrm{~min}$, the pressure was reduced to $1 \times 10^{-2}$ Torr and sputtering commenced using an on-axis YSZ or $\mathrm{Yb}_{2} \mathrm{O}_{3}$ target. The plasma power was $75 \mathrm{~W}$ at $13.56 \mathrm{MHz}$, and the resulting $\mathrm{YSZ}$ and $\mathrm{Yb}_{2} \mathrm{O}_{3}$ buffers were roughly $770 \mathrm{~nm}$ and $50 \mathrm{~nm}$ thick, respectively. During deposition of the multilayered buffers, the substrate was cooled to room temperature and the vacuum broken between sputtering in order to change the target.

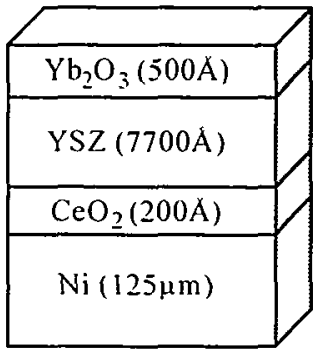

(a)

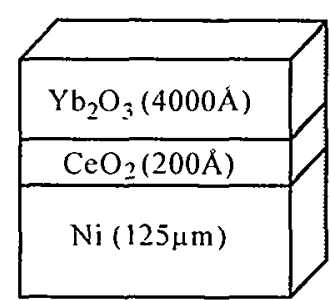

(b)

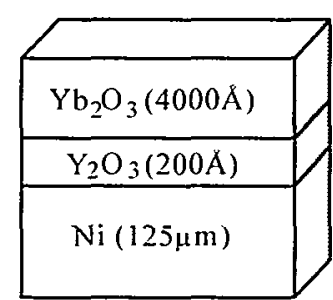

(c)

Fig. 1.23. Various alternative buffer architectures for high- $J_{c}$ YBCO deposits on RABiTS ${ }^{\text {TM. }}$. 


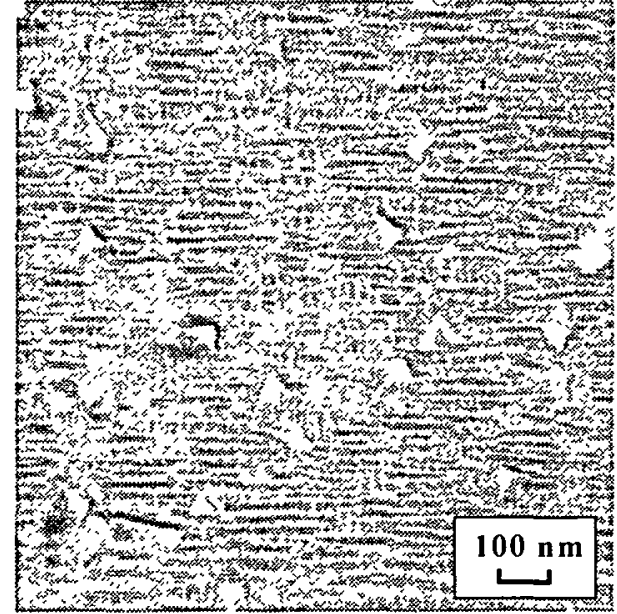

Fig. 1.24. Microstructure of YSZ deposited by e-beam evaporation.

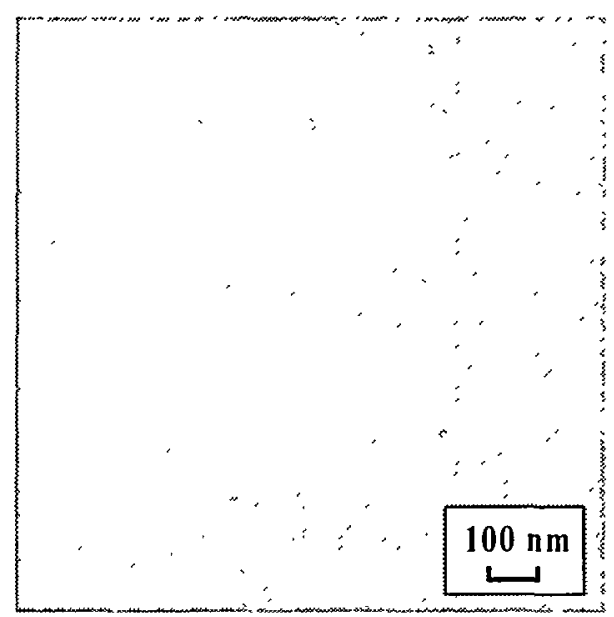

Fig. 1.25. Microstructure of YSZ deposited by RF sputtering.

This further demonstrates the robustness of the RABiTS ${ }^{\mathrm{TM}}$ technique.

A superconducting $\mathrm{YBCO}$ film $350-\mathrm{nm}$ thick was deposited onto the $\mathrm{Yb}_{2} \mathrm{O}_{3} / \mathrm{YSZ} /$ $\mathrm{CeO}_{2} / \mathrm{Ni}^{\mathrm{RABiTS}}{ }^{\mathrm{TM}}$ by PLD at $780^{\circ} \mathrm{C}$ and oxygen pressure of $200 \mathrm{mT}$ Torr. After the YBCO was deposited, the sharpness of the biaxial texture of individual layers was measured using $X$-ray $\omega$-scans (out-of-plane texture) and $\phi$-scans (in-plane texture). A Cu X-ray source was used, with a graphite crystal selecting $\mathrm{K}_{\alpha}$ radiation and a four-circle diffractometer orienting the sample. Figure 1.26 shows both the out-of-plane and in-plane textures of the various

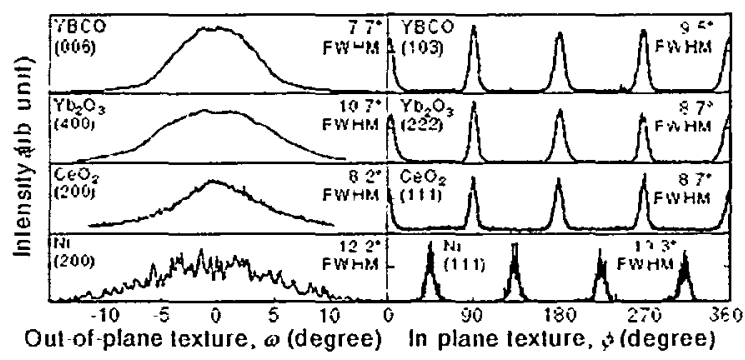

Fig. 1.26. Out-of-plane and in-plane textures of various layers in the $\mathrm{YBCO} /$ $\mathrm{Yb}_{2} \mathrm{O}_{3} / \mathrm{YSZ} \mathrm{CeO}_{2} / \mathrm{Ni}^{\mathrm{RABiTS}}{ }^{\mathrm{TM}}$ sample.

layers involved in this RABiTS ${ }^{\mathrm{TM}}$ architecture. It can be seen from the $\omega$-scans that the out-ofplane textures are sharp, with an FWHM of the (006) $\mathrm{YBCO},(400) \mathrm{Yb}_{2} \mathrm{O}_{3}$, (200) YSZ,

(200) $\mathrm{CeO}_{2}$, and (200)Ni peaks of $6.5,9.4,8.8$, 7.8 , and $10.4^{\circ}$, respectively. Unlike the out-ofplane epitaxy exhibited by $\mathrm{YBCO}$ on $\mathrm{CeO}_{2}$, there is a noticeable reduction in the FWHM of $\mathrm{YBCO}$ on $\mathrm{Yb}_{2} \mathrm{O}_{3}$ as previously found in $\mathrm{YBCO}$ on YSZ. This is likely to be a consequence of the anisotropic growth of $\mathrm{YBCO}$ films resulting in the preferred $c$-axis texturing. In the case of in-plane texture, the FWHM of the (103)YBCO, (222) $\mathrm{Yb}_{2} \mathrm{O}_{3},(111) \mathrm{YSZ},(111) \mathrm{CeO}_{2}$, and $(111) \mathrm{Ni}$ peaks are found to be 8.9, 11.0, 9.3, 7.9, and $9.6^{\circ}$, respectively. The consistency of these FWHM values indicates the existence of excellent epitaxy throughout all the layers. Unlike the out-of-plane texture, no systematic improvement in the in-plane texture on transition from $\mathrm{Yb}_{2} \mathrm{O}_{3}$ to $\mathrm{YBCO}$ has been found. Most important, however, is the singlecomponent epitaxy exhibited by every one of the YBCO films deposited on $\mathrm{Yb}_{2} \mathrm{O}_{3}$ surfaces in this work (a total of 6).

An SEM examination of the HTS shows a smooth, dense, and flat microstructure with a small number of pin holes, which is typical of high-quality YBCO films. The film possesses a zero resistance at $\sim 90 \mathrm{~K}$ with a superconducting transition width of roughly $1 \mathrm{~K}$. Transport $J_{\mathrm{c}}$ (77 K, s.f.) of the YBCO film was found to be $1.2 \times 10^{6} \mathrm{~A} / \mathrm{cm}^{2}$, which compares favorably with 
the best films on the $\mathrm{YSZ} / \mathrm{CeO}_{2} / \mathrm{Ni}$ architecture. In addition. temperature as well as magnetic field dependencies of $J_{\mathrm{c}}$ were measured and are shown in Fig. 1.27 and Fig. 1.28, respectively. Also included for comparison are the characteristics of a high-quality singlecomponent epitaxial YBCO deposited onto the standard $\mathrm{YSZ} / \mathrm{CeO}_{2} / \mathrm{Ni}$ architecture. As seen from these figures, the temperature and field behavior of $\mathrm{YBCO}$ on $\mathrm{Yb}_{2} \mathrm{O}_{3} / \mathrm{YSZ} / \mathrm{CeO}_{2} / \mathrm{Ni}$ are similar to those on standard architecture. These characteristics as well as the high $J_{\mathrm{c}}$ value indicate that $\mathrm{Yb}_{2} \mathrm{O}_{\hat{3}}$ is an excellent buffer material for $\mathrm{YBCO}$.

Once the appropriateness of $\mathrm{Yb}_{2} \mathrm{O}_{3}$ as a buffer material was demonstrated, the RABiTS ${ }^{T M}$ architecture was simplified by eliminating the YSZ layer as shown in Fig. 1.23(b). All the deposition conditions are identical to those previously described, except that the $\mathrm{Yb}_{2} \mathrm{O}_{3}$ buffer layer thickness was increased to $400 \mathrm{~nm}$ to provide sufficient diffusion protection. A YBCO film of $350-\mathrm{nm}$ thickness was deposited onto this $\mathrm{Yb}_{2} \mathrm{O}_{3} / \mathrm{CeO}_{2} / \mathrm{Ni}$ alternative buffer architecture. Excellent out-of-plane and in-plane textures are found in all the layers. Figure 1.29 shows both the out-of-plane and in-plane textures of the various layers involved in this RABiTS ${ }^{\mathrm{TM}}$ architecture. The FWHM of (006)YBCO. $(400) \mathrm{Yb}_{2} \mathrm{O}_{3},(200) \mathrm{CeO}_{2}$, and (200) Ni peaks are 7.7. 10.7. 8.2, and $12.2^{\circ}$, whereas the FWHM of

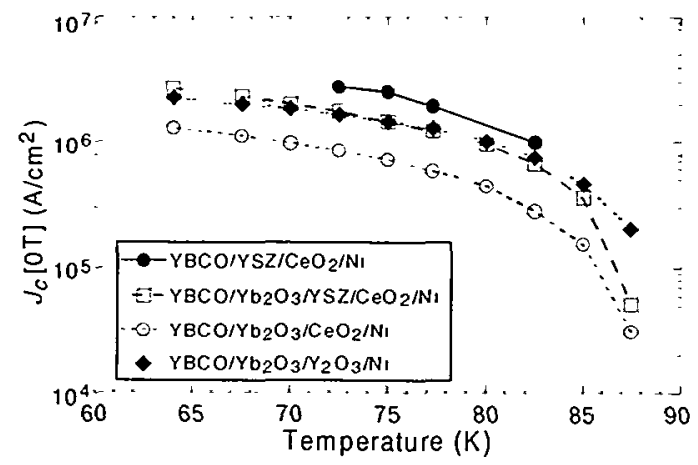

Fig. 1.27. Temperature dependencies of $J_{c}$ of YBCO deposited on various RABiTS $^{\mathrm{TM}}$ architectures.
(103) $\mathrm{YBCO},(222) \mathrm{Yb}_{2} \mathrm{O}_{3},(111) \mathrm{CeO}_{2}$, and (111) Ni peaks are $9.5,8.7,8.7$, and $10.3^{\circ}$, respectively. Thus, for the first time, an excellent single-component YBCO epitaxy was obtained on RABiTSTM that does not possess a YSZ buffer layer.

An SEM examination of the YBCO film revealed a microstructure that is identical to that deposited onto the more complicated $\mathrm{Yb}_{2} \mathrm{O}_{3} / \mathrm{YSZ} / \mathrm{CeO}_{2} / \mathrm{Ni}$ architecture. In addition, the zero-resistance temperature and transition width of this film are also $90 \mathrm{~K}$ and $1 \mathrm{~K}$, respectively. Moreover, Figs. 1.27 and 1.28 show that the temperature and field dependencies of $J_{\mathrm{c}}$ of $\mathrm{YBCO} / \mathrm{Yb}_{2} \mathrm{O}_{3} / \mathrm{CeO}_{2} / \mathrm{Ni}$ behave in the same manner as other high-quality YBCO. However, the $J_{\mathrm{c}}$ ( $77 \mathrm{~K}$, s.f.) of this film is found to be only $0.6 \times 10^{6} \mathrm{~A} / \mathrm{cm}^{2}$, considerably less than that of $\mathrm{YBCO} / \mathrm{Yb}_{2} \mathrm{O}_{3} / \mathrm{YSZ} / \mathrm{CeO}_{2} / \mathrm{Ni}$.

Portions of the YBCO films were chemically etched to expose the interface in order to examine whether any adverse reaction has occurred between HTS and the buffer. Under SEM observation, the $\mathrm{Yb}_{2} \mathrm{O}_{3}$ surface of the $\mathrm{YBCO} / \mathrm{Yb}_{2} \mathrm{O}_{3} / \mathrm{YSZ} / \mathrm{CeO}_{2} / \mathrm{Ni}$ sample remained smooth and uniform as shown in Fig. 1.30. On the other hand, the exposed $\mathrm{Yb}_{2} \mathrm{O}_{3}$ buffer of the $\mathrm{YBCO} / \mathrm{Yb}_{2} \mathrm{O}_{3} / \mathrm{CeO}_{2} / \mathrm{Ni}$ sample exhibited orthogonal line features reminiscent in both the spacing and appearance of the

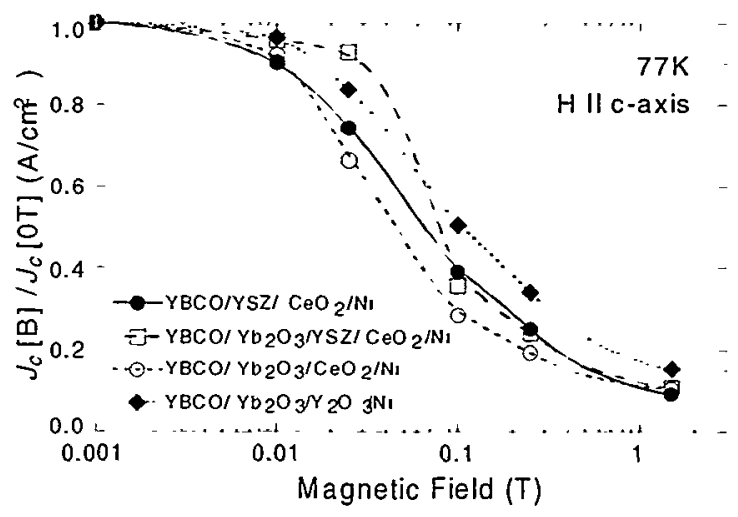

Fig. 1.28. Magnetic field dependencies of normalized $J_{c}$ of YBCO deposited on various RABiTS ${ }^{\text {TM }}$ architectures. 


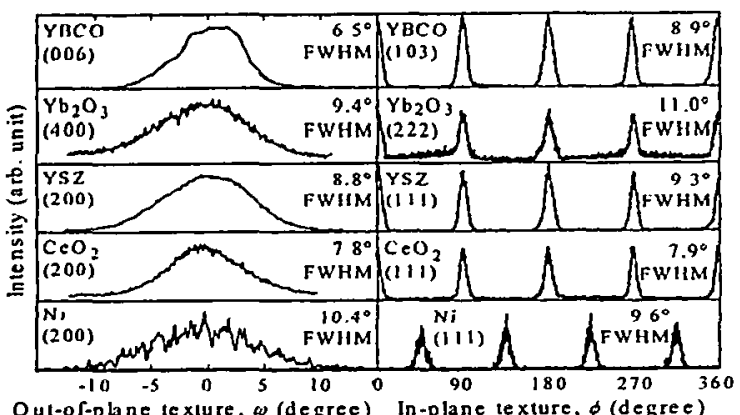

Fig. 1.29. Out-of-plane and in-plane textures of various layers in the YBCO $/ \mathrm{Yb}_{2} \mathrm{O}_{3} / \mathrm{CeO}_{2} / \mathrm{Ni}^{\mathrm{RABITS}}{ }^{\mathrm{TM}}$ sample.

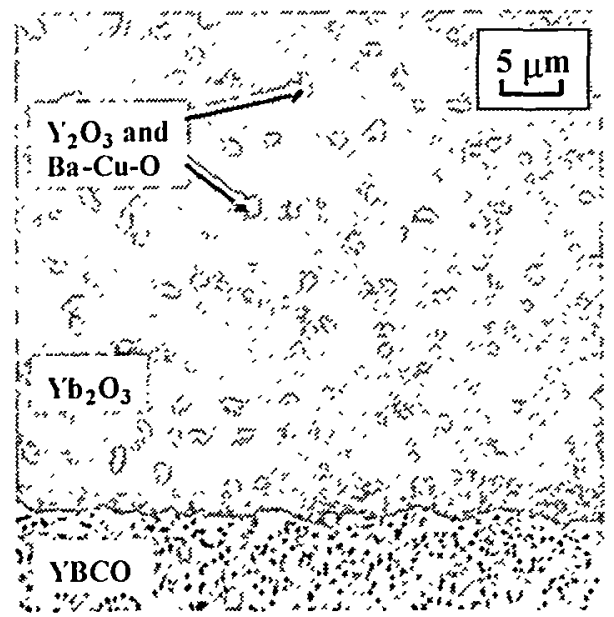

Fig. 1.30. Microstructure of $\mathrm{Yb}_{2} \mathrm{O}_{3}$ buffer after $\mathrm{YBCO}$ has been chemically etched from $\mathrm{YBCO} / \mathrm{Yb}_{2} \mathrm{O}_{3} / \mathrm{YSZ} / \mathrm{CeO}_{2} / \mathrm{Ni}$. $\mathrm{Y}_{2} \mathrm{O}_{3}$ and $\mathrm{Ba}-\mathrm{Cu}-\mathrm{O}$ particles are found to remain on the buffer.

orthogonal cracks frequently found in the $\mathrm{CeO}_{2}$ buffer (Fig. 1.31). Spot energy-dispersive spectroscopy (EDS) analyses at these linear features indicated a consistently higher level of $\mathrm{Ni}$ signal in the spectrum, and Ni-rich oxide particles were frequently found to straddle these linear features. It is possible that cracks were initiated in the $\mathrm{CeO}_{2}$ buffer and propagated into the $\mathrm{Yb}_{2} \mathrm{O}_{3}$ layer, leading to local contamination or disruption of texture in the YBCO film. These results further point to the advantage in eliminating the weak and fragile $\mathrm{CeO}_{2}$ layer in RABiTS ${ }^{\mathrm{TM}}$.

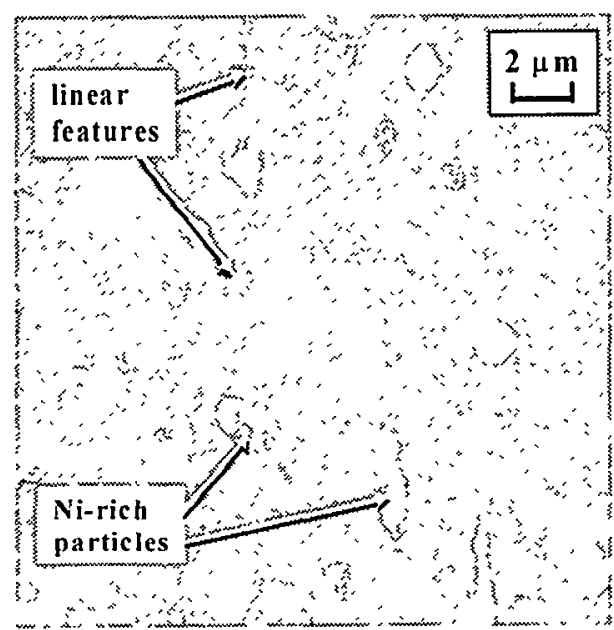

Fig. 1.31. Microstructure of $\mathrm{Yb}_{2} \mathrm{O}_{3}$ buffer after $\mathrm{YBCO}$ has been chemically etched from $\mathrm{YBCO} / \mathrm{Yb}_{2} \mathrm{O}_{3} / \mathrm{CeO}_{2} / \mathrm{Ni}$. Ni-rich particles are found to straddle the linear features.

For replacement of the $\mathrm{CeO}_{2}$ layer, 20-nmthick epitaxial $\mathrm{Y}_{2} \mathrm{O}_{3}$ buffers were deposited onto textured $\mathrm{Ni}$ substrates using e-beam at $650^{\circ} \mathrm{C}$. Yittrium oxide is an excellent alternative buffer because it can consistently be deposited epitaxially onto a $\mathrm{Ni}$ surface, and no crack has ever been observed in any of the samples (more than 10) prepared at our laboratory. Subsequent 400 -nm-thick layers of $\mathrm{Yb}_{2} \mathrm{O}_{3}$ were deposited onto the $\mathrm{Y}_{2} \mathrm{O}_{3} / \mathrm{Ni}$ substrates by $\mathrm{rf}$ magnetron sputtering, resulting in the alternative architecture shown in Fig. 1.23(c). YBCO films of 200-nm to 300-nm thickness were deposited onto these substrates by PLD. Figure 1.32 shows both the out-of-plane and in-plane textures of

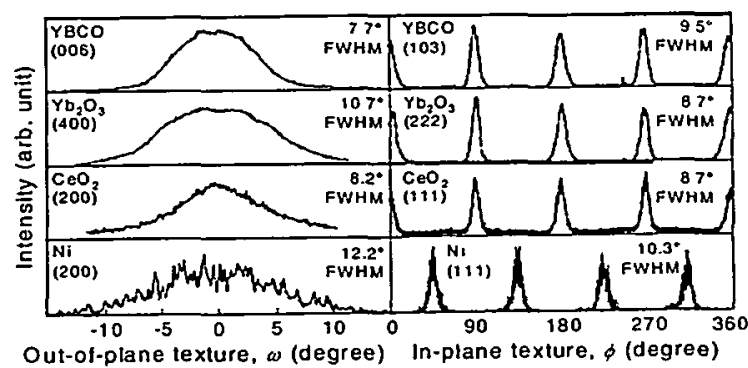

Fig. 1.32. Out-of-plane and in-plane textures of various layers in the YBCO $/ \mathrm{Yb}_{2} \mathrm{O}_{3} / \mathrm{Y}_{2} \mathrm{O}_{3} / \mathrm{Ni}$ RABiTS ${ }^{\mathrm{TM}}$ sample. 
the various layers involved in this RABiTS ${ }^{\mathrm{TM}}$ architecture. The FWHM of (006)YBCO, $(400) \mathrm{Yb}_{2} \mathrm{O}_{3},(200) \mathrm{Y}_{2} \mathrm{O}_{3}$, and (200)Ni peaks are 6.7 10.2 9.5, and $9.2^{\circ}$, whereas the FWHM of (103) YBCO. (222) $\mathrm{Yb}_{2} \mathrm{O}_{3},(111) \mathrm{Y}_{2} \mathrm{O}_{3}$, and (111) Ni peaks are 9.6, 10.3, 10.7, and 9.5 , respectively. The superconducting transition characteristics of these films are similar to the characteristics of the other films reported in this work, and transport $J_{\mathrm{c}}(77 \mathrm{~K}$, s.f.) as high as $1.8 \times 10^{6} \mathrm{~A} / \mathrm{cm}^{2}$ has been obtained. Figures 1.27 and 1.28 show the temperature and field dependencies of a typical $\mathrm{YBCO} / \mathrm{Yb}_{2} \mathrm{O}_{3}$ / $\mathrm{Y}_{2} \mathrm{O}_{3} / \mathrm{Ni}$ with a $J_{\mathrm{c}}\left(77 \mathrm{~K}\right.$. s.f.) of $1.3 \times 10^{6}$ $\mathrm{A} / \mathrm{cm}^{2}$. Both temperature and field dependencies are typical of excellent YBCO films. In addition. SEM examination of the buffer-HTS interface after the YBCO had been chemically etched revealed a smooth and uniform buffer surface. These results show that the $\mathrm{Yb}_{2} \mathrm{O}_{3} / \mathrm{Y}_{2} \mathrm{O}_{3} / \mathrm{Ni}$ altemative $\mathrm{RABiTS}^{\mathrm{TM}}$ architecture can provide high-quality singlecomponent epitaxial YBCO with no cracks in the RABiTS ${ }^{\mathrm{TM}}$. Work is currently under way to develop a single rare earth oxide $\left(\mathrm{RE}_{2} \mathrm{O}_{3}\right)$ buffer architecture to further simplify the RABiTSTM process.

In summary, $\mathrm{Yb}_{2} \mathrm{O}_{3}$ has been shown to be an excellent buffer material to obtain singlecomponent $\mathrm{YBCO}$ epitaxy. By replacing $\mathrm{CeO}_{2}$ with $\mathrm{Y}_{2} \mathrm{O}_{3}$. the cracking problem that often plagues the RABiTS ${ }^{\mathrm{TM}}$ process was eliminated. A value of $J_{\mathrm{c}}(77 \mathrm{~K}$, s.f.) has been obtained as high as $1.8 \times 10^{6} \mathrm{~A} / \mathrm{cm}^{2}$ on this alternative $\mathrm{Yb}_{2} \mathrm{O}_{3} / \mathrm{Y}_{2} \mathrm{O}_{3} / \mathrm{Ni}$ architecture. Work is under way to establish the reproducibility of high- $J_{c}$ YBCO on this new RABiTS ${ }^{\mathrm{TM}}$ architecture, as well as further simplification of the RABiTS ${ }^{\mathrm{TM}}$ process.

\section{PREPARATION OF TEXTURED YBCO FILMS ON $\mathrm{SrTiO}_{3}(100)$ SINGLE- CRYSTAL SUBSTRATES USING ALL-IODIDE PRECURSORS}

In continuation of our effort to develop a non-vacuum process to deposit YBCO using solution precursors, we developed an all-iodide precursor approach to grow epitaxial YBCO films. The iodide system offers the advantage of avoiding the formation of $\mathrm{BaCO}_{3}$ during the post-annealing process and also the $\mathrm{YBCO}$ formation in the absence of water. The respective metal iodides were used as the starting materials. Initially, yttrium iodide and barium iodides were dissolved in 2-methoxyethanol, whereas copper iodide was dissolved in an ammonium iodide/dimethylformamide solution. The solutions were mixed together and concentrated to give a $2.0-\mathrm{M}$ total cation precursor solution. The precursor solutions were spin-coated on $\mathrm{SrTiO}_{3}(100)$ substrates and heattreated at $780-830^{\circ} \mathrm{C}$ in $200-500 \mathrm{ppm}$ oxygen atmospheres. In XRD results from the $\theta-2 \theta$ scan (as shown in Fig. 1.33), omega and phi scans for the films revealed a (100) cube texture. The FWHM values for YBCO films are $1.3^{\circ}$ (inplane epitaxy) and $0.42^{\circ}$ (out-of-plane epitaxy). The YBCO films had a zero-resistance temperature of $\sim 90 \mathrm{~K}$ (as shown in the Fig. 1.33 insert). The YBCO films had a porous microstructure and efforts are being made to

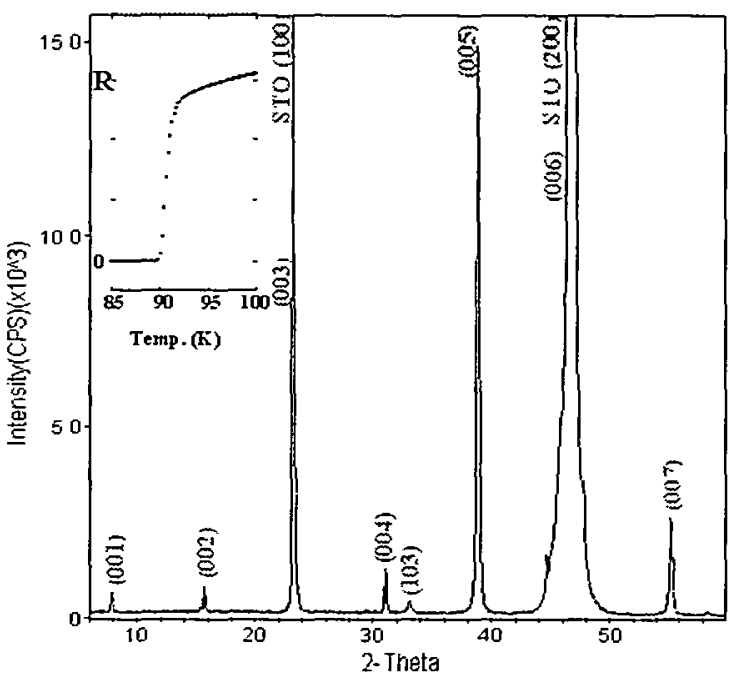

Fig. 1.33. The typical $\theta-2 \theta$ scan for a 2000-Å-thick YBCO film on $\mathrm{SrTiO}_{3}(100)$ substrates indicating the presence of a $c$-axis aligned film. The insert shows the resistance plot for the same YBCO film on $\mathrm{SrTiO}_{3}(100)$ substrates indicating a critical temperature of $\sim 90 \mathrm{~K}$. 
improve the microstructures and hence achieve better properties.

\section{DEMONSTRATION OF THE GROWTH OF HIGH-CURRENT YBCO ON SOL- GEL LaAIO 3 BUFFER LAYER}

We have presently used a sol-gel precursor route to grow $\mathrm{LaAlO}_{3}$ (lanthanum aluminum oxide) buffer layers on $\mathrm{SrTiO}_{3}(100)$ (strontium titanate) single-crystal substrates. The $\mathrm{LaAlO}_{3}$ precursor solutions were spin-coated on $\mathrm{SrTiO}_{3}$ and post-annealed in air at $800^{\circ} \mathrm{C}$ for $20 \mathrm{~min}$. The $\mathrm{LaAlO}_{3}$ films had a smooth surface morphology. The detailed XRD studies indicate the presence of a single-cube texture for $\sim 0.2$ $\mu m$-thick $\mathrm{LaAlO}_{3}$ films. The typical $\mathrm{LaAlO}_{3}$ (111) pole figure for $\mathrm{LaAlO}_{3}$-buffered $\mathrm{SrTiO}_{3}$ substrate is shown in Fig. 1.34.

The deposition, post-annealing, and characterization of sol-gel $\mathrm{LaAlO}_{3}$ films were done at the American Superconductor Corporation (ASC). The YBCO films were then grown on the sol-gel $\mathrm{LaAlO}_{3}$ buffer layers by PLD at ORNL. The XRD results indicate the presence of a textured YBCO film. The thickness of the YBCO film was determined to be $0.2 \mu \mathrm{m}$ from a profilometer scan. The sample

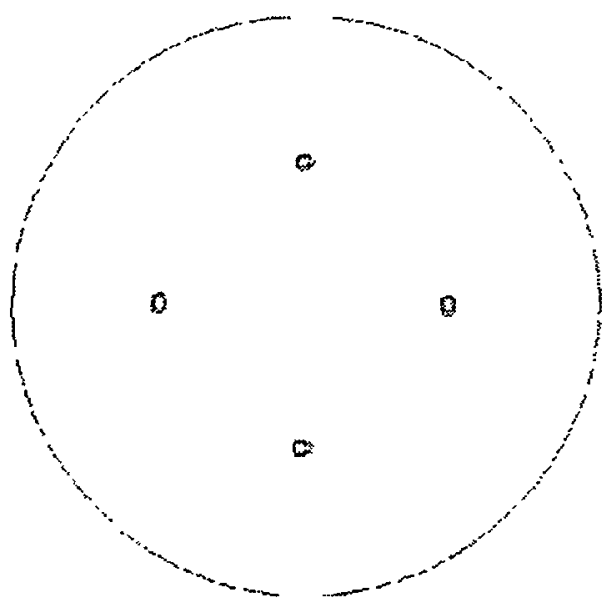

Fig. 1.34. $\mathrm{LaAlO}_{3}(111)$ pole figure for $\sim 0.2-\mu \mathrm{m}$-thick $\mathrm{LaAlO}_{3}$ film deposited on $\mathrm{SrTiO}_{3}(100)$ singlecrystal substrates. dimension was $1 \mathrm{~cm} \times 1 \mathrm{~cm}$. The temperaturedependence resistance for $0.2-\mu \mathrm{m}$-thick $\mathrm{YBCO}$ film on $\mathrm{LaAlO}_{3}$-buffered $\mathrm{SrTiO}_{3}(100)$ substrates is reported in Fig. 1.35. The critical temperature $\left(T_{\mathrm{c}}\right)$ was measured to be $90.5 \mathrm{~K}$. The temperature-dependant $J_{c}$ values [Fig. 1.36(a)] and critical current $\left(I_{\mathrm{c}}\right)$ values [Fig. 1.36(b)] for 0.2- $\mu \mathrm{m}$-thick YBCO film on $\mathrm{LaAlO}_{3}$-buffered $\mathrm{SrTiO}_{3}(100)$ substrates are reported in Fig. 1.36. At $86 \mathrm{~K}$ transport $J_{\mathrm{c}}$ of $0.5 \times 10^{6} \mathrm{~A} / \mathrm{cm}^{2}$ was obtained. The extrapolated $J_{\mathrm{c}}$ at $77 \mathrm{~K}$ was found to be $2.2 \times 10^{6} \mathrm{~A} / \mathrm{cm}^{2}$. Thus, we have demonstrated that high- $J_{\mathrm{c}} \mathrm{YBCO}$ films can be grown on sol-gel $\mathrm{LaAlO}_{3}$ buffer layers on STO.

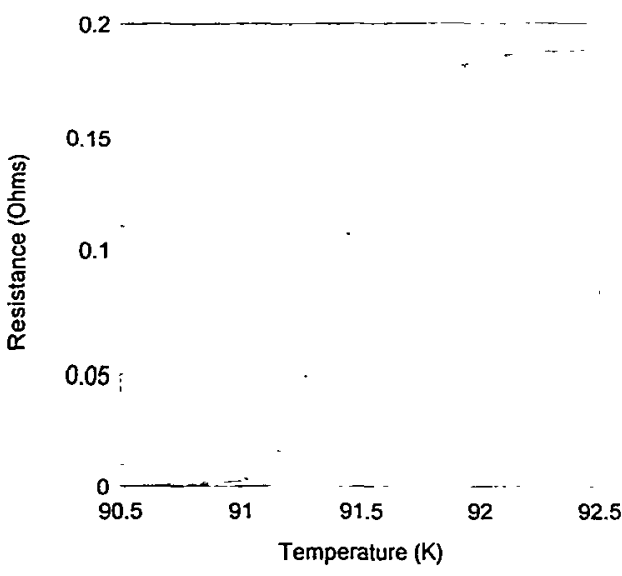

Fig. 1.35. The temperaturedependence resistance for $0.2-\mu \mathrm{m}$ thick YBCO film on $\mathrm{LaAlO}_{3}$-buffered $\mathrm{SrTiO}_{3}(100)$ substrates.

\section{SOLUTION PROCESSING OF $\mathrm{YBa}_{2} \mathrm{Cu}_{3} \mathrm{O}_{7-x}$ THIN FILMS}

It has been observed that randomly oriented polycrystalline HTS materials have poor $J_{c} s$ $<500 \mathrm{~A} / \mathrm{cm}^{2}$. On the other hand, oriented $\mathrm{YBa}_{2} \mathrm{Cu}_{3} \mathrm{O}_{7-\mathrm{\lambda}}$ (YBCO) films grown epitaxially on single-crystal oxide substrates, such as $\mathrm{SrTiO}_{3}(100)$, or on strongly biaxially textured metal substrates, exhibit $J_{\mathrm{c}}$ values $>1 \mathrm{MA} / \mathrm{cm}^{2}$ at $77 \mathrm{~K}$. The aim of this work was to develop a nonvacuum chemical-deposition technique for 


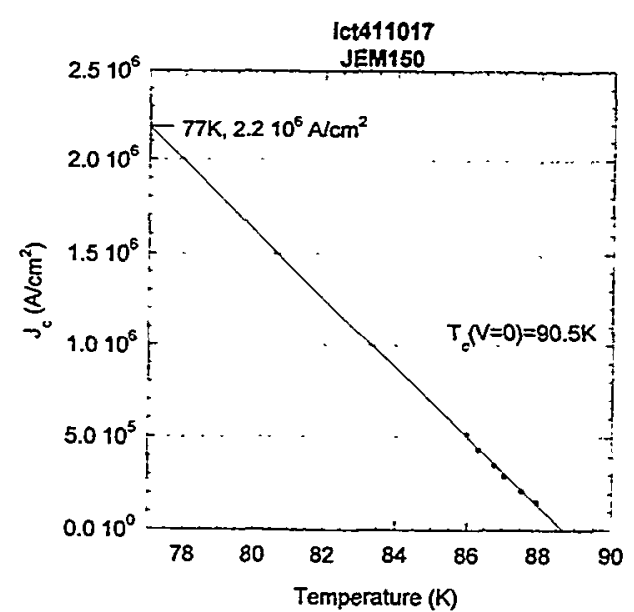

(a)

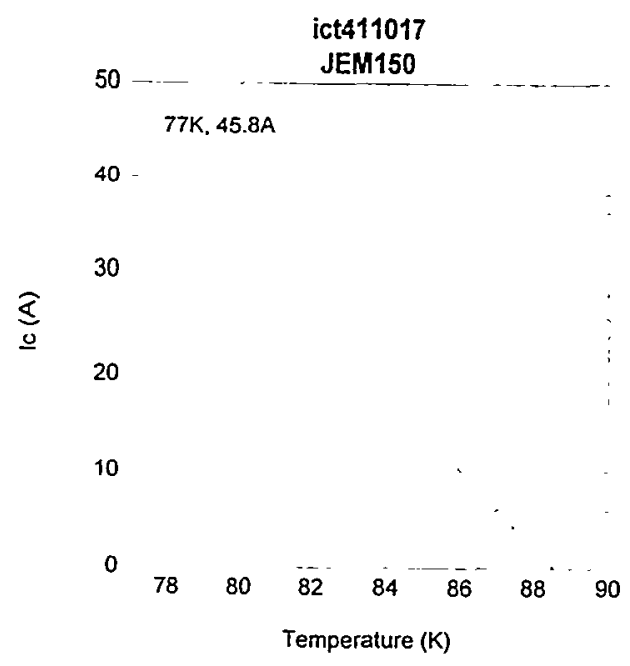

(b)

Fig. 1.36. The temperaturedependence $J_{c}$ values (a) and $I_{c}$ values (b) for 0.2- $\mu$ m-thick YBCO film on $\mathrm{LaAlO}_{3}(100)$ substrates.

YBCO-coated conductors on RABiTS ${ }^{\text {Tu }}$. The RABiTS $^{\text {TM }}$ approach developed at ORNL gives a new approach for the fabrication of losng-length conductors for high-temperature, high-field applications.

We are presently using a metal-organic precursor route. The most commonly used solution techniques may be grouped into three categories: (1) sol-gel process that has 2-methoxyethanol as a reactant and solvent;
(2) hybrid processes that use chelating agents, such as acetylacetonate or diethanolamine, to reduce alkoxide reactivity; and (3) metalorganic decomposition (MOD) technique that uses high-molecular-weight precursors and water-insensitive carboxylates, 2-ethylhexonates, etc.

Recently several groups of workers prepared high- $J_{\mathrm{c}}$ YBCO films on single-crystal substrates using solution-processing routes. McIntyre et al. ' used a trifluoracetate method to prepare YBCO superconducting films with $T_{\mathrm{c}}(\mathrm{R}=0)$ $>92 \mathrm{~K}$ and $J_{\mathrm{c}}\left(\mathrm{T}=77 \mathrm{~K}, \mathrm{H}_{\mathrm{app}}=0\right)>10^{6} \mathrm{~A} / \mathrm{cm}^{2}$ in films of 70- to 80-nm nominal thickness. In the present study, we focus on developing YBCO thin films on $\mathrm{SrTiO}_{3}$ single-crystal substrates using the MOD and sol-gel precursor routes. The chemistry used in both precursor routes is different from that used in the literature work.

\section{Experimental Procedure}

The MOD precursor solution was prepared by mixing yttrium 2-ethylhexonate (STREM Chemicals, $98.5 \%$ ), barium neodecanoate (STREM Chemicals, 95\%), and copper 2-ethylhexonate (STREM Chemicals, 98.2\%) in a molar ratio of $1: 2: 3$, respectively. Solutions were heated on a hot plate $\left(<100^{\circ} \mathrm{C}\right)$ to prepare a homogenous solution, but on cooling the solution became very viscous. A solution suitable for spin-coating was prepared by adding a small amount of 2-ethylhexonaic acid into this viscous precursor solution. The total cation concentration was $0.32 \mathrm{M}$. MOD solutions were spin-coated on $\mathrm{SrTiO}_{3}$ single crystals at $4000 \mathrm{rpm}$ for $40 \mathrm{~s}$ and heated in air for an hour at 275 or $195^{\circ} \mathrm{C}$ at a rate of $2^{\circ} \mathrm{C} / \mathrm{min}$. This procedure was repeated several times to adjust the thickness of the prefired films on the substrate. It has been found that the lowtemperature heating is an important step to achieve a continuous film. For example, films pyrolyzed rapidly at $500^{\circ} \mathrm{C}$ became discontinuous. These prefired films were heattreated at two different $\mathrm{p}\left(\mathrm{O}_{2}\right): 2 \times 10^{-2}$ and $3.5 \times 10^{-4} \mathrm{~atm}$. Film A prepared at a $\mathrm{p}\left(\mathrm{O}_{2}\right)$ of 
$2 \times 10^{-2}$ atm was heated at $450^{\circ} \mathrm{C}$ at a rate of $5^{\circ} \mathrm{C} / \mathrm{min}$. whereas film $\mathrm{B}$ synthesized at $3.5 \times 10^{-4} \mathrm{~atm}$ was heated at $450^{\circ} \mathrm{C}$ at a rate of $15^{\circ} \mathrm{C} / \mathrm{min}$ to burn off the carbon. Finally both films, $A$ and $B$, were annealed at 870 and $800^{\circ} \mathrm{C}$, respectively, in different partial pressures of oxygen. Films were furnace cooled in $100 \%$ oxygen to $500^{\circ} \mathrm{C}$ and were oxygenated at this temperature for $\mathrm{I} h$ and subsequently cooled down at a rate of $1^{\circ} \mathrm{C} / \mathrm{min}$ to room temperature. Films were then post-annealed at 500 or $525^{\circ} \mathrm{C}$ for $2 \mathrm{~h}$ after application of silver contacts and were subsequently cooled down at a rate of $1{ }^{\circ} \mathrm{C} / \mathrm{min}$ to room temperature.

\section{Results and Discussion}

\section{MOD Solution}

The differential thermal analysis (DTA) and TGA data were obtained on yttrium, barium, and copper precursor powders in a $\mathrm{p}\left(\mathrm{O}_{2}\right)$ equal to $2 \times 10^{-4} \mathrm{~atm}$. The TGA scans are shown in Fig. 1.37. All three precursors have sharp thermal decomposition events. The copper precursor has two thermal events at 262.5 and $275^{\circ} \mathrm{C}$ while yttrium and barium precursors have only single thermal events at 475 and $487.5^{\circ} \mathrm{C}$, respectively. The differences in thermal decomposition temperatures can cause inhomogenities in films.

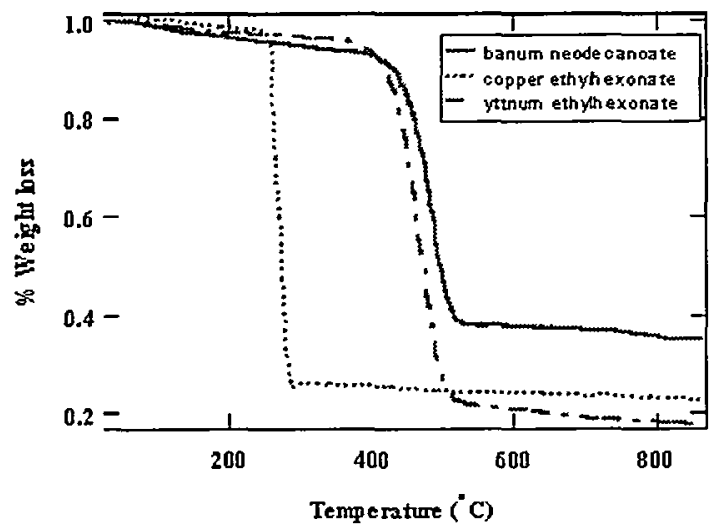

Fig. 1.37. Thermal gravimetric analysis (TGA) plots of barium, copper, and yttrium precursor materials in a $\mathrm{p}\left(\mathrm{O}_{2}\right)$ of $2.0 \times 10^{-4}$ atm.
Figure 1.38 shows the XRD pattern for the film $\mathrm{A}(\mathrm{t} \approx 4000 \AA)$ formed on the $\mathrm{SrTiO}$ (100) substrate by heating at $870^{\circ} \mathrm{C}$ for $4 \mathrm{~h}$. This pattern exhibits $\mathrm{YBCO}$ as the predominant phase with small amounts of $\mathrm{CuO}$ and $\mathrm{Y}_{2} \mathrm{BaCuO}_{5}$ impurities and also a small unidentified peak at a $2 \theta$ of $40.5^{\circ}$. The XRD pattern of film A shows both (00l) and (h00) peaks of $\mathrm{YBCO}$, indicating the presence of both $c$ - and $a$-axis perpendicular orientations to the substrate and also some amount of random phase. The XRD results from the $\omega$ and $\phi$ scans for films grown on the $\mathrm{SrTiO}_{3}$ substrate revealed a (100) cube texture. The FWHM values for YBCO films on $\mathrm{SrTiO}_{3}$ substrates in case of $c$-axis orientation were $0.45^{\circ}$ (out-of-plane epitaxy) and $0.5^{\circ}$ (in-plane epitaxy). A typical $\phi$ scan for the (102) planes are shown in Fig. 1.39. The FWHM value for in-plane crystallographic alignment of $a$-axis orientated material was $2^{\circ}$.

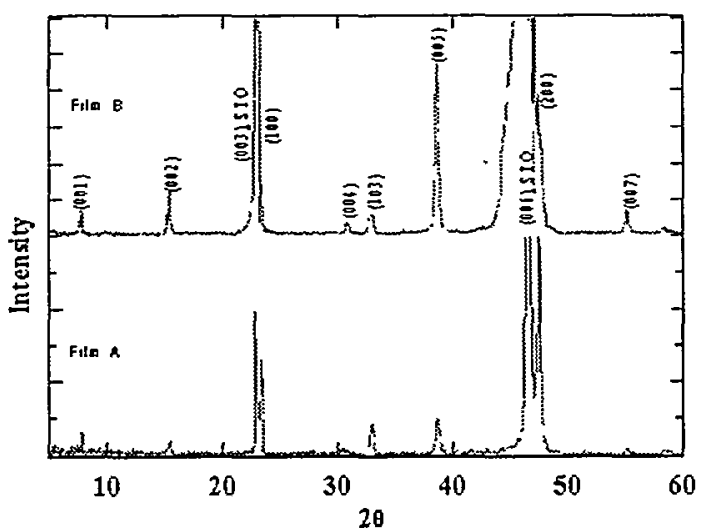

Fig. 1.38. The room temperature powder X-ray diffraction pattern of YBCO films on (001) $\mathrm{SrTiO}_{3}$ substrates.

As shown in Fig. 1.40, an SEM photomicrograph of the film A surface indicates the presence of a smooth microstructure. The microstructure is composed of YBCO platelets with both $c$-and $a$-axis orientations. This microstructure also contains secondary particles, which are presumed to be primarily $\mathrm{Y}_{2} \mathrm{BaCuO}_{5}$ and $\mathrm{CuO}$. Figure 1.41 shows the dc-resistance measurements on film A. The $T_{\text {c. onset }}$ is $88 \mathrm{~K}$ 


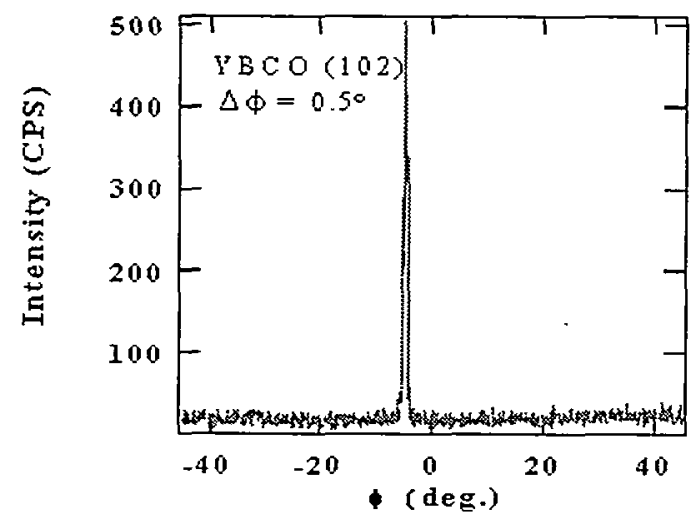

Fig. 1.39. A typical $\phi$ scan featuring the epitaxial nature of $c$-axis oriented YBCO films on $\mathrm{SrTiO}_{3}$ substrates.

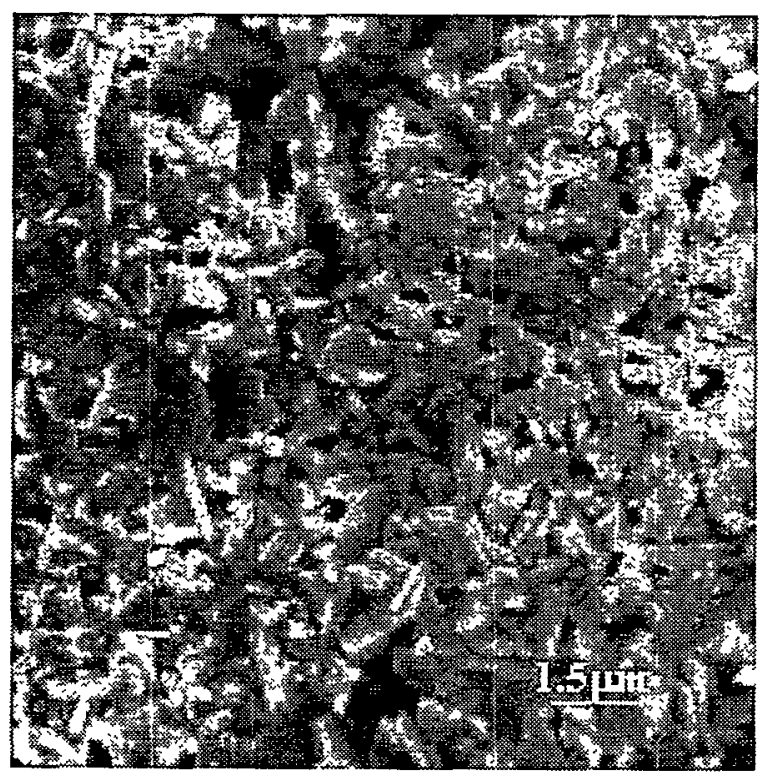

Fig. 1.40. SEM photomicrograph of film $A$.

while film became fully superconducting at $63 \mathrm{~K}$. The XRD pattern (Fig. 1.38) on film B $(\mathrm{t} \approx 1 \mu \mathrm{m}$ ) shows that this film has more YBCO in the $c$-axis orientation compared with film $\mathrm{A}$. The $T_{\text {c.onset }}$ of film B is $89 \mathrm{~K}$ while the $T_{\text {c.zero }}$ occurs at $63 \mathrm{~K}$ as shown in Fig. 1.41. To improve the surface finish of YBCO films processed at a $\mathrm{p}\left(\mathrm{O}_{2}\right)$ of $3.5 \times 10^{-4} \mathrm{~atm}$, it was decided that it might be better if films were heated to $525^{\circ} \mathrm{C}$ to complete the decomposition of precursor materials (Fig. 1.37) before

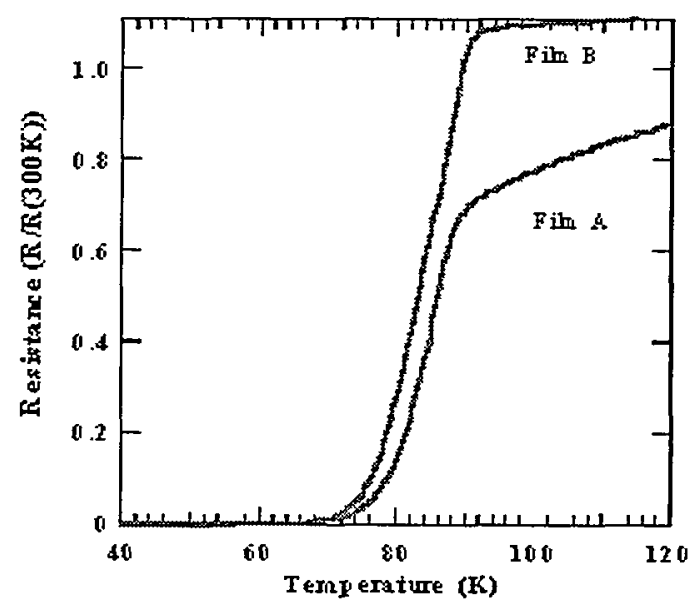

Fig. 1.41. The dc-resistance measurements on film $A$.

annealing to high temperatures. Therefore, a film was heated to $525^{\circ} \mathrm{C}$ at a rate of $15^{\circ} \mathrm{C} / \mathrm{min}$ and kept at that temperature for $20 \mathrm{~min}$ after every coat. To avoid carbon contamination in the film, films were heat-treated in a $100 \%$ oxygen atmosphere at $525^{\circ} \mathrm{C}$ for $8 \mathrm{~h}$. One film was heated to $780^{\circ} \mathrm{C}$ at a rate of $20-25^{\circ} \mathrm{C} / \mathrm{min}$ in a $\mathrm{p}\left(\mathrm{O}_{2}\right)$ of $3.5 \times 10^{-4}$ atm and held for $3 \mathrm{~h}$ at that temperature. The film surface was shiny and smooth. The XRD pattern of this film showed the YBCO phase present predominately in the $a$-axis orientation. The $T_{\mathrm{c}}$ of this film was only $46 \mathrm{~K}$. Another film was heated rapidly to $780^{\circ} \mathrm{C}$, but the $\mathrm{YBCO}$ phase still existed predominately in the $a$-axis orientation. From these data, it appears that low-temperature treatment $\left(\leq 525^{\circ} \mathrm{C}\right)$ to the film is important for the crystal structure of YBCO films prepared from MOD precursors.

\section{Sol-Gel Route}

YBCO films were also prepared by alkoxide precursors. Copper methoxide (Alfa), barium metal (Alfa, 99.99\%) , triethanolamine, and 2-methoxyethanol (Alfa, spectrophotometric grade) were used without further purification. The yttrium iso-propoxide was synthesized in our laboratory. The final YBCO precursor solution was prepared by mixing the yttrium and 
barium methoxyethanolate/2- methoxyethanol solution with the copper methoxide/triethanolamine solution at room temperature. A similar procedure has been used to prepare $\mathrm{TlBa}_{2} \mathrm{Ca}_{2} \mathrm{Cu}_{3} \mathrm{O}_{9-\mathrm{y}}$ superconducting films. The precursor solution was partially hydrolyzed for spin-coating by adding approximately 1 equivalent of water per cation equivalent. The film was dried on the hot plate before the hightemperature annealing. The film was first heattreated at $450^{\circ} \mathrm{C}$ for $1.5 \mathrm{~h}$ and subsequently heated at $860^{\circ} \mathrm{C}$ for $20 \mathrm{~h}$ in a $\mathrm{p}\left(\mathrm{O}_{2}\right)$ of $2 \times 10^{-2} \mathrm{~atm}$.

The XRD pattern of this film is shown in Fig. 1.42. The film is completely $c$-axis oriented and epitaxial. The typical $\phi$ scan for the (102) planes is shown in the Fig. 1.42 inset. The FWHM values for sol-gel YBCO films on $\mathrm{SrTiO}_{3}$ substrates were $0.45^{\circ}$ (in-plane epitaxy) and $0.69^{\circ}$ (out-of-plane epitaxy).

In summary, we have developed MOD and sol-gel solutions for preparing YBCO films. Films prepared on $\mathrm{SrTiO}_{3}$ single crystals from MOD solutions have $c$ - and $a$-axis-oriented YBCO phase. These films also contain some amount of a random phase. On processing the film at a low- $\mathrm{P}\left(\mathrm{O}_{2}\right)$ and a lower low-temperature treatment process, the amount of $c$-axis

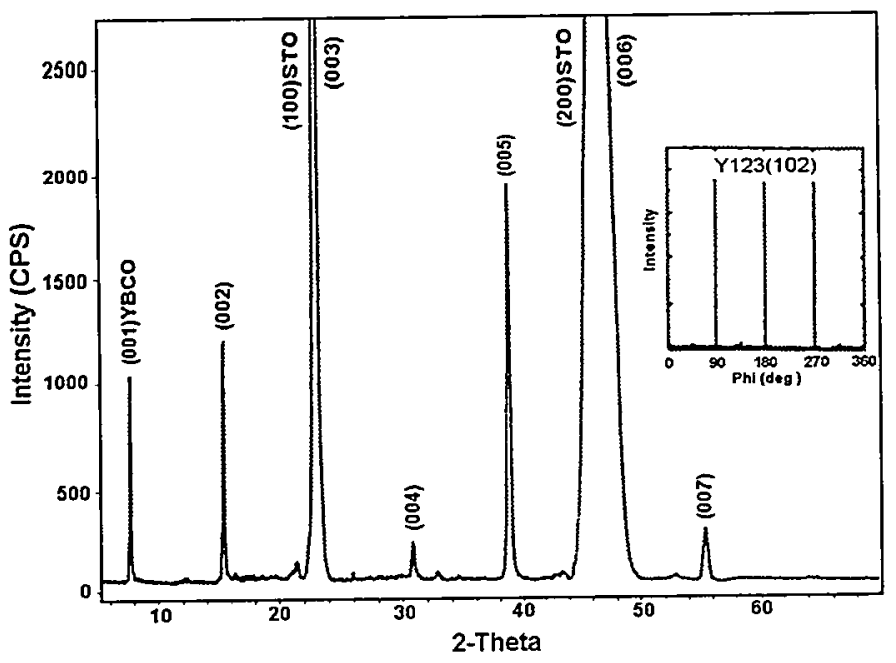

Fig. 1.42. The $X$-ray powder diffraction pattern for the sol-gel YBCO film grown on a $\mathrm{SrTiO}_{3}$ single crystal. The $\phi$ scan (inset) shows the epitaxial nature of $c$-axis-oriented YBCO films on $\mathrm{SrTiO}_{3}$ substrates. orientation increases. The $T_{\text {c.onset }}$ of films is $89 \mathrm{~K}$ whereas the best superconducting transition temperature is $63 \mathrm{~K}$. The sol-gel YBCO films on $\mathrm{SrTiO}_{3}$ single crystals were epitaxial and $c$-axis oriented.

\section{References}

1. P. C. Mclntyre, M. J. Cima, J. A. Smith, Jr., R. B. Hallock, M. P. Siegal, and J. M. Phillips, "Effect of growth conditions on the properties and morphology of chemically derived epitaxial thin films of $\mathrm{Ba}_{2} \mathrm{YCu}_{3} \mathrm{O}_{7-}$, on (001) $\mathrm{LaAlO}_{3}$,"J. Appl. Phys. 71: 1868-77 (1992).

\section{GROWTH OF TEXTURED BUFFER LAYERS AND SUPERCONDUCTORS ON ROLLED-Ni SUBSTRATES USING SOL-GEL ALKOXIDE PRECURSORS}

Solution processing techniques have emerged as potential low-cost, non-vacuum methods to produce long-length conductors. Buffer layers, such as $\mathrm{REAlO}_{3}$ (Rare Earth Aluminates) and $\mathrm{NdGaO}_{\hat{\jmath}}$, are of interest because $J_{\mathrm{c}} \mathrm{s}$ exceeding $1 \times 10^{6} \mathrm{~A} / \mathrm{cm}^{2}$ at $77 \mathrm{~K}$ at zero field have been repeatedly observed from YBCO and Tl-1223 superconductors grown on these layers. The demonstration of the growth of epitaxial buffer layers on biaxially textured metal substrates using sol-gel precursors is necessary for producing good superconducting films. The biaxially textured metal substrates can be obtained by cold-rolling followed by recrystallization. Using textured-Ni substrates, we have demonstrated that high-current YBCO films can be grown with a layer sequence of $\mathrm{YBCO} / \mathrm{YSZ} / \mathrm{CeO}_{2} / \mathrm{Ni}$ through our RABiTS ${ }^{\mathrm{TM}}$ process. In this process, all the buffer layers were grown in vacuum. The rare earth aluminates and gallate buffer layers chosen for this study are chemically inert and promise the possibility of using a single buffer layer. This work was carried 
out in three steps. In the first step, we developed the sol-gel chemistry of the starting precursors. In the second step, we demonstrated the growth of epitaxial films on $\mathrm{SrTiO}_{3}(100)$ single-crystal substrates. In the third step, we developed a process to produce epitaxial films on texturedmetal substrates.

The sol-gel process involves synthesis of a polymerizable solution (often referred to as sol) by mixing or reacting metal alkoxides and metal-organic salts in a common solvent. Alkoxides are referred to as $M(O R) n$ where $M$ is a metal, $n$ is the valency of the metal, and $R$ is an alkyl group. The most common solvent used in this process is 2-methoxyethanol. The complete hydrolysis of the sol forms a rigid gel that can be heat-treated to form powders. Partial hydrolysis of the sol will produce a polymeric viscous liquid. The polymeric precursor solution can be spin-coated, dip-coated, painted, or sprayed on practically any substrates and processed to obtain dense crystalline films. The primary advantage of sol-gel processing over conventional solid-state reaction is that the polymeric network formation of the metalorganic complexes leads to atomic-scale mixing, thus allowing a dramatic reduction in reaction temperatures and time. Our preliminary studies on the growth of epitaxial $\mathrm{LaAlO}_{3}$ films on $\mathrm{SrTiO}_{3}(100)$ substrates using sol-gel alkoxide precursors were published earlier. ${ }^{1}$ In the present study, we report our demonstration of the growth of epitaxial $\mathrm{REAIO}_{3}(\mathrm{RE}=\mathrm{La}, \mathrm{Nd}$, $\mathrm{Gd}, \mathrm{Y}$ ) and $\mathrm{NdGaO}_{3}$ on $\mathrm{SrTiO}_{3}(100)$ substrates. We also report our successful development of the growth of textured $\mathrm{LaAlO}_{3}$ and $\mathrm{NdAlO}_{3}$ films on rolled-Ni substrates. We also demonstrate for the first time that a high- $J_{\mathrm{c}}$ YBCO film can be grown on a sol-gel buffer layer.

\section{Experimental Procedure}

The starting reagents were weighed in an argon-filled glove box, and the solution preparation was carried out under argon, with a Schlenk-type apparatus. Lanthanum isopropoxide (Alfa), and 2-methoxyethanol (Alfa, spectroscopic grade) were used as received. Aluminum isopropoxide (Alfa, $99.99 \%$ ) was sublimed before use. Neodymium isopropoxide, gadolinium isopropoxide, and yttrium isopropoxide were prepared in-house by the direct reaction of the respective metal with isopropanol in the presence of a mercury catalyst. Gallium isopropoxide was prepared by the reaction of gallium chloride with sodium isopropoxide. The details of the synthesis of rare earth isopropoxide and gallium isopropoxide have been submitted for publication elsewhere. Here, we describe the preparation of an all-alkoxide $\mathrm{LaAlO}_{3}$ precursor solution. All the other aluminates and gallates were prepared with a similar procedure.

The $\mathrm{LaAlO}_{3}$ precursor solution was prepared by mixing $3.15 \mathrm{~g}$ ( $10 \mathrm{mmole})$ of lanthanum isopropoxide with $2.04 \mathrm{~g}$ (10 mmole) of aluminum isopropoxide in a $100-\mathrm{mL}$ roundbottomed flask followed by the addition of $50 \mathrm{~mL}$ of 2-methoxyethanol. The mixture was refluxed for $1 \mathrm{~h}$, and approximately $30 \mathrm{~mL}$ of the solvent mixture of isopropanol and 2-methoxyethanol were distilled off. To the resulting viscous yellow liquid, an additional $50 \mathrm{~mL}$ of 2-methoxyethanol was added. The reflux and the distillation process were repeated to ensure complete ligand exchange. Following the second distillation, the solution volume was adjusted to $25 \mathrm{~mL}$ with 2-methoxythanol to give a $0.4-\mathrm{M} \mathrm{LaAlO}$, precursor solution. A partially hydrolyzed solution suitable for spin-coating was prepared by adding approximately 1 equivalent of water ( $1-\mathrm{M} \mathrm{H}_{2} \mathrm{O}$ in 2-methoxyethanol) per cation equivalent. The precursor solution was allowed to age overnight at room temperature prior to the coating process. Part of the starting solutions was fully hydrolyzed, and the resulting gels were dried on a hot plate. The powders obtained were used for differential thermal analysis (DTA) and TGA. For detailed $\mathrm{LaAlO}_{3}$ precursor aging studies, higher equivalents of water per cation were added.

The substrates used for spin-coating in this study were $\mathrm{SrTiO}_{\hat{\jmath}}(100)$ single-crystal 
substrates and textured-Ni substrates. The (100) cube-textured-Ni substrates were prepared by annealing the cold-rolled $\mathrm{Ni}$ substrates to recrystallize at $800^{\circ} \mathrm{C}$ for $2 \mathrm{~h}$ in a high-vacuum furnace. After the $\mathrm{SrTiO}_{3}$ substrates were cleaned ultrasonically in ethanol for a few minutes, the substrates were pre-annealed in 1 -atm $\mathrm{O}_{2}$ at $-900^{\circ} \mathrm{C}$ for $1 \mathrm{~h}$ and slowly cooled to room temperature in flowing $\mathrm{O}_{2}$. Typically three coatings of the partially hydrolyzed precursor solution were applied with a spin-coater operated at $2000 \mathrm{rpm}$ for $45 \mathrm{~s}$. Between each coating, the substrate was pyrolyzed in $\mathrm{O}_{2}$ in a rapid thermal annealer (AG Associates model 610 ) at $800-850^{\circ} \mathrm{C}$ for $2-5 \mathrm{~min}$. The total thickness of the resulting film was approximately $3000 \AA$. On textured-Ni substrates, only one coating of the precursor solution was applied. After the $\mathrm{Ni}$ substrates were coated, they were annealed in a mixture of $4 \% \mathrm{H}_{2}$ and $96 \% \mathrm{Ar}$ (forming gas) at $1160^{\circ} \mathrm{C}$ for $\mathrm{Ih}$ and quenched to room temperature.

The films were analyzed by detailed XRD studies. A Philips Model XRG3100 diffractometer with $\mathrm{Cu} \mathrm{K}_{\alpha}$ radiation was used to record powder diffraction patterns. For texture analysis, a Rigaku rotating anode X-ray generator was used, with a graphite monochromator selecting $\mathrm{Cu} \mathrm{K}_{\alpha}$ radiation and slits defining a $2 \times 2 \mathrm{~mm}^{2}$ incident beam. A four-circle diffractometer was used to collect pole figures, $\omega$ scans, and $\phi$ scans. SEM micrographs were taken using a Hitachi S-4100 Field Emission SEM. The beam voltage used was $15 \mathrm{kV}$. The thickness of the films was determined by Alpha-Step 500 (Tencor Instruments) Profilometer scans. The resistivity and transport $J_{\mathrm{c}}$ was measured using a standard four-probe technique. The values of $J_{c}$ were calculated using a $1-\mu \mathrm{V} / \mathrm{cm}$ criterion. The $\mathrm{Ag}$ contacts were made by sputtering. The YBCO films with $\mathrm{Ag}$ contacts were annealed in 1-atm $\mathrm{O}_{2}$ at $500^{\circ} \mathrm{C}$ for $30 \mathrm{~min}$ and slow cooled to room temperature in pure $\mathrm{O}_{2}$.

\section{Results and Discussion}

The characteristics of the sol-gel buffer layer and the growth of epitaxial YBCO films on sol-gel buffers are discussed in the following sections.

\section{Growth of Epitaxial REAlO $\mathrm{O}_{3}$ Films on $\mathrm{SrTiO}_{3}(100)$ Substrates}

The DTA and TGA data on REAIO; powders in $\mathrm{O}_{2}$ indicated a main exothermic event between 800 and $850^{\circ} \mathrm{C}$. Hence, the $\mathrm{REAlO}_{3}$ films were post-annealed at temperatures $800-850^{\circ} \mathrm{C}$. The XRD results from the $\theta-2 \theta$ scan, and also from $\omega$ and $\phi$ scans for $\sim 3000$ - $\AA$-thick $\mathrm{REAlO}_{3}(\mathrm{RE}=\mathrm{La}, \mathrm{Nd}, \mathrm{Gd}, \mathrm{Y}$ ) films on $\mathrm{SrTiO}_{\hat{3}}(100)$ single-crystal substrates, revealed a single cube-on-cube (100)[010] texture. The FWHM values for $\mathrm{LaAlO}_{3}(003)$, $\mathrm{NdAlO}_{3}(003), \mathrm{GdAlO}_{3}(003)$, and $\mathrm{YAlO}_{3}(003)$ were $0.8,1.5,1.6$, and $2.8^{\circ}$, and that of $\mathrm{LaAlO}_{3}$ (202), $\mathrm{NdAlO}_{3}(202), \mathrm{GdAlO}_{3}(202)$, and $\mathrm{YAlO}_{3}$ (202) were $1.1,1.4,2.1$, and $4.0^{\circ}$, respectively. The (220) pole figures of REAlO ${ }_{3}$ films on $\mathrm{SrTiO}_{\hat{3}}(100)$ substrates also indicated the presence of a single cube-on-cube texture. The sharp texture of $\mathrm{LaAlO}_{3}$ films can be explained in terms of reduced lattice mismatch. The lattice parameters of rare earth aluminates, assuming a pseudo-cubic structure $\left(\mathrm{LaAlO}_{3}=3.79 \AA\right.$, $\mathrm{NdAlO}_{3}=3.76 \AA, \mathrm{GdAlO}_{3}=3.71 \AA, \mathrm{YAlO}_{3}=$ $3.68 \AA$ ), lie closer to that of $\mathrm{SrTiO}_{3}(3.91 \AA)$. The correlation between the texture (FWHM values of $\omega$ and $\phi$ scans) of sol-gel-grown $\mathrm{REAlO}_{3}$ films on $\mathrm{SrTiO}_{3}(100)$ substrates with the lattice mismatch is shown in Fig. 1.43. Because of the similarities between the structures (cubic-perovskite) of $\mathrm{REAlO}_{\hat{\beta}}$ and $\mathrm{SrTiO}_{3}$, the epitaxy phenomenon may simply involve the growth of epitaxial grains during pyrolysis at the film/substrate interface. 


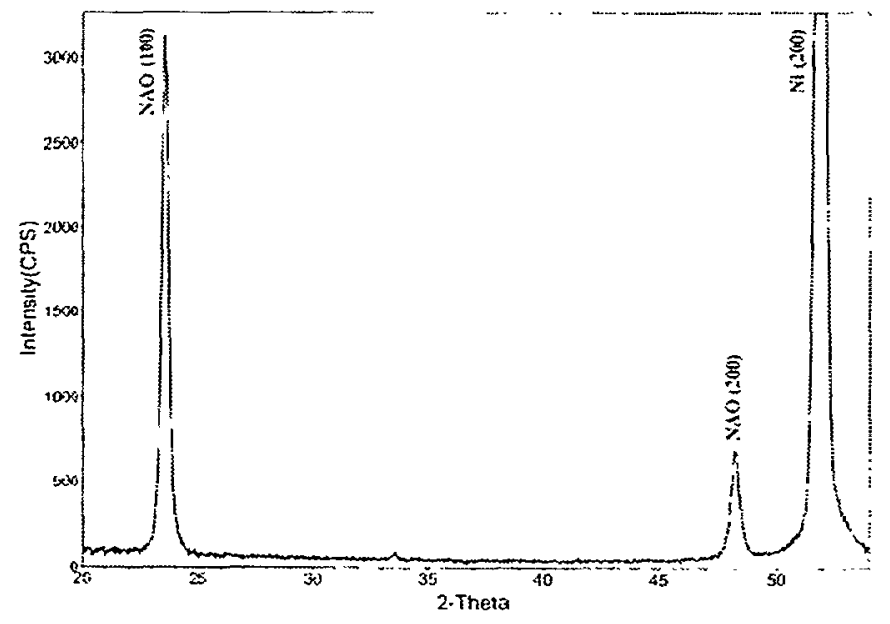

Fig. 1.43. Correlation of the texture (FWHM values of $\omega$ and $\phi$ scans) of sol-gel grown $\mathrm{REAlO}_{3}$ films on $\mathrm{SrTiO}_{3}(100)$ substrates with the lattice mismatch between the film and the substrate.

\section{Growth of Textured REAIO $(R E=L a, N d)$ Films on Ni (100) Substrates}

The crystallization behaviors of the pyrolyzed $\mathrm{LaAlO}_{3}$ and $\mathrm{NdAlO}_{3}$ precursor gels in oxygen and hydrogen atmospheres were reported earlier. ${ }^{2}$ The crystallization of $\mathrm{LaAlO}_{3}$ and $\mathrm{NdAlO}_{3}$ take place at much higher temperatures $\left(\geq 1050^{\circ} \mathrm{C}\right)$ in the presence of hydrogen. Post-annealing of $\mathrm{LaAlO}_{3}$ and $\mathrm{NdAlO}_{3}$ films on textured-Ni (100) substrates in a hydrogen atmosphere is necessary to avoid oxidation of the $\mathrm{Ni}$ substrate. It was proven earlier that the $\mathrm{NiO}$ present at the substrate/film interface will grow with a (111) texture. Detailed XRD results for $1000-\AA$-thick $\mathrm{LaAlO}_{3}$ and $\mathrm{NdAlO}_{3}$ films on textured-Ni (100) substrates indicated the presence of a mixture of two in-plane textures. The $\theta-2 \theta$ scans and $\phi$ scans for $1000-\AA$-thick $\mathrm{NdAlO}_{3}$ films on textured-Ni (100) substrates are shown in Figs. 1.44 and 1.45 , respectively. Figure 1.44 indicates the presence of a $c$-axis-aligned film. In Fig. 1.45, the $\phi$ scan data on $\mathrm{NdAlO}_{3}$ films on $\mathrm{SrTiO}_{3}(100)$ are compared with the $\mathrm{NdAlO}_{3}$ film on $\mathrm{Ni}(100)$ substrates. The FWHM values for $\mathrm{LaAlO}_{3}(002)$ and $\mathrm{NdAlO}_{3}(002)$ were 7.2 and $5.8^{\circ}$. and that of $\mathrm{LaAlO}_{\hat{\mathrm{j}}}(101)$ and $\mathrm{NdAlO}_{3}(101)$ were 13.4 and $5.8^{\circ}$, respectively.
The presence of the two in-plane (100)[010] and (100)[011] textures for $\mathrm{NdAlO}_{3}$ films on $\mathrm{Ni}(100)$ compared with a single texture for $\mathrm{NdAlO}_{3}$ films on $\mathrm{SrTiO}_{3}(100)$ may be the result of the relatively high lattice mismatch between the Ni substrate and the film. A smaller lattice mismatch suggests that $\mathrm{YAlO}_{3}$ should have a better texture on textured-Ni substrates. The aging of the $\mathrm{LaAlO}_{\mathfrak{3}}$ precursor

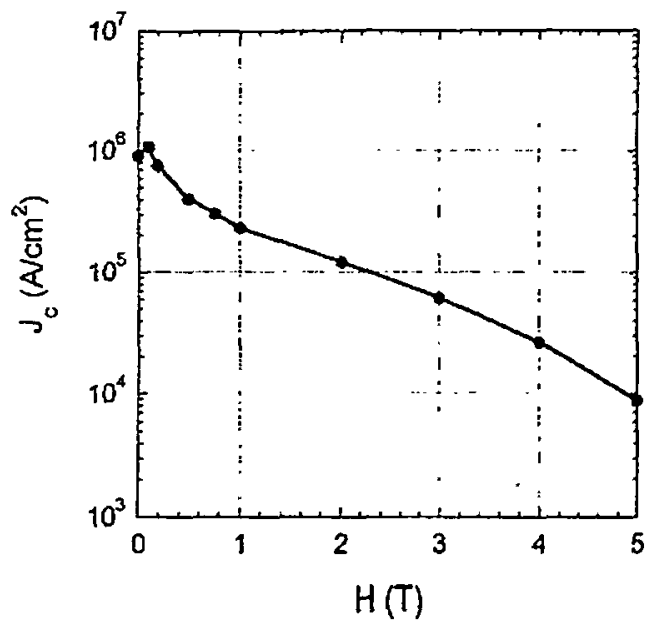

Fig. 1.44. The typical $\theta-2 \theta$ scan for a 1000-Â-thick $\mathrm{NdAIO}_{3}$ film on $\mathrm{Ni}(100)$ substrates.

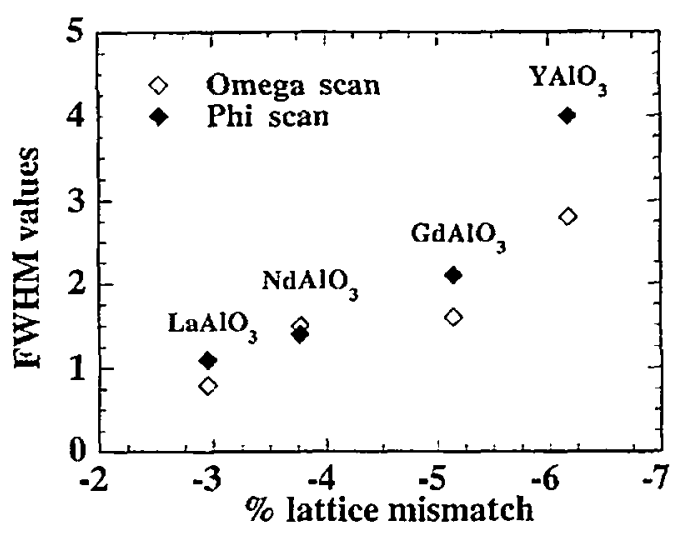

Fig. 1.45. Correlation of the texture (FWHM values of omega and phi scans) of sol-gel grown $\mathrm{REAlO}_{3}$ films on $\mathrm{SrTiO}_{3}(100)$ substrates with the lattice mismatch between the film and the substrate. 
solution and the high degree of hydrolysis produces predominantly aligned $\mathrm{LaAlO}_{3}$ films on textured-Ni substrates. The details of these experiments will be reported later. The PLD YBCO films grown on $\mathrm{LaAlO}_{3}$-buffered $\mathrm{Ni}$ substrates were mostly $c$-axis aligned. A $\theta-2 \theta$ scan for $\mathrm{YBCO}$ on $\mathrm{LaAlO}_{3} / \mathrm{Ni}$ is shown in Fig. 1.46. The $T_{\mathrm{c}}$ for the YBCO film grown on $\mathrm{LaAlO}_{3}$-buffered $\mathrm{Ni}$ substrate was $75 \mathrm{~K}$. This reduced $T_{\mathrm{c}}$ could be the result of the diffusion of $\mathrm{Ni}$ from the substrate (as evident from the presence of NiO impurities in Fig. 1.46) into the YBCO film. An SEM micrograph also indicated poor coverage of the $\mathrm{LaAlO}_{3}$ film on $\mathrm{Ni}$ substrates.

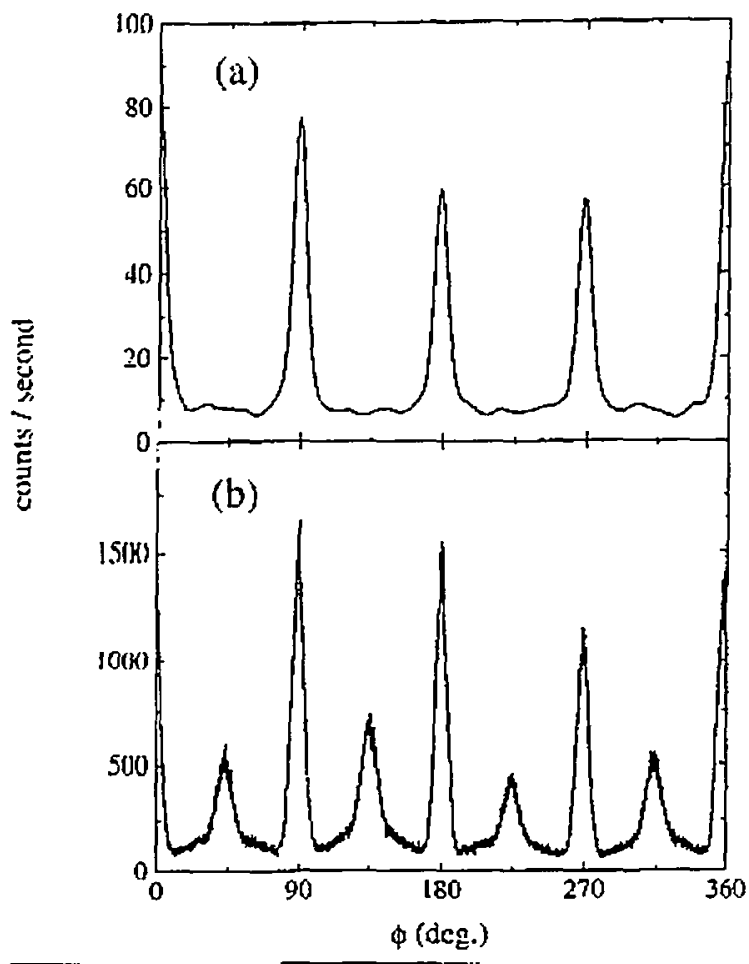

Fig. 1.46. The room-temperature powder pattern for $-0.3-\mu \mathrm{m}$-thick YBCO film on solgel LaAlO ${ }_{3}$-buffered Ni substrates.

\section{Growth of High-Current YBCO Films on Sol-Gel NdGaO ${ }_{3}$ Buffer Layers}

The XRD results for $\sim 3000-\AA$-thick $\mathrm{NdGaO}_{3}$ on $\mathrm{SrTiO}_{3}(100)$ substrates indicated the presence of a single cube-on-cube texture. The YBCO films grown on sol-gel $\mathrm{NdGaO}_{3-}$ buffered $\mathrm{SrTiO}_{3}(100)$ substrates were highly aligned and had good superconducting properties. A $T_{\mathrm{c}}$ of $90.3 \mathrm{~K}$ was observed for this film. The field-dependence $J_{\mathrm{c}}$ for 0.25 - $\mu \mathrm{m}$-thick YBCO films on $\mathrm{NdGaO}_{3} / \mathrm{SrTiO}_{3}$ substrates is shown in Fig. 1.47. A maximum $J_{c}$ of $\sim 1 \times 10^{6} \mathrm{~A} / \mathrm{cm}^{2}$ at $77 \mathrm{~K}$ and zero field was obtained, and also the YBCO film was strongly linked.

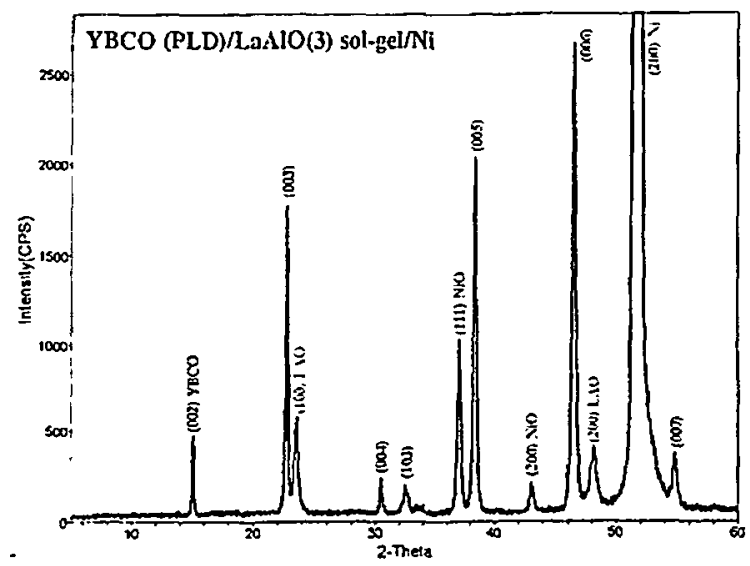

Fig. 1.47. The field dependence of $J_{c}$ for 0.25- $\mu$ m-thick YBCO film on sol-gel $\mathrm{NdGaO}_{3}$ buffered $\mathrm{SrTiO}_{3}(100)$ single-crystal substrates at $77 \mathrm{~K}$.

\section{Conclusions}

Epitaxial REAlO ${ }_{3}(\mathrm{RE}=\mathrm{La}, \mathrm{Nd}, \mathrm{Gd}, \mathrm{Y})$ films were grown on $\mathrm{SrTiO}_{3}(100)$ single-crystal substrates using sol-gel alkoxide precursors. The texture of the $\mathrm{REAlO}_{3}$ films was correlated with the lattice mismatch between the $\mathrm{SrTiO}_{3}$ substrates and the $\mathrm{REAIO}_{3}$ films. The sharp texture of the $\mathrm{LaAlO}_{3}$ films on $\mathrm{SrTiO}_{3}(100)$ substrates can be explained in terms of a reduced lattice mismatch. Highly textured $\mathrm{REAlO}_{3}(\mathrm{RE}=\mathrm{La}, \mathrm{Nd})$ films were also grown on textured-Ni substrates with two in-plane orientations. Efforts are being made to grow $\mathrm{REAlO}_{3}$ on textured-Ni substrates with single texture. The YBCO films grown on $\mathrm{LaAlO}_{\tilde{3}}$ buffered $\mathrm{Ni}$ substrates were $c$-axis aligned. We 
also demonstrated that high-current YBCO films can be grown on sol-gel $\mathrm{NdGaO}_{3}$ buffer layers.

\section{References}

1. S. S. Shoup, M. Paranthaman, D. B. Beach, E. D. Specht, and R. K. Williams, "Solgel synthesis of $\mathrm{LaAIO}_{3}$ : Epitaxial growth of $\mathrm{LaAIO}_{3}$ thin films of $\mathrm{SrTiO}_{3}(100), " J$. Mater. Res. 12: 1017-21 (1997).

2. S. S. Shoup, M. Paranthaman, A. Goyal, E. D. Specht. D. F. Lee. D. M. Kroeger, and D. B. Beach, "Epitaxial thin film growth of lanthanum and neodymium aluminate films on roll-textured nickel using a sol-gel method," J. Am. Ceram. Sec. 81: 3019-21 (1998).

\section{OPTIMIZATION OF BUFFER LAYERS ON ROLLED-Ni SUBSTRATES FOR HIGH-CURRENT YBCO AND TI,Bi-1223-COATED CONDUCTORS USING EX SITU PRECURSOR APPROACHES}

The growth of high-current $\mathrm{YBCO}$ and Tl.Bi-1223 superconducting films on RABiTSTM with the architecture of $\mathrm{CeO}_{2} / \mathrm{YSZ} / \mathrm{CeO}_{2} / \mathrm{Ni}$ using the ex situ precursor approach was previously demonstrated. Here, we report our successful optimization of the buffer layer architectures on rolled-Ni substrates.

The biaxially textured $\mathrm{Ni}(100)$ substrates were obtained by the mechanical deformation of $\mathrm{Ni}$ rods followed by recrystallization to the desired (100) cube texture by annealing at $800^{\circ} \mathrm{C}$ for $2 \mathrm{~h}$ in a high-vacuum furnace. The $\mathrm{CeO}_{2}$ films were deposited on textured-Ni substrates at $\sim 500^{\circ} \mathrm{C}$ by reactive evaporation of Ce metal in the presence of a mixture of $4 \% \mathrm{H}_{2}$ and $96 \% \mathrm{Ar}$ (forming gas). The details of the experimental conditions were published earlier. ${ }^{1.2}$ As per the standard free-energy change for the formation of metal oxides, the $\mathrm{H}_{2} \mathrm{O}$ introduced into the chamber during film growth preferentially oxidizes $\mathrm{Ce}$ metal to form stoichiometric $\mathrm{CeO}_{2}$ over $\mathrm{Ni}$ substrates. The cap $\mathrm{CeO}_{2}$ layers were also deposited using the same conditions. The e-beam evaporation technique was also used to deposit $\mathrm{YSZ}$ at $\sim 500^{\circ} \mathrm{C}$ on $\mathrm{CeO}_{2}$-buffered $\mathrm{Ni}$ substrates. Yttria-stabilized zirconia was used as the source. The YSZ film thickness was varied from 500 to $5000 \AA$. YSZ films were also grown on e-beam $\mathrm{CeO}_{2}$-buffered $\mathrm{Ni}$ substrates at $-700^{\circ} \mathrm{C}$ by $\mathrm{rf}$ magnetron sputtering. The sputtered YSZ films were smooth and dense. The YSZ thickness was typically $9000 \AA$. The $\mathrm{CeO}_{2}$-buffered $\mathrm{YSZ} / \mathrm{CeO}_{2} / \mathrm{Ni}$ substrates were pre-annealed at temperatures ranging from 650 to $780^{\circ} \mathrm{C}$ and low-oxygen partial pressures prior to the superconductor deposition.

Precursor YBCO films were grown on e-beam/sputtered buffers $\left(\mathrm{CeO}_{2} / \mathrm{YSZ} / \mathrm{CeO}_{2} / \mathrm{Ni}\right)$ by e-beam co-evaporation of $\mathrm{Y}, \mathrm{BaF}_{2}$, and $\mathrm{Cu}$. Details of the experimental conditions were reported earlier. ${ }^{3}$ With this method, high- $J_{c}$ YBCO films were grown using humid gas mixtures with low-oxygen partial pressures. The high-temperature anneal under wet conditions resulted in conversion of $\mathrm{Y}, \mathrm{BaF}_{2}$, and $\mathrm{Cu}$ to $\mathrm{YBa}_{2} \mathrm{Cu}_{3} \mathrm{O}_{7-\mathrm{y}} . \mathrm{Tl}, \mathrm{Bi}-1223$ precursor films were deposited at $\sim 90^{\circ} \mathrm{C}$ on all e-beam buffers $\left(\mathrm{CeO}_{2} / \mathrm{YSZ} / \mathrm{CeO}_{2} / \mathrm{Ni}\right)$ by PLD. After deposition, the amorphous precursor films were wrapped in $40-\mu \mathrm{m}$-thick $\mathrm{Ag}$ foil along with an unfired fresh pellet of composition $\mathrm{Tl}_{095} \mathrm{Bi}_{022} \mathrm{Sr}_{16} \mathrm{Ba}_{04} \mathrm{Ca}_{2} \mathrm{Cu}_{3} \mathrm{O}_{9}$. The films were post-annealed in a tube furnace at $780-810^{\circ} \mathrm{C}$ for $40-60 \mathrm{~min}$ under flowing argon. After annealing, films were usually shiny and smooth. Details of the experimental conditions were reported earlier. ${ }^{4}$

The films were analyzed by XRD. A Philips Model XRG3100 diffractometer with $\mathrm{Cu} \mathrm{K} \mathrm{K}_{\alpha}$ radiation was used to record power diffraction patterns. A four-circle diffractometer was used to collect pole figures, $\omega$ scans, and $\phi$ scans. SEM micrographs were taken using a Hitachi S-4100 Field Emission SEM. The thicknesses of the films were determined by both RBS and Alpha-Step 500 (Tencor Instruments) profilometer scans. The resistivity and transport $J_{\mathrm{c}}$ was measured using a standard four-probe 
technique. The values of $J_{c}$ were calculated using a $1-\mu \mathrm{V} / \mathrm{cm}$ criterion. The Ag contacts were made by sputtering. The YBCO films with Ag contacts were annealed in 1-atm oxygen at $500^{\circ} \mathrm{C}$ for $30 \mathrm{~min}$ and slow cooled to room temperature in pure oxygen.

The buffer layer architecture used in this study was $\mathrm{CeO}_{2} / \mathrm{YSZ} / \mathrm{CeO}_{2} / \mathrm{Ni}$. The e-beam and sputtered buffer layer characteristics and the superconducting properties of textured YBCO and $\mathrm{Tl}, \mathrm{Bi}-1223$ films deposited on these buffers are discussed in the following sections.

\section{Stability of All E-Beam Buffer Layers}

In this study, both the $\mathrm{CeO}_{2}$ and $\mathrm{YSZ}$ buffer layers were grown by e-beam evaporation. The thickness of the top and bottom $\mathrm{CeO}_{2}$ layers was 200-400 $\AA$. SEM micrographs indicated that the $\mathrm{CeO}_{2}$ layers were smooth, crack-free, dense, and columnar. As the $\mathrm{CeO}_{2}$ thickness increases, crack formation seems to occur. The SEM picture of a 2000 - $\AA$-thick cracked $\mathrm{CeO}_{2}$ buffer layer is shown in Fig. 1.48. Crack formation may be associated with stress in the $\mathrm{CeO}_{2}$ layers. This is possibly the result of the lattice mismatch between $\mathrm{CeO}_{2}$ and $\mathrm{Ni}$ substrates, thermal expansion mismatch, or the formation of oxide from the $\mathrm{Ce}$ metal during the film

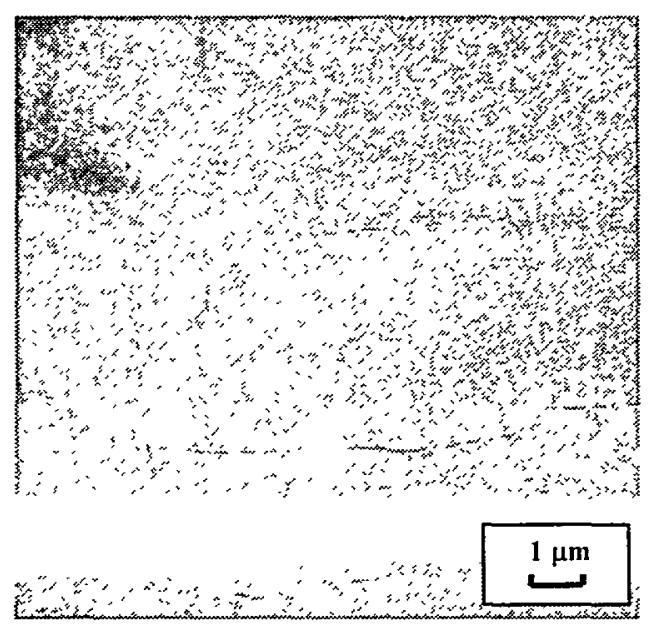

Fig. 1.48. SEM micrograph for a 2000-Å-thick $\mathrm{CeO}_{2}$-buffered Ni substrate. growth. On the other hand, the e-beam YSZ layers were porous and columnar but crack-free. The SEM picture of a 5000 - $\AA$-thick e-beam porous $\mathrm{YSZ}$-buffered $\mathrm{CeO}_{2} / \mathrm{Ni}$ substrate is shown in Fig. 1.49.

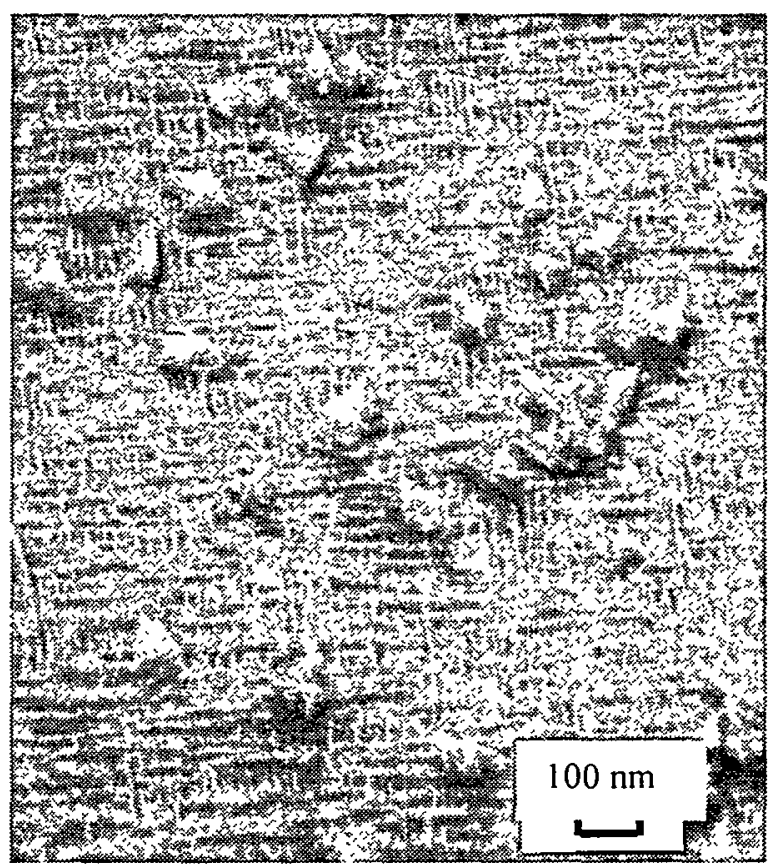

Fig. 1.49. SEM micrograph for a 5000-Åthick e-beam YSZ-buffered $\mathrm{CeO}_{2} / \mathrm{Ni}$ substrate.

Detailed microstructure work was reported earlier. ${ }^{5}$ Detailed X-ray studies indicated the presence of highly aligned $\mathrm{CeO}_{2}$ and $\mathrm{YSZ}$ layers. For study of the effect of compatibility of these buffer layers with the superconductors, the as-grown buffers were annealed in 200-mTorr oxygen and temperatures ranging from 650 to $780^{\circ} \mathrm{C}$. The RBS spectra for both as-grown and annealed e-beam buffers are shown in Fig. 1.50. The thickness estimated from the RBS spectra was $\sim 5000 \AA$ for $Y S Z$ and $200-400 \AA$ for both top and bottom $\mathrm{CeO}_{2}$ layers. For as-grown buffers, the position of the Ce (top and bottom), $\mathrm{Zr}$, and $\mathrm{Ni}$ front edges was sharp. This indicates that the interfaces are sharp. But for the annealed buffers, there was a significant change in the top of the Ni signal. The suppression of 


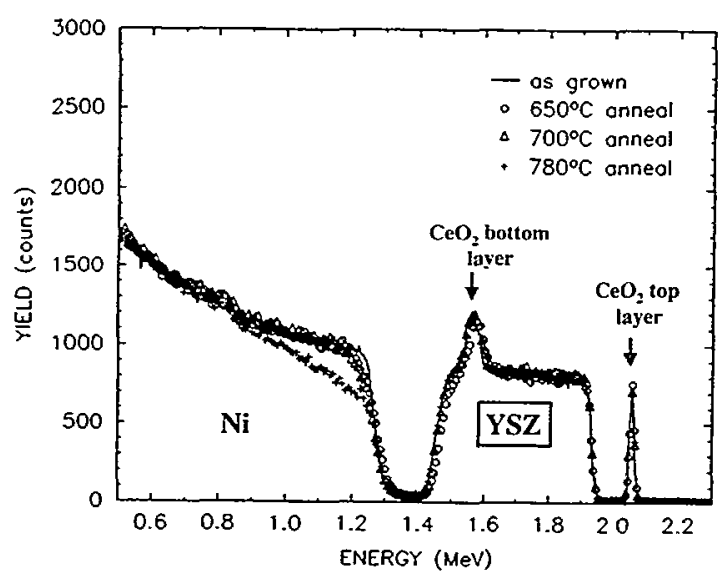

Fig. 1.50. Rutherford backscattering spectra of all e-beam buffers with the architecture of $\mathrm{CeO}_{2} / \mathrm{YSZ} / \mathrm{CeO}_{2} / \mathrm{Ni}$. The spectra were measured with $2.0-\mathrm{MeV} \mathrm{He}^{+}$ions at near-normal incidence, detected at a $160^{\circ}$ scattering angle.

the $\mathrm{Ni}$ yield below the interface indicates that the density of $\mathrm{Ni}$ per unit volume is reduced. This provides evidence for the diffusion of oxygen into the Ni substrate. The diffusion was much more pronounced for the film annealed at $780^{\circ} \mathrm{C}$. This diffusion can be the result of the presence of a porous microstructure for e-beam YSZ layers. The presence of a $\mathrm{NiO}$ impurity peak was also observed in the powder XRD pattern.

\section{Stability of E-Beam $\mathrm{CeO}_{2}$ and Sputtered YSZ Layers}

In this study, the top and bottom $\mathrm{CeO}_{2}$ layers were deposited by e-beam evaporation and the YSZ layer was deposited by rf magnetron sputtering. The thickness of the top and bottom $\mathrm{CeO}_{2}$ layers was $200-400 \AA$. The thickness of the YSZ layers was typically $9000 \AA$. The microstructure of the sputtered YSZ layers was dense, crack-free, and well aligned. The presence of a dense microstructure for the sputtered YSZ layers could be the result of both a high deposition temperature and highly energetic deposition. These buffer layers were annealed in 200-mTorr oxygen and various temperatures, and the corresponding RBS spectra are shown in Fig. 1.51. The thickness of the sputtered YSZ layer was estimated to be $\sim 9000 \AA$. As can be seen from the RBS spectra, the $\mathrm{Ce}$ (both top and bottom), $\mathrm{Zr}$, and $\mathrm{Ni}$ signals remain unchanged for both as-grown and annealed buffer layers. This suggests that there is no considerable oxygen diffusion into the $\mathrm{Ni}$ substrate. Hence, the use of e-beam $\mathrm{CeO}_{2}$ and sputtered YSZ buffers is more suitable for further growth of superconductors. We have reproducibly made several high $-J_{\mathrm{c}} \mathrm{YBCO}$ samples on e-beam/sputtered buffers.

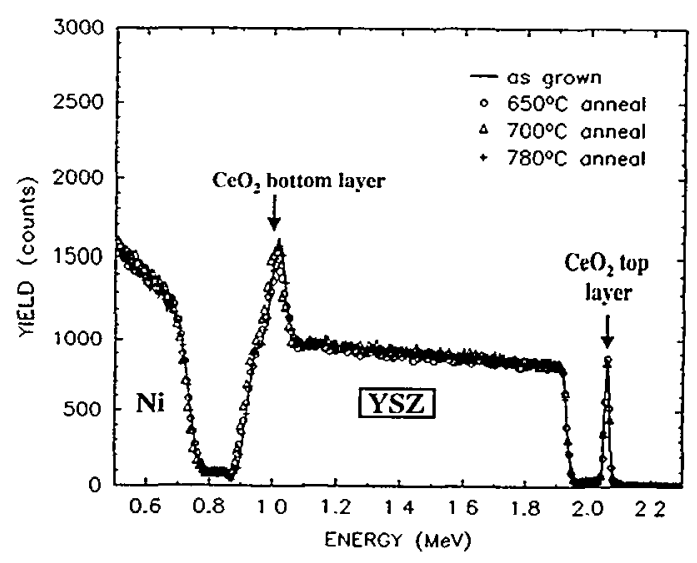

Fig. 1.51. Rutherford backscattering spectra of e-beam $\mathrm{CeO}_{2}$ and sputtered YSZ buffers with the architecture of $\mathrm{CeO}_{2} / \mathrm{YSZ} / \mathrm{CeO}_{2} / \mathrm{Ni}$.

\section{Ex Situ Precursor Approach for Superconducting Films}

The ex situ precursor approach has a number of potential advantages over the in situ process. The precursors can be deposited practically at room temperature followed by a post-anneal process in a furnace to crystallize the superconducting phase. We have used the precursor approach for growing both $\mathrm{Tl}, \mathrm{Bi}-1223$ and YBCO films. Tl,Bi-1223 films were grown on all e-beam buffers. The room-temperature 
powder XRD pattern for a $1.8-\mu \mathrm{m}$-thick TI,Bi-1223 film on all e-beam $\mathrm{CeO}_{2}$-buffered $\mathrm{YSZ} / \mathrm{CeO}_{2} / \mathrm{Ni}$ substrates indicated the presence of a highly $c$-axis-aligned $\mathrm{Tl}, \mathrm{Bi}-1223$ phase. In addition to the $\mathrm{Tl}, \mathrm{Bi}-1223$ phase, a significant amount of $c$-axis-aligned $\mathrm{Tl}, \mathrm{Bi}-1212$ phase was also present. The XRD results from the $\omega$ and $\phi$ scans revealed good epitaxial texturing. Detailed transport property measurements were carried out on 1.8- $\mu \mathrm{m}$-thick textured Tl,Bi-1223 films on all e-beam buffers. The typical $T_{c} \mathrm{~s}$ (zero resistance) observed for these films are in the range of $105-110 \mathrm{~K}$. A maximum transport $J_{c}$ of $4.2 \times 10^{5} \mathrm{~A} / \mathrm{cm}^{2}$ at $77 \mathrm{~K}$ and s.f. was measured. The field-dependent properties for this film are also good up to $3 \mathrm{~T}$. The $J_{\mathrm{c}}$ s observed for Tl,Bi-1223 films on both YSZ (100) and $\mathrm{CeO}_{2}$ buffered YSZ (100) crystals are compared with that of Tl,Bi-1223 films on RABiTSTM in Fig. 1.52. A high $J_{\mathrm{c}}$ of over $1 \mathrm{MA} / \mathrm{cm}^{2}$ at $77 \mathrm{~K}$ was reported earlier ${ }^{6}$ for $\mathrm{Tl}, \mathrm{Bi}-1223$ films grown directly on YSZ substrates. This approach promises that even higher $J_{\mathrm{c}} \mathrm{Tl}, \mathrm{Bi}-1223$ films can be grown on RABiTSTM. Efforts are being made to grow Tl,Bi-1223 films on e-beam/ sputtered buffers with/without a $\mathrm{CeO}_{2}$ cap layer. Because we observe a significant amount of $\mathrm{Tl}, \mathrm{Bi}-1212$ phase in our films, optimization of the starting precursor is also necessary.

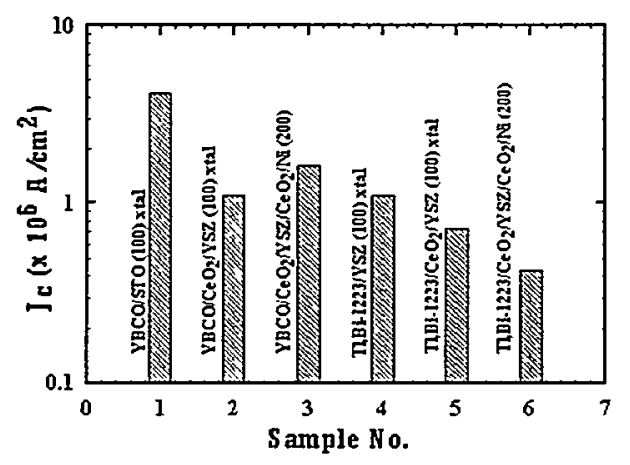

Fig. 1.52. Comparisons of the measured transport $J_{c} s$ for $Y B C O$ and $\mathrm{TI}, \mathrm{Bi}-1223$ films on RABiTS ${ }^{\mathrm{TM}}$ with that of films on single-crystal substrate with/without a $\mathrm{CeO}_{2}$ cap layer.
YBCO films were grown on e-beam/ sputtered buffers. The room-temperature powder XRD pattern for $\sim 0.3-\mu \mathrm{m}$-thick YBCO films on e-beam $\mathrm{CeO}_{2}$-buffered $\mathrm{YSZ}$ (sputtered) $/ \mathrm{CeO}_{2} / \mathrm{Ni}$ substrates indicated the presence of a highly $c$-axis-aligned YBCO film. A small amount of $\mathrm{NiO}$ impurity was observed in the film. XRD results from the $\omega$ and $\phi$ scans for YBCO films on e-beam/sputtered buffers revealed good epitaxial texturing. Detailed pole figure analysis indicated the presence of a single cube texture for $\mathrm{YBCO}, \mathrm{CeO}_{2}$, and $\mathrm{YSZ}$ layers. The $\mathrm{YBCO}$ films on RABiTS ${ }^{\text {TM }}$ had a $T_{\mathrm{c}}$ of about $90 \mathrm{~K}$. A maximum $J_{c}$ measured for $\sim 0.3-\mu$ m-thick YBCO film on e-beam/sputtered buffers was $1.6 \times 10^{6} \mathrm{~A} / \mathrm{cm}^{2}$ at $77 \mathrm{~K}$ and s.f. The measured $J_{c}$ for the YBCO film on RABiTS ${ }^{\mathrm{TM}}$ is compared with that for the YBCO film on $\mathrm{SrTiO}_{3}(100)$ and $\mathrm{CeO}_{2}$-buffered YSZ (100) crystals in Fig. 1.51. We have reproducibly measured high $J_{c} \mathrm{~s}$ of over $1 \mathrm{MA} / \mathrm{cm}^{2}$ for several YBCO films on e-beam/sputtered buffers. We have also recently measured an average $I_{c}$ of 8.0 A with a variation of less than $4 \%$ between each $1-\mathrm{cm}$ segment of a 2-cm-long YBCO film on RABiTS ${ }^{\mathrm{TM}}$. This translates to a $J_{\mathrm{c}}$ of about $8.0 \times 10^{5} \mathrm{~A} / \mathrm{cm}^{2}$ at $77 \mathrm{~K}$ and s.f. The photograph of the YBCO film on 5-cm-long RABiTSTM is shown in Fig. 1.53.

In summary, we have optimized the buffer layer architecture $\left(\mathrm{CeO}_{2} / \mathrm{YSZ} / \mathrm{CeO}_{2} / \mathrm{Ni}\right)$ for growing high-current $\mathrm{YBCO}$ and $\mathrm{Tl}, \mathrm{Bi}-1223$ conductors on RABiTSTM using ex situ precursor approaches. We have also

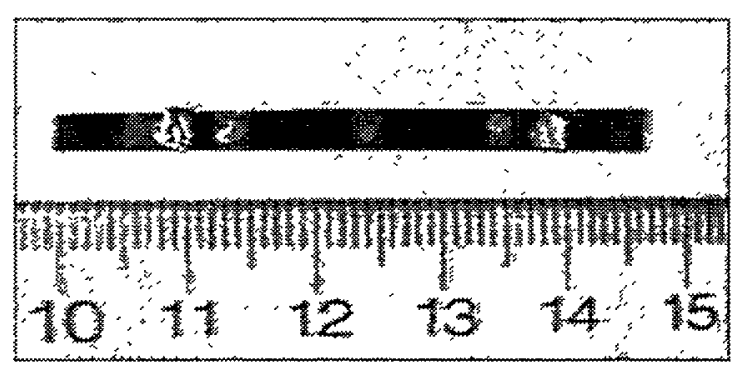

Fig. 1.53. The photograph of the $5-\mathrm{cm}$ long YBCO film on e-beam/sputtered $\mathrm{CeO}_{2} / \mathrm{YSZ} / \mathrm{CeO}_{2} / \mathrm{Ni}$ substrate. This film carried an $I_{\mathrm{c}}$ of 8 A over $2 \mathrm{~cm}$ of the middle section. The voltage taps are clearly seen in the picture. 
demonstrated that the e-beam/sputtered buffer layer combination is more suitable for reproducibly fabricating high $-J_{\mathrm{c}}$ YBCO films. RBS studies indicate that the YSZ sputtered films were quite stable up to $780^{\circ} \mathrm{C}$ and 200-mTorr oxygen. The microstructure of the thin e-beam $\mathrm{CeO}_{2}$ films and sputtered YSZ films was dense, crack-free, and columnar.

\section{References}

1. M. Paranthaman, F. A. List, D. F. Lee, A. Goyal. R. Feenstra, D. P. Norton, C. Park, D. T. Verebelyi, D. K. Christen. P. M. Martin, E. D. Specht, and D. M. Kroeger, "Fabrication of high-current $\mathrm{YBa}_{2} \mathrm{Cu}_{3} \mathrm{O}_{7}$ coated conductors using rolling-assisted biaxially textured substrates." in Proceedings of the 9th CIMTEC World Ceramics Congress and Forum on New Materials. P. Vicenzini (ed.), Florence, Italy, June 14-19, 1998.

2. M. Paranthaman, A. Goyal, F. A. List, E. D. Specht, D. F. Lee, P. M. Martin, Q. He, D. K. Christen, D. P. Norton, J. D. Budai, and D. M. Kroeger, "Growth of biaxially textured buffer layers on rolled-Ni substrates by electron beam evaporation," Physica C 275: 266-72 (1997).

3. R. Feenstra, T. B. Lindemer. J. D. Budai, and M. D. Galloway, "Effect of oxygen pressure on the synthesis of $\mathrm{YBa}_{2} \mathrm{Cu}_{3} \mathrm{O}_{7-}$, thin films by post-deposition annealing," J. Appl. Phys. 69: 6569-85 (1991).

4. Z. F. Ren, W. Li, D. Z. Wang. J. Y. Lao, J. H. Wang, M. Paranthaman, D. T. Verebelyi, D. K. Christen, D. F. Lee, A. Goyal, and D. M. Kroeger, "In-plane aligned superconducting $\mathrm{Tl}_{078} \mathrm{Bi}_{022} \mathrm{Sr}_{1.6} \mathrm{Ba}_{0.4} \mathrm{Ca}_{2} \mathrm{Cu}_{3} \mathrm{O}_{9}$ films on rolling assisted biaxially textured substrates (RABiTS), Physica $C$, in press.

5. Chau-Yun Yang, S. E. Babcock, A. Goyal, M. Paranthaman, F. A. List, D. P. Norton. D. M. Kroeger, and A. Ichinose, -Microstructure of electron-beam evaporated epitaxial yttria-stabilized zirconia/ $\mathrm{CeO}$, bilayers on biaxially textured Ni tape," Physica C 307: 87-98 (1998).
6. Z. F. Ren, W. Li, D. Z. Wang, J. H. Wang, M. Paranthaman, D. T. Verebelyi, and D. K. Christen, "Growth and characterization of superconducting films $\mathrm{Tl}_{0.78} \mathrm{Sr}_{1.6} \mathrm{Ba}_{04} \mathrm{Ca}_{2} \mathrm{Cu}_{3} \mathrm{O}_{9}$ on $\mathrm{CeO}_{2}$-buffered single crystal YSZ," Physica C 306: 149-53 (1998).

\section{LOW-COST COMBUSTION CHEMICAL VAPOR DEPOSITION OF EPITAXIAL BUFFER LAYERS AND SUPERCONDUCTORS}

\section{Introduction}

A key issue for the fabrication of highcurrent coated conductors is the ability to produce long lengths of wire inexpensively. The Ion-Beam-Assisted-Deposition (IBAD) and RABiTSTM techniques have yielded high-quality films with $J_{\mathrm{c}} \mathrm{s}$ of over $1 \mathrm{MA} / \mathrm{cm}^{2}$ at $77 \mathrm{~K}$ on short research coupons. Both techniques are currently being scaled to accommodate a meter length of wire. LANL has produced a YBCO tape with an $I_{c}$ of $29 \mathrm{~A}$ at $75.4 \mathrm{~K}$ over a $1-\mathrm{m}$ length. ORNL has developed a reel-to-reel, e-beam evaporation system to deposit epitaxial oxide buffer layers and $\mathrm{Y}-\mathrm{BaF}_{2}-\mathrm{Cu}$ precursors on 0.5 - to $2-\mathrm{m}$ lengths of textured substrates. However, because IBAD and RABiTS ${ }^{\mathrm{TM}}$ involve vacuum processes, such as PLD and e-beam evaporation, scale-up is expensive and difficult in the manufacture of kilometer lengths of wire. Drawbacks include expensive laser and vacuum equipment, limited-size reaction chambers, and slow deposition rates.

The combustion chemical vapor deposition (CCVD) process is an inexpensive, openatmosphere deposition process that is not limited by the size of the deposition chamber and could be easily scaled and multiplexed to continuously fabricate buffer-layer/ superconductor and even passivation-layer coating structures on kilometer lengths of textured substrate moving on a reel-to-reel system. Figure 1.54 gives the schematic representation for a CCVD system. In CCVD, 


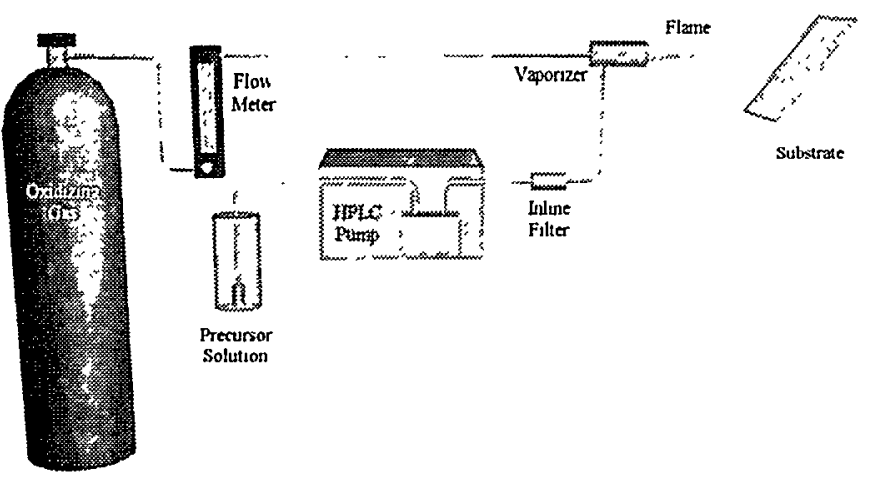

Fig. 1.54 Schematic representation of the system to deposit CCVD coatings.

the film precursors are generally dissolved in a solvent that also acts as the combustible fuel. This solution is atomized to form submicron droplets, which are then convected to and combusted in the flame. The heat from the flame provides the energy required to evaporate the droplets and to dissociate the precursors; the latter then react and vapor deposit onto the substrate to form the coating. Substrate temperatures may be as low as $100^{\circ} \mathrm{C}$, thus enabling depositions onto a wide variety of materials, including plastics. Because CCVD processing occurs at ambient temperature and pressure, depositions within clean hoods equipped with ultra-low penetrating air (ULPA) filters are possible, thus minimizing the airborne contaminants that can be entrained in the deposited film. This ability is required for the high quality necessary in electronic coatings such as high- $J_{\mathrm{c}}$ superconductors.

\section{Experimental Aspects}

Thin films of the buffer layers $\mathrm{CeO}_{2}, \mathrm{YSZ}$, $\mathrm{SrTiO}_{3}, \mathrm{LaAlO}_{3}, \mathrm{Y}_{2} \mathrm{O}_{3}$, and $\mathrm{Yb}_{2} \mathrm{O}_{3}$ were deposited using the CCVD technique. Appropriate amounts of low-cost precursors, such as acetylacetonates and 2-ethylhexanoates, were combined in organic solvents to yield stoichiometric films. These coatings were deposited onto oxide single-crystal substrates of (100) $\mathrm{MgO}$ or (100) $\mathrm{LaAlO}_{3}$. The deposition time was typically $10 \mathrm{~min}$ at gas temperatures of $700-1000^{\circ} \mathrm{C}$. Substrates were

ultrasonically cleaned in toluene and rinsed with isopropanol prior to use. Two rare earth superconductors, $\mathrm{YBCO}$ and $\mathrm{YbBCO}$, were prepared by dissolving low-cost inorganic precursors, such as acetates or nitrates, in distilled water. Deposition of the superconducting films occurred over $40-120 \mathrm{~min}$ at gas temperatures of $900-950^{\circ} \mathrm{C}$. These films were then annealed in oxygen for $1-5 \mathrm{~h}$ following deposition. Silver doping was added into the YBCO precursor solution. Single-crystal $\mathrm{LaAlO}_{3}$ and $\mathrm{MgO}$ were used as substrates for the superconductor depositions and were cleaned as described. The XRD patterns and pole figures were collected using a Siemens Hi-STAR area detector. A four-circle diffractometer was used to collect $\omega$ scans, $\phi$ scans, and additional pole figures. Micrographs were taken using a Hitachi S-800 Field Emission SEM. The resistivity and transport $J_{c} s$ were measured at ORNL using a standard four-probe technique. The values of the $J_{\mathrm{c}} \mathrm{s}$ were calculated using a $1-\mu \mathrm{V} / \mathrm{cm}$ criterion. The Ag contacts were made by sputtering.

\section{Results and Discussion}

\section{Buffer layers}

The buffer layers $\mathrm{CeO}_{2}, \mathrm{YSZ}, \mathrm{SrTiO}_{3}$, $\mathrm{LaAlO}_{3}, \mathrm{Y}_{2} \mathrm{O}_{3}$, and $\mathrm{Yb}_{2} \mathrm{O}_{3}$ have been deposited epitaxially onto oxide single-crystal substrates using $\mathrm{CCVD}$. $\mathrm{CeO}_{2}$ was deposited onto a $\mathrm{LaAlO}_{3}$ single-crystal substrate with a singlecube texture and good in- and out-of-plane alignment (Table 1.1). YSZ was then deposited by CCVD on top of this $\mathrm{CeO}_{2}$ layer. The majority of the YSZ was deposited as one cube texture, but there was a minor $45^{\circ}$ rotation ( $<1 \%$ intensity) present. YSZ also displayed good in- and out-of-plane alignment as listed in Table 1.1. The coatings are very dense, smooth, and continuous as can be seen in an SEM micrograph of $\mathrm{CeO}_{2}$ on $\mathrm{MgO}$ (Fig. 1.55). 
Table 1.1. Phi and omega scan results of epitaxial buffer layers

\begin{tabular}{lll}
\hline & $\begin{array}{l}\text { In-plane } \\
\text { (FWHM) }\end{array}$ & $\begin{array}{l}\text { Out-of-plane } \\
\text { (FWHM) }\end{array}$ \\
\hline & $(220)$ & $(200)$ \\
$\mathrm{CeO}_{2}$ on $\mathrm{LaAlO}_{3}$ & $2.45^{\circ} \pm 0.05$ & $1.688^{\circ} \pm 0.006$ \\
$\begin{array}{l}\mathrm{YSZ}_{\text {on }} \mathrm{CCVD} \mathrm{CeO}_{3} \\
\text { on } \mathrm{LaAlO}_{3}\end{array}$ & $3.37^{\circ} \pm 0.01$ & $2.37^{\circ} \pm 0.01$ \\
& $(110)$ & $(200)$ \\
& $2.020^{\circ} \pm 0.004$ & $1.67^{\circ} \pm 0.01$ \\
\hline
\end{tabular}

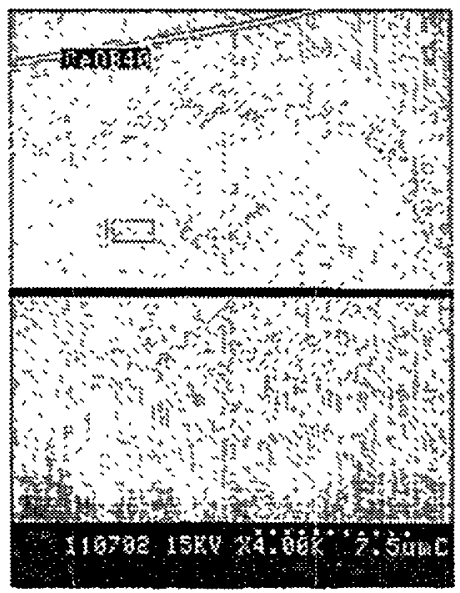

Fig. 1.55. SEM micrograph of $\mathrm{CeO}_{2}$ on $\mathrm{MgO}$.

$\mathrm{SrTiO}_{3}$ was deposited by CCVD onto a $\mathrm{MgO}$ single-crystal substrate as previously described. A single cube-on-cube texture was displayed with excellent in- and out-of-plane alignment (Table 1.1). This coating is fairly smooth and dense as well.

Recently, three more buffer layers were studied using the CCVD technique. An epitaxial layer of $\mathrm{LaAlO}_{3}$ was deposited onto a layer of epitaxial $\mathrm{SrTiO}_{3}$ deposited onto a (100) $\mathrm{MgO}$ single-crystal by CCVD. A (110) pole figure is shown in Fig. 1.56. Buffer layers of $\mathrm{Y}_{2} \mathrm{O}_{3}$ and $\mathrm{Yb}_{2} \mathrm{O}_{3}$ were originally suggested by ORNL as a means to simplify the buffer-layer architecture and to provide greater compatibility, both chemically and mechanically, with a wider range of substrates including reduced magnetic substrates. Both layers were deposited epitaxially onto a single-crystal $\mathrm{LaAlO}_{3}$ substrate with $\mathrm{Y}_{2} \mathrm{O}_{3}$ as the bottom and $\mathrm{Yb}_{2} \mathrm{O}_{3}$ as the top layer. Fig. 1.57 shows a (222) pole figure of the $\mathrm{Yb}_{2} \mathrm{O}_{3}$ top layer.

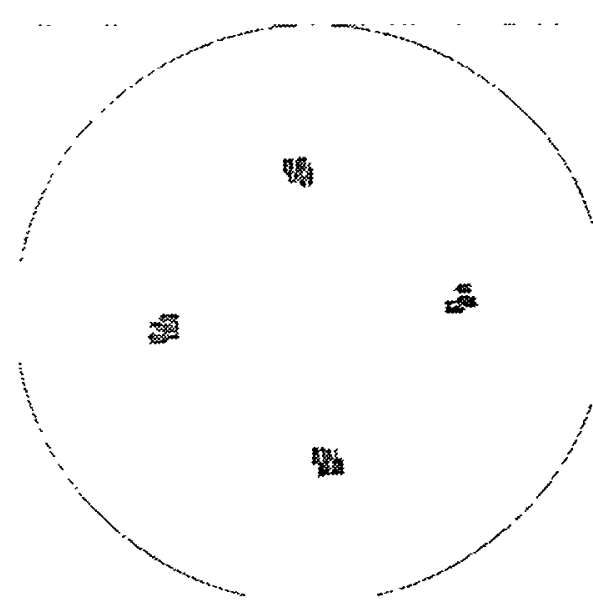

Fig. 1.56. (110) Pole figure of $\mathrm{LaAlO}_{3}$ on CCVD SrTiO ${ }_{3}$ on MgO.

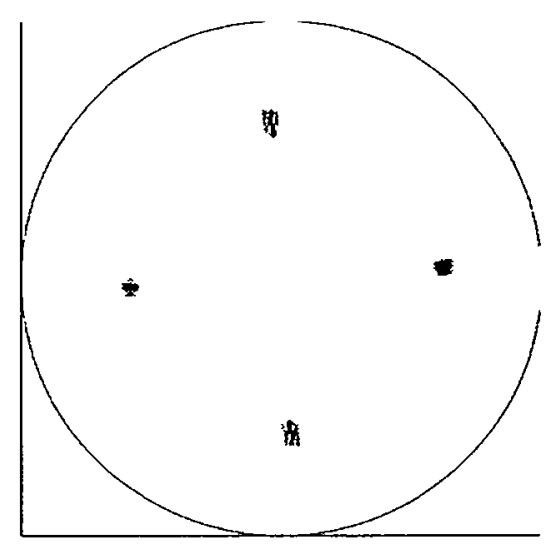

Fig. 1.57. (222) Pole figure of $\mathrm{Yb}_{2} \mathrm{O}_{3}$ on CCVD $\mathrm{Y}_{2} \mathrm{O}_{3}$ on LAO.

\section{Superconductors}

Typically CCVD employs organic precursors and solvents to deposit the desired 
coating. Initial YBCO depositions onto singlecrystal $\mathrm{LaAlO}_{3}$ were made using a typical CCVD solution; however, these depositions resulted in $\mathrm{BaCO}_{3}, \mathrm{CuO}$, and YBCO phases; also, $X R D$ characterization revealed that the YBCO coating had a random orientation. Furthermore, neither variation of the substrate/post-annealing temperature nor adjustment of the solute concentrations had any effect in eliminating the carbonate phase or producing oriented YBCO coatings. Hence, a water-based solution was used. This resulted in elimination of $\mathrm{BaCO}_{3}$ formation. With the introduction of the non-carbon-containing CCVD system, the production of epitaxial YBCO coatings on (100) $\mathrm{LaAlO}_{3}$ with minor traces of $\mathrm{CuO}$ was made possible in the open atmosphere. Epitaxial YBCO coatings were also deposited on a CCVD-coated $\mathrm{SrTiO}_{3}$ layer on $\mathrm{MgO}$. Transition temperatures, $T_{c}$, measured on these early samples were well below that typically seen for YBCO. In general, the YBCO coatings grown on $\mathrm{MgO}$ exhibited two in-plane orientations while those grown on $\mathrm{LaAlO}_{3}$ or the CCVD-coated $\mathrm{SrTiO}_{3}$ layer on $\mathrm{MgO}$ had a single epitaxial orientation. In- and out-of-plane alignment of the coatings was excellent, and the values are listed in Table 1.2. The YBCO coatings are very dense and continuous but contain too many hillocks (Fig. 1.58).

Table 1.2. Phi and omega scan results of epitaxial superconductors

\begin{tabular}{ccc}
\hline & $\begin{array}{c}\text { In-plane } \\
\text { (FWHM) }\end{array}$ & $\begin{array}{c}\text { Out-of-plane } \\
\text { (FWHM) }\end{array}$ \\
\hline & $(103)$ & $(006)$ \\
& $0.9^{\circ}$ & $0.5^{\circ}$ \\
$\begin{array}{l}\text { YBCO }(5 \mathrm{wt} \% \mathrm{Ag}) \\
\text { on } \mathrm{LaAlO}\end{array}$ & $(103)$ & $(005)$ \\
& $1.36^{\circ}$ & $0.52^{\circ}$ \\
\hline
\end{tabular}

Epitaxial coatings of $\mathrm{YbBa}_{2} \mathrm{Cu}_{3} \mathrm{O}_{7-\lambda}$ ( $\mathrm{YbBCO}$ ) were deposited onto single-crystal $\mathrm{LaAlO}_{3}$ using the procedure described for
YBCO. These depositions were conducted inside a Class 100 clean room. Excellent in- and out-of-plane alignment was achieved as can be seen in Table 1.2. The films are very dense and continuous as shown in Fig. 1.59 but once again contain too many hillocks. A $0.3-\mu \mathrm{m}$-thick $\mathrm{YbBCO}$ coating was electrically characterized and exhibited a $\mathrm{T}_{\mathrm{c}}^{\text {zero }} \sim 86 \mathrm{~K}$ and $J_{\mathrm{c}} \sim 150,000 \mathrm{~A} / \mathrm{cm}^{2}$ at zero field $(77 \mathrm{~K})$. The resistance vs temperature plot is shown in Fig. 1.60.

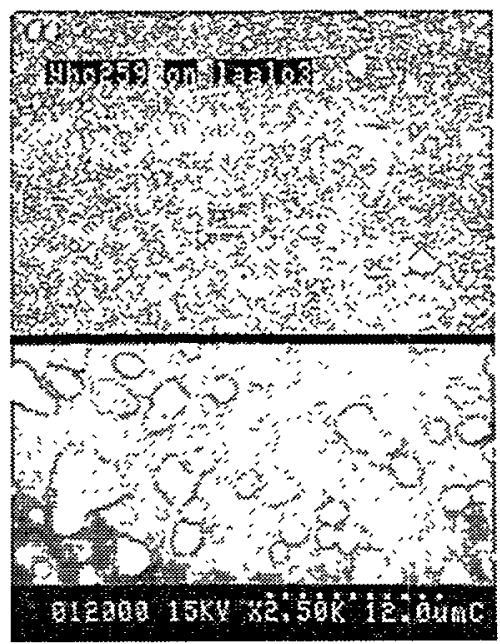

Fig. 1.58. SEM micrograph of epitaxial YBCO (5 wt \% Ag) on $\mathrm{LaAlO}_{3}$.

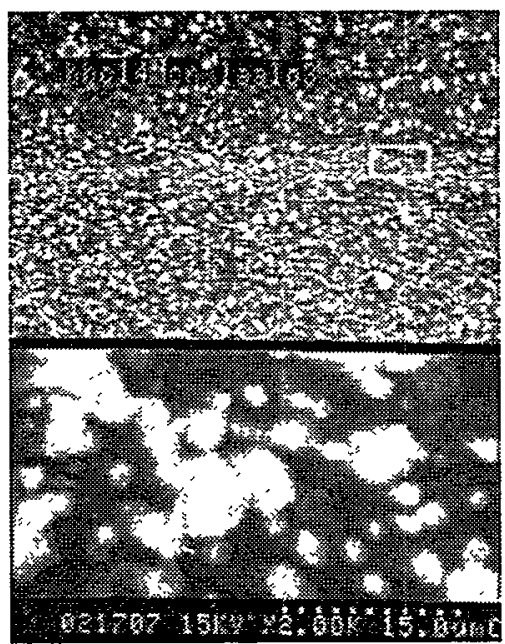

Fig. 1.59. SEM micrograph of epitaxial YbBCO on $\mathrm{LaAlO}_{3}$. 


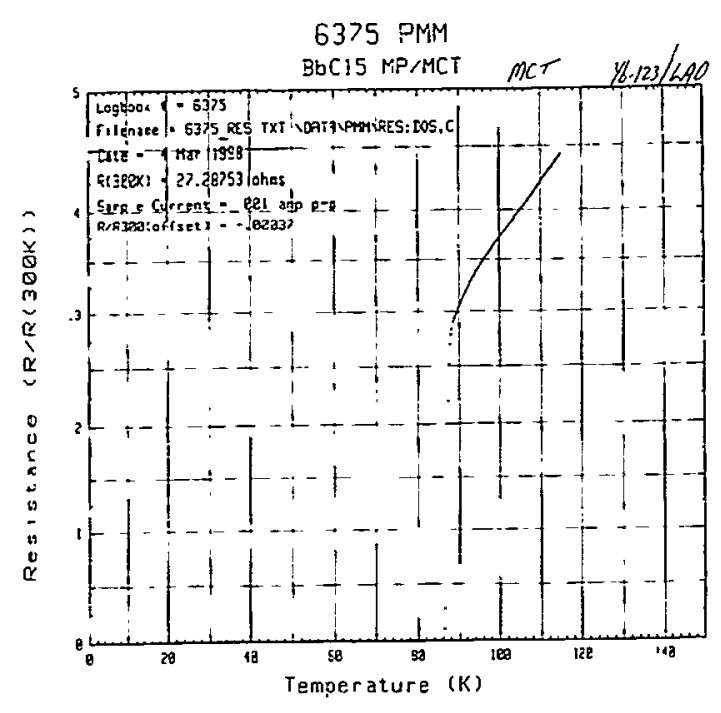

Fig. 1.60. Resistance vs temperature curve for a 0.3- $\mu \mathrm{m}$-thick YbBCO film on $\mathrm{LaAlO}_{3}$.

\section{Conclusions}

The buffer layers $\mathrm{CeO}_{2}, \mathrm{YSZ}, \mathrm{SrTiO}_{\hat{3}}$, $\mathrm{LaAlO}_{3}, \mathrm{Y}_{2} \mathrm{O}_{3}$, and $\mathrm{Yb}_{2} \mathrm{O}_{3}$ were deposited epitaxially onto single-crystal substrates using the CCVD technique. These films are smooth, dense. and continuous. Efforts will now focus on growing these buffer layers with a single inplane orientation on textured Ni. The feasibility of using the CCVD process to deposit epitaxial superconducting materials, such as $\mathrm{YBCO}$ and $\mathrm{YbBCO}$, on single-crystal substrates was also demonstrated. A YbBCO film exhibiting a $T_{\mathrm{c}}^{\text {zero }}$ of $\sim 86 \mathrm{~K}$ and a $J_{\mathrm{c}} \sim 150,000 \mathrm{~A} / \mathrm{cm}^{2}$ at zero field $(77 \mathrm{~K})$ was made. Experiments to increase these values will be performed.

\section{MELTING BEHAVIOR OF Bi-2212/Ag CONDUCTORS}

The processing of $\mathrm{Bi}-2212 / \mathrm{Ag}$ includes a critical partial melting step that involves temperatures between 885 and $890^{\circ} \mathrm{C}$. We have used DTA measurements to study the effects of lot-to-lot variation/Ag content and maximum processing temperatures on melting behavior.

Five lots of commercial $\mathrm{Bi}-2212$ from two vendors were studied. All of the powder had the same nominal composition $\mathrm{Bi}-2212-0.1 \mathrm{Ag}$, and measurements were made in flowing oxygen. Most of the samples were contained in $\mathrm{MgO}$ crucibles and heated to $885-900^{\circ} \mathrm{C}$ at a rate of $5^{\circ} \mathrm{C} / \mathrm{min}$. They were then held at the maximum temperature for $7 \mathrm{~min}$ and cooled to $800^{\circ} \mathrm{C}$ at $5^{\circ} \mathrm{C} / \mathrm{min}$. Increasing the holding time to $30 \mathrm{~min}$ and decreasing the cooling rate to $2{ }^{\circ} \mathrm{C} / \mathrm{min}$ had no effect on the results.

The melting endotherms were diffuse and not nearly as well defined as curves for congruently melting materials. Average onset values for four lots of powder from one vendor varied from 865 to $867^{\circ} \mathrm{C}$, and the value for the second vendor's powder was $871^{\circ} \mathrm{C}$. The maximum temperature had a large effect on the subsequent solidification process. For maximum temperatures below about $895^{\circ} \mathrm{C}$, there was no nucleation barrier to solid phase formation, and samples from all five lots began to release heat as soon as cooling was initiated. Heating to $\sim 900^{\circ} \mathrm{C}$ introduced a nucleation barrier and these samples supercooled to $858-864^{\circ} \mathrm{C}$.

Adding $20 \mathrm{wt} \% \mathrm{Ag}$ eliminated the effect of maximum processing temperature on the solidification process. Samples heated to temperatures between 885 and $900^{\circ} \mathrm{C}$ all showed some supercooling and no evidence of solid formation at temperatures above the onset of the melting reaction. This was also the case for Ag-clad tapes fabricated from two lots of powder. For these tapes, the melting onset was at about $861^{\circ} \mathrm{C}$ and the solidification exotherm began at $855^{\circ} \mathrm{C}$. The solidification exotherms were much better defined than the diffuse melting endotherms.

These studies show that $\mathrm{Ag}$ participates in the melting process. Data for various lots of powder may have some value as an indicator of batch quality, but the actual melting behavior in a silver sheath can be significantly different. The data also suggest that the Ag sheathes are probably attacked during the melting process 
and that the effect of the Ag content of the powders should be investigated further.

\section{THERMAL CONDUCTIVITY OF PARTIALLY SUBSTITUTED $\mathrm{YBa}_{2} \mathrm{Cu}_{3} \mathrm{O}_{7-\delta}$}

Several studies ${ }^{1.2,3}$ have shown that the thermal conductivity, $\lambda$, of $\mathrm{YBa}_{2} \mathrm{Cu}_{3} \mathrm{O}_{7-\delta}, \mathrm{Y} 123$, does not undergo a sudden change at the superconducting transition temperature, $T_{c}$, and reaches a maximum at roughly $T_{c} / 2$. The two explanations that have been proposed for this behavior are (a) enhancement of the phonon conductivity as a result of the disappearance of phonon scattering by the unpaired electrons and (b) electronic energy transport at temperatures well below $T_{\mathrm{c}}$. At present the electronic transport mechanism that is based on $\mathrm{d}$-wave superconductivity ${ }^{4-8}$ appears to be more generally accepted.

In a recently published study ${ }^{9}$ of the thermal conductivity of $\mathrm{YBa}_{2} \mathrm{Cu}_{4} \mathrm{O}_{8}(\mathrm{Y} 124)$, we suggested that both electrons and phonons make significant contributions to the $\lambda$ of superconducting Y124 and Y123. For Y123, it seemed that the relative roles of phonons and electrons might be experimentally identified by making $\lambda$ measurements on partially substituted Y123. This article reports $\lambda$ measurements on several Y123 materials in which $S r$ replaces some of the $\mathrm{Ba}$ and $\mathrm{Dy}$ or $\mathrm{Yb}$ replaces some of the $\mathrm{Y}$. In particular the measurements on $\mathrm{Y}_{0.5} \mathrm{Yb}_{0.5} \mathrm{Ba}_{2} \mathrm{Cu}_{3} \mathrm{O}_{7-\delta}$ show that interesting lowtemperature effects can be produced by partial substitution.

\section{Sample Preparation and Properties}

The polycrystalline Y123 and partially substituted Y123 samples were prepared by mixing and grinding the oxides, firing in oxygen at $950^{\circ} \mathrm{C}$, and regrinding to form a sinterable powder that was then pressed into pellets and sintered at $950^{\circ} \mathrm{C}$. Phase purity, as determined by XRD, was generally greater than $99 \%$, and carbon contents as low as $80 \mathrm{ppm}$ were obtained. Examination by SEM-energydispersive X-ray (EDAX) microanalysis showed that, at least to the scale of $1 \mu \mathrm{m}$, the samples were solid solutions. Density and room temperature resistivity values for the samples are shown in Tables 1.3 and 1.4.

Resistivity data obtained before and after the $\lambda$ measurements were obtained show that the samples degraded in the vacuum environment. Resistivity-temperature data obtained after the low-temperature $\lambda$ measurements are shown in Fig. 1.61. These results showed zero resistance $T_{\mathrm{c}}$ values of 89 and $87.2 \mathrm{~K}$ for $\mathrm{Y} 123$ and $\mathrm{Y}_{0.5} \mathrm{Yb}_{0.5} \mathrm{Ba}_{2} \mathrm{Cu}_{3} \mathrm{O}_{7-\delta}$. Descriptions of the two thermal conductivity measurement devices that were employed have been presented previously. 9,10

Table 1.3. Characteristics of cut-bar thermal conductivity samples

\begin{tabular}{ccc}
\hline Nominal composition & $\begin{array}{c}\text { Density } \\
\text { (\% theoretical) }\end{array}$ & $\begin{array}{c}\text { Room temperature } \\
\text { resistivity } \\
\left(10^{-8} \Omega \mathrm{m}\right)\end{array}$ \\
\hline $\mathrm{Y}_{0.5} \mathrm{Yb}_{0.5} \mathrm{Ba}_{1.4} \mathrm{Sr}_{0.6} \mathrm{Cu}_{3} \mathrm{O}_{7-\delta}$ & 89.8 & 1077 \\
$\mathrm{Y}_{0.5} \mathrm{Yb}_{0.5} \mathrm{Ba}_{1.4} \mathrm{Sr}_{0.6} \mathrm{Cu}_{3} \mathrm{O}_{7-\delta}$ & 90.1 & 1101 \\
$\mathrm{Y}_{0.2} \mathrm{Dy}_{0.8} \mathrm{Ba}_{1.4} \mathrm{Sr}_{0.6} \mathrm{Cu}_{3} \mathrm{O}_{7-\delta}$ & 87.9 & 638 \\
$\mathrm{DyBa}_{1.4} \mathrm{Sr}_{0.6} \mathrm{Cu}_{3} \mathrm{O}_{7-\delta}$ & 85.7 & 695 \\
$\mathrm{Y}_{0.5} \mathrm{Yb}_{0.5} \mathrm{Ba}_{2} \mathrm{Cu}_{3} \mathrm{O}_{7-\delta}$ & 97.5 & 883 \\
\hline
\end{tabular}

${ }^{a}$ Corrected for porosity. 
Table 1.4. Characteristics of samples used for low temperature measurements

\begin{tabular}{|c|c|c|c|c|c|}
\hline \multirow[t]{2}{*}{$\begin{array}{l}\text { Sample } \\
\text { composition }\end{array}$} & \multirow[t]{2}{*}{$\begin{array}{l}T_{\mathrm{c}}^{a} \\
(\mathrm{~K})\end{array}$} & \multicolumn{2}{|c|}{$\begin{array}{l}\text { Room temperature } \\
\text { electrical resistivity } \\
\left(10^{-8} \Omega \mathrm{m}\right)\end{array}$} & \multirow[t]{2}{*}{$\begin{array}{c}\text { Density } \\
\text { (\% theoretical) }\end{array}$} & \multirow[t]{2}{*}{$\begin{array}{c}\text { Room-temperature } \\
\text { absolute seebeck cocfficient } \\
\mu \mathrm{VK}^{-1}\end{array}$} \\
\hline & & Initial $^{c}$ & Final $^{c}$ & & \\
\hline $\mathrm{YBa}_{2} \mathrm{Cu}_{3} \mathrm{O}_{7-\bar{\delta}}$ & 88.8 & 871 & 3407 & 95.9 & 2.38 \\
\hline $\mathrm{Y}_{0.5} \mathrm{Yb}_{0.5} \mathrm{Cu}_{3} \mathrm{O}_{7-\delta}$ & 87.2 & 1082 & 1792 & 96.0 & -0.20 \\
\hline
\end{tabular}

${ }^{a}$ Measured resistively after the $\lambda$ data had been generated.

${ }^{b}$ Corrected to theoretical density.

'Values measured before and after the thermal conductivity data were taken.

${ }^{d}$ Measured after the $\lambda$ data had been generated.

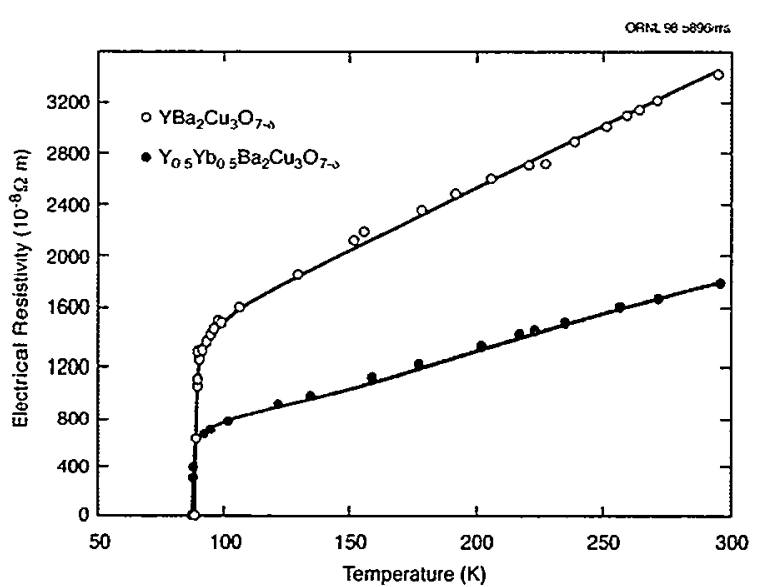

Fig. 1.61. Electrical resistivity data for Y123 and YYb123. Four-probe dc measurements were obtained after the thermal conductivity data had been obtained.

\section{Experimental Results}

Ambient temperature $\lambda$ data for five partially substituted $\mathrm{Y} 123$ samples are shown in Fig. 1.62. Data for three Y123 samples ${ }^{11}$ are included for comparison. Lower temperature data for $\mathrm{Y} 123$ and $\mathrm{Y}_{0.5} \mathrm{Yb}_{0.5} \mathrm{Ba}_{2} \mathrm{Cu}_{3} \mathrm{O}_{7-\delta}$ are shown in Fig. 1.63. Data from the cut-bar $\lambda$ apparatus are included in Fig. 1.63. The results for two measurements on samples from different batches of partially substituted Y123 differ by $4 \%$.

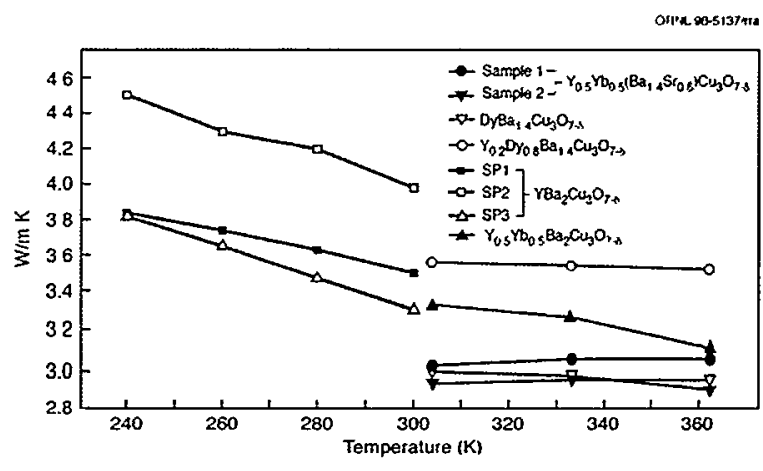

Fig. 1.62. Ambient temperature thermal conductivity data for five partially substituted Y123 samples. [Source: D. W. Yarbrough, R. K. Williams, and D. R. Schockley, p. 554 in Thermal Conductivity 22, ed. T. W. Tong, Technomic, Lancaster, Pa. (1994)].

\section{Discussion}

The data presented in Fig. 1.62 show that partial substitution reduces both the magnitude and temperature dependence of the $\lambda$. The resistivities of these samples varied from 638 to $1100 \times 10^{-8} \Omega \mathrm{m}$, but the $\lambda$ data do not show much correlation with resistivity. This indicates that the phonon $\lambda$ component, $\lambda_{\mathrm{p}}$, dominates. Using the Sommerfeld Lorenz number, $L_{0}$, to make a correction for the electronic component $\lambda_{e}$, yields estimates of $\lambda_{p}$ for $Y 123$ and the partially substituted samples.

At $295 \mathrm{~K}$, the average $\lambda_{\mathrm{p}}$ value for $\mathrm{Y} 123$ is $2.73 \mathrm{Wm}^{-1} \mathrm{~K}^{-1}( \pm 3 \%)$ and the values for the 


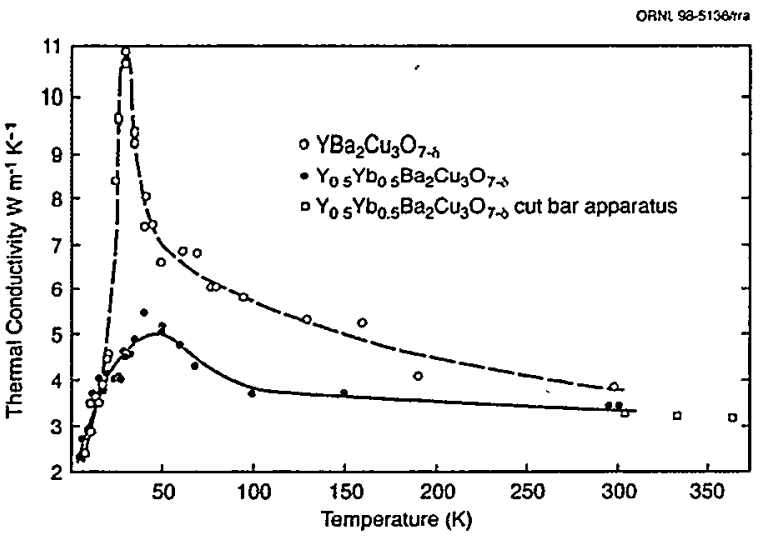

Fig. 1.63. Thermal conductivity data for polycrystalline $\mathrm{Y} 123$ and $\mathrm{Y}_{0.5} \mathrm{Yb}_{0.5} \mathrm{Ba}_{2} \mathrm{Cu}_{3} \mathrm{O}_{7-\delta}$. The lower temperature measurements were made in a guarded longitudinal heat-flow apparatus [Source: R. K. Williams, J. O. Scarbrough, J. M. Schmintz, and J. R. Thompson, Phys. Rev. B 57, 10923 (1998)] and data obtained in an ambient temperature cutbar apparatus are included to demonstrate accuracy and batch-to-batch variability.

partially substituted samples are 10 to $30 \%$ lower. Presumably this reduction is associated with phonon-point-defect scattering, but it should be noted that the reduction does not correlate very well with composition. The largest $\lambda_{\mathrm{p}}$ reduction was observed for $\mathrm{DyBa}_{1.4} \mathrm{Sr}_{0.6} \mathrm{Cu}_{3} \mathrm{O}_{7-\hat{\delta}}$.

The lower temperature $\lambda$ data are shown in Fig. 1.63. The $\lambda$ values for $\mathrm{Y} 123$ reach a maximum at $0.3 T_{\mathrm{c}}$ and the maximum has usually been observed ${ }^{2,3}$ at about $0.5 T_{\mathrm{c}}$. The lowered $\lambda$ maximum may be associated with sample degradation as discussed previously.

The $\mathrm{Yb}$ for $\mathrm{Y}$ partial substitution reduces the maximum $\lambda$ by $\sim 50 \%$, and the maximum value occurs at $\sim 0.5 T_{\mathrm{c}}$. One explanation for this reduction is that point-defect scattering persists to low temperatures, which requires a low characteristic temperature. An analysis ${ }^{9}$ of the $\lambda$ data for Y123 suggests that this may be the case. The $\lambda_{\mathrm{p}}$ estimates shown in Fig. 1.64 also suggest a low characteristic temperature and strong point-defect scattering. These $\lambda_{p}$ estimates were obtained by correcting for electronic transport

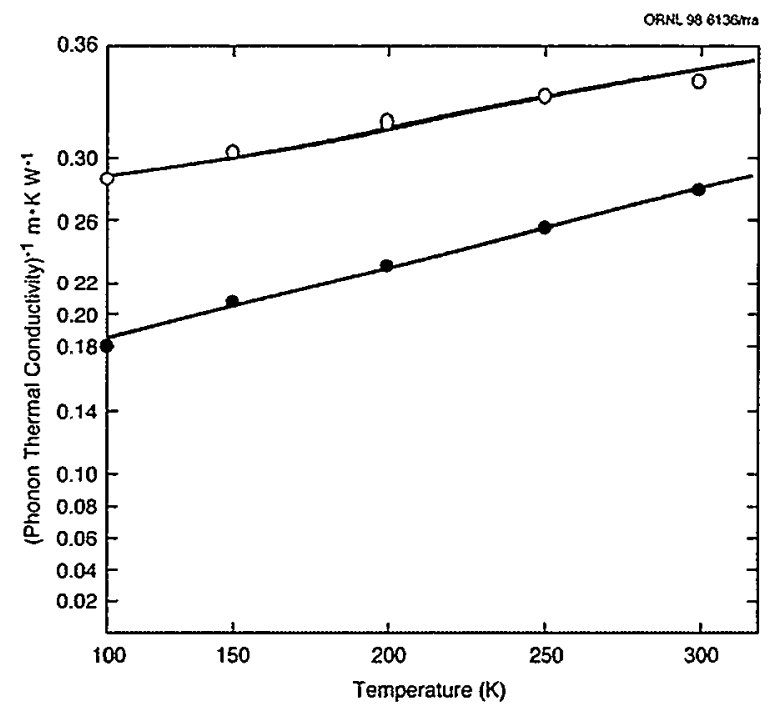

Fig. 1.64. Estimated phonon thermal resistivity curves for $\mathrm{Y} 123$ and $\mathrm{Y}_{0.5} \mathrm{Yb}_{0.5} \mathrm{Ba}_{2} \mathrm{Cu}_{3} \mathrm{O}_{7-\delta}$. The Sommerfield Lorenz number and the data shown in Fig. 1.61 were used to correct for electronic transport.

by using the resistivity data shown in Fig. 1.61 with $L_{0}$. For $\mathrm{Y}_{0.5} \mathrm{Yb}_{0.5} \mathrm{Ba}_{2} \mathrm{Cu}_{3} \mathrm{O}_{7-\delta}$ the result is that $\lambda_{p}$ is reduced relative to $Y 123$, and the temperature dependence becomes weaker. Callaway's model ${ }^{12}$ predicts this kind of behavior. Extrapolating this two-component description of the normal state data down to $\sim 50 \mathrm{~K}$ yields $\lambda$ values that agree with the experimental data. The $\lambda_{e}$ estimates fall slowly as the temperature is lowered, and they were graphically extrapolated to $\sim 50 \mathrm{~K}$. The $\lambda_{\mathrm{p}}$ extrapolations were based on Fig. 1.64.

At lower temperatures, the $\lambda$ data for both samples vary as $T_{\mathrm{n}}$ where $\mathrm{n} \sim 0.4$. This has also been reported by Cohn et al. ${ }^{3}$ and is similar to the $T$ dependence found for $\mathrm{YBa}_{2} \mathrm{Cu}_{4} \mathrm{O}_{8}$. This behavior may be the result of the presence of unpaired charge carriers that can transport energy and scatter phonons. ${ }^{9}$

The results that have been presented suggest that the Y123 $\lambda$ peak has a phonon component. Further tests require additional data on other $\mathrm{Y}-\mathrm{Yb}$ composition, and also data for partially substituted $Y 123$ containing a lighter rare earth, such as Nd. Phonon-point-defect scattering 
theory predicts the composition and massdifference dependence of the $\lambda_{\mathrm{p}}$ and, assuming that $\lambda_{c}$ remains unaffected, would allow an experimental separation of $\lambda_{c}$ and $\lambda_{p}$. Another approach might be to change $\lambda_{c}$ without changing $\lambda_{\mathrm{p}}$. Unsubstituted Nd 123 is not a line compound ${ }^{13}$ and $\mathrm{Nd}^{+3}$ ions on the $\mathrm{Ba}^{+2}$ sites constitute charge perturbations that should scatter unpaired electrons.

\section{References}

1. A. Jezowski, K. Rogacki, R. Horyn, and J. Klamut, Physica C 153-155, 1347 (1988).

2. S. J. Hagen, Z. Z. Wang, and N. P. Ong, Phys. Rev. B 40, 9389 (1989).

3. J. L. Cohn, S. A. Wolf, T. A. Vanderah, V. Selvamanickam, and K. Salama, Physica C 192, 435 (1992).

4. Y. Pogorelov, M. A. Arranz, R. Villar, and S. Vieira, Phys. Rev. B 51, 15474 (1995).

5. K. Krishana, J. M. Harris, and N. P. Ong, Phys. Rev. Lett. 75, 3529 (1995).

6. T. Wolkhausen, Physica C 234, 57 (1994).

7. M. Houssa and M. Ausloos, Physica C 257, 321 (1996).

8. L. Tewordt and T. Wolkhausen, Solid State Commun. 70, 839 (1989).

9. R. K. Williams, J. O. Scarbrough, J. M. Schmitz, and J. R. Thompson, Phys. Rev. B 57, 10923 (1998).

10. R. K. Williams, R. K. Nanstad, R. S. Graves and R. G. Berggren, J. Nucl. Mater. 115, 211 (1983).

11. D. W. Yarbrough, R. K. Williams, and D. R. Shockley, in Thermal Conductivity 22, ed. T. W. Tong (Technomic, Lancaster, Pa.), p. 554 (1994).

12. J. Callaway, Phys. Rev. 122, 787 (1961).

13. T. B. Lindemer, E. D. Specht, P. M. Martin, and M. L. Flitcroft, Physica $C$ 255, 65 (1995).

\section{PLUME-INDUCED STRESS IN PULSED-LASER DEPOSITED $\mathrm{CeO}_{2}$ FILMS}

Understanding and controlling stresses in thin films is an important issue for any deposition processes. Stress can lead to film cracking and delamination, as well as to variations in film properties. Stresses that result from thermal expansion coefficient mismatch or lattice mismatch between the film and substrate are generally independent of the deposition process. However, specific defect structures inherent to the deposition process can introduce additional compressive or tensile stress components. Metal films, such as $\mathrm{Cu}$, are often characterized by tensile strain when deposited by evaporation. The origin of this tensile strain is generally believed to be an attractive interaction across voids within the film. In contrast, the simultaneous bombardment with energetic ionic or neutral species during film deposition can result in compressive stress for many systems. For example, intrinsic compressive stress has been observed in $\mathrm{Y}_{2} \mathrm{O}_{3}$ films deposited by reactive sputtering because of the bombardment of energetic Ar ions during deposition. The origin of compressive stress as a result of energetic bombardment is associated with subsurface damage from the impinging energetic species leading to interstitial defects. The kinetic energy necessary for the onset of recoil implantation of surface atoms into the film interior through bombardment is material dependent, but is often observed for ion bombarding energies of a few eV or greater.

For many thin-film systems, the tailoring of stress in the film becomes possible through the bombardment of the depositing film with energetic species during film growth. In pulsedlaser deposition (PLD), the kinetic energies of ions and neutral species in the ablation plume can range from a few tenths to as high as several hundred $\mathrm{eV}$. These energies should be sufficient to modify the stress state of films through defect formation as has been documented for ionbeam-assisted approaches. Unfortunately, few 
studies have addressed this issue for PLD. One study on the homoepitaxial growth of $\mathrm{SrTiO}_{3}$ using PLD showed the presence of compressive stress in the films as indicated by lattice distortion. Further work is needed to better understand the role of ablation energies in determining film stress, in particular to delineate the effects of plume kinetic energies from other possible sources of lattice distortion, including deviations in oxygen content in the films.

We have examined the intrinsic stress induced by energetic species in the laser ablation plume for $\mathrm{CeO}_{2}$ films deposited using PLD. Cerium oxide is an interesting oxide buffer layer because of a favorable lattice match with silicon and the HTS materials and is an important material for optical coatings because of its relatively high refractive index. In addition, $\mathrm{CeO}_{2}$ is an attractive binary oxide model system, because it has been the subject of previous studies on ion bombardment effects during film growth. In this study, we have attempted to delineate the specific effects of plume energetics in determining the compressive stress by manipulation of the ion and neutral kinetic energies using inert $\mathrm{Ar}$ as the background gas. Previous work indicates that the ablation of $\mathrm{CeO}_{2}$ results in a significant flux of ejected $\mathrm{Ce}^{+}$ions with kinetic energies ranging from 10 to $50 \mathrm{eV}$ for laser energy densities on the order of 1.7 to $6.7 \mathrm{~J} / \mathrm{cm}^{2}$ in a background pressure of $10^{-6}$ Torr or less. At higher background pressures, gas-phase collisions between the ablated species and background gas molecules reduce the kinetic energies, allowing one to tune the energy distribution. The specific energies depend on the ablation process at the target and the collision cross-section of the ablated species with the background gases. The oxidation kinetics are kept relatively unchanged by maintaining a fixed oxygen partial pressure for different Ar background pressures.

A KrF (248 nm) excimer laser was used as the laser ablation source. The laser energy density was maintained at $\sim 3 \mathrm{~J} / \mathrm{cm}^{2}$ with a repetition rate of $5 \mathrm{~Hz}$. Deposition was performed at 100 and $700^{\circ} \mathrm{C}$ in order to delineate the effects of thermal expansion mismatch and in situ annealing at the deposition temperature. The substrates used were (100) YSZ and thin (111) Si. The (111) Si substrates were useful for determining stress by measuring the degree of bowing induced in the substrate as a result of the stress in the (111) textured polycrystalline $\mathrm{CeO}_{2}$ films. The films on the (100) YSZ were generally epitaxial for both the 100 and $700^{\circ} \mathrm{C}$ deposition temperatures. These films were used to measure the stress-induced lattice parameter distortion. The thermal expansion coefficient of YSZ is nearly identical to that for $\mathrm{CeO}_{2}$. Base pressure for the vacuum system was $\sim 5 \times 10^{-6}$ Torr. The total background pressure was varied from $5 \times 10^{-6}$ to $2 \times 10^{-3}$ Torr using argon and oxygen as the background gases. For total pressure greater than or equal to $4 \times 10^{-4}$ Torr, the oxygen partial pressure was maintained near $4 \times 10^{-4}$ Torr.

For $\mathrm{CeO}_{2}$ films deposited at $100^{\circ} \mathrm{C}$ using PLD, we observe significant compressive stress for films deposited at lower total background pressures as a result of energetic ions and neutral species in the ablation plume. Figure 1.65 shows a surface profile scan of a 660 -nm-thick $\mathrm{CeO}_{2}$ film deposited at 5-mTorr background pressure and $4 \times 10^{-4}$ Torr oxygen partial pressure on $110-\mu \mathrm{m}$-thick Si showing significant bowing as a result of the compressive stress in the film. On the basis of the mechanical properties of the Si substrate, one can calculate the stress in the film evident in the substrate bowing using the expression:

$$
\sigma_{s}=E, d^{2}[\sigma(1-v) t R]^{-1},
$$

where $v_{1}$ is Poisson's ratio of the substrate, $E_{\text {, }}$ is the Young's modulus of the substrate, $t$ is the film thickness, $d$ is the substrate thickness, and $R$ is the radius of curvature for the Si substrate. Using this, a compressive stress of $2 \mathrm{GPa}$ is calculated for this sample.

The presence of compressive strain was also manifested by a tetragonal distortion of the $\mathrm{CeO}_{2}$ crystal lattice for epitaxial films on (100) YSZ. Figure 1.66(a) shows the $c$-axis lattice parameter of epitaxial $\mathrm{CeO}_{2}$ films deposited on 


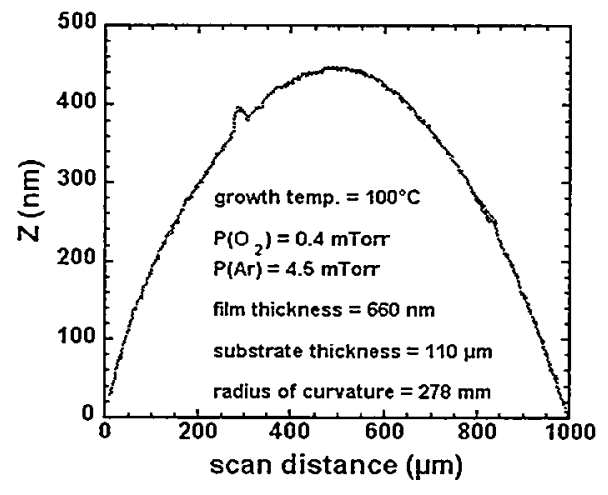

Fig. 1.65. Surface profile scan of $\mathrm{CeO}_{2}$ film deposited on thin $\mathrm{Si}$ (111).
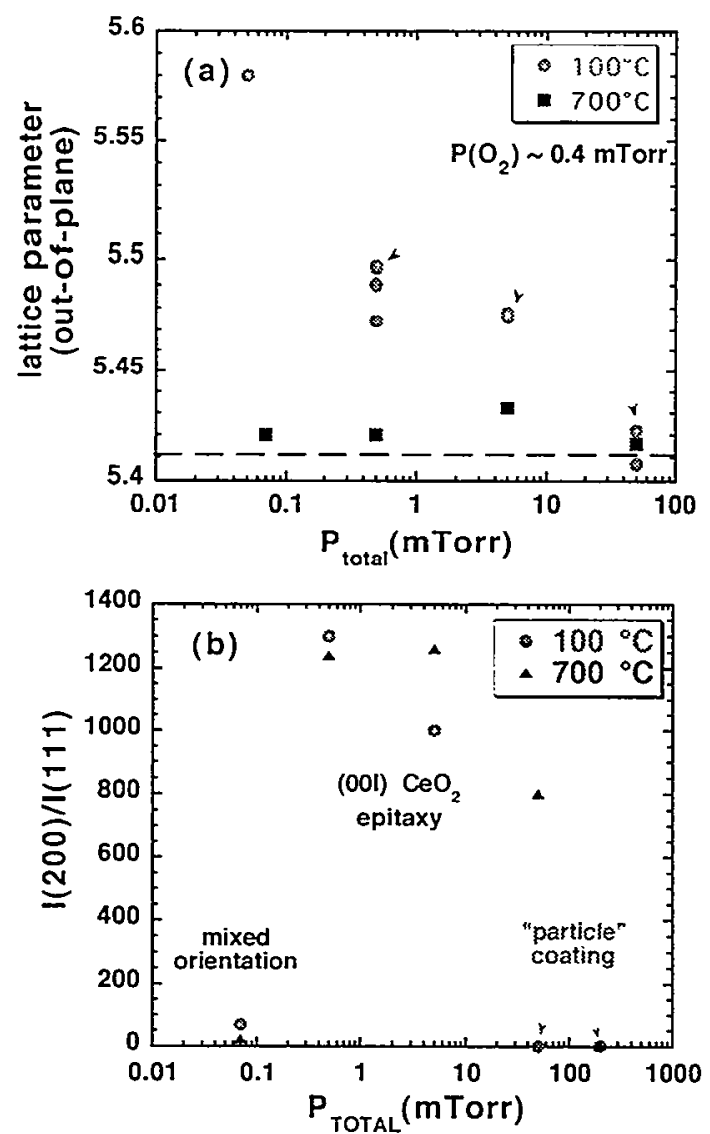

Fig. 1.66. Plot of (a) out-of-plane lattice parameter and (b) XRD I(200)/(111) intensity ratio as a function of total background pressure for $\mathrm{CeO}_{2}$ films deposited using PLD.
(100) YSZ substrates for various background pressures ranging from $10^{-5}$ to $200 \mathrm{mT}$ Torr. The oxygen partial pressure is maintained at $4 \times 10^{-4}$ Torr for all cases except for the lowest pressure in which no background gas was intentionally introduced. The large lattice distortion is a manifestation of both the stresses in the film as well as defects in the film, such as oxygen vacancies, that expand the $\mathrm{CeO}_{2}$ unit cell volume independent of stress. In order to delineate these effects, we must determine the "unstrained" lattice spacing that the film would assume given a release of the stress. From measurements of both the in-plane and out-ofplane lattice spacing of the film, the nominally cubic lattice parameter of the film in the absence of stress can be determined by the equation:

$$
a_{0}=\left[\left(1-v_{f}\right) a_{1}+2 v_{f} a\right]\left[1-v_{f}\right]^{-1},
$$

where $v_{1}$ is the Poisson's ratio of $\mathrm{CeO}_{2}, a_{1}$ is the out-of-plane lattice parameter, and $a_{11}$ is the inplane lattice parameter of the film. From this, one can determine the film stress, $\sigma_{\mathrm{s}}$, using:

$$
\sigma_{s}=\left[E_{f}\left(a-a_{a}\right)\right]\left[\left(1-v_{f}\right) a_{a}\right]^{-1},
$$

where $E_{f}$ is the Young's modulus, $a_{11}$ is the film in-plane lattice parameter, and $a_{o}$ is the "unstrained" lattice parameter of the $\mathrm{CeO}_{2}$ film. Table 1.5 shows the compressive stress as a function of total background pressure for several films. For films deposited at constant oxygen pressure, the compressive stress decreases as the background gas pressure is increased, reflecting a reduction in the kinetic energy of ablated species through collisions. The relatively low stress in films deposited in vacuum probably reflects the poor crystallinity as a result of oxygen deficiency. Also shown in the table is the "unstrained" lattice spacing, $a_{0}$, as a function of total background pressure. For films deposited at $5 \mathrm{mT}$ Torr or less, the unstrained lattice parameter is significantly expanded relative to the bulk $\mathrm{CeO}_{2}$ value. This suggests that the energetic $\mathrm{Ce}^{*}$ ions preferentially sputter oxygen atoms, leaving an oxygen-depleted $\mathrm{CeO}_{2}$ lattice. This is consistent with Monte Carlo 
Table 1.5. Lattice spacing and strain for various $\mathrm{CeO}_{2}$ films

\begin{tabular}{clllllll}
\hline $\begin{array}{c}\text { Temp. } \\
\left({ }^{\circ} \mathrm{C}\right)\end{array}$ & $\begin{array}{c}\mathrm{P}_{\left(\mathrm{O}_{2}\right)} \text { (mTorr) } \\
(\mathrm{mT})\end{array}$ & $\begin{array}{c}\mathrm{P} \text { (total) } \\
(\mathrm{mTorr})\end{array}$ & $\begin{array}{c}\mathrm{a}_{\mathrm{T}} \\
(\AA)\end{array}$ & $\begin{array}{c}\mathrm{a}_{1} \\
(\AA)\end{array}$ & $\begin{array}{c}\mathrm{a}_{\mathrm{O}} \\
(\AA)\end{array}$ & $\begin{array}{c}\sigma_{\mathrm{XRD}} \\
(\mathrm{GPa})\end{array}$ & $\begin{array}{c}\sigma_{\text {BOwiNG }} \\
(\mathrm{GPa})\end{array}$ \\
\hline 100 & 0 & 0.05 & $=5.5$ & 5.5 & 5.5 & - & 0.8 \\
100 & 0.4 & 0.4 & 5.477 & 5.403 & 5.443 & 1.7 & - \\
100 & 0.4 & 0.4 & 5.487 & 5.40 & 5.45 & 2.0 & 2.9 \\
100 & 0.4 & 5 & 5.482 & 5.42 & 5.454 & 1.5 & 2.0 \\
100 & 0.4 & 50 & 5.4 & - & - & - & - \\
700 & 0.4 & 0.4 & 5.417 & 5.41 & 5.414 & 0.17 & - \\
\hline
\end{tabular}

simulations by others that show a lower energy threshold for the removal of oxygen from the $\mathrm{CeO}_{2}$ surface compared with $\mathrm{Ce}$. A volume expansion is typical for oxygen deficiency in bulk $\mathrm{CeO}_{2-}$. The largest unstrained lattice expansion is observed for the film deposited in vacuum. A preliminary measurement of the kinetic energy distribution for the ablation plume in vacuum was performed using an ion probe. Energies of several hundred $\mathrm{eV}$ were observed. These energies are relatively high for laser ablation plumes and account for the significant lattice distortions in the films.

For films deposited at $700^{\circ} \mathrm{C}$, the stress and volume expansion in the films were significantly less than that observed at $100^{\circ} \mathrm{C}$, although it was not zero. The reduction in stress and lattice distortion is presumably the result of the in situ annealing of plume-induced defects. The observation of some stress and lattice distortion reiterates the general need to consider plumeinduced stress, even in high-temperature film growth using PLD.

In addition to the stress, it is instructive to also consider the crystallinity of the films as monitored by XRD peak intensity. Figure 1.66(b) shows the (200)/(111) peak intensity ratio for the epitaxial $\mathrm{CeO}_{2}$ films on (100) YSZ. Superior epitaxial crystallinity is achieved for the intermediate pressure range 0.5 to $5 \mathrm{mTorr}$. At the higher pressures, the degree of epitaxy diminishes drastically. In fact, the films deposited in 50 and $200 \mathrm{mTorr}$ at $100^{\circ} \mathrm{C}$ resemble a particulate film with no adhesion to the substrate. It is unclear whether these particles nucleate in the gas or on the substrate surface. Figure 1.67 shows a cross-

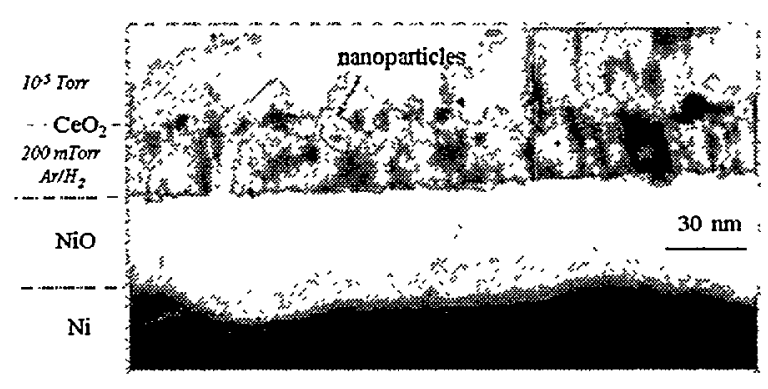

Fig. 1.67. Cross-section transmission electron microscope image of $\mathrm{CeO}_{2}$ film deposited on (100) Ni showing the presence of nanoparticles.

section transmission electron microscopy image of a $\mathrm{CeO}_{2}$ film grown epitaxially on a (001) $\mathrm{Ni}$ surface at a deposition temperature of $710^{\circ} \mathrm{C}$. The initial $30 \mathrm{~nm}$ was nucleated in the presence of $200 \mathrm{mTorr} \mathrm{Ar} / 2 \% \mathrm{H}_{2}$ mixture. This was followed by deposition in vacuum $\left(10^{-5}\right.$ Torr base pressure) and $4 \times 10^{-4}$ Torr oxygen background. A transition in film microstructure is observed for the different background pressures. The film deposited at $200 \mathrm{mTorr}$ $\mathrm{Ar} / 2 \% \mathrm{H}_{2}$ exhibits a uniaxial structure whereas the microstructure of the film grown at $10^{-5}$ Torr vacuum is reminiscent of a columnar structure. These changes in microstructure are similar to that observed for films deposited in the presence of an energetic ion beam. Note also that the initial layer deposited at high background pressure is decorated with nanocrystals. The size of these nanoparticles ranges from 5 to $10 \mathrm{~nm}$ in diameter. The layers deposited at lower pressures have no nanoparticles. This is consistent with the particulate-like coatings for the $\mathrm{CeO}_{2}$ films deposited at $100^{\circ} \mathrm{C}$ in high 
background pressure and reiterates the fact that the formation of nanoparticles by laser ablation must be considered in film growth at background pressures greater than $50 \mathrm{mTorr}$. This will be particularly true for binary oxide films where the formation of stable nanoparticle phases involves only two atomic constituents.

In conclusion, we have shown that energetic ions and/or neutral species in a laser ablation plume can induce significant compressive stress in deposited films. To some extent, the background pressure during ablation can be used to manipulate the ion energies and control the resulting compressive stresses. However, a sufficient increase in the background pressures may lead to the formation of nanoparticles in the deposited films. 


\section{Technical Progress in Applications Development}

\section{HIGH-TEMPERATURE SUPERCONDUCTING CABLE}

This project report covers only the nonproprietary Oak Ridge National Laboratory (ORNL) contributions to the High Temperature Superconducting (HTS) Cable Project with Southwire Company for FY 1998. During the fiscal year, the project made a major transition with the award to Southwire of a Superconductivity Partnership Initiative agreement that was formally signed on June 29, 1998. For this multiyear joint development project, Southwire will construct a 30.5 -m-long, three-phase HTS cable complete with electrical and thermal insulation, outer enclosures, and cable terminations to demonstrate the feasibility of this promising electric utility application. The cable will be installed between two overhead utility towers and will supply $1.25 \mathrm{kA}$ of current at $12.5 \mathrm{kV}$ to the utility and building wire manufacturing plants located at Southwire Company Headquarters in Carrollton, Georgia. The cable will be tested during FY 2000 under real-use situations and will demonstrate Southwire's expertise in HTS cables and confidence that this technology can be supplied to the electric utility industry. To reach this goal, a 5-m-long single-phase HTS cable with all accessories rated at $12.5 \mathrm{kV}$ and $1.25 \mathrm{kA}$ has been designed and was tested at ORNL during FY 1998 in a laboratory environment as a proof-of-design concept.

This annual progress report covers:

- 5-m cable manufacture,

- ac losses of prototype HTS transmission cables,

- testing of the dependence of the number of layers on the performance of an HTS cable prototype,

- HTS cable test facility design and initial results,

- electrical dielectric testing,
- $\quad$ superconducting transformer project, and

- insulation studies at ORNL in support of superconducting power applications.

\section{5-m Cable Manufacture}

A 5-m HTS cable was machine wrapped in Southwire's new HTS cable manufacturing facility. The cable uses coaxial conductors wrapped from bismuth-strontium-calciumcopper oxide (BSCCO-2223) superconducting tapes provided by Intermagnetics General Corporation (IGC). A cryogenic dielectric is used as the inner and outer HTS coaxial conductors, which are insulated with an electrical dielectric that is impregnated in liquid nitrogen. The electrical dielectric is made from tapes that were also machine wrapped on the cable. The cable is flexible because both the superconducting tapes and electrical dielectric tapes are wrapped with butt gaps on a flexible cable former. The cable former also serves as part of the liquid nitrogen flow path providing cable cooling. A dedicated 6,000-square-foot cable manufacturing facility was built to wrap this 5-m single-phase cable and the three-phase $30.5-\mathrm{m}$ cable to be wrapped next year. The area has been allocated in one of the Southwire manufacturing plants, and cables are wrapped in a clean room environment. A wrapping machine was obtained in October 1996 and refurbished for the project. Based upon the successful wrapping of the 5-m cable, new motor drives have been installed to further improve the precision of the wrapping lay angle and butt gap.

\section{AC Losses of Prototype HTS Transmission Cables}

Over the past three years, Southwire and ORNL have jointly designed, built, and tested nine, $1-\mathrm{m}$ long, prototype HTS transmission 
cables. Complete test results of cables \#1, \#2, and \#5 were reported earlier. ${ }^{1.2}$ Cable \#7 was used to study the dependence of the number of layers on the performance of the cable by stripping the outermost layer after each test sequence. The results of that test are reported in the next article on p. 2-7. A theory of calculating hysteresis loss of cables made of multilayer helically wound HTS tapes has been developed by Dresner. ${ }^{3}$ This theory differs from others in that it accounts for the broad resistive transition of the HTS tapes and thus can calculate the ac loss both below and above the critical current $\left(I_{c}\right)$ of a cable. The latter is interesting because the HTS cables can be operated stably above their critical currents because of the broad resistive transition. This paper summarizes the ac loss measurements of five of the prototypes and compares the losses with each other and with Dresner"s theory.

\section{Differences in the Cables}

Table 2.1 lists the parameters of the prototype cables. All cables were wound of Bi-2223/Ag HTS tapes made by IGC about $3.5-\mathrm{mm}$ wide by $0.2-\mathrm{mm}$ thick. The tapes were helically wound on a stainless steel former with lay angles of about $15^{\circ}$ or $30^{\circ}$ as shown in Table 2.1. The lay angles were about the same for the different layers of each cable. Most cables were wound with an alternating pattern of left and right senses, except cable \#9, which was wound with left-left and right-right senses. Kapton insulating tapes were used between neighboring layers of the cables, except in cables \#8 and \#9 where the insulating tapes were used only between layer \#2 and layer \#3. Cable \#3 had 10 layers of tapes, and the rest had 4 layers. Cable \#3 was wound on a 2.54-cm-diameter former, and the rest were wound on 38.1 -cm-diameter formers. Cable \#5i designates the remaining 2-layer cable after the outer two layers were stripped off the original cable \#5.

\section{Measuring Techniques for ac Loss}

Two different techniques were used in measuring the ac loss of the cables. The prototype cables were cooled in a liquid nitrogen bath at $77 \mathrm{~K}$. They were powered by a current transformer. Line frequency $60-\mathrm{Hz}$ ac currents of up to $2 \mathrm{kA}$ rms were used to charge the cables.

\section{Calorimetric Measurement}

Initially, all ac losses of the cables were measured with a calorimetric technique. ${ }^{4}$ In this approach, the cable was thermally insulated from the bath with a Micarta or G-10 tube filled with wax. A radial temperature gradient was developed by the ac-loss-induced temperature rise of the conductor. The temperature rise, $\Delta \mathrm{T}$, on the surface of the cable relative to the liquid nitrogen bath was measured by thermocouples. The calibration of temperature rise versus loss rate was done with dc currents through the cable itself at values higher than the $I_{c}$ of the cable.' The product of the voltage drop and the current gave the power for the measured temperature rise. This technique is straightforward but timeconsuming. At the low-loss range, it is also limited by the sensitivity of the thermocouples used (about $10 \mathrm{mK}$ in our setup). Depending on how well the cable was insulated, each test resulted in a different $\Delta T$-vs-loss rate curve and a maximum $\Delta T$ before which the cable would overheat. Overall, ac loss rates on the order of $0.01 \mathrm{~W} / \mathrm{m}$ to $10 \mathrm{~W} / \mathrm{m}$ were measured.

\section{Electrical Measurement}

More recently, an electrical technique was also used to measure the ac loss of most of the prototype cables. The voltage across the cable and the phase-angle between the voltage and the current signals were measured by a digital lock-in amplifier. The product of the current and the voltage component in phase with the current gave the ac loss $(P=I \cdot V \operatorname{Cos} \theta)$. This measurement can be done much more quickly, 
Table 2.1. Prototype cable parameters

\begin{tabular}{lccccc}
\hline Cable number & $\# 3$ & $\# 4$ & $\# 5 \mathrm{i}$ & $\# 8$ & $\# 9$ \\
\hline No. of layers & 10 & 4 & 2 & 4 & 4 \\
No. of tapes & 200 & 112 & 48 & 104 & 100 \\
Cable ID $(\mathrm{mm})$ & 25.7 & 38.4 & 38.2 & 38.4 & 38.2 \\
Cable OD $(\mathrm{mm})$ & 35.1 & 41.7 & 40.4 & 41.4 & 40.1 \\
Lay angle $\left(^{\circ}\right)$ & 15 & 15 & 30 & 28 & 28 \\
Lay pattern & $+-+-+-t-t-$ & +-+- & +- & +-+- & ++-- \\
Cable $I_{\mathrm{c}}^{*}(\mathrm{~A})$ & 1630 & 975 & 895 & 1605 & 1267 \\
& 1050 & 600 & 864 & 1465 & 1128 \\
n-value & 3.5 & 1.5 & 5 & 3.5 & 7 \\
\hline
\end{tabular}

*The two sets of $I_{\mathrm{c}} \mathrm{s}$ (critical currents) were the results measured at two test sequences.

and the range of measurement can be very wide. However, when the loss voltage is small compared with the inductive voltage of the cable, the phase angle is near $90^{\circ}$. A slight error in the phase-angle measurement can lead to a big error (because of the cosine) in the loss result. Thus, it is important to correct any phase error that may be introduced from the reference signal relative to the true current phase. The location of the voltage tap and how the lead wires are routed can also give false results. For example, in one test setup, routing the voltage lead through the interior of the cable former resulted in a peaking out of the ac loss and lower loss at higher currents, a result that did not make sense.

The electrical measurements of the ac losses were performed months after all the cables were measured calorimetrically. The G-10 tube and the wax were removed from the cable for the electrical measurement. Different voltage tap locations were used in the two measurements. Different dc critical currents, $I_{c}$, were measured. Both sets of $I_{\mathrm{c}}$ are listed in Table 2.1.

The lower $I_{c}$ values from the later measurements could be the result of damage in removing the tube and wax, thermal degradation, or different voltage tap locations. The more than $30 \%$ decrease for cables \#3 and \#4 can be explained. The current lead connections for Cable \#3 were made by clamping on the solder joints themselves, whereas they were on Cu-plugs for the rest of the cables. Thus, more damage in the lead sections was conceivable for cable \#3. For cable $\# 4$, tape damages were visible on the cable. This was also reflected in the particularly low n-value of this cable. On the other hand, the resistive transition n-values were not changed much in the two measurements for most of the cables. Hence, average n-values are listed in Table 2.1.

\section{Summary of Dresner's Loss Theory of HTS Cables}

\section{Hysteresis Losses in Power Law Cryoconductors}

The HTS tapes have a broad resistive transition (i.e., their resistivities increase gradually from unmeasurably small values at low currents to high values at high currents). 
Therefore, the critical-state theory (which assumes a sharp transition at critical current) of hysteresis loss developed for low-temperature superconductors needs to be modified. The measured curves of resistivity, $\rho$ of HTS vs current density. $J$. can be reasonably well fitted by a power law: $\rho=\kappa \cdot J_{n}$. Using this power law. Dresner ${ }^{5}$ calculated hysteresis losses in slab superconductors. [The slab assumption was based on the fact that HTS tapes generally have large aspect ratios $(-20)$.] By a combination of dimensional and numerical technique, Dresner derived formulas for the time- and spaceaveraged hysteresis power density, $\mathrm{Q}\left(\mathrm{W} / \mathrm{m}_{3}\right)$, for losses driven by either a sinusoidal transport current or an external field. For a peak transport current density of $J_{p}$, Dresner found:

$$
\begin{gathered}
Q=G(n, \beta) \cdot b^{-1} \cdot\left(v \mu_{0} / J_{c}\right)^{(n+1)(n-2)} \\
\cdot E_{c}^{1(n+2)} \cdot\left(J_{p} b\right)^{\mathrm{K}},
\end{gathered}
$$

where $\beta=J_{\mathrm{p}} / J_{\mathrm{c}}, \kappa=(3 n+4) /(n+2), b$ is the tape thickness, $v$ is the frequency, $\mu_{0}$ is the magnetic permittivity of free space $\left(4 \pi \times 10^{-7} \mathrm{Henry} / \mathrm{m}\right), E_{\mathrm{c}}$ is the criteria for the critical current. $E_{\mathrm{c}}$ can be $1 \mu \mathrm{V} / \mathrm{cm}$ or any other reasonable value as long as the corresponding critical current density, $J_{c}$, is used. Two asymptotic curves were found in that study.

In the limit of incomplete penetration, $\beta<$

$$
G(n, \beta) \approx 1 / 6+0.17 \cdot n^{-0.42^{-}} .
$$

Note that in this limit, Q is proportional to $J_{\mathrm{p}}$ to the $(3 n+4) /(n+2)$-power. In the case of very large n-value, this power equals the critical-state model value of 3 . Even for the lowest $n$-value (1.5) of our cables, this power is calculated to be 2.4-not too much smaller.

In the limit of extreme full penetration, $\beta>1$

$$
\begin{aligned}
& G(n, \beta)=D(n) \cdot \beta^{n(n+1)(n \cdot 2)} \\
& \cdot\left(E_{c} /\left[v \mu_{0} J_{c} b^{2}\right]\right)^{(n-1)(n-2)},
\end{aligned}
$$

where $D(n)+\pi^{-05} \Gamma[(n+3) / 2] / \Gamma[(n+4) / 2]$, and $\Gamma$ is the gamma function. In this limit, $Q$ is proportional to $J_{\mathrm{p}}$ to the $(n+2)$-power. This is understandable from the $J^{2} \rho$ resistive power loss where $\rho$ is proportional to $J^{n}$.

\section{Current Distribution in Multilayer Helical Cables}

Most HTS transmission cables consist of several layers of tapes wound helically on a hollow cylindrical former. Because the layers are in parallel, the question arises as to how the current distributes within and among them. Dresner considered the case where there are an even number of layers with adjacent layers having the same number of tapes, the same winding angle, but opposite sense of winding.

In the limiting case of incomplete penetration in a two-layer cable, the cable current is distributed in thin sheaths near the surfaces of each layer. In the outer layer, a current of $1 \cdot \cos 2 \Theta$ is flowing in an outer sheath and of $1 \cdot(\sin 2 \Theta-\cos 2 \Theta) / 2$ is flowing in an inner sheath $(\Theta$ is the lay angle). In the inner layer, there is a current of $I / 2$ flowing in the outer sheath and no current is flowing in the inner sheath. An important consequence of this result is that under the above assumptions there is no magnetic field at all within the inner layer or in the bore of the former. Thus, in the limit of incomplete penetration (of the outer two layers), only the outer two layers carry current, even when there are more than two layers. To compare the helical cable with the case where all the tapes are isolated from one another and share the current equally, one needs to multiply the above current distribution factor to the loss for the cable. In terms of hysteresis power loss per unit length of a cable, $\mathrm{P}_{\text {cable }}$ was found in the limit of incomplete penetration to be 


$$
\begin{gathered}
P_{\text {cable }}=2 \pi D b \cdot 4^{\kappa-1}\left[\cos ^{2 \kappa} \Theta\right. \\
\left.+\left(/ \sin ^{2} \Theta-\cos ^{2} \Theta / / 2\right)^{\kappa}+2^{-\kappa}\right] \cdot Q
\end{gathered}
$$

where $D$ is the diameter of the cable.

In the limiting case of full penetration, the current is equally shared among the tapes so that there is no difference from the situation in which all the tapes of the cable are isolated from one another. In this limit, the power loss per unit length was found to be

$$
P_{\text {cablc }}=L \pi D b \cdot Q \text {, }
$$

where $L$ is the number of layers. Note also that when converting the rms or peak current density to cable current, one needs to use the surface area of the tapes of the outer two layers ( $2 \mathrm{Nab}$ ) in the limit of incomplete penetration, and the total surface area of the cable $(L N a b)$ in the limit of full penetration, where $N$ is the number of tapes per layer and $a$ is the width of a tape.

\section{Comparison of Different Measurement Results}

The calorimetrically and electrically measured ac losses of cable \#3 as a function of rms currents are shown in Fig. 2.1 together with

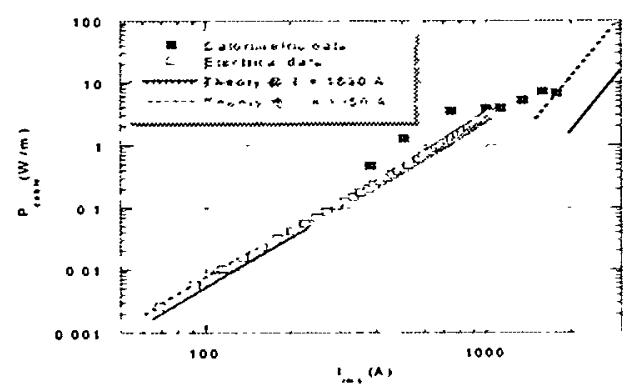

Fig. 2.1. AC loss of cable \#3 measured by two different techniques.
Dresner's theoretical calculations. It is seen that the two sets of data agree with each other reasonably well over the range where the data overlap. As was noted earlier, the electrical measuring technique was more sensitive and data were extended to a far lower loss range. The agreement of the data with Dresner's incomplete penetration asymptote is surprisingly good. Note that Dresner's theory predicted that (for the situation considered) only the outer two layers carry currents in this limit. The data fully confirmed this prediction. Note that the two incomplete penetration asymptotes based on the two different measured $I_{\mathrm{c}} \mathrm{s}$ were drawn to currents where $I_{\mathrm{p}}$ equaled about $90 \%$ of the $I_{\mathrm{c}}$ of the outer two layers. It is interesting to note that the data seemed to follow the same trend beyond these currents.

Figure 2.2 shows similar comparison curves for cable \#9. This cable was built to simulate a 2-layer winding of a 4-layer cable. Namely, the layers were wound with a left-left-right-right pattern. The theoretical curves in Fig. 2.2 were calculated based on a 2-layer cable with double-tape thickness, $2 \mathrm{~b}$. The agreement between the two sets of data is even better. They also agree with the theoretical curves quite well. The two-layer simulation seemed to work. The data also showed an increase in slope of the loss curve toward the complete penetration asymptotes.

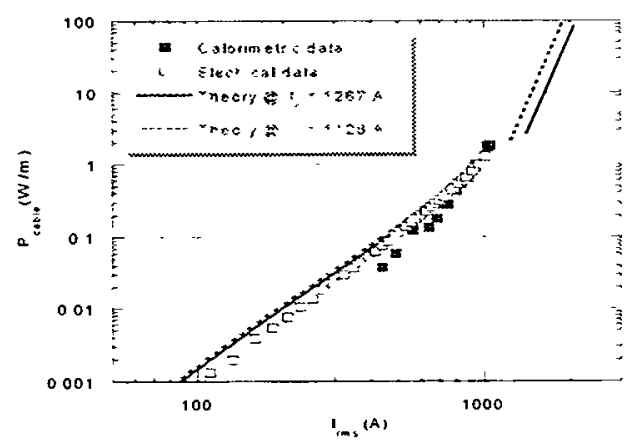

Fig. 2.2. AC loss of cable \#9 measured by two different techniques. 


\section{Comparison of ac Losses of Different Cables}

Figure 2.3 summarizes the ac loss data of the five cables listed in Table 2.1 as a function of the rms currents. It is seen that cables \#3 and \#4 had higher losses than the other three cables at all currents. This might be the result mostly of the damage of these two cables as discussed earlier in the section on current distribution. The data of cables \#5i and \#9 seem to follow parallel curves. The ac loss rates of $1-3 \mathrm{~W} / \mathrm{m}$ were measured at $1 \mathrm{kA}$ rms.

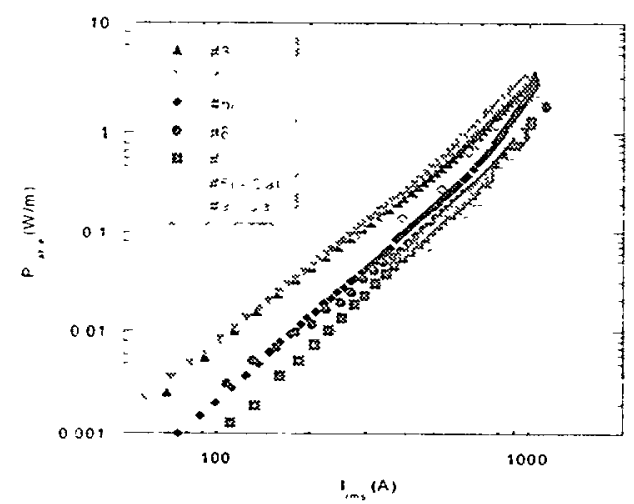

Fig. 2.3. AC loss data of the five different cables. For clarity, electrical data are shown for all cables, and calorimetric data are shown for two cables only.

Equations $I$ and 2 show that the dependence of $\mathrm{P}_{\text {cahlc }}$ on $I_{\mathrm{p}} / I_{\mathrm{c}}$ takes the form:

$$
P_{\text {cathle }} \propto I_{c}^{\alpha} \cdot\left(I_{p} / I_{c}\right)^{\kappa} \text {, }
$$

in the incomplete penetration limit, where $\alpha=$ $(2 n+3) /(n+2)$. Because these prototype cables had different $I_{c} \mathrm{~s}$, in Fig. 2.4 we plot the normalized ac loss, $\mathrm{P}_{\text {cable }} / I_{\mathrm{c}}$ versus $I_{\mathrm{p}} / I_{\mathrm{c}}$ for the cables. Note that $a$ ranged from 1.71 to 1.89 for the present cables - not too far from the critical state model value of 2 . The proportional constant of Eq. 6 depends mainly on the geometric factor of the cable. For clarity, only the theoretical curves for cables \#3 and \#9 were included in the figure for comparison.

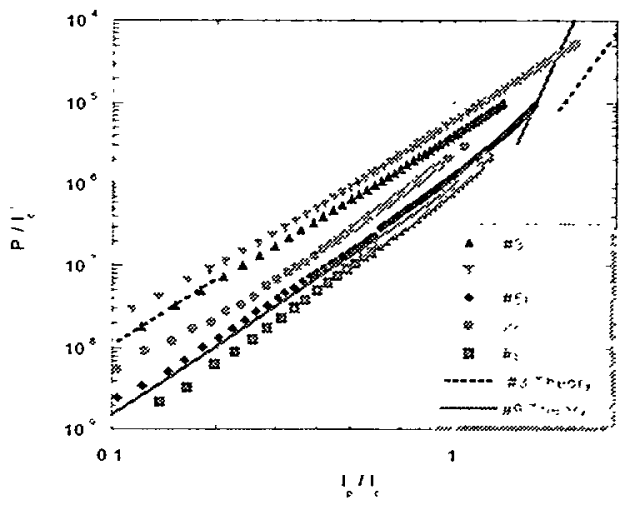

Fig. 2.4 Normalized ac losses vs $I_{\mathrm{p}} / I_{\mathrm{c}}$ of the five different cables. For clarity, only the theoretical curves of cables \#3 and \#9 are shown.

Cable \#4 had the highest normalized ac loss. This may mostly be the result of its particularly low n-value. The two 2-layer cables \#5i and \#9 had the lowest losses. In Fig. 2.3, cable \#8 showed a lower ac loss than cable \#5i. But when its higher $I_{c}$ was discounted, it showed a higher normalized loss in Fig. 2.4. Thus, two layers would result in lower ac loss than four layers. The lower normalized ac loss of cable \#9 than cable \#5i probably came from the tighter winding (as is evidenced from Table 2.1 on the smaller build in cable diameter) of this cable.

\section{Conclusions}

The ac losses of prototype HTS transmission cables were measured with both a calorimetric and an electrical technique. The results of these two measurements compared quite well despite the time lapse and handling of the cables between the two measurements.

Comparison of the loss data with the calculations of Dresner's theory also fared surprisingly well. Dresner's prediction that current flows only in the outer two layers at low currents bears out well. Thus, a cable with just a few layers is desirable. Cables with more layers will not reduce the ac loss at low currents but 
will carry more current. Tight winding of the HTS tapes will also reduce ac loss of the cable.

\section{References}

1. J. W. Lue et al., "Test of two prototype high-temperature superconducting transmission cables," IEEE Trans. Applied Superconductivity 7 (2): 303-05 (1997).

2. J. A. Demko et al., "Test results for different high temperature superconducting transmission cable prototypes," Advances in Cryogenic Engineering 43, in press.

3. L. Dresner, "AC losses in transmission line cables," paper MM2 presented at International Cryogenic Materials Conference (ICMC98), University of Twente, Enschede, Netherlands, May 10-13, 1998, proceedings to be published in Physica $C$.

4. C. Schmidt, "Calorimetric ac loss measurement in the microwatt range: A new simplified measuring technique," Cryogenics 34: 3 (1994).

5. L. Dresner, "Hysteresis losses in power-law cryoconductors, II," Applied Superconductivity 4 (7/8): 337-341 (1996).

\section{Testing of the Dependence of the Number of Layers on the Performance of an HTS Transmission Cable Prototype}

Testing of Southwire's HTS prototype transmission cable \#7 was conducted to determine the dc voltage-current (V-I) characteristics and ac loss with different numbers of layers of HTS tapes. The 1-m-long prototype transmission cable was originally fabricated with four layers of HTS tape. The layer descriptions are provided in Table 2.2. There was insulation between the first layer and the former, and between the second and third layers as indicated by the last column of the table. The four layers of HTS tape were soldered to a copper end plug to which the power supply cables were connected.
Table 2.2. Southwire Company HTS cable \#7 construction details

\begin{tabular}{cccc}
\hline Layer & $\begin{array}{c}\text { Number of tapes } \\
\text { in the layer }\end{array}$ & $\begin{array}{c}\text { Lay angle } \\
\text { (degrees) }\end{array}$ & Insulated \\
\hline 1 & 25 & +29.8 & Yes \\
2 & 26 & -27.7 & No \\
3 & 28 & +28.2 & Yes \\
4 & 29 & -29.2 & No \\
\hline
\end{tabular}

Measurements were made of the dc V-I characteristics and ac loss of the cable as received and after sequentially stripping the outermost layer so that a series of measurements for four-, three-, two-, and one-layer cable configurations were completed. The differences in the cable performance are compared.

\section{Measurements}

A set of dc measurements that consist of the V-I curves and the necessary calibration data for calorimetric measurements of the ac loss were performed on each cable configuration using a 3000-A dc power supply. The calibration data consisted of measuring the temperature rise for dc currents greater than the critical current $\left(I_{c}\right)$. The cable current was measured using a shunt in series with the cable. The cable $I_{c}$ was defined using the criterion $E_{c}=1 \mathrm{mV} / \mathrm{cm}$. The dc V-I characteristics are shown in Fig. 2.5 for cable \#7 with different numbers of layers. As expected, there is a shift to higher voltages at lower currents simply because there is less superconductor in the cable. The $I_{\mathrm{c}}$ also decreases as each layer is removed.

For the one-layer cable, data are plotted for two thermal cycles in order to determine whether there was any thermal degradation of the HTS during the set of experiments. A thermal cycle consisted of a cooldown of the cable from room temperature to a steady-state temperature of liquid nitrogen at atmospheric pressure. The first cycle is actually the fourth thermal cycle undergone by the cable. It is not 


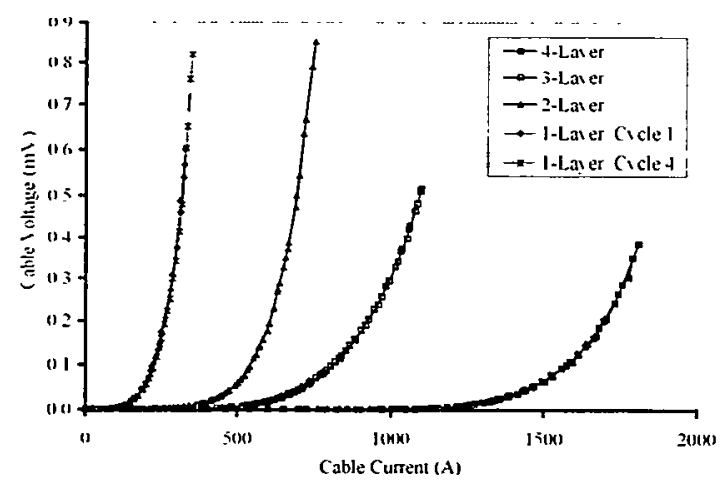

Fig. 2.5. Southwire Company HTS cable \#7 V-I curves for the four-, three-, two-, and one-layer cables.

known whether there was any degradation in the performance of these tapes from the first three cycles. It is evident that no degradation as a result of thermal cycling is indicated during these last four cycles.

As shown in the V-I curves in Fig. 2.5, the cable in all four configurations exhibited the classical power law behavior. In this paper, the resistivity power-law exponent $n$, or $n$-value, is defined for $I>I_{c}$ by the expressions explained in Dresner. ${ }^{1.2}$ These are

$$
\begin{aligned}
& V=C_{1} I^{n-1}, \\
& \rho=C_{2} I^{n} .
\end{aligned}
$$

The $I_{c}$ for each cable configuration and the cable n-values are summarized in Table 2.3. From the table it can be seen that there is a significant drop in the $I_{c}$ of the cable as the outer layers are removed. In addition, the n-value drops by $34 \%$ from the four-layer cable to the three-layer cable. Since the $n$-value is much lower, the resistive transition is much broader. The n-value for the two-layer cable is slightly higher than that for the three-layer cable but is still lower than that for the four-layer cable. The configurations with the odd number of layers had the lowest n-values because they should have the least cancellation of the axial magnetic fields produced by the current flowing in the layers.
Table 2.3. Southwire Company HTS cable \#7 dc characteristics for different numbers of layers in the cable

\begin{tabular}{cccc}
\hline $\begin{array}{l}\text { Layers in } \\
\text { cable }\end{array}$ & $\begin{array}{c}I_{\mathrm{c}} \\
(a)\end{array}$ & $\begin{array}{c}I_{\mathrm{c}} \text { /tape } \\
(\mathrm{A} / \text { tape })\end{array}$ & $\mathrm{n}$ \\
\hline 4 & 1540 & 14.3 & 8.3 \\
3 & 881 & 11.2 & 5.5 \\
2 & 539 & 10.6 & 6.5 \\
1 & 214 & 8.6 & 4.2 \\
\hline
\end{tabular}

The $I_{\mathrm{c}}$ per tape consistently decreases with decreasing number of layers in the cable from 4 to 1 . There are several factors that have been shown to contribute to the degradation of $I_{\mathrm{c}}$ in a transmission cable. These are thermal cycling, mechanical strain from bending around slightly smaller diameters, ${ }^{3.4}$ and magnetic field effects from the neighboring layers. ${ }^{5}$ In addition, damage to the HTS tapes may have occurred during the removal of the G-10 tube, wax, and outer layer of tapes from the sample between each set of measurements.

\section{AC Loss Theories}

Two theoretical approaches to determining the ac loss of a power transmission cable are applied in this work. The monoblock model ${ }^{6}$ is valid for $I_{\mathrm{p}}<I_{\mathrm{c}}$. The monoblock model was formulated assuming that the superconducting tapes that comprise a cable behave like a superconducting monoblock tube. According to the monoblock theory, the ac loss can be calculated using:

$$
\begin{gathered}
P=\frac{f \mu_{0} I_{c}^{2}}{2 \pi h^{2}}\{(2-F h) F h \\
+2(1-F h) \ln (1-F h)\},
\end{gathered}
$$


where

$$
h=\frac{D^{2}-D_{0}^{2}}{D^{2}} \text {, }
$$

and

$$
F=\frac{I_{p}}{I_{c}} .
$$

Also $f$ is the frequency of the applied ac current, $\mu_{0}$ is the magnetic permittivity of free space, $I_{p}$ is the peak current in a cycle, $D$ is the outer diameter of the superconductor, $D_{0}$ is the inner diameter of the superconductor. The monoblock model is based on the critical state model, which corresponds to $n$ equal to infinity.

The second theory applied in this work is by Dresner. ${ }^{1.2}$ The Dresner theory provides for the calculation of the ac loss for $I_{p}<I_{c}$ (incomplete penetration regime) and also where $I_{\mathrm{p}}>I_{\mathrm{c}}$ (extreme full penetration regime). The Dresner theory applies for finite n-values such as observed in empirical V-I curves. In addition, the Dresner theory makes provision for the winding angle of the tapes in each layer. ${ }^{\text {? }}$ Further details of this theory are beyond the scope of this report.

\section{AC Loss Measurements}

The ac loss measurements were performed using the calorimetric approach for all of the cable configurations. For the one-layer cable, however, electrical ac loss measurements were also conducted. In the calorimetric method, the prototype HTS transmission cable is placed inside a G-10 tube. The annular space between the tube and the HTS cable is filled with wax. The ends of the tube are sealed with Stycast 2850 epoxy. Only the copper bus, used to attach the power supply cables, is left outside of the tube. The sample is instrumented with voltage taps and two type-E thermocouples at the middle of the cable. Calibration data consisting of the temperature rise for a known power dissipated in the cable is obtained with dc current for $I>I_{\mathrm{c}}$. The power is determined from the dc voltage and current measurements.

As mentioned previously in this article, the calorimetric measurements are limited for low ac loss measurements at low ac currents by an unresolvable temperature rise and by a thermal runaway situation for high ac losses at high currents. An example of a thermal runaway is presented in Fig. 2.6 for the four-layer cable carrying an ac current of $925 \mathrm{~A}_{\mathrm{nns}}$.

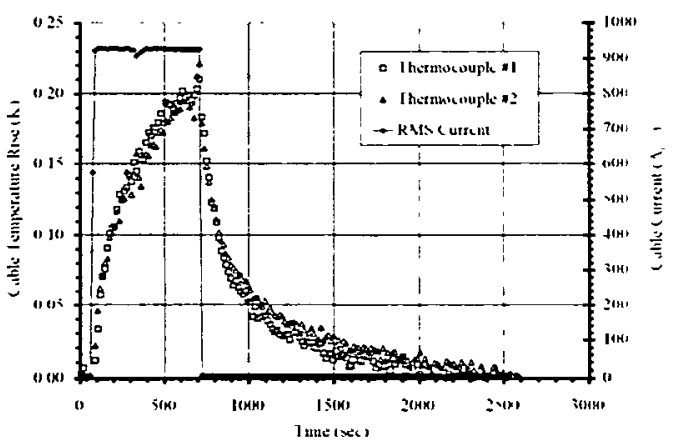

Fig. 2.6. Temperature rise during a thermal runaway of Southwire Company four-layer HTS cable \#7 at I = $925 A_{\text {rms }}$.

Thermal runaway occurs if the cable is operated with inadequate cooling. When a calorimetric method is used for determining the ac loss, a thermally insulating barrier is constructed around the cable in order to provide a measurable temperature rise. For the typical ac loss data presented previously, there is enough heat transfer to the surrounding liquid nitrogen bath to balance the heat generation (ac loss) of the cable so that it reaches a stable temperature. When the cable heat generation (ac loss) is too large, the cable temperature will continue to rise as shown in Fig. 2.6.

The measurements show that it took almost 600 seconds to increase the cable temperature by $0.2 \mathrm{~K}$. This indicates that the HTS cable should respond slowly for small increments of current above some stable operating limit. It is not yet known what the response of the cable would be to a short-duration, high-current pulse. 
The electrical ac loss measurements are conducted using a lock-in amplifier to measure the total voltage across the sample, the current. and the angle $q$ between these two vectors. A suitable reference signal for the lock-in is obtained from a Rogowski coil. The ac loss is then given by the following:

$$
P=V I \cos \theta \text {. }
$$

In Fig. 2.7. the ac loss measurements are plotted against the root mean square cable current, $\mathrm{I}_{\text {nus. }}$. As would be expected, the ac loss at a particular current is higher for the cables with fewer layers largely because there are fewer tapes in the cable.

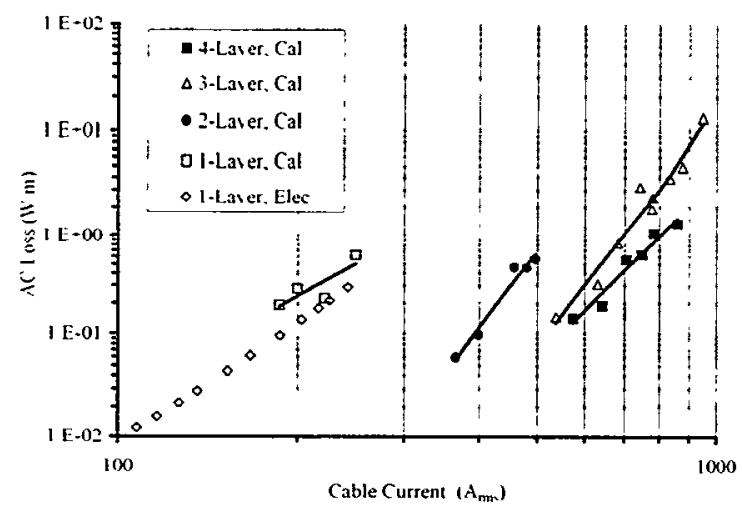

Fig. 2.7. Southwire Company HTS cable \#7 ac loss measurements for four-, three-, two-, and one-layer configurations.

For the one-layer cable, both calorimetric and electrical ac loss data are shown in the figure. The agreement between the two techniques is fair. The electrical method has better resolution of lower ac losses and does not have as much scatter in the data as the calorimetric method.

In Fig. 2.8, the ac loss data, scaled by the critical current squared, are plotted against the ratio of the peak current in the cycle $I_{\mathrm{p}}$, to the cable critical current. $I_{c}$. The scaled current indicates how far the peak current in a cycle is into the resistive part of the $\mathrm{V}$-I curve. When the data fall below $I_{\mathrm{p}} / I_{\mathrm{c}}=1$, the cable is super-

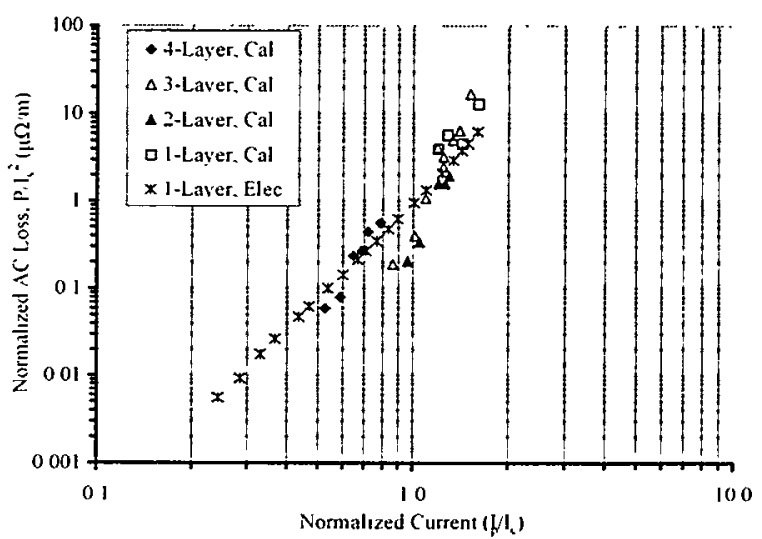

Fig. 2.8. Southwire Company HTS prototype cable \#7 normalized ac loss comparison for four-, three-, two-, and one-layer configurations.

conducting throughout the whole ac cycle. All of the data for the four-layer cable fall below $I_{\mathrm{p}} / I_{\mathrm{c}}=1$. All of the calorimetric data for the one-layer cable are above this point. The one-layer electrical data and two-, and three-layer calorimetric data points fall on both sides of this line. According to the Dresner theory there should be a change in the slope of the ac loss curve from the incomplete penetration $\left(I_{\mathrm{p}} / I_{\mathrm{c}}<1\right)$ to the fully complete penetration regime $\left(I_{\mathrm{p}} / I_{\mathrm{c}}>1\right)$. There is sufficient scatter in these data that this trend is not clearly observed in this figure. With these scaling parameters, the data fall within a narrow band on the graph. Thus, the scaled ac losses are similar for all four cable configurations.

The ac loss measurements for the one-layer and four-layer configuration are compared with the previously discussed theories in Fig. 2.9. The four-layer cable is typical of many power transmission cable prototypes. The one-layer results provide an important special case for theoretical development and comparisons.

The agreement between the calorimetric data and both monoblock and Dresner theories for the four-layer cable is acceptable. The monoblock model results in slightly higher losses than the Dresner theory for the incomplete regime. As displayed in Fig. 2.8, all 


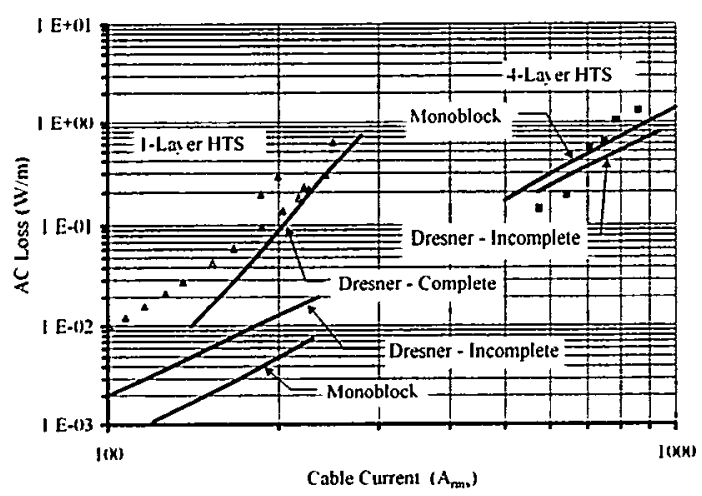

Fig. 2.9. Comparisons of four-layer and one-layer cable configuration ac loss measurements with monoblock theory and Dresner theory.

the data for the four-layer cable fall below $I_{\mathrm{p}} / I_{\mathrm{c}}=1$ so the HTS cable is superconducting for the entire ac cycle. For these data, both the monoblock and Dresner incomplete regime theories provide slopes in the ac loss curves that are in agreement with the measured data.

For the one-layer cable, all of the calorimetric data falls above $I_{\mathrm{p}} / I_{\mathrm{c}}=1$ and some of the electrical measurements were below this condition. It is seen that the Dresner theory results in higher ac loss predictions and agrees with the measured data better than the monoblock model for the one-layer configuration. Also the slope predicted by the Dresner complete penetration regime theory agrees with the slope of the calorimetric data. For the low current data $\left(I_{\mathrm{p}} / I_{\mathrm{c}}<1\right)$ both the Dresner theory and monoblock theory predict slopes that are parallel to the data but underpredict the magnitude of the ac losses.

\section{Summary}

Measurements of the dc V-I characteristics and the ac loss have been made on Southwire Company cable \#7 in the original four-layer configuration and by sequentially stripping the outer layer to make a three-, two-, and one-layer cable. The results indicate that the four-layer cable carried the highest current (as expected). The calorimetric and electrical ac loss measurements were in agreement for the one-layer cable. The electrical method provides higher sensitivity at lower currents and the sample preparation is much simpler than with the calorimetric method.

The measured ac loss data were scaled using the critical current squared. The scaled ac loss of the HTS prototype transmission cables were similar in the four-, three-, two-, and one-layer configurations.

The measured data for the four-layer and one-layer cable were compared against calculations using both the monoblock model and the Dresner model. Both models predicted the ac loss well for the four-layer cable where $I_{\mathrm{p}} / I_{\mathrm{c}}<1$. For the one-layer case, both the monoblock model and the Dresner model give lower than measured ac losses. The Dresner model comes closer to the data and is able to predict losses in both regimes where $I_{\mathrm{p}} / I_{\mathrm{c}}<1$ as well as for $I_{\mathrm{p}} / I_{\mathrm{c}}>1$.

The HTS cable had a long response time for small current increases over some stable operating limit. Additional work is required to understand the response of a HTS cable to shortduration high-current pulses.

\section{References}

1. L. Dresner, "Hysteresis losses in power law cryoconductors," Applied Superconductivity 4(4): 167-72 (1996).

2. L. Dresner, "Hysteresis losses in power law cryoconductors, part II," Applied Superconductivity 4(7/8): 337-41 (1996).

3. J. W. Lue, M. S. Lubell, E. C. Jones, J. A. Demko, D. M. Kroger, P. M. Martin, U. Sinha. and R. L. Hughey, "Test of two prototype high-temperature superconducting transmission cables," IEEE Transactions on Applied Superconductivity 7(2): 302-05 (June 1997).

4. J. W. Lue, J. A. Demko, M. S. Lubell, M. Tomsic, and U. Sinha, "Development of strengthened bundle high temperature superconductors," Advances in Cryogenic Engineering 43 (in press). 
5. J. A. Demko, J. W. Lue, M. S. Lubell, U. Sinha, J. Tolbert, and L. Dresner, "Test results for different high temperature superconducting transmission cable prototypes," Advances in Cryogenic Engineering 43 (in press).

6. G. Vellego and P. Metra, “An analysis of the transport losses on HTSC single-phase conductor prototypes," Supercond. Sci. Technol. 8: 476-83 (1995).

7. L. Dresner, "AC losses in transmission line cables," paper MM2, International Cryogenic Materials Conference (ICMC'98), University of Twente. Enschede, Netherlands. May 10-13, 1998, proceedings to be published in Physica $C$.

\section{HTS Cable Test Facility Design And Initial Results}

A versatile. HTS cable test facility has been designed and built at ORNL in a joint program between ORNL and Southwire Company under a U.S. Department of Energy Superconducting Partnership Initiative. The facility mission is to evaluate the performance of prototype HTS power transmission cables at lengths in the 1 to $5+$ meter range including cable joints. Data from the facility will be used to design a three-phase, 30-m HTS power transmission line. Power supplies are available for steady-state currents of $3000 \mathrm{~A} \mathrm{(dc)} \mathrm{and} 2000 \mathrm{~A} \mathrm{(ac)}$ and for currents up to $25.000 \mathrm{~A}(\mathrm{dc}$ ) for pulsed loading (all at low voltage). Cryogenic cooling is provided by an Air Products liquid nitrogen supply system with the design capability of providing about a kilowatt of cooling at nitrogen pressures up to 10 bar over a temperature range of about 67 to $77 \mathrm{~K}$ (via a subcooler pumped by an adjacent standard mechanical vacuum pump).

Electrical and cryogenic data are taken by dedicated sensors scanned by three 10-channel multimeters connected via cable (for lowvoltage signals) and fiberoptic (for signals with the potential to be at high voltage) to a PC-based. data-acquisition system using the
LabView program. These diagnostics allow measurement of the dc V-I characteristics and the ac losses of the cable, dielectric integrity via a partial discharge measurement, and cryogenic performance at rated voltage $(7.2 \mathrm{kV}$ ac rms) and current $(1250 \mathrm{~A})$. A high-voltage power supply is available (rated at $100 \mathrm{~mA}$ at $100 \mathrm{kV}$ ) to test the cable at a peak voltage level of 2.5 times the operating voltage.

\section{Facility Description}

The facility (a sketch is provided as Fig. 2.10) is located in an enclosed room in the high bay area on the second floor of Building 9201-2 in the Y-12 Plant at ORNL. The 5-m HTS cable is between two terminations, one on the east end of the facility, the other on the west end. The 5-m HTS cable is housed in a stainless steel pipe that contains the nitrogen used for cooling (pressure of $1-10$ bar, temperature $67-77 \mathrm{~K}$ ). Each termination has two main feedthroughs, one making the transition from ambient (295 K) to vacuum (295 K) and the

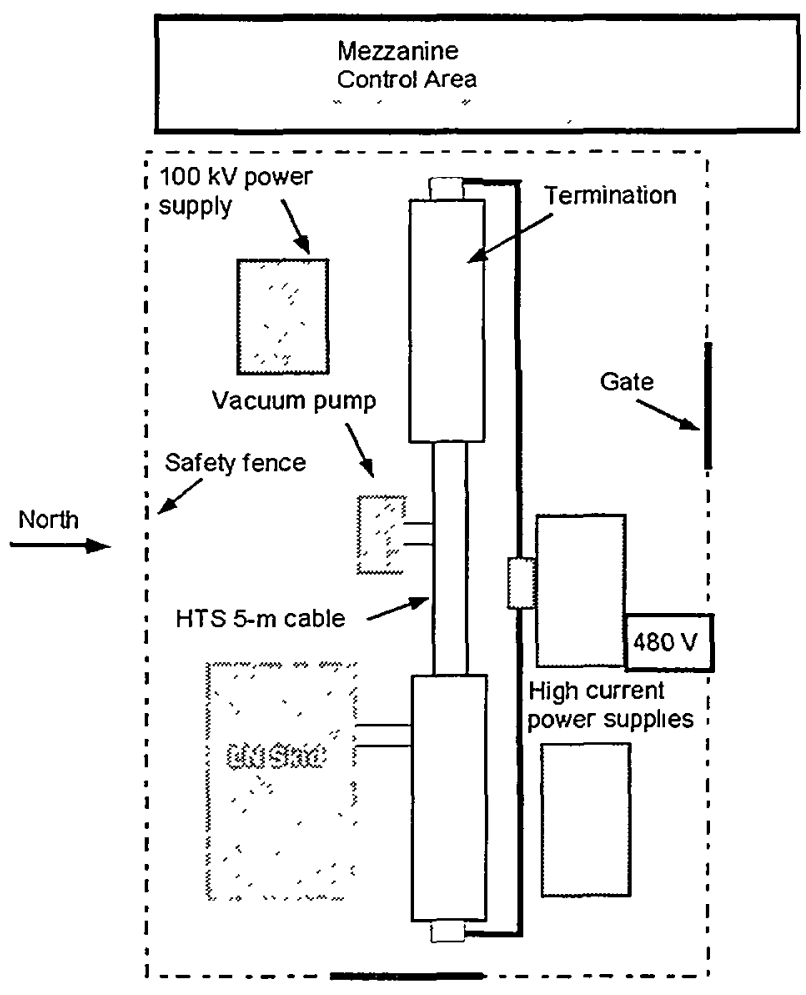

Fig. 2.10. Facility layout. 
second making the transition from vacuum to subcooled $(67-77 \mathrm{~K})$ liquid nitrogen at 1-10 bar. These feedthroughs will be rated for full cable current and voltage. There are also similar but slightly smaller feedthroughs in each termination for the HTS outer (shield) cable which is rated for full cable current. The two terminations are pumped through a common 6-in. vacuum header by a mechanical/ turbomolecular pumping station shown in Fig. 2.10; typical vacuum is in the $10^{-5}$ to $10^{-4}$ Torr range which is sufficient for thermal insulation when combined with multiple layers of superinsulation.'

The power supplies shown in Fig. 2.10 are driven by the $480-\mathrm{V}$ welding outlet on the north wall of the facility and provide steady-state currents of $3000 \mathrm{~A}(\mathrm{dc})$ and $2000 \mathrm{~A}$ rms (ac). Because they are driven by the same outlet, only one supply will be used for a given operation or experiment. The dc supply is connected to each termination by insulated copper cables rated for the supplied current. The ac supply consists of a variac (driven by the $480-\mathrm{V}$ outlet) that connects to a transformer. The secondary of the transformer is a long, insulated copper cable running from the east to west termination and threading through the transformer shown in Fig. 2.10.

The liquid nitrogen skid provides cooling (nominally $1 \mathrm{~kW}$ at $67-77 \mathrm{~K}$ ) for the HTS cable and the two terminations. Figure 2.11 , which is a photograph of the test facility, shows the skid in the background with the insulated piping. There are two nitrogen dewars (the 180-L pressure dewar and a $240-\mathrm{L}$ auxiliary dewar rated for 16-bar internal pressure) that operate at up to 10-bar pressure to maintain overall system pressure in the skid and cable. There is another 160- $\mathrm{L}$ dewar containing a heat exchanger coil used as a subcooler. The shell side is pumped by the skid vacuum pump (rated at $200 \mathrm{~m}^{3} / \mathrm{h}$ ) to maintain the nitrogen bath temperature in the range $67-77 \mathrm{~K}$. The process cooling fluid (nitrogen at 1-10 bar) flows through the tube side of the subcooler and is cooled below $77 \mathrm{~K}$ prior to entering the cable supply manifold.

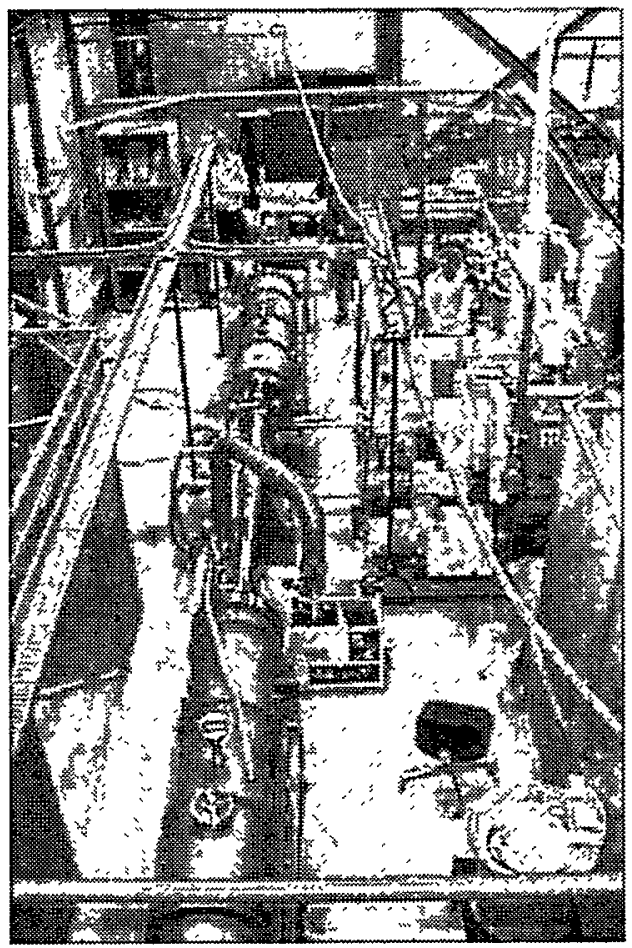

Fig. 2.11. Photograph of test facility.

Nitrogen leaving the cable/terminations flows to the inlet of the circulation pump which provides the pressure head for the closed loop flow of the $1-10$ bar nitrogen. There is a $41,600-\mathrm{L}$ liquid nitrogen tank outside the building (that is maintained at about 4-5 bar) to supply nitrogen for initial fill of the pressure and auxiliary dewars; to replenish gaseous nitrogen pumped from the subcooler bath by the skid vacuum pump; and to make up small, intrinsic mass losses, such as nitrogen gas, through the recirculation pump labyrinth seal. The control area on the mezzanine contains two of the three ten-channel multimeters used for low-voltage data acquisition, a PC with LabView, a video monitor that views the skid control panel, the interlocked (with the fence gates) control unit for the high-voltage power supply, and the partial discharge unit.

\section{Initial 5-m Cable Data}

The single-phase, 5-m cable (see Fig. 2.12) is a prototype of the longer $30-\mathrm{m}$, three-phase, cable to be tested in late 1999 at the Southwire 


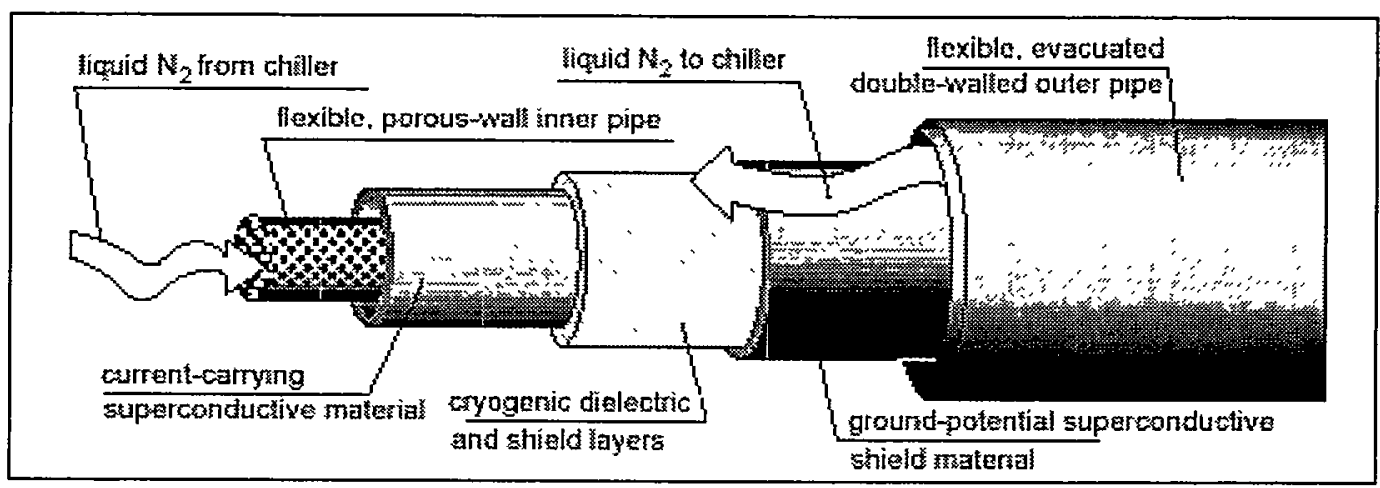

Fig. 2.12. Cable cross section.

Company cable manufacturing complex in Carrollton. Ga. The inner cable conductor consists of four layers of helically wound, Bi-2223/Ag tapes supplied by Intermagnetics General. Four layers were chosen to provide enough capability for the design current of $1250 \mathrm{~A}$. The tapes were machine-wound at a 30-degree angle (to optimize ac losses) on a stainless steel former with an outer diameter of $38 \mathrm{~mm}$. The layer winding sequence is ++--. Cryoflex dielectric tape is wrapped in 16 layers between the inner and outer HTS conductors. The outer HTS cable conductor is similar to the inner conductor and provides shielding of the currents flowing on the inner conductor and thus eliminates magnetic fields or eddy currents in the external structure. The outer HTS cable conductor is at ground potential.

The facility was cooled down to the range $74-84 \mathrm{~K}$. Figure 2.13 shows a typical cooldown interval. The higher end of this range was achieved simply by using liquid nitrogen from the large external tank; the lower end was achieved using the liquid nitrogen skid. In this configuration, the $160-\mathrm{L}$ subcooler dewar was pumped by a mechanical vacuum pump to provide a bath of subcooled nitrogen. The pressurized nitrogen on the tube side of the subcooler heat exchanger is used to cool the two terminations and cable. This pressurized, subcooled nitrogen is circulated in a closed loop by a $2.3-\mathrm{kW}$ recirculation pump. In the testing reported in the next discussion, the total heat load of the system was determined by measuring the boil-off of subcooled nitrogen in the subcooler dewar with no make-up flow. Boil-off rates of $0.5-0.6$ volume $\% / \mathrm{min}$ corresponded to a total heat load of 2.5 to $3 \mathrm{~kW}$. The incremental heat load of the cable and two terminations is small; based on a simple measurement of change in the subcooler nitrogen boil-off rate, it is less than $500 \mathrm{~W}$.

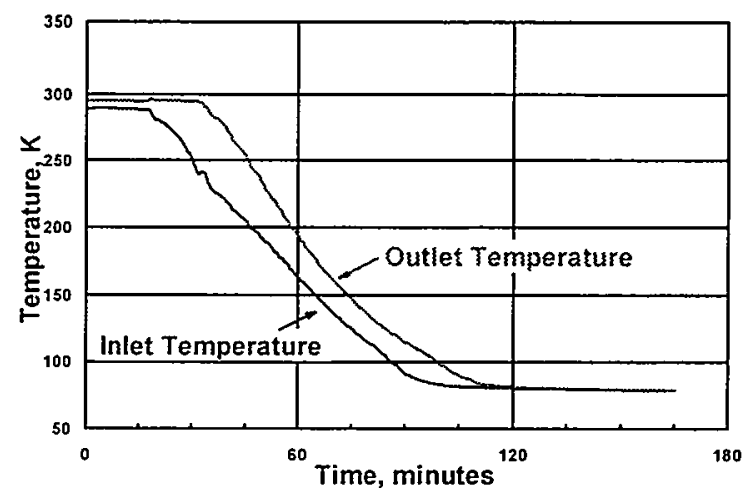

Fig. 2.13. Typical cooldown transient.

A series of dc voltage-current scans was performed to characterize the critical current for this 5-m cable (defined as the point where the cable voltage drop is $1 \mu \mathrm{V} / \mathrm{cm}$ ). A typical curve is shown in Fig. 2.14 for an average cable temperature of $74.5 \mathrm{~K}$. The measured curves of resistivity (proportional to voltage drop), $\rho$ of HTS tapes versus current density, $J$, can be reasonably well fitted by a power law: $\rho=k \times J_{\mathrm{n}}$. Using this power law dependence, Dresner ${ }^{2}$ calculated hysteresis losses in slab superconductors. The curve in Fig. 2.14 was 


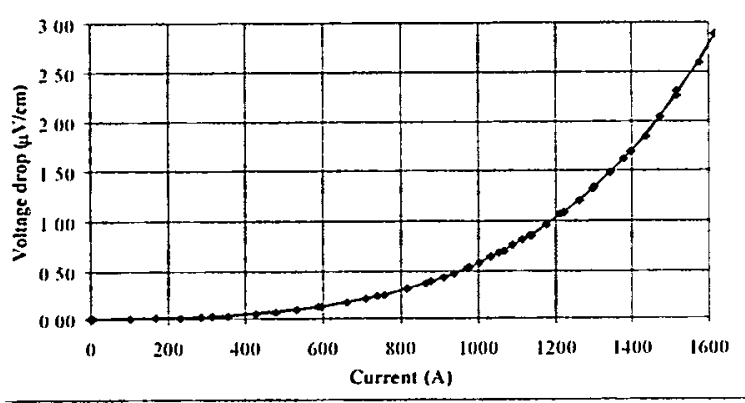

Fig. 2.14. DC voltage-current scan at $74.5 \mathrm{~K}$.

fitted to a power law dependence of the voltage drop (cable resistance) to the cable current with an exponent $n=2.9$ over a current range of 500-1200 A.

Several of these curves were generated over cable temperatures in the range $74-83 \mathrm{~K}$ by varying the vacuum level in the subcooler. As shown in Fig. 2.15, the critical current increases nearly linearly as the cable temperature is decreased. For cable temperatures below about $73 \mathrm{~K}$, the experimental curve extrapolates to critical currents above the design current of $1250 \mathrm{~A}$. There is a tradeoff between lowering cable critical currents and ac losses as temperature decreases by subcooling the nitrogen coolant and the complexity and parasitic power losses of the high throughput pumping system used to achieve the vacuum levels required for subcooled operation.

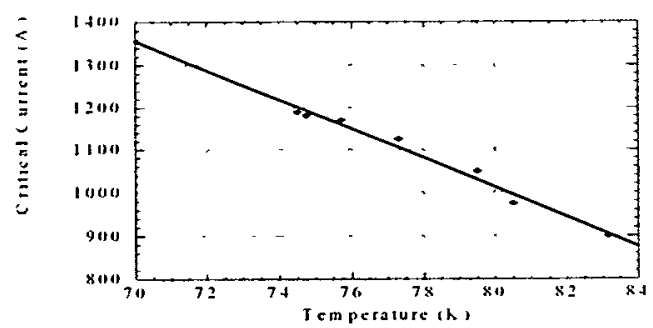

Fig. 2.15. Cable critical current as a function of temperature.

The voltage drop along the cable and the phase angle $f$ between the current and voltage was measured as a function of ac rms current with a calibrated Rogowski coil with an integrator as the reference signal to a lock-in amplifier. The resistive power losses were then calculated, normalized to the cable length and plotted as a function of rms current in Fig. 2.16. The exponent of ac loss dependence on current calculated from the Dresner model ${ }^{2}$ in the limit of incomplete current penetration is $(3 n+4) /(n+2)$ and is $n+2$ for complete penetration.

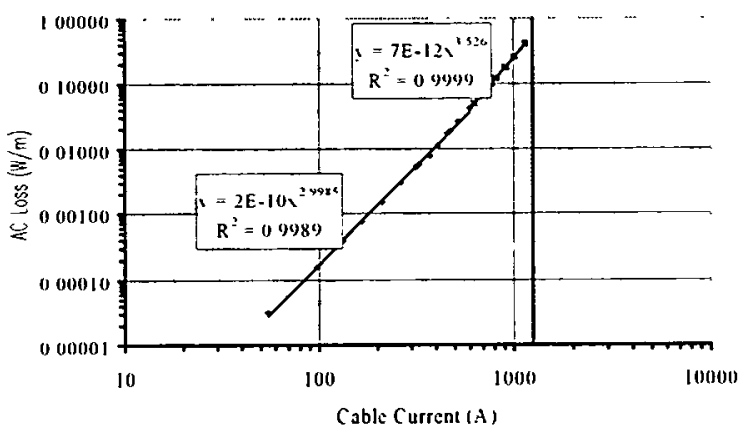

Fig. 2.16. Cable ac losses as a function rms current.

Using a value of $n=2.9$ from Fig. 2.14 data, the expected power dependence is about 2.6 in the low-penetration region and 4.9 in the highpenetration region. The actual fit to the data in Fig. 2.16 is with an exponent 2.99 in the lowpenetration region; this agrees fairly well with the Dresner model and is almost exactly the value of 3 predicted by simple critical state models. The exponent of 3.9 at higher current levels in Fig. 2.14 cannot be compared directly with theory because these currents are in a transition region before full penetration. The cable temperature was about $76 \mathrm{~K}$. As can be seen from a slight extrapolation to the design current of $1250 \mathrm{~A}$, the ac losses are still less than $1 \mathrm{~W} / \mathrm{m}$-phase, which was the one of the design goals of the cable project. These results are consistent with earlier measurements on $1-\mathrm{m}$, hand-wound, prototype HTS cables. ${ }^{3.4}$ Note that unoptimized thermal losses from a $77 \mathrm{~K}$ cable are expected to be several W/m-phase.

The low-voltage part of the test program has been completed and the 5-m cable has met or exceeded all performance parameters providing confidence in the basic design approach. The 
next 5-m cable testing phase will begin

following a brief opening to replace the existing feedthroughs with new designs rated for $20 \mathrm{kV}$.

\section{References}

1. J. A. Demko, "Cryogenic multi-layer insulation." Cold Facts, newsletter of the Cryogenic Society of America, 14(2) (1998).

2. L. Dresner, "AC losses in transmission line cables." paper MM2 presented at the International Cryogenic materials Conference (ICMC'98), University of Twente, Enschede, Netherlands. May 10-13, 1998, proceedings to be published in Physica $C$.

3. J. W. Lue, J. A. Demko, L. Dresner, U. Sinha, and J. C. Tolbert, "AC losses of prototype HTS transmission cables." to be published in IEEE Trans. on Applied Superconductivity (1999).

4. J. A. Demko. J. W. Lue, U. Sinha, R. L. Hughey. L. Dresner, and S. K. Olsen, "Testing of the dependence of the number of layers on the performance of a HTS transmission cable prototype." to be published in IEEE Trans. on Applied Superconductivity (1999).

\section{Electrical Dielectric Testing}

Southwire has developed a proprietary tape dielectric, Cryoflex ${ }^{\mathrm{TM}}$. as a cryogenic dielectric. During the year, a series of ac sheet sample breakdown tests have been completed on Cryoflex ${ }^{\mathrm{TM}}$ to identify its electrical strength, and modifications have been made to improve the testing procedures. The breakdowns have been completed on sheet samples at cryogenic temperatures and pressures above atmospheric. A model cable test facility and testing apparatus, also capable of testing model cables at cryogenic temperatures and pressures above atmospheric, has been under construction during the year. Further information on electrical dielectric testing can be found in "Insulation Studies at ORNL in Support of Superconducting Power Applications" on p. 2-20.

\section{SUPERCONDUCTING TRANSFORMER PROJECT}

\section{Final Assembly of 1-MVA Transformer at Waukesha Electric Systems}

\section{Final assembly of the 1-MVA} demonstration transformer was completed at the Waukesha Electric Systems (WES) main plant during the first part of FY 1998. ORNL and IGC personnel worked closely with the WES engineers and crafts during this period.

Figure 2.17 is a schematic of the 1-MVA design. The responsibilities of the various team members for the major subassemblies are also indicated. The coils are wound with about 1400 m of IGC's low-cost coated Bi-2212 conductor on fiberglass mandrels and cooled to $25 \mathrm{~K}$ with a closed-cycle cryocooler. The windings incorporate several innovations to reduce ac losses. The high-voltage winding is rated at $72.5 \mathrm{~A}$ and $13.8 \mathrm{kV}$ rms and contains 288 turns. The low-voltage winding is rated at $145 \mathrm{~A}$ and $6.9 \mathrm{kV} \mathrm{rms}$, and contains 144 turns. A liquid-nitrogen-cooled heat shield surrounds the windings. The shield is built in four electrically insulated quadrants so that it will not act as a shorted turn around the core. $A$ superinsulated, horizontal LN supply tank is supported above the shield by struts attached to

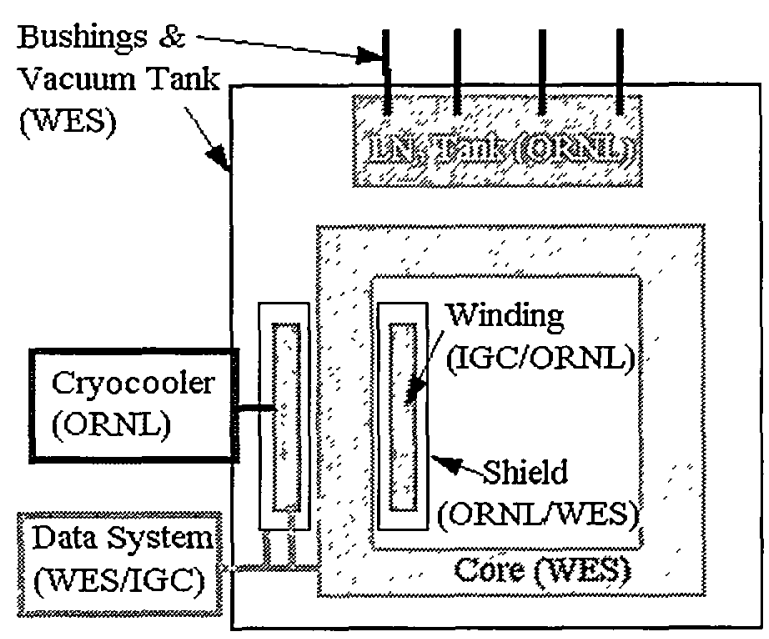

Fig. 2.17. Schematic of the 1-MVA transformer. 
the upper-core clamp structure. Four vertical ducts extend from the vessel body to the top of the vacuum tank. The high-voltage bushings and winding electrical leads enter the vessel through these ducts. The LN bath thus serves to heatsink the leads to $77 \mathrm{~K}$. The leads exit the tank through a feedthrough at the bottom and continue to the winding. The laminated steel core is enclosed in the vacuum tank with the cryogenic components and has its own cooling system. Figure 2.18 is a photo of the completed assembly, ready for installation in the vacuum tank.

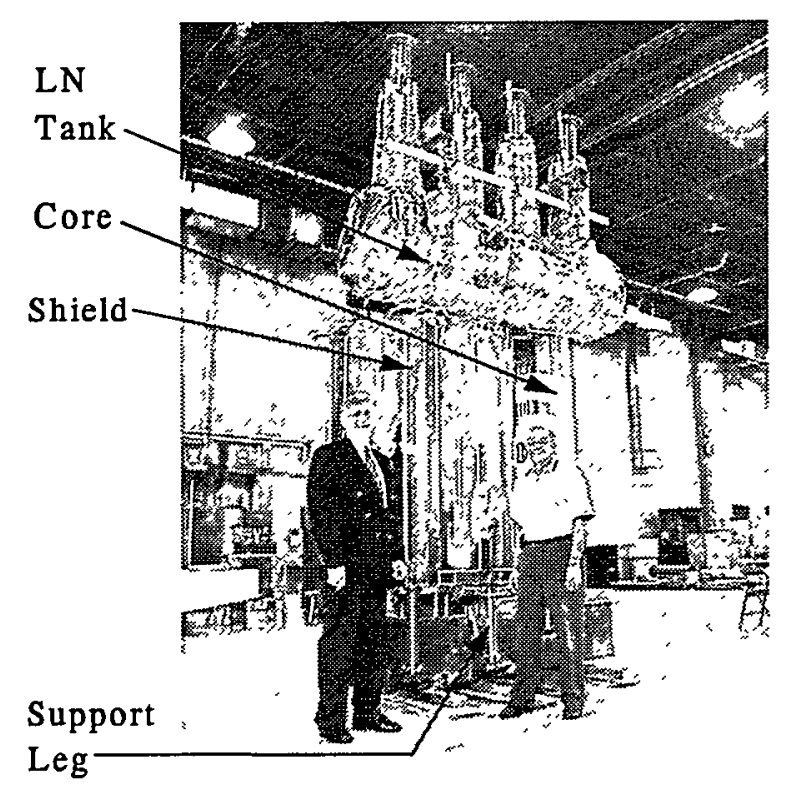

Fig. 2.18. Completed 1-MVA transformer assembly before tanking.

The major assembly activities included:

1. Leak check of all subassemblies

2. Electropolishing the LN shield segments to reduce radiation heat loads

3. Installation and insulation of winding current leads

4. Mounting the assembled winding and shield on the core

5. Assembly of the upper core limb and clamps

6. Mounting the $\mathrm{LN}$ tank on the upper core clamps

7. Mounting the cryocooler on the vacuum tank
8. Interconnection of the LN shield and LN tank piping

9. Completion of winding cooling connections 10. Installation of the completed winding/core assembly into the vacuum tank

11. Interconnection of all piping and instrumentation wiring with vacuum tank interfaces

12. Final leak checks on the completed transformer

13. Assembly and checkout of the dataacquisition system

\section{Testing}

\section{Evacuation and Cooldown}

Test runs on the 1-MVA transformer were carried out at WES during February and March of 1998. Figure 2.19 shows the completed transformer during the tests. Evacuation of the tank to the $10^{-3}$ Torr range took 4 days. Leak checks showed only a small leak in the nitrogen in the $10^{-5}-\mathrm{atm}-\mathrm{cm}^{3} / \mathrm{s}$ range, which was not considered significant enough to repair. After cooldown and fill of the LN tank and shield, precooling of the winding was started with $\mathrm{LN}$. After 4 days, the windings reached $125 \mathrm{~K}$. The precooling rate was limited by a maximum winding temperature differential of $75 \mathrm{~K}$, which was imposed to reduce the chance of damage. At this point, the nitrogen was shut off and the cryocooler was started. Over the next four days, the cryocooler reduced the $1200-\mathrm{lb}$ cold mass

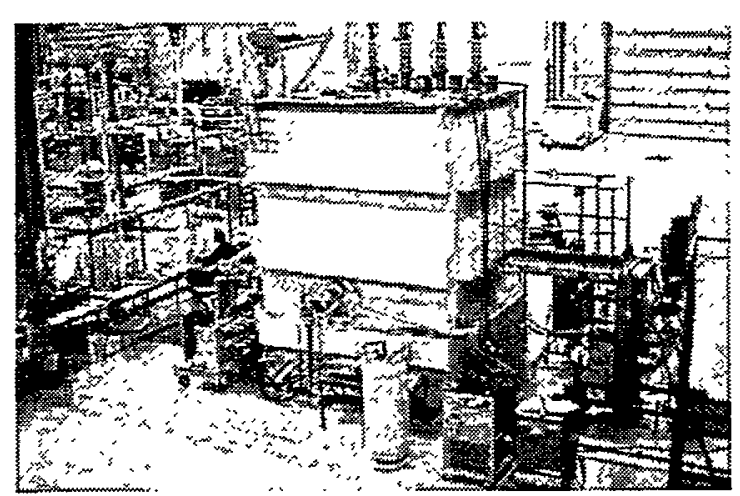

Fig. 2.19. Overall view of completed transformer on test at Waukesha. 
temperature to the $20-\mathrm{K}$ range, and the tank vacuum improved to $2.2 \times 10^{-6}$ Torr. After cooldown was complete, the $\mathrm{LN}$ consumption rate was about $160 \mathrm{~L}$ per day. Figure 2.20 shows a plot of the winding temperatures and voltages with a small dc current vs time. Although the transition temperature of the $\mathrm{Bi}-2212$ material is about $80 \mathrm{~K}$, the voltage began to drop rapidly at $100 \mathrm{~K}$ because much of the winding was colder than the sensors plotted here.

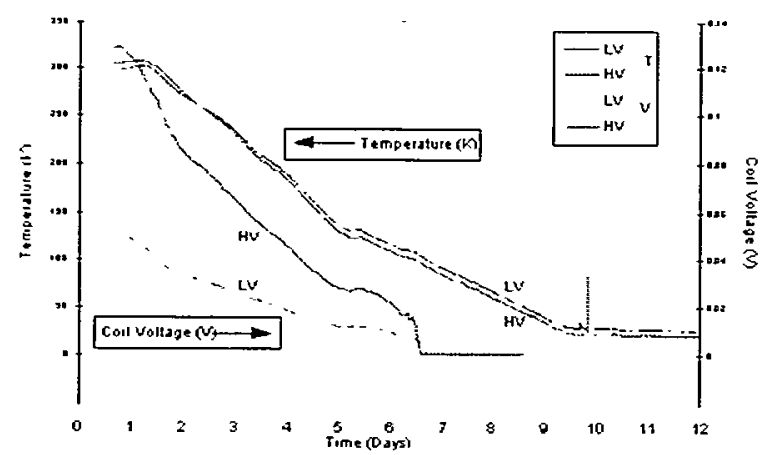

Fig. 2.20. Winding cooldown temperatures and voltages vs time.

\section{Electrical Tests}

The transformer was subjected to shortcircuit, open-circuit, and load tests with simultaneous current and voltage. Table 2.4 summarizes the results. Preliminary tests in Section a, including ratio, capacitance, dissipation factor, and sensor operation indicated that the winding insulation and instrumentation were good.

\section{Short-Circuit Tests}

To determine the transformer fault impedance, short-circuit tests were performed in $\mathrm{HV}$-winding current increments of $10 \mathrm{~A}$, starting at $10 \mathrm{~A}$. Each increment of current was held for several minutes. Typical voltages at three values of current are shown in Section b of Table 2.4. As expected, the dependence of voltage on current was linear within $0.3 \%$. The percent fault impedance is defined as

$$
\begin{gathered}
\% I_{z}=100 \times\left(V_{\text {shon }}\right) /\left(V_{\text {rated }}\right)= \\
100 \times(232 V) /(13800 V)=1.68 \%,
\end{gathered}
$$

where $V_{\text {shor }}$ is measured at full rated current. This is slightly smaller than the design value of $2 \%$.

Figure 2.21 shows temperatures at several points in the winding as well as the high-voltage winding current during the short-circuit tests. When the current exceeded about half rated value, strong ac loss heating began to appear at several points in the winding. After reaching the rated current of $72.5 \mathrm{~A}$, with all temperatures rising, the current was reduced to half this value. Temperatures in all winding sections then dropped or slowed their rise toward equilibrium levels. All temperatures dropped when the current was reduced to zero. The local ac losses at each thermometer location were estimated by comparing the observed temperature rises with those produced by currents in stainless steel heater tapes that were co-wound with the HTS conductor. An estimate of the total losses at half rated current, obtained by integrating crudely over the estimated local losses, corresponds approximately to the 20 to $30 \mathrm{~W}$ of cooling available from the cryocooler at the temperature of the test.

\section{Open-Circuit and Load Tests}

A tuned resonant circuit shown in Fig. 2.22 was used for load tests. This circuit allowed tests with full reactive power without supplying heavy real power. A $1200-k V A R$ capacitive load was connected across the low-voltage winding, and a tunable tapped air-core inductor was placed in parallel with the high-voltage winding. Open-circuit voltages were stepped up in 1-kV increments, with a 5-min hold at each level. Section c of Table 2.4 shows the open-circuit exciting currents and the corresponding percentages of operating current. Core loss as 
Table 2.4. Summary of electrical tests

\begin{tabular}{lccc}
\hline & a. Preliminary tests & \\
& Ratio & $\begin{array}{c}\text { Capacitance } \\
(\mathrm{pF})\end{array}$ & $\begin{array}{c}\text { Dissipation } \\
\text { Factor } \\
(\%)\end{array}$ \\
\hline HV to LV & 2.000 & 1297 & 0.16 \\
HV to ground & -- & 610 & 0.20 \\
LV to ground & -- & 708 & 0.11 \\
\hline
\end{tabular}

b. Short-circuit test

\begin{tabular}{ccc}
$\begin{array}{c}\text { Voltage } \\
(\mathrm{rms})\end{array}$ & $\begin{array}{c}\text { V Current } \\
\text { (A rms) }\end{array}$ \\
\hline (Impedance=1.68\%) & 64.7 & 20.2 \\
& 160.5 & 50.0 \\
& 232.0 & 72.2 \\
\hline
\end{tabular}

\begin{tabular}{|c|c|c|c|c|}
\hline \multicolumn{5}{|c|}{ c. Open-circuit test } \\
\hline & $\begin{array}{l}\text { Voltage } \\
(\mathrm{kV} \text { rms })\end{array}$ & $\begin{array}{l}\text { Current } \\
\text { (A rms) }\end{array}$ & $\begin{array}{l}\% \text { Rated } \\
\text { current }\end{array}$ & $\begin{array}{l}\text { Loss } \\
(W)\end{array}$ \\
\hline \multirow{4}{*}{$\begin{array}{l}\text { (Losses from in-phase } \\
\text { component) }\end{array}$} & 7.0 & 0.29 & 0.40 & 856 \\
\hline & 8.0 & 0.34 & 0.47 & 1085 \\
\hline & 9.0 & 0.40 & 0.55 & 1378 \\
\hline & 10.0 & 0.48 & 0.66 & 1645 \\
\hline \multicolumn{5}{|c|}{ d. Load test } \\
\hline & $\begin{array}{c}\text { Voltage } \\
\text { (kV rms) }\end{array}$ & $\begin{array}{l}\text { Current } \\
\text { (A rms) }\end{array}$ & MVA & \\
\hline & 6.4 & 39 & 0.25 & \\
\hline & 8.0 & 49 & 0.39 & \\
\hline
\end{tabular}

measured by a wattmeter is also shown. Note that the loss is not equal to the product of exciting current and voltage because it includes only the in-phase voltage component. As expected from classical transformer circuit models, the loss is closely proportional to the square of the exciting voltage. Extrapolation of the loss curve to the rated $13.8 \mathrm{kV}$ gives $2800 \mathrm{~W}$, or $0.28 \%$ of the rated power.

After each three or four $1-\mathrm{kV}$ steps, a load test was performed at a voltage $1 \mathrm{kV}$ below the highest previous open-circuit voltage. This was done to minimize the chance of a voltage breakdown in a power test, where the stored 


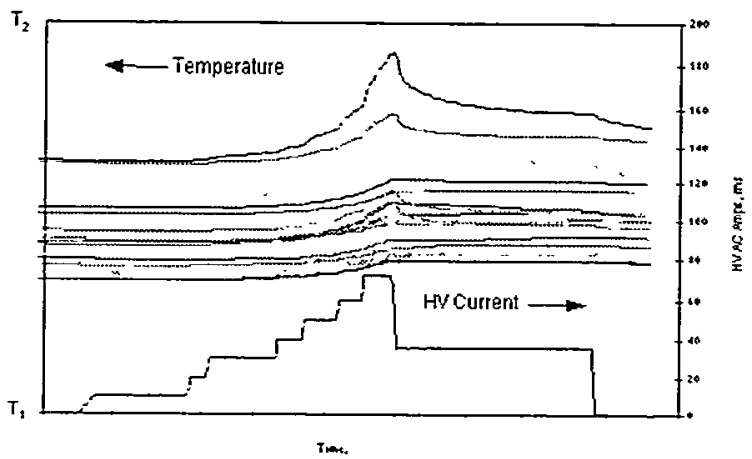

Fig. 2.21. Short-circuit winding temperatures and currents.

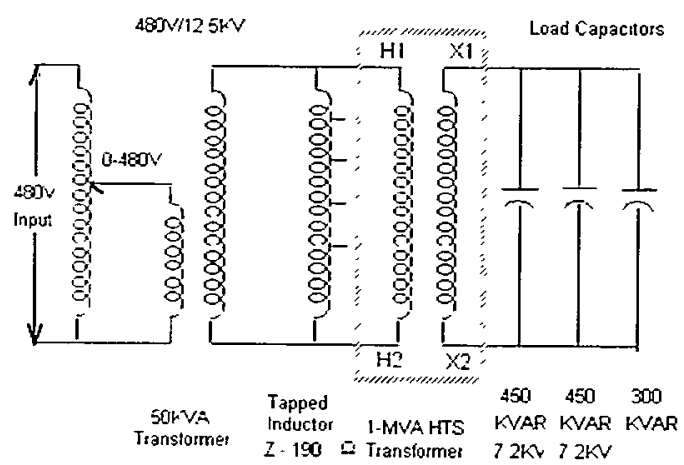

Fig. 2.22. Resonant circuit for load tests.

energy of the inductor and capacitors could cause greater damage. The highest voltage reached in power tests was $8 \mathrm{kV}$. During the next series of open-circuit tests, a power-supply tripoff occurred at $11 \mathrm{kV}$ after $1 \mathrm{~min}$. High partial discharge was seen above about $6 \mathrm{kV}$ when the voltage was reapplied. Because full voltage could not be reached, it was decided to lower the load impedance and retune the circuit for higher currents at lower voltages. Section $d$ of Table 2.4 shows the load test results. In the final test at $4.5 \mathrm{kV}$ with the lower load impedance, a current of $150 \mathrm{~A} \mathrm{rms}$, over twice rating. and power of $0.68 \mathrm{MVA}$ were reached for a short time. Augmented cooling was needed for this test because of high ac losses, but the test demonstrates the mechanical integrity of the transformer at high overloads.
After the electrical tests were completed, the tank was closed off from the vacuum pumps for about $5 \mathrm{~h}$. The tank vacuum was completely stable at $2.4 \times 10^{-6}$ Torr during this time, indicating that active pumping was not necessary.

The product of the highest voltage and the highest short-term current obtained separately during the tests is $11 \mathrm{kV} \times 150 \mathrm{~A}=1.65 \mathrm{MVA}$. The unit is now being inspected to determine the source of the voltage breakdown. This is not thought to be a fundamental design problem and probably results from the large number of sensor leads coming from the winding. These leads would not be present in a commercial transformer. After the breakdown is repaired, further tests will be carried out to investigate both long-term and transient fault current operation.

\section{INSULATION STUDIES AT ORNL IN SUPPORT OF SUPERCONDUCTING POWER APPLICATIONS}

ORNL is conducting research into aspects of multicomponent insulation systems for use in power apparatus. During the past year, efforts have concentrated on the development of basic techniques for use in the measurement and characterization of cryogenic insulation, enlargement and upgrade of laboratory facilities, and application-specific testing of proprietary systems.

Insulation systems studies require a careful blending of basic, small-scale, scientific measurements and theory of dielectrics with larger more elaborate sub-scale engineering studies. The small-scale studies provide guidance and understanding of the breakdown mechanisms and also the initial information needed to design the sub-scale experiments. These latter sub-scale experiments are generally proprietary in nature, expensive, and crucial to the overall success of larger scale applications.

Because bulk breakdown of small-scale systems is well characterized in the literature, 
program efforts are concentrating on the dielectric performance at the interface between two different insulating materials and largescale studies of bulk performance. The systems under study include vacuum/solid, gas/solid, liquid/solid, and solid/solid interfaces. The facility upgrades include a new high-bay, highvoltage laboratory and control room for impulse testing cryogenic model cable (Fig. 2.23) and a laboratory where model cables can be constructed in-house (Fig. 2.24). Modifications were made to the ac power supply to allow for termination of the supply output voltage for various external triggers, such as partial discharge, pressure, breakdown, etc. These triggers have adjustable sensitivities.

High-voltage testing of the insulation for HTS high-voltage power cables were performed in two experimental apparatuses, one for testing the insulation in sheet form with simulated buttgaps and one for testing model cables. In the latter, a mandrel is wrapped with tape insulation

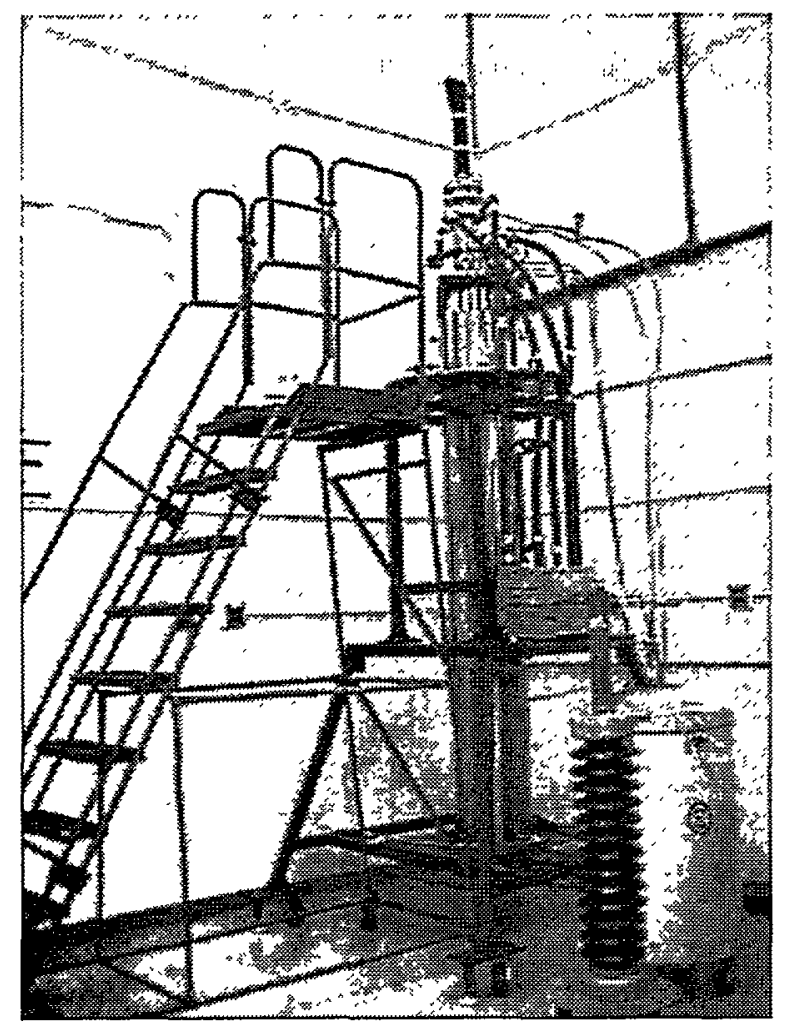

Fig. 2.23. High-bay high-voltage laboratory and control room at ORNL.

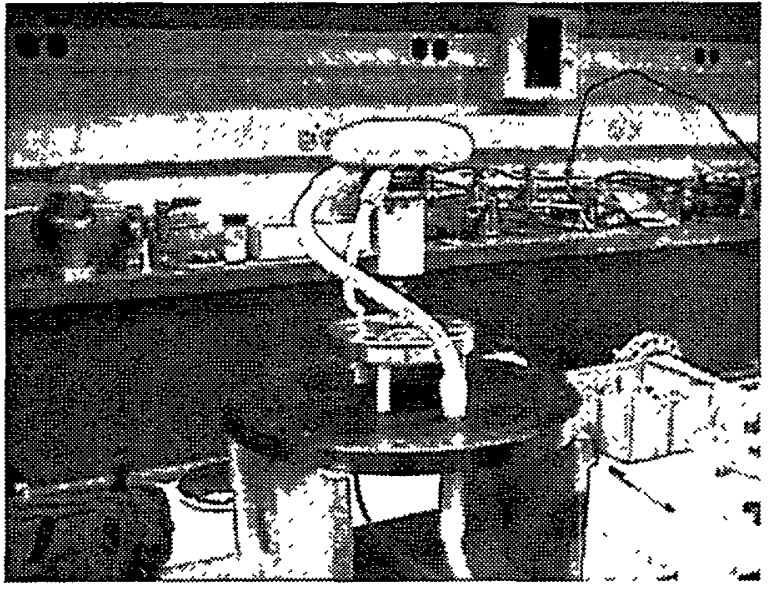

Fig. 2.24. Laboratory at ORNL for inhouse construction of model cables.

to simulate actual cables with butt-gaps that are identical to those in an actual cable.

For the sheet tests, electrodes had to be developed in order to provide a known uniform electric field strength and to suppress partial discharge and surface flashover (SFO) near the electrode edge. This was accomplished by embedding Rogowski-profiled electrodes in epoxy and covering the electrode surface with dielectric grease. With sufficient electrode preparation, clean punctures were obtained for both ac and impulse testing. Experiments were conducted for 1-, 3-, and 5-layer samples of several candidate tape materials both with and without simulated butt gaps in a liquid nitrogen bath over a pressure range from 1 to 8 bar.

For the model cable tests, a facility for constructing a model cable was developed and put into service that allowed the wrapping of tape insulation and the construction of stress cones to relieve the electrical stress at the cable ends. A high-pressure dewar for high-voltage testing of the 4-ft model cables was also placed in service. The dewar can be pressurized up to $15 \mathrm{~atm}$ and incorporates instrumentation for liquid nitrogen level and temperature. The liquid nitrogen temperature can also be controlled by an outer liquid nitrogen bath that can be subcooled. This facility will allow ORNL to produce design parameters, such as insulation thickness, lay angle, butt gap spacing, and stress 
cone design, for optimizing the insulation design.

Design of another high-pressure, highvoltage dewar for performing partial discharge and aging studies was completed and is being fabricated by a commercial vendor. Aging studies are expected to begin in the next fiscal year.

The SFO of fiberglass-reinforced plastics (G-10) and film materials in liquid nitrogen are being conducted as necessary. Specifically, ORNL is presently investigating the generic SFO of G-10 and other composites with interfaces to both vacuum and cryogenic gases. To calibrate and confirm the experimental techniques. ac breakdown measurements were made on both room temperature and $77 \mathrm{~K}$ vacuum gaps to assess breakdown statistics and the effect of electrode conditioning (Fig. 2.25). Bulk breakdown experiments are also planned for other cryogenic gases. These results will ultimately be compared with G-10 SFO in the presence of the same gas or vacuum conditions.

As expected, breakdown strengths in vacuum increase considerably with conditioning (i.e.. as ac voltage is increased. conditioning

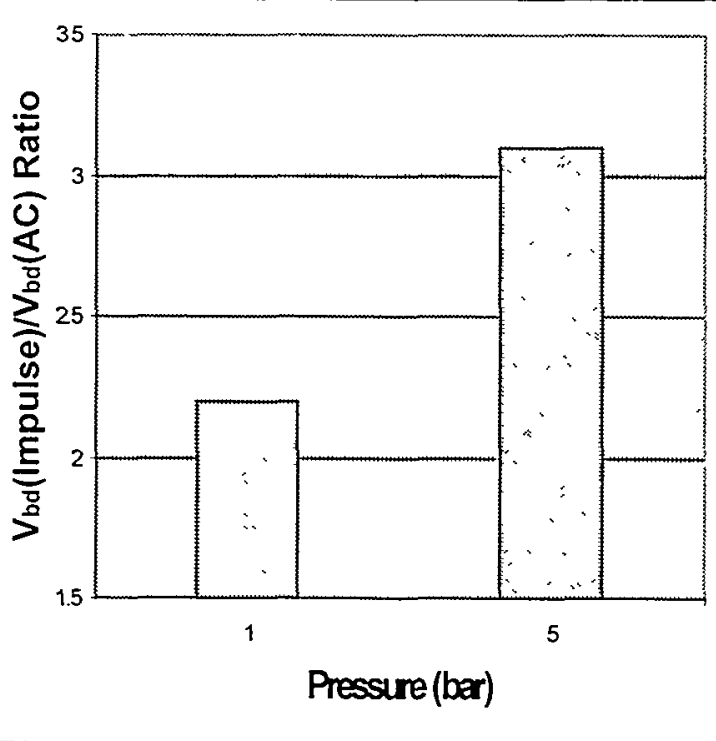

Fig. 2.25. Ratio of impulse breakdown to $A C$ as a function of $\mathrm{LN}_{2}$ pressure for cryoflex insulation. sparks improve the ultimate standoff voltage). This would imply that any system containing a vacuum/solid interface might require some form of conditioning to improve performance statistics. Cooling the electrodes to $\mathrm{LN}_{2}$ temperature increased the standoff voltage of a simple vacuum gap by about $15 \%$. Both improved vacuum and reduced surface gases at the electrode surfaces account for this effect. Results also indicate a decrease in breakdown strength with increasing gap. The breakdown strength obeys a classic power law dependence of the following form: $d^{n} \times E=$ constant, where $d$ is the gap and $E$ is the electric field in $\mathrm{V} / \mathrm{m}$, with $n=0.41$.

Problems were observed with commercially available flexible tubes carrying $\mathrm{LN}_{2}$ coolant to the test apparatus. Partial discharge in the tube produces aging/deterioration of the insulation that eventually leads to puncture of the insulation. Deterioration starts at the tube end (where the electrode joins the tube) and propagates through the tube before eventually leading to puncture. This failure indicates a need to examine the $\mathrm{LN}_{2}$ interface problem more completely. 


\section{Summary of Technology Partnership Activities}

\section{BACKGROUND}

Oak Ridge National Laboratory (ORNL) is a key participant in DOE's national effort on electric power applications of high temperature superconductivity (HTS). ORNL has formed effective teams that combine the resources of the Laboratory with the entrepreneurial drive of private companies. New technology partnership mechanisms, a feature of the ORNL Superconducting Technology Program for Electric Power Systems since its inception in 1988, have resulted in 40 superconductivity "pilot center" cooperative agreements and 6 cooperative research and development agreements (CRADAs). Ten agreements were active during FY 1998. In addition, licensing agreements, joint inventions, and joint publications with the private industry partners have ensured that there is technology transfer throughout the program.

Technology partnering on Laboratoryindustry teams can occur in several ways. Spinoff technology partnering involves the licensing of patentable Laboratory inventions to industry, continued product or process development to the point of demonstration of precommercial viability, or both. In the ORNL program the cooperative development level of technology partnering is emphasized: joint Laboratory-industry teams work on a problem that (1) requires combined resources and expertise and (2) has a clear objective of precompetitive research and technology development. For the project to succeed, each partner depends on the success of the other.

Most of the cooperative projects with private industry and the Laboratory precompetitive research and development projects are developing key technology in which commercialization of the results is expected to occur after a minimum of 3 to 5 years. Some activities are also of a higher-risk, longer-term nature for which new markets, or a shift of markets, to embrace HTS are expected if the project succeeds. For example, the ORNL rolling-assisted biaxially textured substrates (RABiTS ${ }^{\mathrm{TM}}$ ) process represents a new way to produce strongly linked YBCO wires using an industry-scalable process. This wire may still be the only option for practical performance levels in high magnetic fields at liquid nitrogen temperatures $(65-77 \mathrm{~K})$.

\section{RELATIONSHIP TO THE DOE MISSION}

The ORNL program mission is that of its program sponsor, DOE's Office of Power Technologies, Superconductivity Program: to develop the technology base necessary for industry to proceed to commercialization of electric energy applications of HTS. HTS will enable new energy-efficient motors, transformers, and transmission lines and will also provide electric power equipment manufacturers with strategic technology for global competitiveness. Electric utilities can defer acquisition of new transmission rights-ofway with successful introduction of superconducting cables. System stability and protection will be enhanced with the introduction of fault current limiters. Distributed utility systems in the future, which will include distributed generation systems, will benefit from the small size and weight of the next generation of electric power equipment. Finally, oil-free power transformers and cables will provide a cost-effective, more environmentally friendly option for the utility sector.

\section{FUNDING}

DOE funding for the program, subcontracting activities in 1998, and a 
Table 3.1. Superconducting Technology Program funding: authorization and outlay by fiscal year

\begin{tabular}{lccccc}
\hline & \multicolumn{5}{c}{ New budget authorization/outlay } \\
& \multicolumn{5}{c}{$(\$ \times 1000)$} \\
\hline Direct scientific and technical $^{\prime \prime}$ & 3,334 & 3,434 & 2,995 & 3,046 & 5,356 \\
Management and outreach & $\underline{298}$ & $\underline{300}$ & $\underline{310}$ & $\underline{310}$ & $\underline{400}$ \\
$\quad$ Subtotal-ORNL & 3,632 & 3,734 & 3,305 & 3,356 & 5,756 \\
Subcontracts" & 496 & 198 & 1,290 & 1,021 & 2,437 \\
Funds-out cooperative agreements & $\underline{821}$ & $\underline{611}$ & $\underline{2866}$ & $\underline{789}$ & $\underline{589}$ \\
\multicolumn{1}{c}{ Total program } & 4,949 & 4.543 & 4,881 & 5,166 & 8,782 \\
\hline
\end{tabular}

"Details are provided in separate table. Funds-out cooperative agreements provide partial financial support to U.S. industry for cost-shared cooperative research and development.

summary of funds-out cooperative agreements are shown in Tables 3.1 and 3.2 .

\section{TECHNOLOGY PARTNERSHIP APPROACH}

Our interdisciplinary approach uses all resources available at ORNL to meet the program goals for joint Laboratory-industry development of HTS technology for electric power applications. Our superconductivity agreement mechanism interlinks research and development projects with industry and universities that optimize utilization of facilities, expertise. and program resources for the benefit of all participants. This program also coordinates the ORNL activities with the other national laboratories, government agencies, university centers, and industry groups.

Cooperative agreements ensure that technology development is industry-driven. The Office of Science and Technology Partnerships and patent counsel work together to place these agreements. Where appropriate, these efforts are coordinated with projects within ORNL that are funded by the DOE Office of Energy Research, as well as Work for Others and ORNL
Director's Research and Development Fund projects.

Effective funds-out to industry is used to supplement industry cost share. In FY 1998, $\$ 2.8$ million in funds-out to industry and universities was provided through cooperative agreements and subcontracts. To keep industry involved from the start of the program and to ensure commercialization potential, all of these technology partnering mechanisms are augmented by CRADAs, user agreements, and licensing activities.

Responsiveness to American industry has high priority in this program. An ORNL ad hoc technical review committee, consisting of a project manager, a scientific coordinator, a manager for conductor development, and a manager for applications development, reviews all inquiries from industry and recommends a project for possible funding. This review ensures that (1) the proposed work fits the program mission, (2) the work is collaborative, (3) there is legitimate commercial interest, and (4) the work is feasible. Substantial privatesector cost share is required on cooperative agreements.

ORNL provides support to the DOE Headquarters (DOE-HQ) Superconductivity 
Table 3.2 Superconductivity Program

Summary of Cooperative Agreements Active in FY 1998

\begin{tabular}{|c|c|c|c|c|c|c|}
\hline \multirow{3}{*}{ Participant } & \multirow{3}{*}{ Approved term } & \multirow{3}{*}{ Type } & \multicolumn{3}{|c|}{$\begin{array}{c}\text { Total agreement } \\
\text { cost share }(\$ \times 1000) \\
\end{array}$} & \multirow{3}{*}{ Technology area } \\
\hline & & & \multicolumn{2}{|c|}{ By DOE } & \multirow{2}{*}{$\begin{array}{l}\text { By } \\
\text { Industry }\end{array}$} & \\
\hline & & & $\begin{array}{c}\text { To } \\
\text { ORNL } \\
\end{array}$ & $\begin{array}{c}\text { To } \\
\text { Industry } \\
\end{array}$ & & \\
\hline American Superconductor & $8 / 15 / 96-8 / 14 / 99$ & $\mathrm{FI}$ & 500 & 0 & 1165 & $\begin{array}{l}\text { BSCCO-2223 Wire Development Group and SBIR } \\
\text { project }\end{array}$ \\
\hline Intermagnetics General Corporation & $6 / 15 / 97-6 / 30 / 98$ & $\mathrm{FO}$ & 117 & 125 & 125 & HTS transformer \\
\hline MicroCoating Technologies & $9 / 15 / 97-3 / 31 / 2000$ & $\mathrm{FI}$ & 50 & 0 & 1000 & Develop coated-conductor technology \\
\hline $\begin{array}{l}\text { Midwest Superconductivity/ } \\
\text { Westinghouse Electric }\end{array}$ & $6 / 25 / 96-6 / 24 / 98$ & C & 300 & 0 & $\begin{array}{r}1035 \\
160 \\
1195\end{array}$ & Develop coated-conductor technology \\
\hline Midwest Superconductivity & $4 / 1 / 98-9 / 30 / 1998$ & FO & 100 & 150 & 62 & $\begin{array}{l}\text { Develop coil technology using MOCVD/RABiTS } \\
\text { wire }\end{array}$ \\
\hline Oxford Instruments & $1 / 94-1 / 31 / 99$ & $\mathrm{C}$ & 275 & 0 & 475 & $\begin{array}{l}\text { Develop technology for dip-coated BSCCO-2212 } \\
\text { wire and RABiTS }\end{array}$ \\
\hline Plastronic. Inc. & $5 / 1 / 97-7 / 4 / 99$ & $\mathrm{Fl}$ & 25 & 0 & 220 & $\begin{array}{l}\text { High-strength. low-ac-loss high-temperature } \\
\text { superconductor }\end{array}$ \\
\hline Southwire Company & $2 / 1 / 97-1 / 31 / 99$ & FO & 2726 & 500 & 2173 & Develop HTS cable technology \\
\hline $\begin{array}{l}\text { 3M-Southwire-LANL-ORNL } \\
\text { 3M } \\
\text { Southwire } \\
\text { LANL } \\
\text { ORNL }\end{array}$ & $4 / 3 / 97-4 / 99$ & $\mathrm{C}$ & 600 & $960^{h}$ & $\begin{array}{r}1375 \\
324 \\
1699\end{array}$ & $\begin{array}{l}\text { Development of HTS wire using coated-conductor } \\
\text { technologies }\end{array}$ \\
\hline \multicolumn{7}{|c|}{ FY 1998 active subcontracts } \\
\hline Imtech & $10 / 3 / 94-9 / 30 / 98$ & & & 248 & & $\begin{array}{l}\text { Superconducting powder synthesis/scale-up. } \\
\text { strengthened substrates }\end{array}$ \\
\hline $\begin{array}{l}\text { Massachusetts Institute of } \\
\text { Technology }\end{array}$ & $\begin{array}{l}4 / 29 / 96-3 / 31 / 98 \\
4 / 1 / 98-3 / 31 / 99\end{array}$ & & & $\begin{array}{l}215 \\
120\end{array}$ & & Stability of HTS conductors and coils \\
\hline
\end{tabular}


Table 3.2 (continued)

University of Houston.

Texas Center for Superconductivity

University of Tennessee

National Institute of Standards and

Technology (Gaithersburg)

National Institute of Standards and Technology (Boulder)

Energetics. Inc.

Bob Lawrence \& Associates

University of South Carolina

University of Wisconsin

Stanford University

University of Wisconsin
Total agreement

cost share $(\$ \times 1000)$

\begin{tabular}{|c|c|c|c|c|}
\hline \multirow{2}{*}{ Approved term } & \multirow{2}{*}{ Type } & \multicolumn{2}{|c|}{ By DOE } & \multirow{2}{*}{$\begin{array}{c}\text { By } \\
\text { Industry }\end{array}$} \\
\hline & & $\begin{array}{l}\text { To } \\
\text { ORNI. }\end{array}$ & $\begin{array}{c}\text { To } \\
\text { Industry }\end{array}$ & \\
\hline
\end{tabular}

Ongoing

$11 / 1 / 95-10 / 31 / 98$

360

25

30

50

$5 / 15 / 95-12 / 31 / 97$

Ongoing

9/22/93-11/30/98

515

$3 / 1 / 98-2 / 28 / 2001$

180

4/96-7/96

$8 / 96-7 / 97$

$8 / 97-7 / 98$

$2 / 17 / 97-2 / 16 / 98$

$2 / 17 / 98-2 / 16 / 99$

$4 / 1 / 98-3 / 31 / 99$

5/1/97-7/98

$10 / 1 / 98-9 / 30 / 2001$

513

$10 / 1 / 98-9 / 30 / 2001$
Technology area

Postdoctoral research fellowships (4.5)

Supply epitaxial films of thallium-based hightemperature superconducting materials

Processing YBCO and BSCCO superconductors fo high-current leads and conductors (two students)

Students (3) - Deposited-conductor development BSCCO and TBCCO phase diagram support

Electromechanical properties of superconductors for applications

Technical and analytical support to ORNI.

Technical and economic benefits assessment and market study

High-temperature conductor development and characterization

TEM and magneto-optic imaging studies on RABiTS

Ion-beam assisted deposition of buffer layers and in situ deposition of $\mathrm{YBCO}$ by electron beam evaporation

BSCCO critical currents and microstructures. YBCO coated conductor microstructure. and pulse tube cryocooler research 
Table 3.2 (continued)

\begin{tabular}{|c|c|c|c|c|c|c|}
\hline \multirow{3}{*}{ Participant } & \multirow{3}{*}{$\Lambda$ pproved term } & \multirow{3}{*}{ Type } & \multicolumn{3}{|c|}{$\begin{array}{c}\text { Total agreement } \\
\text { cost share }(\$ \times 1000) \\
\end{array}$} & \multirow{3}{*}{ Technology area } \\
\hline & & & \multicolumn{2}{|c|}{ By DOE } & \multirow{2}{*}{$\begin{array}{l}\text { By } \\
\text { Industry }\end{array}$} & \\
\hline & & & $\begin{array}{c}\text { To } \\
\text { ORNL }\end{array}$ & $\begin{array}{c}\text { To } \\
\text { Industry }\end{array}$ & & \\
\hline University of Houston & $10 / 1 / 98-9 / 30 / 2001$ & & & 165 & & $\begin{array}{l}\text { Research into high-rate photon-assisted MOCVD for } \\
\text { YBCO onto buffered. textured metallic substrates. }\end{array}$ \\
\hline Marshall O. Pace & $11 / 17 / 97-11 / 16 / 98$ & & & 24 & & $\begin{array}{l}\text { High-voltage breakdown studies on cryogenic } \\
\text { insulation }\end{array}$ \\
\hline Horatio Rodrigo & $11 / 97-3 / 98$ & & & 35 & & $\begin{array}{l}\text { Set up impulse high-voltage generator and conduct } \\
\text { vacuum and cryogenic breakdown measurements }\end{array}$ \\
\hline \multicolumn{7}{|c|}{$\begin{array}{l}{ }^{a} \mathrm{FJ}=\text { funds-in: } \mathrm{FO}=\text { funds-out: and } \mathrm{C}=\mathrm{CRADA} \text {. } \\
{ }^{h} \mathrm{DOE} \text { to LANL. }\end{array}$} \\
\hline
\end{tabular}


Program for Electric Power Systems by identifying. guiding, and monitoring research and development at ORNL and ORNL subcontractor sites and by performing coordination, analysis. and planning of activities related to the national program.

Some of the various activities performed as part of this task include the following:

- technical. project, and budget guidance;

- project identification and development;

- exploratory research and development:

- support of consultants and subcontracts providing technical, program, or technology partnering support:

- identification, placement, and technical monitoring of subcontractors, review committee members, and workshop guests;

- guidance and support on technology partnering:

- publication of reports and proceedings from workshops:

- identification and initiation of cooperative agreements, interagency agreements (i.e., National Institute of Standards and Technology), and memoranda of understanding:

- distribution of reports to program managers;

- coordination of the Laboratory's Industrial Overview Committee;

- preparation of assessments to address technical, economic, regulatory, and institutional issues in the DOE program;

- coordination of interlaboratory technical team meetings:

- assistance to the DOE-HQ program manager in preparation of the Superconducting Technology Program Annual Operating Plan:

- collection and dissemination of programmatic information and programwide assessments;

- assistance in organizing the HTS Wire Development Workshop (in partnership with ANL and LANL); and
- review of industrial collaboration opportunities through multilaboratory meetings and conference calls.

ORNL works with the other program laboratories to address such issues as communication among program participants, workshop and meeting implementation, planned competitive solicitations and superconductivity agreements, and coordination of technical and economic assessments.

An Industrial Overview Committee is charged with reviewing program activities and advising Laboratory management as to program progress, policy, and direction. The committee consists of representatives of electric utilities, original equipment manufacturers, and HTS wire manufacturers. This committee meets once a year at ORNL, Argonne National Laboratory (ANL), or Los Alamos National Laboratory (LANL).

\section{PROGRAM MEASURES}

One new cooperative agreement was executed during FY 1998: Midwest

Superconductivity, Inc. New statements of work were negotiated with American Superconductor Corporation (ASC), Waukesha Electric Systems, Southwire Company, MicroCoating Technologies, Oxford Superconducting Technology, and EURUS Technologies, Inc. Three new invention disclosures were submitted by ORNL. These are listed in Table 3.3. Also, three new patent license agreements were executed in FY 1998: MicroCoating Technologies (Chamblee, Ga.); $3 \mathrm{M}$ Company (St. Paul, Minn.); and EURUS Technologies, Inc. (Tallahassee, Fla.). The license agreements are for ORNL's patented RABiTS ${ }^{\mathrm{TM}}$ superconducting coated conductor wire technology. All licenses and issued patents are shown in Tables 3.4 and 3.5. 
Table 3.3. Superconducting Technology Program (FY 1998) invention disclosures

\begin{tabular}{cll}
\hline ERID No. & \multicolumn{1}{c}{ Subject } & \multicolumn{1}{c}{ Submitted by } \\
\hline 458 & $\begin{array}{l}\text { Method of making high-critical-current } \\
\text { density YBCO superconducting layers on } \\
\text { metallic substrates (CRADA ORNL97- } \\
\text { MULT-0460)* }\end{array}$ & $\begin{array}{l}\text { R. Feenstra, D. K. Christen, and } \\
\text { M. Paranthaman }\end{array}$ \\
467 & $\begin{array}{l}\text { Formation of biaxially textured buffer layers } \\
\text { by e-beam evaporation and magnetron } \\
\text { sputtering }\end{array}$ & $\begin{array}{l}\text { M. Paranthaman, D. F. Lee, D. M. Kroeger, } \\
\text { and A. Goyal }\end{array}$ \\
534 & $\begin{array}{l}\text { Biaxially textured buffer layer for textured } \\
\text { metallic substrates (HTSPC-023)* }\end{array}$ & D. F. Lee, D. M. Kroeger, and A. Goyal \\
\hline
\end{tabular}

*Numbers in parentheses are cooperative agreement numbers under which the work was conducted. 
Table 3.4. Superconducting Technology Program patent license agreements

\begin{tabular}{|c|c|}
\hline ESID No. & Company \\
\hline $1039-X$ & Superconductive Components, Inc. \\
\hline $\begin{array}{l}\text { 1640-X (RABiTSTM) } \\
\text { (two licenses) }\end{array}$ & Midwest Superconductivity, Inc. \\
\hline 1640-X (RABiTSTM) & $\begin{array}{l}\text { Oxford Superconducting } \\
\text { Technology }\end{array}$ \\
\hline 1640-X (RABiTSTM $)$ & $\begin{array}{l}\text { CCVD, Inc., dba MicroCoating } \\
\text { Technologies }\end{array}$ \\
\hline 1640-X (RABiTSTM) & EURUS Technologies \\
\hline 1640-X (RABiTS $\left.{ }^{\mathrm{TM}}\right)$ & $3 \mathrm{M}$ \\
\hline
\end{tabular}


Table 3.5. Superconducting Technology Program patents issued

\begin{tabular}{lll}
\hline No. & \multicolumn{1}{c}{ Subject } & Date issued \\
\hline $\begin{array}{l}\text { No. 5,357,756 } \\
\text { (ESID 1185-X) }\end{array}$ & Bipolar pulse field for magnetic refrigeration & October 25, 1994 \\
$\begin{array}{l}\text { No. 5,395,821 } \\
\text { (ESID 1039-X) }\end{array}$ & $\begin{array}{l}\text { Method of producing PB-stabilized superconductor precursors } \\
\text { and method of producing superconductor articles therefrom }\end{array}$ & March 7, 1995 \\
$\begin{array}{l}\text { No. 5,525,583 } \\
\text { (ESID 1471-X) }\end{array}$ & $\begin{array}{l}\text { To American Superconductor for Superconducting Magnetic Coil } \\
\text { No. 5,546,261 }\end{array}$ & Hermetically sealed superconducting magnet motor \\
No. 5,646,097 & Method of fabricating a (1223) Tl-Ba-Ca-Cu-O superconductor & Ju, 1996 \\
No. 5,739,086 & $\begin{array}{l}\text { Structures having enhanced biaxial texture and method of } \\
\text { fabricating same }\end{array}$ & August 13,1996 \\
No. 5,741,377 & $\begin{array}{l}\text { Structures having enhanced biaxial texture and method of } \\
\text { fabricating same }\end{array}$ & April 14, 1999 \\
No. 5,830,828 & Process for fabricating continuous lengths of superconductors & April 21, 1998 \\
\hline
\end{tabular}




\section{FY 1998 Presentations and Publications}

Bhattacharya, R. N., R. D. Blaugher, A. Natarajan, C. M. Carlson, P. A. Parilla, D. S. Ginley, M. Paranthaman, A. Goyal, and D. M. Kroeger, "Thick-Film Processing for Tl-Oxide Wire and Tape," Journal of Superconductivity 11 (1) (1998).

Bhattacharya, R. N., and R. D. Blaugher (NREL); Z. F. Ren, W. Li, and J. H. Wang (SUNY-Buffalo); and M. Paranthaman, D. T. Verebelyi, and D. K. Christen (ORNL), "Superconducting Epitaxial Thallium Oxide Films by the Electrodeposition Method," Physica C 304, 55-65 (1998).

Bhattacharya, R. N., and R. D. Blaugher (NREL); Z. F. Ren, W. Li, and J. H. Wang (SUNY-Buffalo); and M. Paranthaman, D. T. Verebelyi, and D. K. Christen (ORNL), "Superconducting Epitaxial $(\mathrm{TlBi})_{0} \mathrm{Sr}_{1.6} \mathrm{Ba}_{0.4} \mathrm{Ca}_{2} \mathrm{Cu}_{3} \mathrm{Ag}_{0.2} \mathrm{O}$, Film from an Electrodeposited Precursor," Electrochemical and Solid State Letters 1 (4), 165-67 (1998).

Bhattacharya, R., P. A. Parilla, and R. D. Blaugher (NREL); Z. F. Ren, W. Li, and J. H. Wang (SUNYBuffalo); Y. T. Wang and A. M. Hermann (Univ. of Colorado); and M. Paranthaman, A. Goyal, D. T. Verebelyi, and D. K. Christen (ORNL), "Superconducting Thallium Oxide Films from Electrodeposited Precursors," paper presented at the 1998 Applied Superconductivity Conference, Palm Desert, California, September 13-18, 1998, and submitted for publication in IEEE Transactions on Applied Superconductivity.

Cantoni, C., D. P. Norton, D. M. Kroeger, M. Paranthaman, D. K. Christen, D. Verebelyi, R. Feenstra, D. F. Lee, E. D. Specht, V. Boffa, and S. Pace, "Phase Stability for the In Situ Growth of $\mathrm{Nd}_{1+\lambda} \mathrm{Ba}_{2-\lambda} \mathrm{Cu}_{3} \mathrm{O}_{y}$ Films Using Pulsed-Laser Deposition," accepted for publication in Applied Physics Letters.

Carlson, C. M., and J. C. Price (Univ. Colorado); D. S. Ginley, D. Niles, and R. Blaugher (NREL); A. Goyal, M. Paranthaman, D. M. Kroeger, and D. K. Christen (ORNL), "Laser-Ablated Epitaxial $\mathrm{LaAlO}_{3}$ Buffer Layers on Biaxially Textured Ni Substrates for Superconducting Tapes," Physica C 304, 82-88 (1998).

Christen, D. K., "Current Limits to Wire Technology," Nature 392 (April 30, 1998).

Christen, D. K., D. T. Verebelyi, R. Feenstra, D. P. Norton, C. Park, Q. He, C. S. Prouteau, M. F. Chisholm, J. D. Budai, E. D. Specht, A. Goyal, M. Paranthaman, D. F. Lee, and D. M. Kroeger, "Superconducting Transport in Coated Conductors and Related Model Systems," abstract submitted to Materials Research Society 1998 Fall Meeting, Boston, Mass., November 30-December 4, 1998.

Cui, X., F. A. List, D. M. Kroeger, A. Goyal, D. F. Lee, J. Mathis, E. D. Specht, P. M. Martin, R. Feenstra, D. T. Verebelyi, D. K. Christen, and M. Paranthaman. "Reel-to-Reel Continuous Deposition of Epitaxial $\mathrm{CeO}_{2}$ Buffer Layers on Biaxially Textured Ni Tapes by Electron Beam Evaporation," paper presented at the 1998 Applied Superconductivity Conference, Palm Desert, California, September 13-18, 1998, and submitted for publication in IEEE Transactions on Applied Superconductivity. 
Demko. J. A., et al., "Testing of the Dependence of the Number of Layers on the Performance of a HTS Transmission Cable Prototype," paper presented at the 1998 Applied Superconductivity Conference, Palm Desert, California. September 13-18, 1998, and submitted for publication in IEEE Transactions on Applied Superconductivity.

Glavee, G. N. (Lawrence University), R. D. Hunt, and M. Paranthaman (ORNL), "Low-Temperature Preparation of $\mathrm{BaCeO}_{3}$ and $\mathrm{Ce}_{075} \mathrm{Zr}_{0.25} \mathrm{O}_{2}$ Thin Films Using Sol-Gel Processing Techniques," paper accepted for publication in Materials Research Bulletin.

Gouge. M. J., J. A. Demko, J. W. Lue, J. P. Stovall (ORNL), and R. L. Hughey, R. Martin, and U. Sinha (Southwire), "HTS Cable Test Facility: Design and Initial Results," paper presented at the 1998 Applied Superconductivity Conference, Palm Desert. California, September 13-18, 1998, and submitted for publication in IEEE Transactions on Applied Superconductivity.

Goyal. A., J. Mathis, C. Park. M. Paranthaman, X. Cui, D. K. Christen, E. D. Specht, D. M. Kroeger, J. D. Budai, Q. He, H. R. Kerchner, E. Hatfield, and P. M. Martin (ORNL), "High $J_{\mathfrak{c}}$, High $J_{e}$ Conductors Fabricated by Epitaxial Deposition of YBCO on RABiTS," paper presented to the 1998 Applied Superconductivity Conference, Palm Desert, Calif., September 13-18, 1998.

Goyal, A.. D. P. Norton, D. K. Christen, E. D. Specht, M. Paranthaman, D. M. Kroeger, J. D. Budai, Q. He, F. A. List, R. Feenstra, H. R. Kerchner, D. F. Lee, E. Hatfield, P. M. Martin, J. Mathis, and C. Park. "Epitaxial Superconductors on Rolling-Assisted Biaxially Textured Substrates (RABiTS): A Route Towards High Critical Current Density Wire," Applied Superconductivity 4 (10/11) (October/November 1996).

Goyal. A.. E. D. Specht, Z. L. Wang, and D. M. Kroeger, "Grain Boundary Studies of High-Temperature Superconducting Materials Using Electron Backscatter Kikuchi Diffraction," Ultramicroscopy 67. 35-57 (June 1, 1997).

He. Q.. D. K. Christen, R. Feenstra, D. P. Norton, M. Paranthaman, E. D. Specht, D. F. Lee, A. Goyal, and D. M. Kroeger (ORNL), "Growth of Biaxially Oriented Conductive $\mathrm{LaNiO}_{3}$ Buffer Layers on Textured Ni Tapes for High- $\mathrm{T}_{\mathrm{c}}$ Coated Conductors," paper submitted to Physica $C$.

Kerchner. H. R., and E. H. Brandt, "Alternating Current Power Loss in Superconductive Films," submitted to Physical Review Letters.

Kerchner. H. R., D. P. Norton, J. D. Budai, D. K. Christen, D. M. Kroeger, E. D. Specht, Q. He, M. Paranthaman, D. F. Lee, B. C. Sales, F. A. List, and R. Feenstra, "Alternating Current Losses in Biaxially Textured $\mathrm{YBa}_{2} \mathrm{Cu}_{3} \mathrm{O}_{7-\delta}$ Films Deposited on Ni Tapes," Appl. Phys. Lett. 71 (14), 2029-31 (October 1997).

Kunchur. M. N. (Univ. SC), D. K. Christen (ORNL), and B. I. Ivlev (Landau Institute of Theoretical Physics), "Decomposition of the Hall Angle in the Mixed State of Superconductors," Physica C 307, 241-44 (1998). 
Lawrence, L. R., Jr., C. Cox, and D. Broman, "High Temperature Superconductivity: The Products and Their Benefits," Oak Ridge National Laboratory Report No. ORNL/Sub/97-SX339V2, July 1998.

Lee, D. F., "Review of Fabrication Techniques of Second-Generation HTS Wires," paper presented to the Materials Engineering Laboratory at Texas Center for Superconductivity, University of Houston, December 23, 1997.

$\mathrm{Li}, \mathrm{Z}$., "Prospects for the Medium- and Long-Term Development of China's Electric Power Industry and Analysis of the Potential Market for Superconductivity Technology," Oak Ridge National Laboratory Report No. ORNL/Sub-97-SX339V/1, May 1998.

List, F. A., A. Goyal, M. Paranthaman, D. P. Norton, E. D. Specht, D. F. Lee, and D. M. Kroeger (ORNL), "High $\mathrm{J}_{\mathrm{c}}$ YBCO Films on Biaxially Textured Ni with Oxide Buffer Layers Deposited Using Electron Beam Evaporation and Sputtering," Physica C 302, 87-92 (1998).

Lue, J. W., and J. A. Demko, L. Dresner (consultant), R. L. Hughey, U. Sinha, and J. C. Tolbert (Southwire), and S. K. Olsen. (Technical University of Denmark), "AC Losses of Prototype HTS Transmission Cables," paper presented at the 1998 Applied Superconductivity Conference, Palm Desert, California, September 13-18, 1998, and submitted for publication in IEEE Transactions on Applied Superconductivity.

Lue, J. W., and M. S. Lubell (ORNL), and M. J. Tomsic (Plastronic), "AC Losses of HTS Tapes and Bundles with De-Coupling Barriers," paper presented at the 1998 Applied Superconductivity Conference, Palm Desert, California, September 13-18, 1998, and submitted for publication in IEEE Transactions on Applied Superconductivity.

Mathis, J. E., A. Goyal, F. A. List. M. Paranthaman, D. K. Christen, E. D. Specht. D. M. Kroeger, D. F. Lee, and P. M. Martin, "Biaxially Textured $\mathrm{YBa}_{2} \mathrm{Cu}_{3} \mathrm{O}_{7-\delta}$ Conductors on Rolling Assisted Biaxially Textured Substrates with Critical Current Densities of 2-3 MA/cm²." Jpn. J. Appl. Phys. 37, 11B (1998).

Norton, D. P., C. Park, J. D. Budai, S. J. Pennycook, and C. Prouteau, "Plume-Induced Stress in PulsedLaser Deposited $\mathrm{CeO}_{2}$ Films,"submitted to Applied Physics Letters.

Norton, D. P., C. Park, C. Prouteau, D. K. Christen, M. F. Chisholm, J. D. Budai, A. Goyal, E. Y. Sun, D. F. Lee, D. M. Kroeger, E. Specht, and M. Paranthaman, "Epitaxial $\mathrm{YBa}_{2} \mathrm{Cu}_{3} \mathrm{O}_{7}$ Films on Rolled Textured Metals for High-Temperature Superconducting Applications," submitted to the 4th International Workshop on Oxide Electronics (Bethesda, Maryland, Dec. 9-12, 1997) and to be published in Journal of Metls. Science and Engineering $B$.

Paranthaman, M., D. B. Beach, J. S. Morrell, A. Goyal, E. D. Specht, J. E. Mathis, D. T. Verebelyi, and D. K. Christen (ORNL) and S. S. Shoup (MicroCoating Technologies), "Growth of Textured Buffer Layers and Superconductors on Rolled Ni Substrates Using Sol-Gel Alkoxide Precursors," paper submitted to proceedings of CIMTEC World Ceramics Congress and Forum on New Materials, Florence, Italy, June 14-19, 1998. 
Paranthaman. M., and B. C. Chakoumakos (ORNL), "Synthesis and Characterization of Bulk $\mathrm{HgBa}_{2} \mathrm{Ca}_{n-1} \mathrm{Cu}_{n} \mathrm{O}_{2 n+2+o}(\mathrm{n}=1,2,3,4)$ Superconductors," pp. 133-152. In A. Narlikar (ed.), Studies of High Temperature Superconductors. Vol. 26. Nova Science Publishers. Commack, N.Y.

Paranthaman. M., A. Goyal, D. P. Norton, D. F. Lee, E. D. Specht, P. M. Martin, D. M. Kroeger, D. K. Christen, C. Park, and J. E. Mathis, "Fabrication of High Current $\mathrm{YBa}_{2} \mathrm{Cu}_{3} \mathrm{O}_{7-3}$ Coated Conductors Using Biaxially Textured Buffer Layers on Rolled-Ni Substrates," abstract submitted to the $9^{\text {th }}$ International Conference on Modern Materials and Technologies Topical Symposium VI. Florence, Italy, June 14-19, 1998.

Paranthaman. M.. D. F. Lee, R. Feenstra, A. Goyal, D. T. Verebelyi, D. K. Christen, E. D. Specht, F. A. List. P. M. Martin, and D. M. Kroeger (ORNL), D. F. Ren, W. Li, D. Z. Wang, J. Y. Lao, and J. H. Wang (SUNY-Buffalo), "Optimization of Buffer Layers on Rolled-Ni Substrates for HighCurrent YBCO and Tl,Bi-1223 Coated Conductors using Ex Situ Precursor Approaches," paper presented at the 1998 Applied Superconductivity Conference, Palm Desert, California, September 13-18, 1998, and submitted for publication in IEEE Transactions on Applied Superconductivity.

Paranthaman, M., D. F. Lee, A. Goyal, F. A. List, J. E. Mathis, D. M. Kroeger, R. Feenstra, and D. K. Christen, "Growth of High Current YBCO Coated Conductors on Biaxially Textured Nickel Substrates," paper presented to the 1998 Applied Superconductivity Conference, Palm Desert, Calif., September 13-18, 1998.

Paranthaman, M., S. S. Shoup, D. B. Beach, A. Singhal, J. S. Morrell, A. Goyal, E. D. Specht, and D. M. Kroeger, "Growth of Biaxially Textured Buffer Layers and Superconductors on Rolled-Ni Substrates Using Sol-Gel Alkoxide Precursors," abstract submitted to the $9^{\text {th }}$ International Conference on Modern Materials and Technologies Topical Symposium VI, Florence, Italy, June 14-19, 1998.

Paranthaman, M., S. S. Shoup, D. B. Beach, R. K. Williams, and E. D. Specht, "Epitaxial Growth of $\mathrm{BaCrO}_{3}$ Films on Single Crystal Oxide Substrates using Sol-Gel Alkoxide Precursors" Materials Research Bulletin 32 (12), 1697-1704 (1997).

Parilla, P. A., C. M. Carlson, Y. T. Wang, R. N. Bhattacharya, R. D. Blaugher, and D. S. Ginley (NREL); and M. Paranthaman, A. Goyal, D. K. Christen, and D. M. Kroeger (ORNL), "Buffer Layers and Thallination of Tl-based Superconductors on Flexible Metal Substrates," paper presented at the 1998 Applied Superconductivity Conference, Palm Desert, California, September 13-18, 1998, and submitted for publication in IEEE Transactions on Applied Superconductivity.

Park. C., D. P. Norton, J. D. Budai, D. K. Christen, D. Verebelyi, R. Feenstra, D. F. Lee, A. Goyal, D. M. Kroeger, and M. Paranthaman, "Bend Strain Tolerance of Critical Currents for $\mathrm{YBa}_{2} \mathrm{Cu}_{3} \mathrm{O}_{7}$ Films Deposited on Rolled-Textured (001) Ni," Appl. Phys. Lett. 73 (13) (September 28, 1998).

Park, C., D. P. Norton, D. K. Christen, D. T. Verebelyi, R. Feenstra, J. D. Budai, D. F. Lee, A. Goyal, E. D. Specht, D. M. Kroeger, and M. Paranthaman, "Long-Length Fabrication of YBCO on Rolling Assisted Biaxially Textured Substrates (RABiTS) Using Pulsed Laser Deposition," paper presented at the 1998 Applied Superconductivity Conference, Palm Desert, California, 
September 13-18, 1998, and submitted for publication in IEEE Transactions on Applied Superconductivity.

Prouteau, C., G. Duscher, D. K. Christen, N. D. Browning, S. J. Pennycook, M. F. Chisholm, D. P. Norton, A. Goyal, and C. Park, "Correlation of Transport Properties with Grain Boundary Atomic Structure in High $\mathrm{T}_{\mathrm{c}}$ Superconducting Films and Tapes," p. 1015 in Proceedings of the 10th International Symposium on Superconductivity (ISS'97), K. Osamura and I. Hirabayashi (eds.), Gifu, Japan, 1998.

Ren, Z. F., W. Li, D. Z. Wang, J. Y. Lao, and J. H. Wang (SUNY-Buffalo); and M. Paranthaman, D. T. Verebelyi, and D. K. Christen (ORNL), "Growth and Characterization of Superconducting Films $\mathrm{Tl}_{078} \mathrm{Bi}_{0.22} \mathrm{Sr}_{1.6} \mathrm{Ba}_{04} \mathrm{Ca}_{2} \mathrm{Cu}_{3} \mathrm{O}_{9}$ on $\mathrm{CeO}_{2}$-Buffered Single Crystal YSZ," Physica C 306, 149-53 (1998).

Rupich, M. W., W. Palm, W. Zhang, E. Siegal, S. Annavarapu, L. Fritzemeier, M. D. Teplitsky, and C. Thieme (American Superconductor), and M. Paranthaman (ORNL), "Growth and Characterization of Oxide Buffer Layers for YBCO Coated Conductors," paper presented at the 1998 Applied Superconductivity Conference, Palm Desert, California, September 13-18, 1998, and submitted for publication in IEEE Transactions on Applied Superconductivity.

Schwenterly, S. W., "High-Voltage Testing of Superconducting Power Apparatus," paper accepted for publication in Cryogenics.

Schwenterly, S.W., B.W. McConnell, et al., " Performance of a 1-MVA HTS Demonstration Transformer," paper presented at the 1998 Applied Superconductivity Conference, Palm Desert, California, September 13-18, 1998, and submitted for publication in IEEE Transactions on Applied Superconductivity.

Sheth, A., V. Lasrado, and M. White (UTSI) and M. Paranthaman (ORNL), "Bench-Scale Evaluation of Batch Mode Dip-Coating of Sol-Gel LaAlO 3 Buffer Material," paper presented at the 1998 Applied Superconductivity Conference, Palm Desert, California, September 13-18, 1998, and submitted for publication in IEEE Transactions on Applied Superconductivity.

Shoup, S. S., M. Paranthaman, A. Goyal, E. D. Specht, D. F. Lee, D. M. Kroeger, and D. B. Beach, "Epitaxial Thin Film Growth of Lanthanum and Neodymium Aluminate Films on Roll-Textured Nickel Using a Sol-Gel Method," J. Amer. Ceram. Soc. 81 (11), 3019-21 (1998).

Shoup, S. S., S. Shanmugham, D. Cousins, and A. T. Hunt (MicroCoating Technologies), and M. Paranthaman, A. Goyal, P. M. Martin, and D. M. Kroeger (ORNL), "Low-Cost Combustion Chemical Vapor Deposition of Epitaxial Buffer Layers and Superconductors," paper presented at the 1998 Applied Superconductivity Conference, Palm Desert, California, September 13-18, 1998, and submitted for publication in IEEE Transactions on Applied Superconductivity.

Singhal, A.., M. Paranthaman, E. D. Specht, R. D. Hunt, D. B. Beach, P. M. Martin, and D. F. Lee, "Solution Processing of $\mathrm{YBa}_{2} \mathrm{Cu}_{3} \mathrm{O}_{7-\mathrm{x}}$ Thin Films," Mat. Res. Soc. Symp. Proc. 495 (1998). 
Solovyov, V. F., H. J. Wiesmann, and M. Suenaga (BNL), and R. Feenstra (ORNL), "Thick $\mathrm{YBa}_{2} \mathrm{Cu}_{3} \mathrm{O}_{7}$ Films by Post Annealing of the Precursor by High Rate E-Beam Deposition on $\mathrm{SrTiO}_{3}$ Substrates," paper submitted to Physica $C$.

Specht, E. D., A. Goyal, D. F. Lee, F. A. List, D. M. Kroeger, M. Paranthaman, R. K. Williams, and D. K. Christen, "Cube-Textured Nickel Substrates for High-Temperature Superconductors," Superconductor Science and Technology 11 (10), 945-49 (October 1998).

Sun. E. Y.. A. Goyal, D. P. Norton, C. Park, D. M. Kroeger, M. Paranthaman, and D. K. Christen (ORNL). "High-Resolution TEM/AEM Characterization of Epitaxial Oxide Multilayers Fabricated by Laser Ablation on Biaxially Textured Ni," submitted to the Journal of Materials Research.

Tirumala. S. P.. D. F. Lee. D. M. Kroeger, and K. Salama, "Effects of Stoichiometric Variation and Cooling Rate on the Phase Formation and Critical Current Density of Bi-2223 Powder-in-Tube Tapes Made from Aerosol Precursor," Supercond. Sci. Technol. 11, 496-504 (1998).

Verebelyi. D. T.. D. K. Christen, C. Prouteau, G. Duscher, N. D. Browning, S. J. Pennycook, M. F. Chisholm, D. P. Norton, C. Park, and E. D. Specht, "Correlations Between Superconducting Transport Properties and Atomic Structure of YBCO Single Grain Boundaries in Large Magnetic Fields," paper presented at the 1998 Applied Superconductivity Conference, Palm Desert, California, September 13-18, 1998, and submitted for publication in IEEE Transactions on Applied Superconductivity.

Walker. M. S.. et al., "Preliminary Test of a Cryocooled 1-MVA HTS Transformer," invited presentation at the 1998 International Workshop on Superconductivity, Okinawa, Japan, July 13-15, 1998.

Walker. M. S.. (IGC) et al.. "l-MVA HTS Demonstration Transformer and Other Power Applications," abstract submitted to the International Workshop on Superconductivity to be held, July 13-15, 1998. in Okinawa, Japan.

Williams. R. K.. P. M. Martin, and J. O. Scarbrough (ORNL), "Thermal Conductivity of Partially Substituted $\mathrm{YBa}_{2} \mathrm{Cu}_{3} \mathrm{O}_{7 . \delta \delta}$ " submitted to Physical Review $B$.

Williams, R. K., J. O. Scarbrough, J. M. Schmitz, and J. R. Thompson, "Thermal Conductivity of Polycrystalline $\mathrm{YBa}_{2} \mathrm{Cu}_{4} \mathrm{O}_{8}$ from 10 to $300 \mathrm{~K}$," Physical Review B 57 (17) (May 1, 1998).

Yang. Chau-Yun, and S. E. Babcock (Univ. of Wisconsin); A. Goyal, M. Paranthaman, F. A. List, D. P. Norton, and D. M. Kroeger (ORNL); and A. Ichinose (Central Research Inst. of Electric Power Industry, Japan), "Microstructure of Electron-Beam-Evaporated Epitaxial Yttria-Stabilized Zirconia/ $\mathrm{CeO}_{2}$ Bilayers on Biaxially Textured Ni Tape," Physica C 307, 87-98 (1998). 


\section{INTERNAL DISTRIBUTION}

\author{
1. D. B. Beach \\ 2. E. E. Bloom \\ 3. M. A. Brown \\ 4. J. D. Budai \\ 5. T. G. Chirayil \\ 6. D. K. Christen \\ 7. D. F. Craig \\ 8. X. Cui \\ 9. F. V. Damiano \\ 10. J. A. Demko \\ 11. L. M. Dickens \\ 12. L. B. Dunlap \\ 13. R. Feenstra \\ 14. R. G. Gilliland \\ 15. M. J. Gouge \\ 16. G. R. Gruzalski \\ 17. A. Goyal \\ 18-27. R. A. Hawsey \\ 28. D. R. James \\ 29. H. R. Kerchner \\ 30. D. M. Kroeger \\ 31. L. A. Langley \\ 32. D. F. Lee
}

\author{
33. F. A. List III \\ 34. J. W. Lue \\ 35. P. M. Martin \\ 36. J. E. Mathis \\ 37. B. W. McConnell \\ 38. D. P. Norton \\ 39. M. Paranthaman \\ 40. C. Park \\ 41. J. B. Roberto \\ 42. I. Sauers \\ 43. A. C. Schaffhauser \\ 44. S. W. Schwenterly \\ 45. J. Sheffield \\ 46. V. K. Sikka \\ 47. E. D. Specht \\ 48. J. P. Stovall \\ 49. D. T. Verebelyi \\ 50-54. W. Koncinski \\ 55. J. VanCoevering \\ 56. R. K. Williams \\ 57-58. Laboratory Records Dept. \\ 59. Laboratory Records- $\mathrm{RC}$ \\ 60. Central Research Library
}

\section{EXTERNAL DISTRIBUTION}

61. L. Adams, EURUS Technologies, 2031 East Paul Dirac Dr., Innovation Park, Tallahassee FL 32310

62. D. M. Adamson, U.S. DOE, Office of Power Technologies, EE-10, U.S. Department of Energy, 1000 Independence Ave. SW, Washington, D.C. 20585-0121

63. N. Aversa, Consultant, Waukesha Electric Systems, 400 S. Prairie Ave., Waukesha, WI $53186-5937$

64. U. Balachandran, Argonne National Laboratory, ET/212, 9700 South Cass Avenue, Argonne, IL 60439-4838

65. R. D. Blaugher, National Renewable Energy Laboratory, 1617 Cole Boulevard, Golden, CO 80401

66. S. Bray, National Institute of Standards and Technology, 325 Broadway, Boulder, CO 80303

67. J. G. Daley, EE-12, U.S. Department of Energy, Office of Power Technologies, 5H-078/FORS, 1000 Independence Avenue, S.W., Washington, DC 20585-0121

68. D. Driscoll, Rockwell Automation, 24800 Tungsten Road, Cleveland, OH 44117

69. K. Efferson, American Magnetics, Inc., P.O. Box 2509, Oak Ridge, TN 37831-2509 
70. J. Ekin, National Institute of Standards and Technology, 325 Broadway, Boulder, CO 80303

71. G. H. Epstein. Intermagnetics General Corporation, P.O. Box 461, Latham, NY 12110 0461

72. L. B. Fritzemeier, American Superconductor Corporation, Two Technology Drive, Westborough MA 01581

73. A. Funkenbusch, 3M Corporate Research Tech. Dev. Laboratory, 3M Center Bldg. 2181-05, St. Paul, MN 55144-1000

74. J. R. Gaines, Superconductive Components, Inc., 1145 Chesapeake Ave., Columbus, OH 43212

75. P. M. Grant, Electric Power Research Insititute, P.O. Box 10412, Palo Alto, CA 94303

76. P. Haldar, Intermagnetics General Corporation, P.O. Box 461, Latham, NY 12110-0461

77. Z. Haq, Energetics, Inc., 501 School St. S.W., Suite 500, Washington DC 20024

78. R. L. Hughey, Jr., Southwire Company, One Southwire Drive, Carrollton, GA 30119

79. A. T. Hunt, MicroCoating Technologies, 3901 Green Industrial Way, Chamblee, GA 30341

80. H. S. Hsu, Imtech, 12417 Butternut Circle, Knoxville, TN 37922

81. A. J. Jelacic. EE-12, U.S. Department of Energy, Office of Power Technologies, 5H-078/FORS, 1000 Independence Avenue, S.W., Washington, DC 20585-0121

82. R. H. Jones, Rochester Gas and Electric, 89 East Avenue, Rochester, NY 14649-0001

83. A. Lamanna, Energetics, Inc., 501 School St. S.W., Suite 500, Washington DC 20024

84. D. C. Larbalestier, University of Wisconsin-Madison, Applied Superconductivity Center, 1500 Engineering Drive, Madison. WI 53706-1687

85. W. C. Lin, U.S. Department of Energy, Office of Assistant Manager for Energy Research and Development, Oak Ridge Field Office, P.O. Box 2008, Oak Ridge, TN 37831-6269

86. K. R. Marken. Jr., Oxford Superconducting Technology, P.O. Box 429, Carteret, NJ 07008-0429

87. S. P. Mehta, Waukesha Electric Systems, 400 S. Prairie Ave., Waukesha, WI 53186-5937

88. J. W. Muehlhauser, University of Tennessee Space Institute, B. H. Goethert Parkway, MS 8, Tullahoma, TN 37388-8897

89. C. E. Oberly. WL/POOX-2, Aerospace Power Div., Wright Laboratory, 2645 Fifth St., WPAFB OH 45433-6563

90. D. E. Peterson, Los Alamos National Laboratory, Superconductivity Technology Center, P.O. Box 1663, MS K763, Los Alamos, NM 87545

91. W. C. Pittman, Hqtrs, U.S. Army Aviation and Missile Command, Attn: AMSAM-RDMG, Redstone Arsenal, AL 35898-5000

92. G. B. Riley, American Superconductor Corporation, Two Technology Drive, Westborough, MA 01581

93. J. Romans, EURUS Technologies, 2031 East Paul Dirac Dr., Innovation Park, Tallahassee FL 32310

94. M. W. Rupich, American Superconductor Corporation, Two Technology Dr., Westborough, MA 01581

95. S. Shanmugham, MicroCoating Technologies, 3901 Green Industrial Way, Chamblee, GA 30341

96. S. S. Shoup, MicroCoating Technologies, 3901 Green Industrial Way, Chamblee. GA 30341

97. U. K. Sinha, Southwire Company, One Southwire Drive, Carrollton, GA 30119

98. J. Storer, 3M Industrial and Consumer Sector, 3M Center, Bldg. 60-1N-01, St. Paul, MN 55144-1000 
99. M. Suenaga, Brookhaven National Laboratory, Bldg. 480, P. O. Box 5000, Upton, Long Island, NY 11973-5000

100. M. J. Tomsic, Plastronic, Inc., 11641 N. Dixie Dr., Tipp City, OH 45371

101. T. Vanderah, National Institute of Standards and Technology, Ceramics Division, Building 223, A-256, Gaithersburg, MD 20899

102. J. Voight, Sandia National Laboratories, MS 1405, P.O. Box 5800, Albuquerque, NM 87185-1405

103. J. E. Wagner, Waukesha Electric Systems, 400 S. Prairie Ave., Waukesha, WI 53186-5937

104. M. S. Walker, Intermagnetics General Corporation, P.O. Box 461, Latham, NY 12110 0461

105. D. O. Welch, Brookhaven National Laboratory, Materials Science Division, Upton, Long Island, NY 11973

106. J. W. Wilson, Midwest Superconductivity, Inc., 1315 Wakarusa Dr., Lawrence, KS 66049

107. J. V. Worth, Oxford Superconducting Technology, P.O. Box 429, Carteret, NJ 070080429

108. G. J. Yurek, American Superconductor Corporation, Two Technology Drive, Westborough, MA 01581 